\title{
DESIGN OF EXPERIMENTATION TO SYSTEMATICALLY DETERMINE THE INTERACTION BETWEEN ELECTROSPINNING VARIABLES AND TO OPTIMIZE THE FIBER DIAMETER OF ELECTROSPUN POLY (D,L-LACTIDE-CO-GLYCOLIDE) SCAFFOLDS FOR TISSUE ENGINEERED CONSTRUCTS
}

\author{
A Thesis Presented to the Faculty of \\ California Polytechnic State University, San Luis Obispo
}

In Partial Fulfillment of the Requirements for the Degree Master of Science in Biomedical Engineering

By

Yvette S. Castillo

June 2012 
(C) 2012

Yvette S. Castillo

ALL RIGHTS RESERVED 
TITLE:

AUTHOR:

DATE SUBMITTED:

COMMITTEE CHAIR:

COMMITTEE MEMBER:

COMMITTEE MEMBER:
Design of Experimentation to Systematically

Determine the Interaction Between Electrospinning

Variables and to Optimize the Fiber Diameter of

Electrospun Poly (D,L-lactide-co-glycolide)

Scaffolds for Tissue Engineered Constructs

Yvette S. Castillo

June 2012

Kristen O'Halloran Cardinal, PhD

Daniel Walsh, PhD

Lanny Griffin, $\mathrm{PhD}$ 


\section{Abstract}

DESIGN OF EXPERIMENTATION TO SYSTEMATICALLY DETERMINE THE

INTERACTION BETWEEN ELECTROSPINNING VARIABLES AND TO OPTIMIZE THE

FIBER DIAMETER OF ELECTROSPUN POLY (D,L-LACTIDE-CO-GLYCOLIDE)

SCAFFOLDS FOR TISSUE ENGINEERED CONSTRUCTS

Yvette S. Castillo

Cardiac disease causes approximately a third of the deaths in the United States. Furthermore, most of these deaths are due to a condition termed atherosclerosis, which is a buildup of plaque in the coronary arteries, leading to occlusion of normal blood flow to the cardiac muscle. Among the methods to treat the condition, stents are devices that are used to restore normal blood flow in the atherosclerotic arteries. Before advancement can be made to these devices and changes can be tested in live models, a reliable testing method that mimics the environment of the native blood vessel is needed. Dr. Kristen Cardinal developed a tissue engineered blood vessel mimic to test intravascular devices.

Among the scaffolding material used, electrospun poly (lactide-co-glycolide) (PLGA) has been used as an economic option that can be made in house. PLGA is a biodegradable co-polymer, and when electrospun, creates a porous matrix with tailorable properties. Currently, the standard PLGA electrospinning protocol produces consistent fibrous scaffolds with a mean fiber diameter of 5-6 microns. Research indicates that cell adhesion is more successful in fibrous matrices with a mean fiber diameter at the nanometer level. However, because previous work in the Tissue Engineering Laboratory at Cal Poly sought to ensure a consistent fibrous, there was no 
model or equation to determine how to change the electrospinning parameter settings to create scaffolds with an optimal mean fiber diameter.

To fill this need, biomedical engineering senior Steffi Wong created a design of experiment to systematically approach the electrospinning variables and determine how they interacted with each other, as well as their effect on fiber diameter. The aims of this thesis were to perform the said design of experiments and determine a model to predict the resulting mean fiber diameter of a scaffold based on the electrospinning parameters as well as to determine what combination of parameters would lead to a scaffold with an optimal mean fiber diameter between 100-200 nanometers. The variables tested were solution concentration, gap distance, flow rate, and applied voltage. Each scaffold was imaged and a mean fiber diameter was calculated and used as the predicted variable in a regression analysis, with the variables indicated above as the predictors. The goal of 100-200 nanometer mean fiber diameter was not reached. The smallest mean fiber diameter calculated was 2.74 microns_-half of that of the standard protocol. The regression analysis did result in a model to describe how the voltage, gap distance, and flow rate affected the fiber diameter. 


\section{Acknowledgements}

I would like to thank my advisor, Dr. Kristen O'Halloran Cardinal for her continual support with my work on the electrospinner, and for allowing me into her laboratory team early on. Her extensive knowledge of the field has helped tremendously in the completion of this thesis.

I would also like to thank the members of my committee, Dr. Daniel Walsh and Dr. Lanny Griffin. Your knowledge of materials and systematic approach to engineering have provided guidance for my work.

I thoroughly enjoyed being part of the lab team. You all made it enjoyable. I would especially like to thank Colby James and Tiffany Peña for your past work on the electrospinner. Your work and ideas gave me a large boost. Your dedication to the electrospinner was motivating. I would also like to thank Katelyn Goodwin and Edward Siemsen for helping with many of spins. In addition, Steffi Wong for taking our data and turning it into a design of experiment that I was able to run.

Finally, I would like to thank my family. Mom and Dad-you have been nothing but supportive while I finished my degree. Your love and encouragement during the difficult times helped me stay focused and motivated. I look up to both of you for everything you have accomplished that made it possible for me to study engineering. 


\section{Table of Contents}

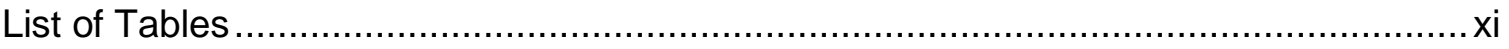

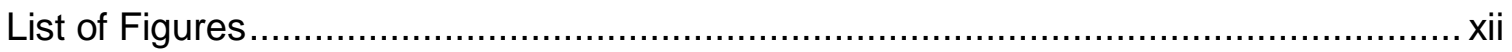

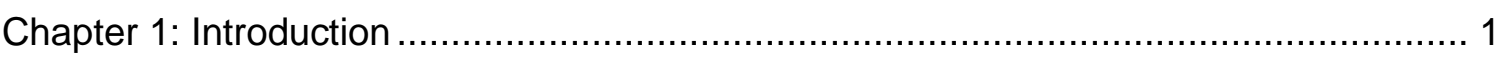

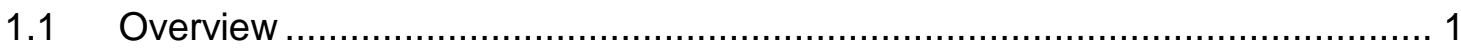

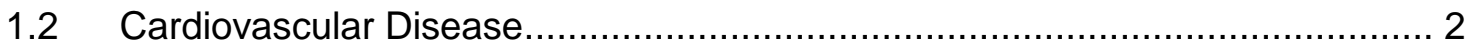

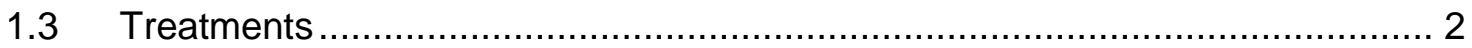

1.3.1 Coronary Artery Bypass Grafts....................................................... 3

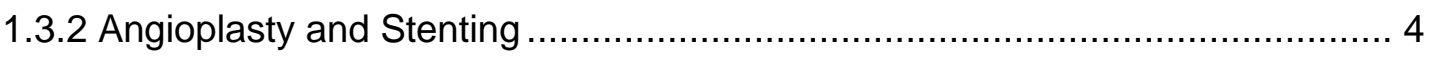

1.3.3 Food and Drug Administration Regulation …….................................... 5

1.4 Tissue Engineered Blood Vessel Mimic System: The BVM …....................... 6

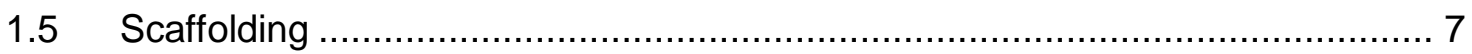

1.5.1 PLGA

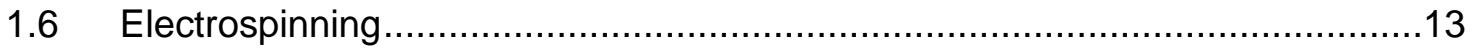

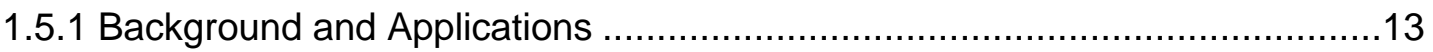

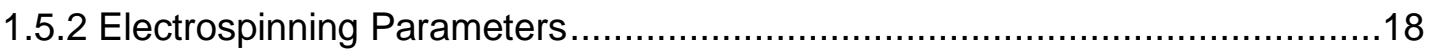

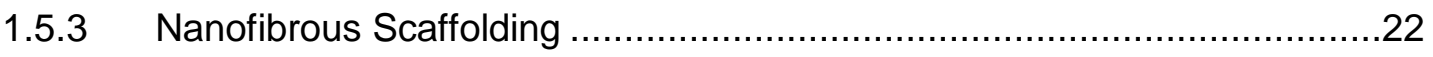

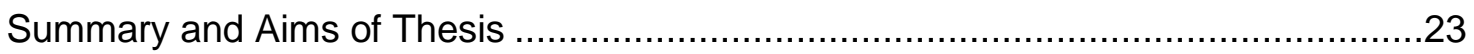

Chapter 2: Preliminary Electrospinning Trials .......................................................24

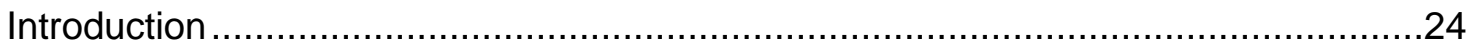

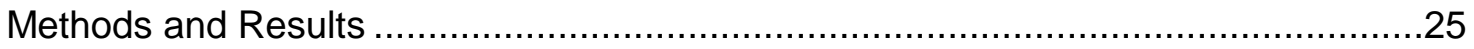




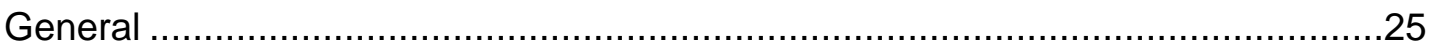

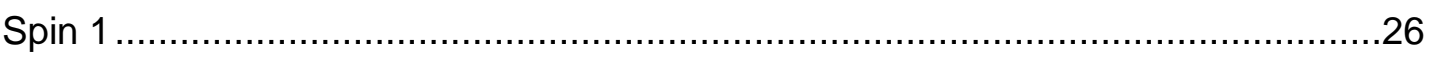

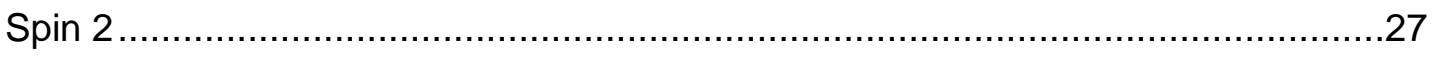

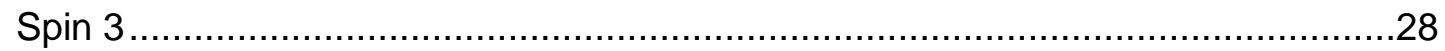

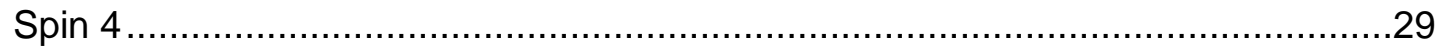

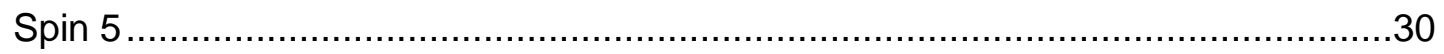

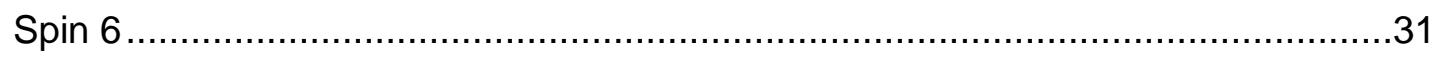

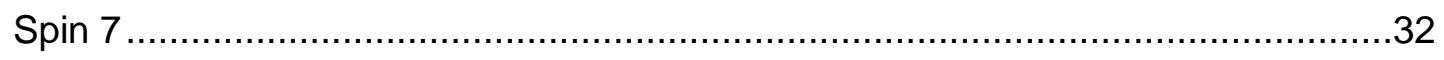

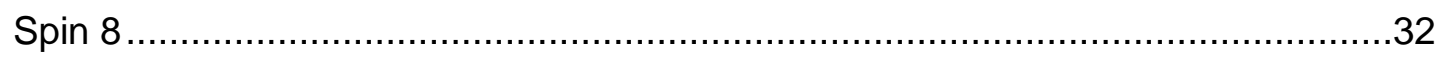

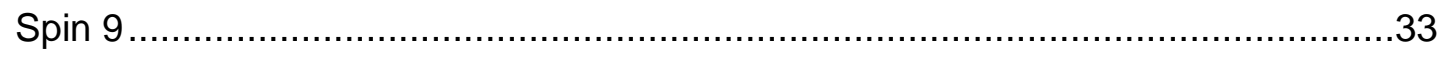

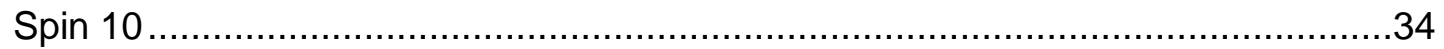

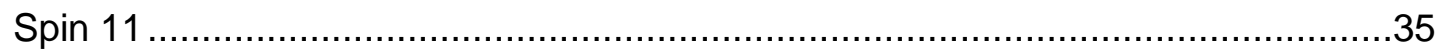

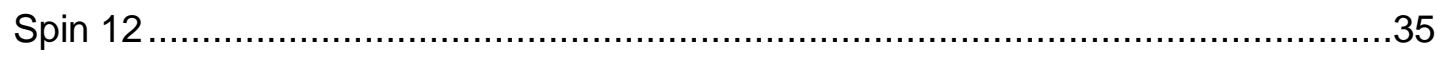

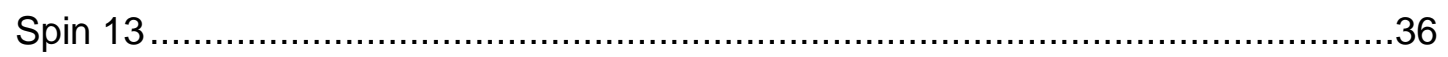

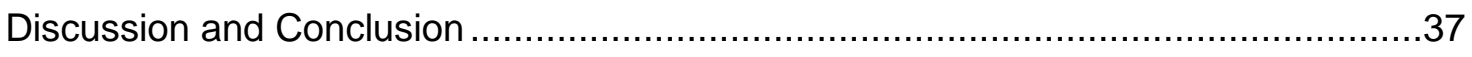

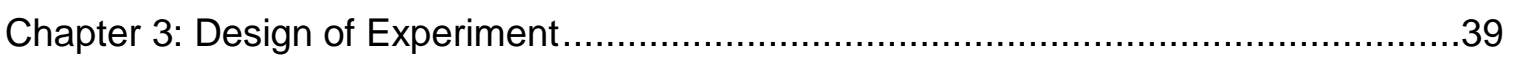

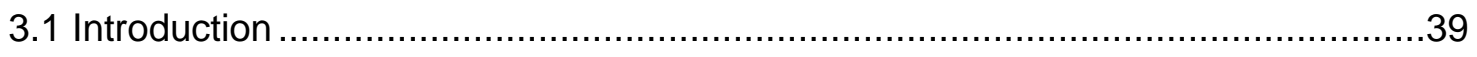

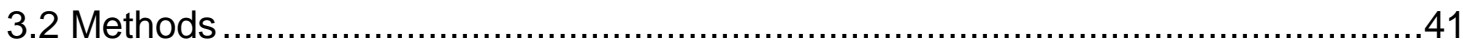

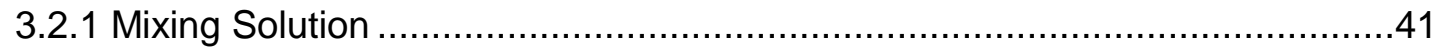

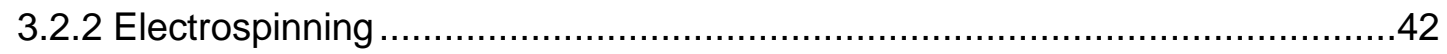

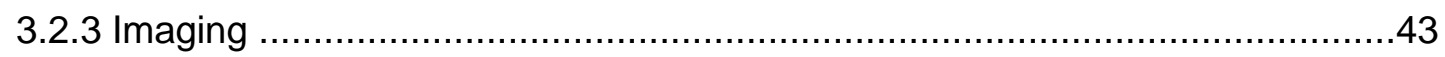




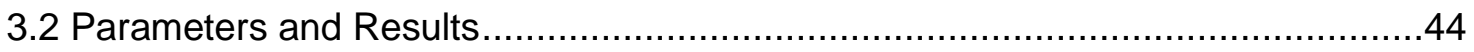

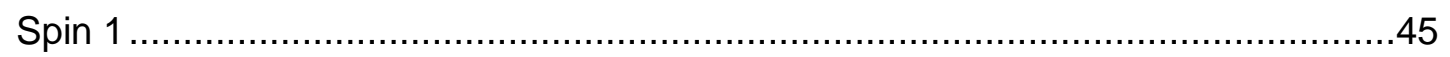

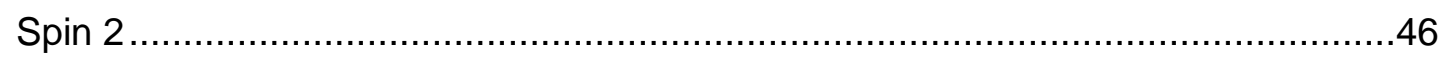

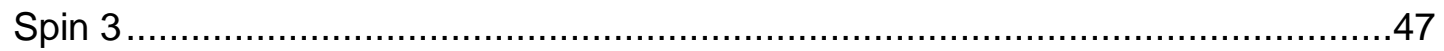

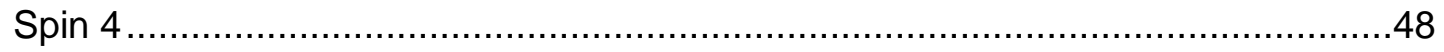

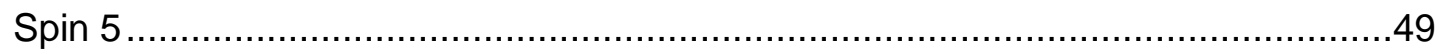

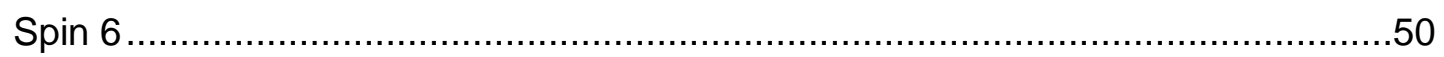

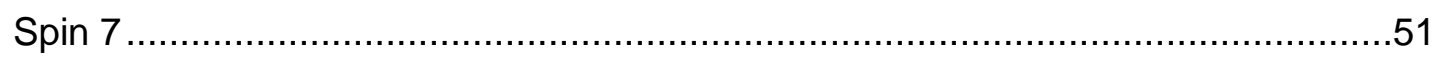

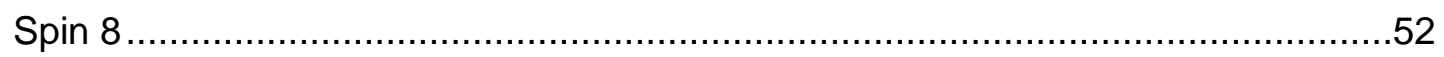

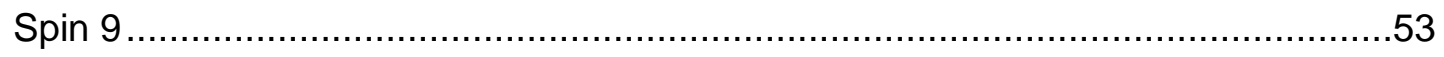

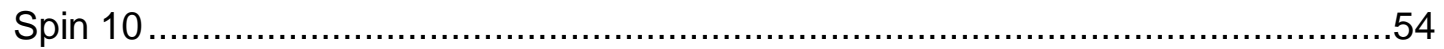

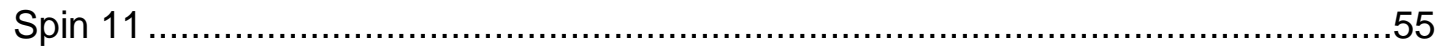

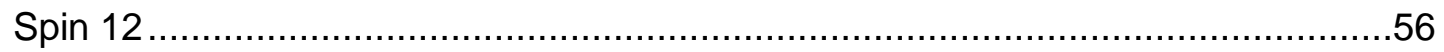

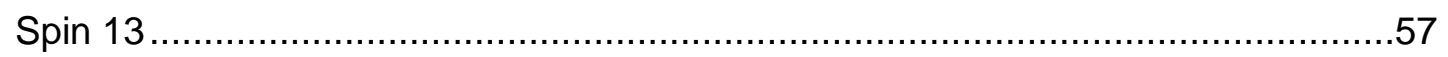

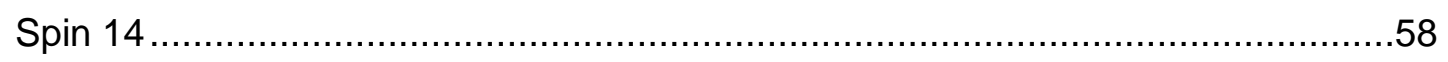

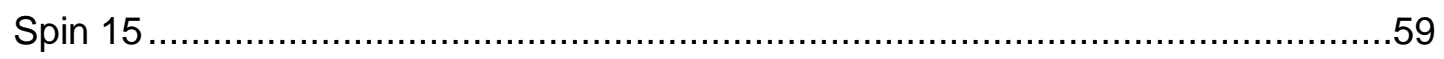

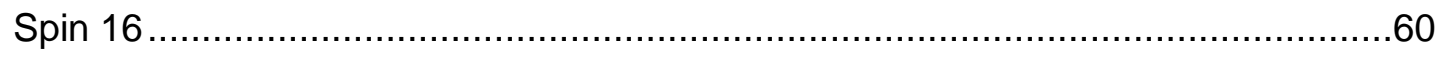

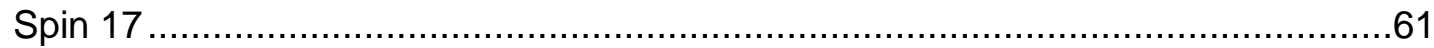

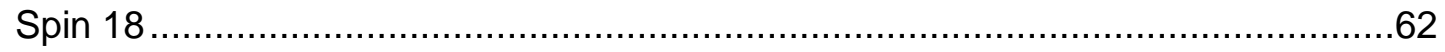

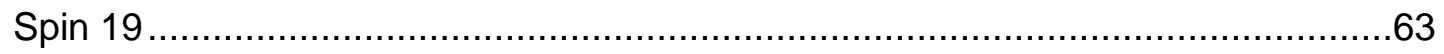

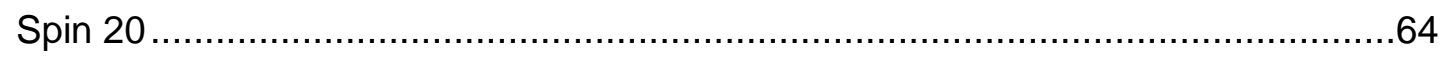




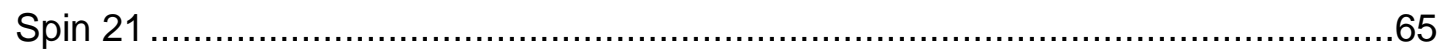

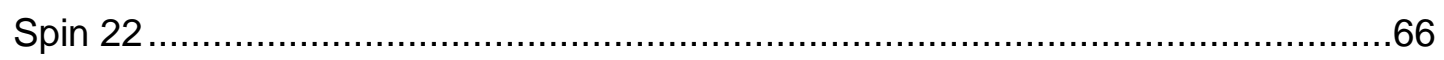

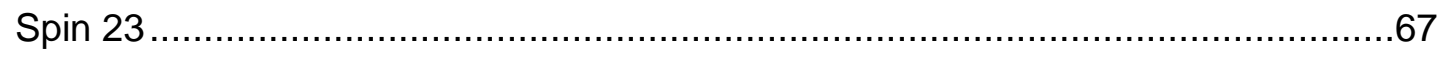

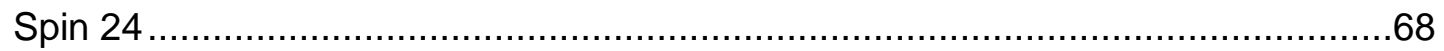

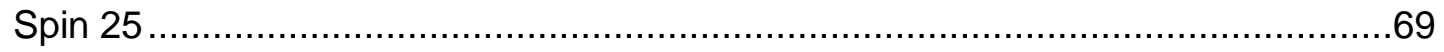

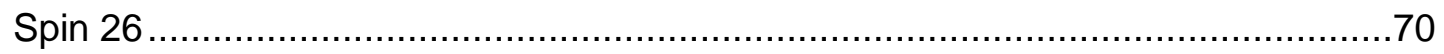

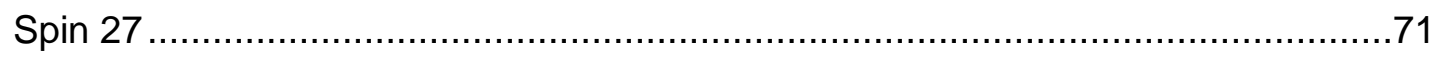

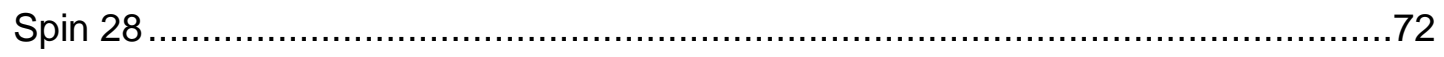

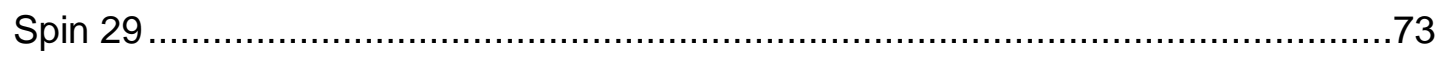

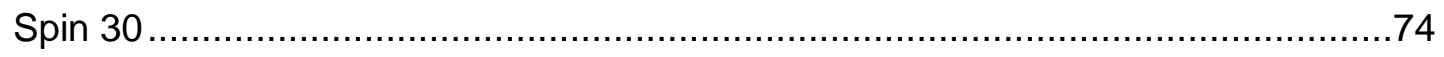

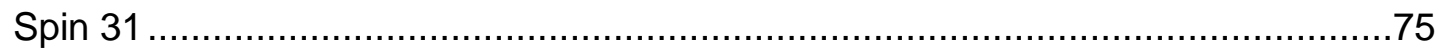

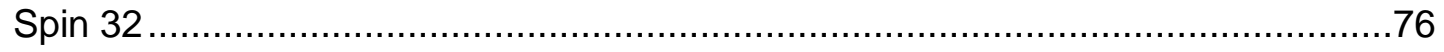

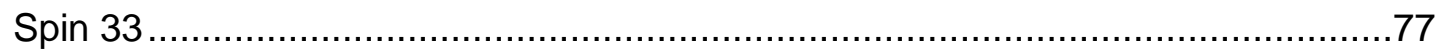

Summary of DOE Measurements and Observations .........................................

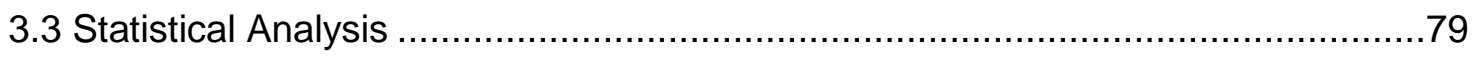

3.3.1 Settings as a predictor for Average Fiber Diameter of a Scaffold ...................80

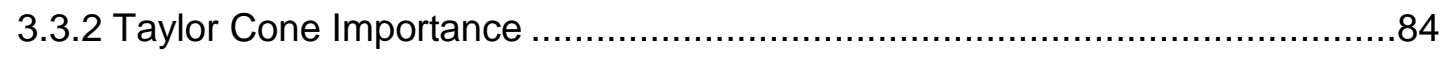

3.3.3 Variation of fibers along the length of the scaffold......................................86

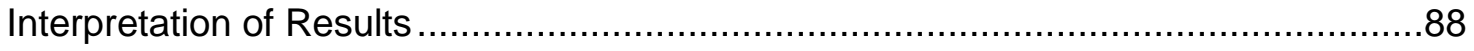

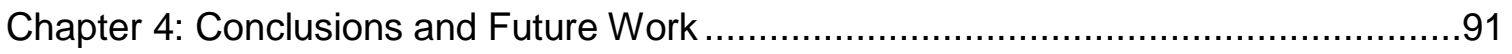

Summary …… 


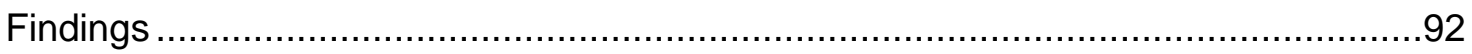

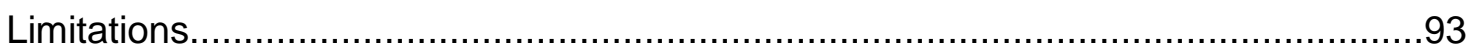

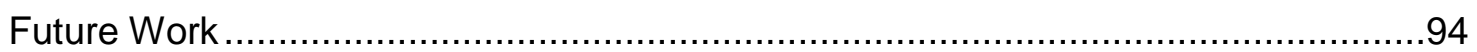

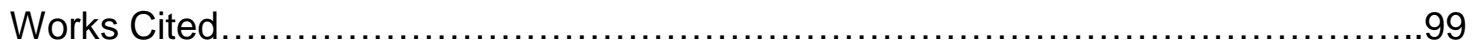

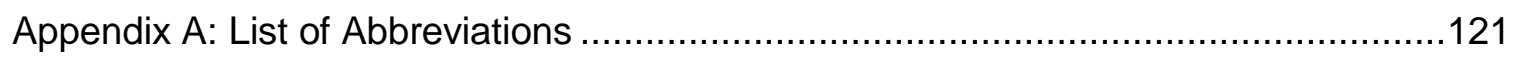

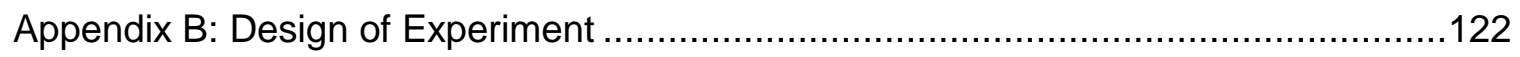

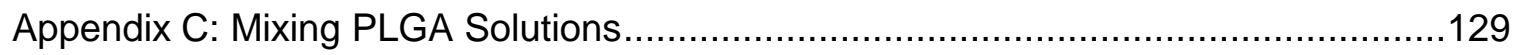

Appendix D: Electrospinning Setup and Protocol.............................................132

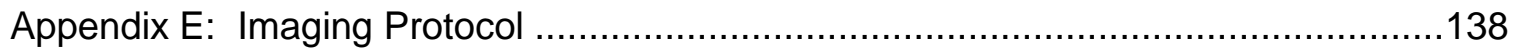

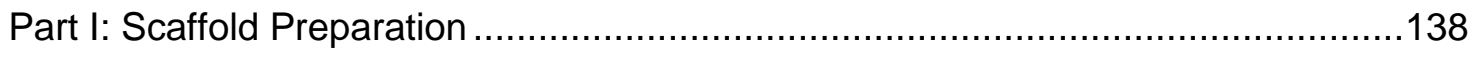

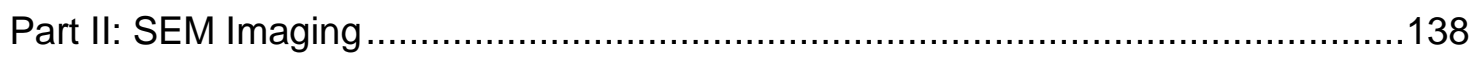

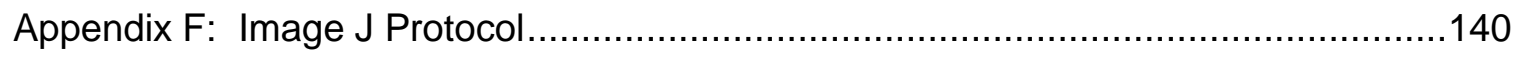

Appendix G: List of Images and Measurements .............................................

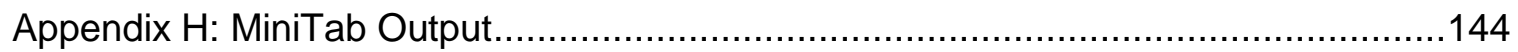




\section{List of Tables}

Table 1: Standard sterilization techniques and their applicability to PLGA [35].

Table 2: Design of Experiment Set up including the run order and factor selection for each trial. Each combination is only performed once [159].

Table 3: Spin with factor settings and mean fiber diameter and standard deviation. ......79

Table 4: Possible factor combinations and expected mean fiber diameter based on

DOE model. The highlighted rows are combinations ideal for the current

electrospinning setup.

Table 5: Table of mean fiber diameter and standard deviations for each section of the fibrous scaffolds.

Table 6: Bill of Materials 


\section{List of Figures}

Figure 1: Diagramed steps of angioplasty procedure with deployed stent [16] ...............4

Figure 2: Solid model of BVM used at Cal Poly laboratory with bioreactor chamber, media reservoir, and direction of fluid flow labeled [18] .........................................

Figure 3: SEM image of decellularized arteries at 400x [27] ...................................

Figure 4: SEM image off ePTFE scaffold at 148x. The arrows indicate the direction of

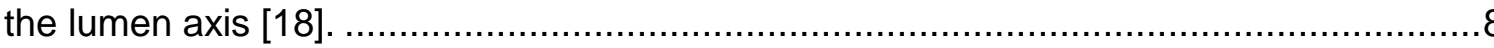

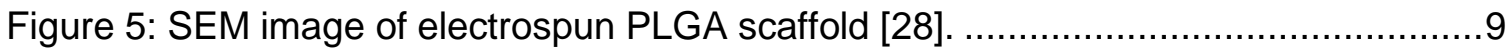

Figure 6: Structural formulae of PGA (left) and PLA (right)....................................10

Figure 7: In vivo resorption rates of radiolabelled PLGA with differing mole ratios of

PLA and PGA [34].

Figure 8: Basic electrospinning setup, including syringe ejecting polymer, which is charged by a high voltage supply, creating the Taylor cone imaged. The liquid jet seeks to land on the grounded collector [49].

Figure 9: Onset and development of bending instability during electrospinning jet elongation [71].

Figure 10: Mandrel electrospinning set up diagraming the movement of the mandrel (translation and rotation), as well as the measurement of gap distance. Modified from C. Ayres 2009 publication [109].

Figure 11: Spin 1 lumen imaged at 500x, spun with the standard protocol. .26

Figure 12: Spin 2 SEM image at 600x with standard electrospinning protocol and $12 \%$ solution concentration depicting uneven fiber diameter

Figure 13: Spin 3 SEM image at 600x depicting globular formations. 28

Figure 14: Spin 5 SEM image at 500x with inconsistent fiber diameters. 30

Figure 15: Spin 9 SEM image at 500x with large fibers dispersed. .33 
Figure 16: SEM image of Spin 10 at 800x depicting fibers with a mean fiber diameter of 2.8 microns.

Figure 17: Spin 13 SEM image at 600x with standard protocol with 18kV applied

voltage, $6.0 \mathrm{ml} / \mathrm{hr}$ flow rate, and a gap distance of 8 inches.

Figure 18: Diagram of scaffold preparation for imaging. Smaller pieces labeled

A-E were imaged $(0.5 \mathrm{~cm})$ and longer pieces saved in case of damaged/lost images $\ldots . .43$

Figure 19: Spin 1, section B, image 3 SEM image with corresponding measurements,

as will be including for each image in Appendix $\mathrm{G}$.

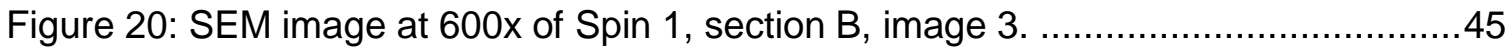

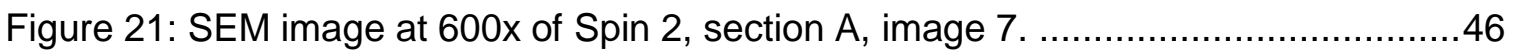

Figure 22: SEM image at $600 x$ of Spin 3 lumen.............................................. 47

Figure 23: Image of Spin 4 exterior. Note flaky material adjacent to scaffold. ..............48

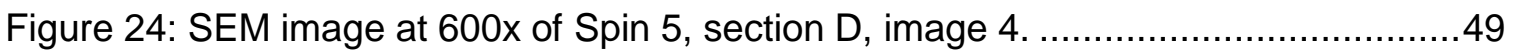

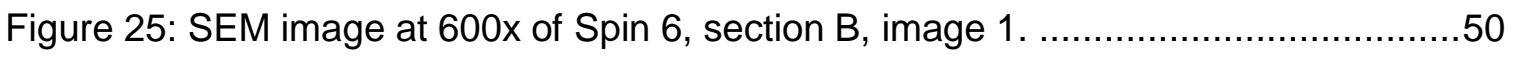

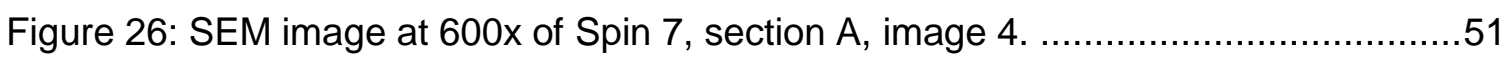

Figure 27: Image of Spin 8 exterior since lumen could not be SEM imaged. ................52

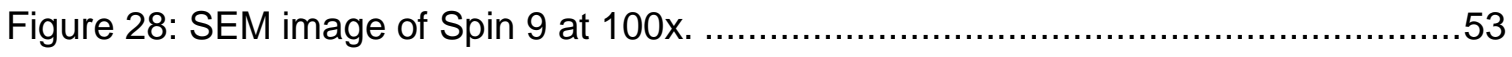

Figure 29: SEM image at $800 x$ of Spin 10, section B, image 1. .............................54

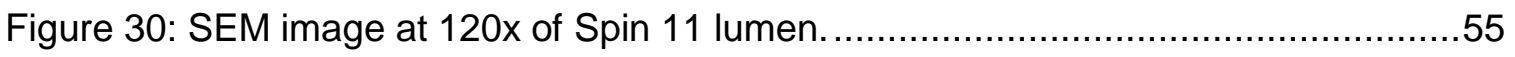

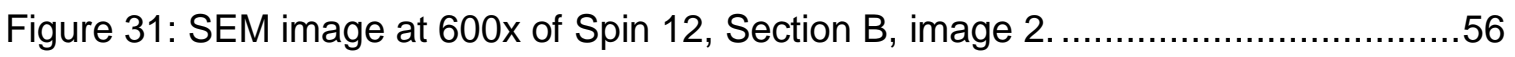

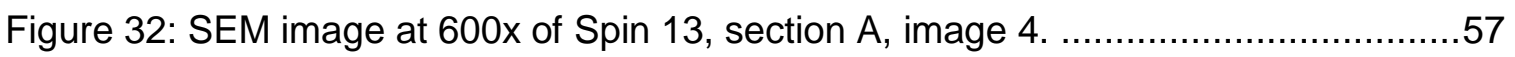

Figure 33: Exterior image of Spin 14, since lumen could not be imaged. .....................58

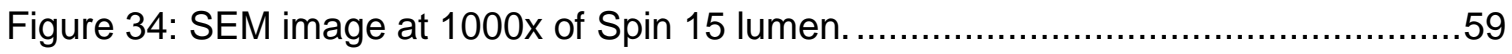

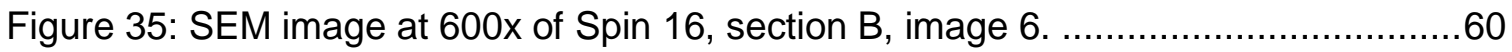

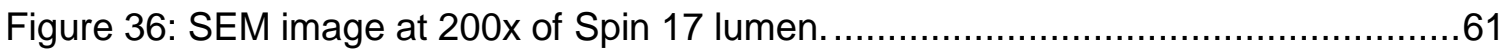

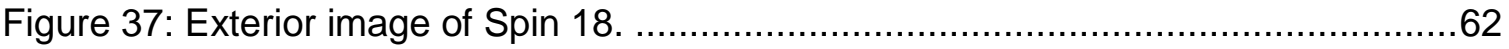


Figure 38: SEM image at 180x of Spin 19 lumen.

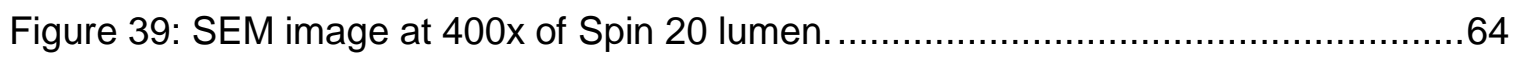

Figure 40: SEM image at $600 x$ of Spin 21 , section A, image 3. ..............................65

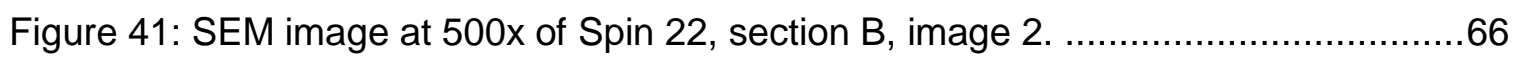

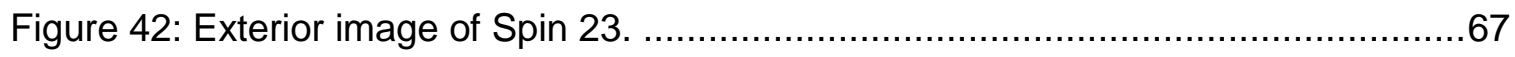

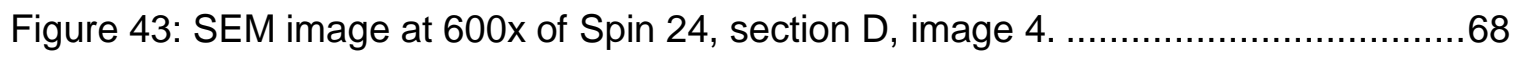

Figure 44: SEM image at 180x of Spin 25 lumen..............................................69

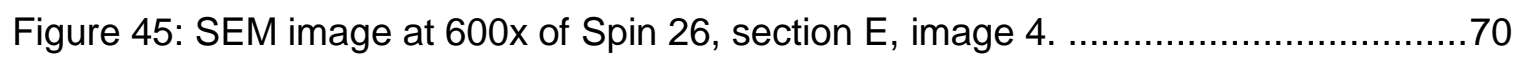

Figure 46: SEM image of Spin 27 lumen. ..................................................... 71

Figure 47: SEM image at $600 x$ of Spin 28 , section A, image 2. .............................72

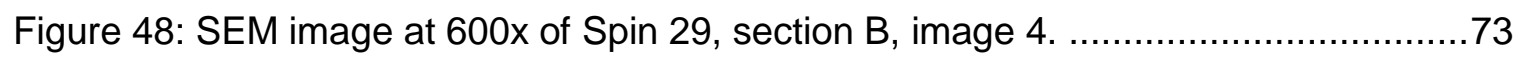

Figure 49: SEM image at $600 x$ of Spin 30 , section E, image 2. ............................. 74

Figure 50: SEM image at 150x of Spin 31 lumen............................................... 75

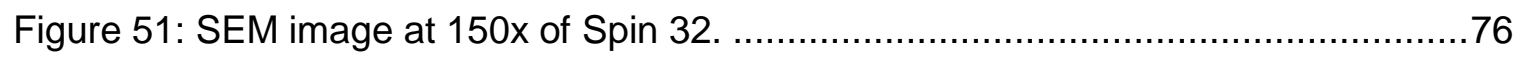

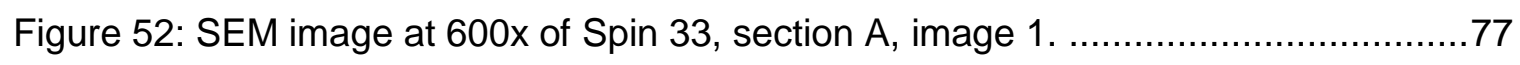

Figure 53: SEM image of Spin 11 lumen depicting globular structure rather than

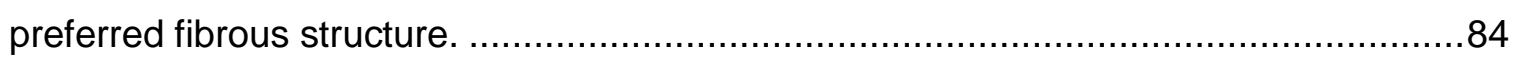

Figure 54: Ideal Taylor cone with a single jet of solution ejecting from the tip [160]......85

Figure 55: Bar chart depicting relationship between Taylor cone appearance

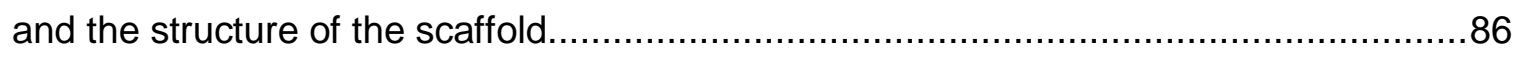

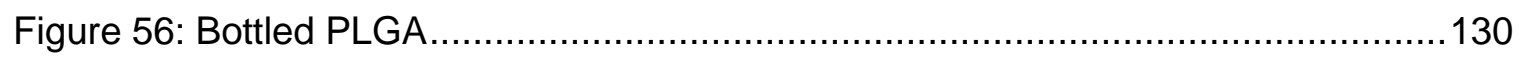

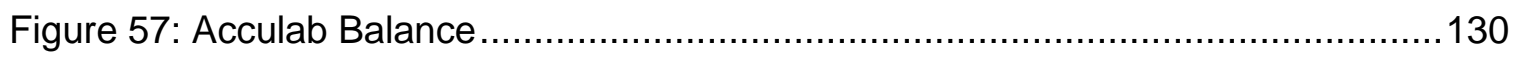

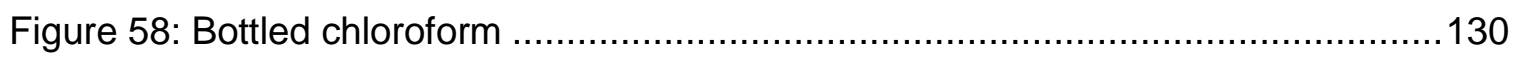

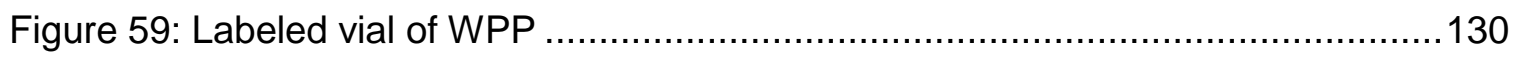

Figure 60: Green ground wire location on back of the collector .............................. 132

Figure 61: Location of the yellow power wire on the DC motor control box ..................132 
Figure 62: Entire electrospinner in the containment chamber

Figure 63: Polymer build up on collector that needs cleaning

Figure 64: Multimeter lead placement to measure resistance

Figure 65: Syringe usage to acquire polymer solution

Figure 66: Syringe/needle placement on syringe pump and within needle hole on

containment chamber.

Figure 67: Position of collector for electrospinning...... 134

Figure 68: Attachment of red high voltage wire on needle tip. 135

Figure 69: DC motor control box. .135

Figure 70: External power source. .135

Figure 71: Main power switch 136

Figure 72: High voltage switch. .136 


\section{Chapter 1: Introduction}

\subsection{Overview}

The focus of this thesis involved honing the current electrospinning method introduced by past students as a method of creating scaffolding for a tissue engineered blood vessel mimic (BVM). The relevance of the BVM lies in properly mimicking a blood vessel—coronary arteries in this case—to serve as an economical testing system for intravascular devices. Electrospinning has already been used by other researchers working with scaffolding, and has been used in the Tissue Engineering lab at Cal Poly to create polymer tubes for blood vessel growth. Currently, the resulting scaffold is made

of fibers at the micrometer level, however literature suggests that nanofibrous scaffolding is ideal. Therefore, this thesis used a DOE to improve the process of creating scaffolding with smaller fibers, to create a more suitable environment for cell proliferation.

The following sections provide relevant research in the cardiovascular and tissue engineering field, as well as background on the BVM and where electrospinning fits. Electrospinning is a simple process to run, however is complex in the way the parameters interact to create the resulting scaffold. Detail on the workings of the process, as well as insight and interpretation of previous research and the parameters involved are provided to give understanding into the methodologies of the DOE and interpretation of the results. 


\subsection{Cardiovascular Disease}

According to the mortality data from 2007 , cardiovascular disease accounted for $33.6 \%$ of deaths in the United States [1]. More specifically, CAD accounted for 1 out of every 6 deaths in the US. Atherosclerosis can lead to CAD. It is a condition that occurs when plaque builds up on the walls of the arteries, which clogs the arteries, inhibiting blood flow to the heart. This can then lead to a clot, which can cause a myocardial infarction causing the ischemic heart muscle to die $[1,2]$

The causes and initiation of atherosclerosis are not entirely known. It can be due to lesions in the endothelium caused by high levels of HDL cholesterol or triglycerides, high blood pressure, or exposure to toxins such as cigarette smoke. The lesion allows the deposition of fats, platelets, calcium and other debris into the arterial wall [1]. Monocytes, T lymphocytes, and platelets all act on the lesion and generate chemotactic factors and mitogens that alter the structure of the smooth muscle cells, which migrate into the tunica media and proliferate, forming the fatty lesions that characterize atherosclerosis [3].

Because of the health risks of atherosclerosis, numerous treatments have been developed to assist in improving blood flow to the heart muscle, outside of pharmaceuticals.

\subsection{Treatments}

The treatments available for patients with CAD are exactly that-treatmentsand not cures for the condition. Because lifestyle is a large factor, if a treatment is applied, the atherosclerosis will continue to grow worse unless diet or exercise is

modified. In addition, restenosis—the stenosis or narrowing of the artery occurring again—can occur [4]. Restenosis can be caused by a number of factors such as 
thrombus formation, vascular remodeling, smooth muscle cell proliferation, and elastic recoil of the expanded artery [5]. Patients with CAD often have multiple procedures of the ones listed below due to restenosis.

\subsubsection{Coronary Artery Bypass Grafts}

Over 500,000 coronary artery bypasses are performed per year in the United States [2]. The procedure involves bypassing a clogged artery with a native or artificial vessel to keep oxygenated blood flowing to the heart muscle [6]. Autologous grafts commonly used are the mammary artery or great saphenous vein for small diameter vessels $[7,8]$. In some cases, these native grafts are not available due to damage or previous use, and there is a need for an alternative. Diseased arteries can alternatively be replaced with artificial grafts, often made of e-PTFE or Dacron [9]. These synthetic grafts have been found to be less successful functioning as smaller diameter vessels, such as coronary arteries [10]. Some issues associated with synthetic grafts are thrombosis and hyperplasia(excessive tissue in growth). These are especially prevalent in small diameter vessels because of the small flow area. Also, it is difficult for a synthetic material to match the compliance of a native vessel to transmit arterial pressure-which is important to blood flow and cell proliferation-as well as be able to repair and grow with time [11].

Due to potential issues with autologous or synthetic conduits, tissue engineered blood vessels have been explored as another option for bypass procedures. Artificial scaffolding is used as a matrix where cells are seeded to create a semi synthetic graft [12]. These types of grafts take time to grow and not all hospitals may have access to the technology. For time sensitive cases, tissue engineered vascular grafts (TEVGs) may not be the best option. Bovine grafts have also been used as an alternative, 
however long term studies revealed an increased chance of infection, thrombosis, and in some cases the presence of aneurysms [13,14].

\subsubsection{Angioplasty and Stenting}

Angioplasty can offer a lower cost and lower risk alternative when treating atherosclerosis. The procedure involves inserting a catheter with a deflated balloon on the tip. When the balloon reaches the blocked area, it is inflated, the plaque is compressed, and the coronary artery is unblocked [15]. Stent placement is a form of permanent angioplasty, as depicted in Figure 1. Once the plaque is pushed against the endothelial wall, a stent—a tube generally made from a biocompatible metal-is left to hold the plaque against the wall. Restenosis however can still occur, though studies comparing coronary stent placement against standard balloon angioplasty found reduced rates of restenosis [5].
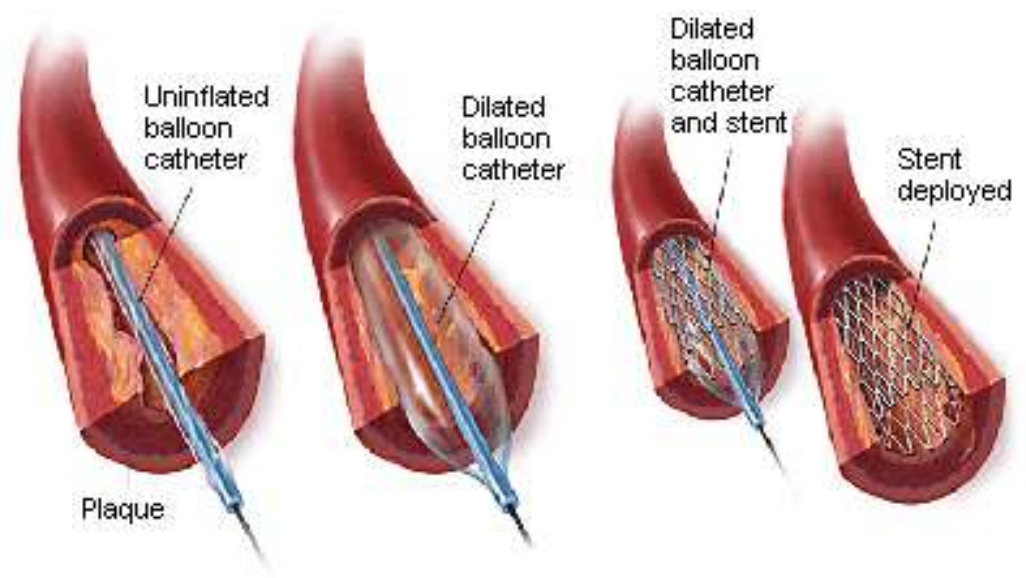

Figure 1: Diagramed steps of angioplasty procedure with deployed stent [16]. 


\subsubsection{Food and Drug Administration Regulation}

FDA requires in vitro/in vivo/bench testing for most medical device treatments of CAD. Coronary stents, formerly categorized at cardiovascular stents, are now in their own device category in the cardiovascular panel [17]. The FDA defines this device as "a metal scaffold placed via a delivery catheter into the coronary artery or saphenous vein graft to maintain the lumen." Coronary stents are a Class III device due to the risk involved with implantable devices, and require a PMA submission. The PMA requires a multitude of information confirming safety and efficacy, with laboratory tests that can cost a company large sums of money to complete. In addition, the coronary stent has recognized consensus standards involving FEA testing, measurements of elastic recoil, corrosion testing, and in vitro pulsatile durability testing [17]. There are numerous FDA approved bench and in vitro testing methods available that can test for hemocompatibility, carcinogenicity, and other FDA required biocompatibility. However, an environment that mimics the coronary artery would be advantageous and economical in assessing the vascular response to new treatment options, if anything as a precursor for testing done for the FDA and in research and development work. 


\subsection{Tissue Engineered Blood Vessel Mimic System: The BVM}

Tissue engineering is an optimal approach to mimicking the environment of a native coronary artery. The purpose of the BVM is to simulate the environment of a blood vessel using tissue engineering techniques. A scaffold-synthetic or biologicseeded with cells is used within a bioreactor-imaged in Figure 2 below. The bioreactor includes a peristaltic pump to move the media, and the chamber containing the BVM or tissue engineering blood vessel.

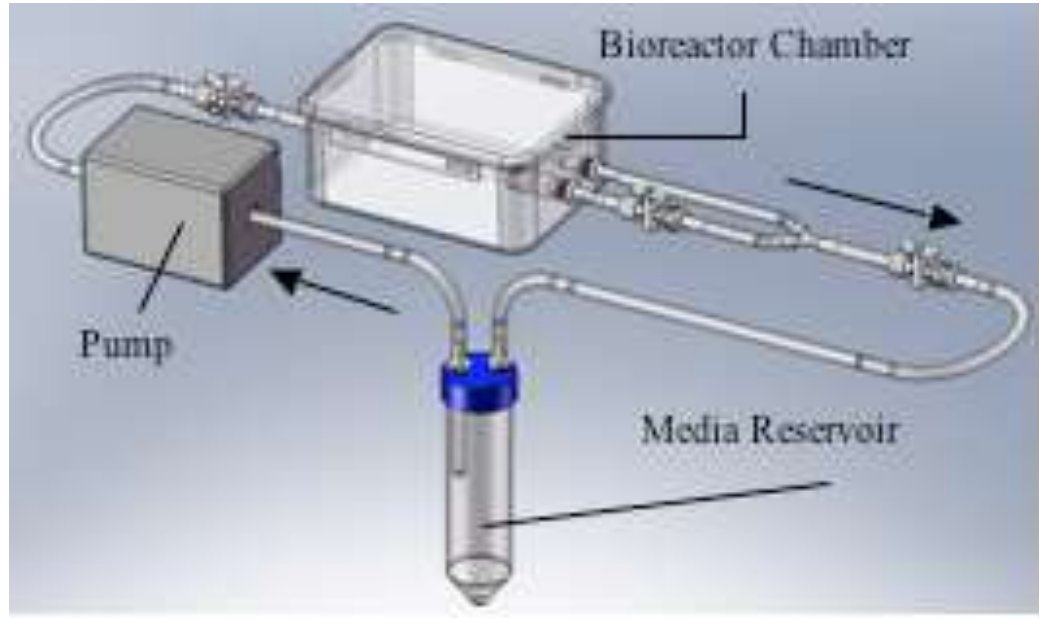

Figure 2: Solid model of BVM used at Cal Poly laboratory with bioreactor chamber, media reservoir, and direction of fluid flow labeled [18].

In general, a bioreactor should furnish an even distribution of cells on scaffolding, maintain the desired concentration of gasses and nutrients in the media, provide nominal mass transfer to the tissue, and expose cells to physical stimuli [19]. There are static and dynamic types of bioreactors, however multiple studies have found that cell and tissue growth respond better and are increased by mechanical stress under fluid flow, compared to static conditions [20,21]. These conditions are provided in the BVM bioreactor. As mentioned, once the BVM has been created and cultivated in its 
bioreactor system, it can potentially serve as a testing environment for stents and other vascular therapies.

One of the most crucial layers of the vessel_for the purposes of creating a blood vessel mimic - is the intima. This is a lining of endothelial cells that helps maintain the patency of the vessel in a native environment. Creating this layer of viable endothelial cells on the scaffold is crucial to a successful tissue engineered blood vessel system [22]. The BVM is composed of endothelial cells seeded on a scaffold, which with time becomes an endothelial layer that can mimic that of a coronary artery. It is important that the scaffold used should mimic the native vessel as much as possible to increase the accuracy of the testing done within the system. Both biologic and synthetic scaffolding can be used, including scaffolds such as decellularized tissues, ePTFE, or PLGA.

\subsection{Scaffolding}

A critical element of the BVM is the scaffolding. The porosity, alignment, and other elements of its architecture affect cell proliferation[23,24]. Figure 3 shows a decellularized porcine vessel structure, which is what scaffolds should mimic. Figure 4 and Figure 5 are SEM images of the artificial materials used for scaffolding in our laboratory: ePTFE and PLGA respectively. All three have pros and cons. The biologic scaffold provides the best mimic, however gathering the material can be more expensive or time consuming. The ePTFE scaffolding is advantageous the architecture is aligned, which better promotes the ECM [25]. Also, because it is flexible, the scaffold can tested while mimicking tortuous anatomy, rather than just a straight scaffold. A disadvantage is that the material is expensive. PLGA is copolymer that is electrospun in the Cal Poly laboratory, creating a fibrous scaffold. It is economic to create. Also, the porosity and fibrous structure are ideal. In addition, the processing parameters selected for 
electrospinning can alter the material properties of the scaffold. Disadvantages include the stiffness of the material and its sensitivity to various chemicals [26].

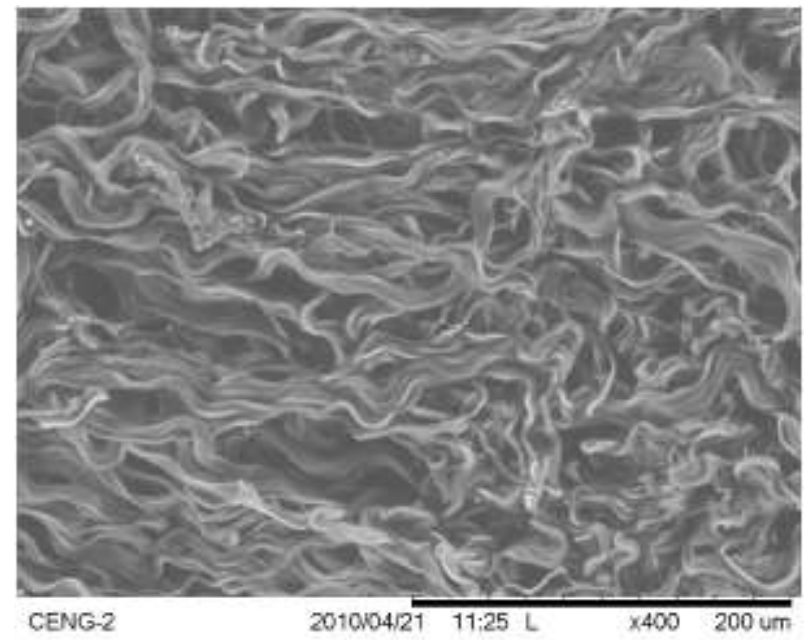

Figure 3: SEM image of decellularized arteries at 400x [27].

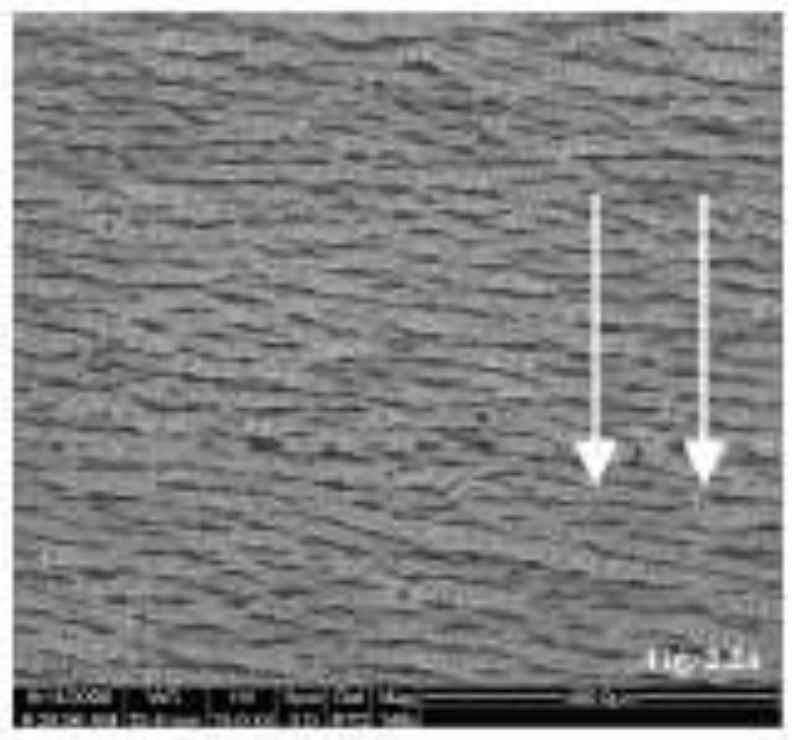

Figure 4: SEM image off ePTFE scaffold at 148x. The arrows indicate the direction of the lumen axis [18]. 


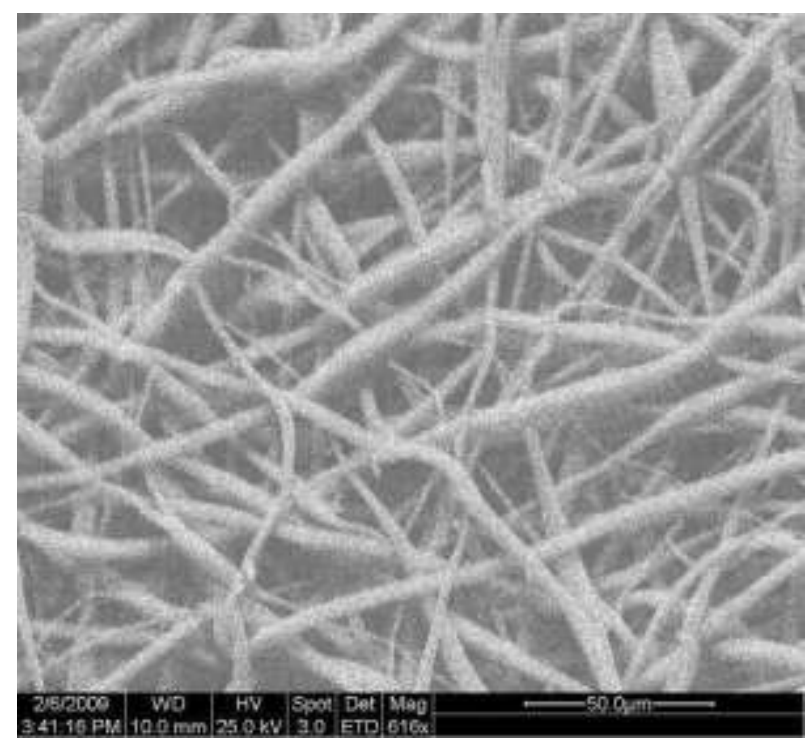

Figure 5: SEM image of electrospun PLGA scaffold [28].

This thesis focuses on the in house production of artificial scaffolding. The artificial scaffolds can be integrated with biological proteins to better mimic the biological scaffold. For example, past studies found the polymer polydioxanone and elastin more successful than just polydioxanone alone [29]. Another study involving PLGA with collagen proved the inclusion of biologics to promote cell proliferation and mimic mechanical properties of a bovine iliac [30]. However, another student studied the possibility of spinning collagen, but solvent was expensive which offset the economical goal of the scaffold, and unsuccessful scaffolds resulted after a few trials. In addition, the process of extracting collagen often destroys some of its mechanical properties.

This thesis uses solely PLGA, mixed with chloroform because it is economical compared to many polymers and can use a non-expensive solvent. Detail of its material properties both advantageous and not, are discussed below. 


\subsubsection{PLGA}

PLGA is composed of PLA and PGA, shown below above in Figure 6, which create a mixture of both of their physical and morphological properties. Both are biodegradable via hydrolysis, and for the purposes of this thesis, degrades nonhomogenously because the scaffold is a large "device" [31,32]. PGA is highly degradable via hydrolysis of the ester bonds. In vivo, PGA will lose all of its strength after four weeks, and can be completely resorbed in 6 months [9]. The degradability is highly dependent on the ratio of the two polymers, as depicted in Figure 7 below, but also on the shape of device, and the porosity among other factors. Because PGA is more susceptible to hydrolysis, the more PGA in the co-polymer, the faster it will degrade within the body, or within media designed to mimic the body [33].

\section{Poly (glycolic acid)}

\section{Poly (lactic acid)}

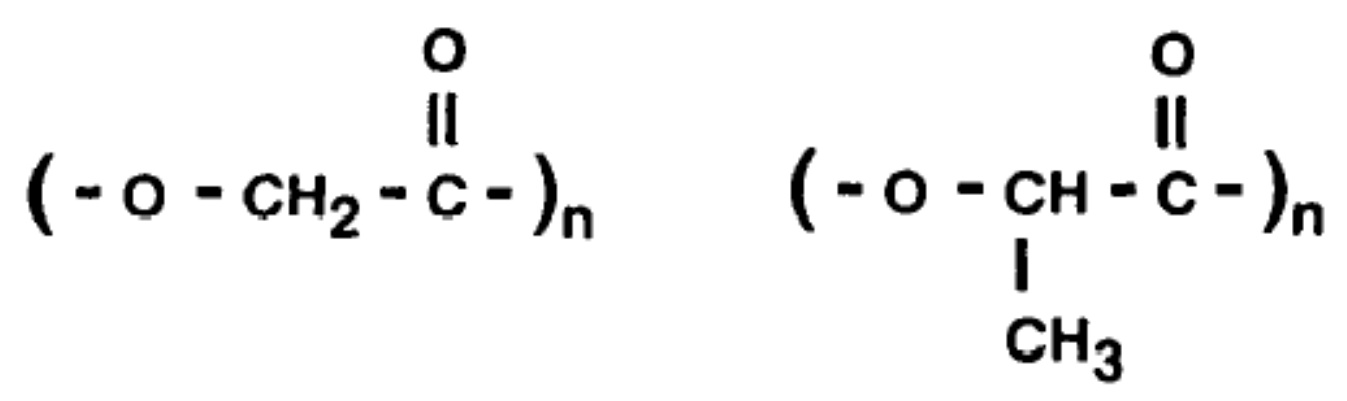

Figure 6: Structural formulae of PGA (left) and PLA (right). 


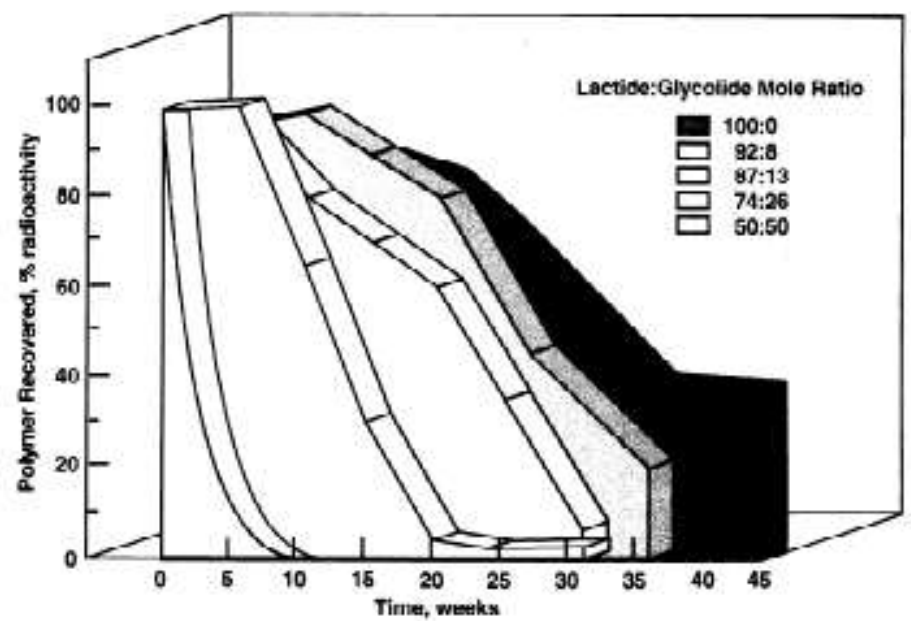

Figure 7: In vivo resorption rates of radiolabelled PLGA with differing mole ratios of PLA and PGA [34].

In addition, PLGA can be sterilized, which is important for biomedical applications. Table 1 lists common sterilization techniques and their compatibility with PLGA. PLA and PGA polymers are thermoplastic, thus do not do well when exposed to excessive heat, and because of the hydrolysis degradation, are damaged by moisture. Radiation can also cause damage. Steam sterilization tends to use high moisture and high temperatures above $100^{\circ} \mathrm{C}$, which depending on the composition of the copolymer, can exceed the glass transition temperature [35]. Doing so will change the material properties of the polymer, affecting its usage in the biomedical industry where the interactions with living tissue or cells are crucial. In some cases, only the molecular weight is affected, which will more than likely affect the degradation rate [36]. Depending on the application, such a disadvantage may not be crucial. Gamma radiation also affects the molecular weight by attacking shorter chains via chain scission [37]. This can affect the degradation, but studies have also reported tensile strength reduction in PLA and PGA polymers [38,39]. Tests comparing PGA samples to gamma irradiated PGA samples revealed gamma irradiated samples degraded faster [40]. 
Finally chemical sterilization, such as EtO is ideal for polymers, such as PLGA that are so sensitive to heat and moisture. Unfortunately, residues and extractables could prove potentially dangerous. The amount of gas absorbed can be controlled, however exposure to some sort of aeration or degassing post EtO sterilization could reduce gas residue to safer levels $[41,42]$.

PLA, and PGA, and also PLGA have also been tested for successful biocompatibility. Rat epithelial cells, human fibroblasts and osteosarcoma exhibited successful proliferation, though some cell inhibition was observed $[43,44]$. More appropriately, tests of PGA fiber meshes found positive interactions with live tissue [45]. On the contrary, some studies have discovered the production of toxic byproducts in vitro possibly due to the acidic nature of the degradation [46].

Table 1: Standard sterilization techniques and their applicability to PLGA [35].

\begin{tabular}{|c|c|c|}
\hline Sterilization technique & Advantages & Disadvantages \\
\hline $\begin{array}{l}\text { Steam sterifization } \\
\text { (high steam pressure, 120-135 C) }\end{array}$ & No toxic residues & $\begin{array}{l}\text { Deformation/degradation due to water } \\
\text { attack, limited usage for PLA-PGA }\end{array}$ \\
\hline $\begin{array}{l}\text { Dry heat sterilization } \\
(160-190 \mathrm{C})\end{array}$ & No toxic residues & $\begin{array}{l}\text { Melting and softening of polymer, not usabie } \\
\text { for PLA-PGA }\end{array}$ \\
\hline $\begin{array}{l}\text { Raciation } \\
\text { (ionizing or } 7 \text { ) }\end{array}$ & $\begin{array}{l}\text { High penetration, low chemical } \\
\text { reactivity, quick effect }\end{array}$ & $\begin{array}{l}\text { Instability and deterioration, cross-linking/ } \\
\text { breakage of polymer chains }\end{array}$ \\
\hline $\begin{array}{l}\text { Gas sterilization } \\
\text { (ethylene oxide) }\end{array}$ & Low temperature range & $\begin{array}{l}\text { Lengthy process due to degassing, residues } \\
\text { are toxic }\end{array}$ \\
\hline
\end{tabular}

PLGA can be fabricated in numerous ways, including nanoprecipitation, compression molding, and spray drying [47]. The method of electrospinning will be the focus of this thesis. PLGA processing methods include electrospinning. PLGA can be successfully electrospun in fibrous tubular structures, which fit the need of the Cal Poly tissue engineering laboratory for creating BVM scaffolds. 


\subsection{Electrospinning}

\subsubsection{Background and Applications}

The electrospinning process involves a polymer solution held by surface tension at the end of a needle within an electric field. The most basic setup involves a high voltage supply (between $0-30 \mathrm{kV}$ ), an electrically conducting spinner, and a grounded collector, diagramed in Figure 8 [48].

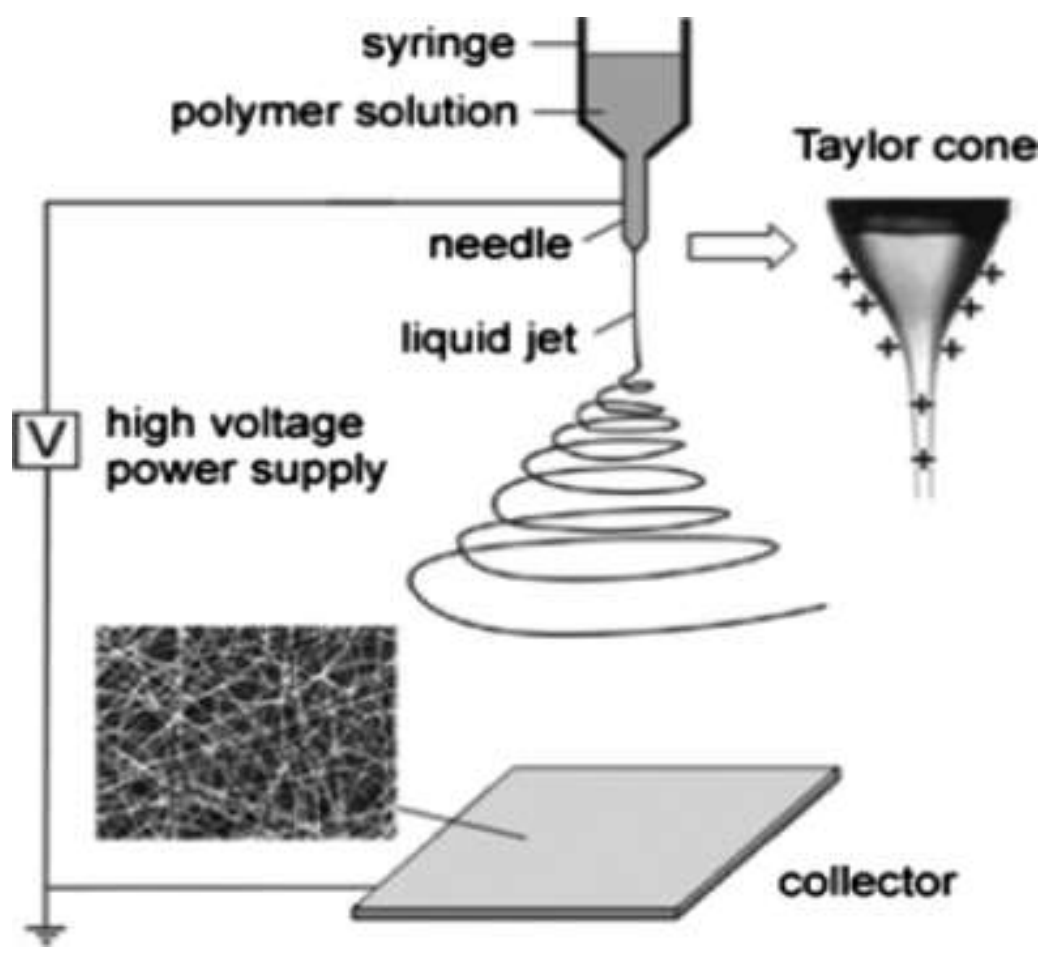

Figure 8: Basic electrospinning setup, including syringe ejecting polymer, which is charged by a high voltage supply, creating the Taylor cone imaged. The liquid jet seeks to land on the grounded collector [49].

The basic idea of electrospinning began in 1934 when Anton and Formhals patented an experimental set up for producing polymer filaments using electrostatic force[50-52]. The field causes a charge on the surface, and the mutual charge acts against the surface tension. The solution then elongates and forms a conical shape 
known as the Taylor cone from which a charged jet of solution is ejected from the tip. The trajectory of the tip is controlled by the electric field, and as the jet travels the solution evaporates, leaving a polymer fiber that randomly collects on some sort of grounded material. The result is a woven mesh or fabric. Various solutions have been used, such as water soluble polymers, biopolymers, and liquid crystalline polymers. The resulting fibers can range from and beyond 0.05 microns and 5 microns [53,54]. The electrospinning process derived from the electrospraying of liquids [55]. Since the 1960s, numerous industries have employed electrospinning for fiber reinforcement, textiles, separation membranes, and insecticides[56-61].

The flight from the needle tip to the collector involves solution being evaporated leaving a fiber behind seeking a grounded material. The solution has the opposing forces of the charge from the voltage seeking to separate the fibers, and the viscoelastic forces such as surface tension seeking to keep the solutions together. Forces competing are the electrostatic force acting on the charged jet due to the electric field between the needle and collector, the Coulombic electrostatic repulsion between adjacent charged elements within the jet which is responsible for stretching, viscoelastic forces and surface tension which act against stretch. A hyperbolic conical shape forms at the tip of the needle termed a Taylor cone. Its formation comes from the repulsive electrostatic forces overcoming the surface tension of the solution, and a jet of fiber ejects from its tip [62]. While the jet is in the air, the diameter decreases, which would suggest that a larger gap distance would result in a smaller fiber diameter, and as it decreases the surface charge density increases. These repulsive forces split the jet and smaller jets spiral out. The process repeats until multiple small jets are present that seek grounding $[54,63]$. 


\section{Taylor cone}

Taylor studied the jet and coined the "Taylor cone", claiming that an angle of $49.3^{\circ}$ is ideal for the conical shape when the surface tension forces balance the electric field [53]. This conical shape and ideal angle has been independently verified by other researchers, which agree the cone should be at an angle below $50^{\circ}$ [64-67]. The two forces that create the Taylor cone drop and the resulting jet are opposing electrostatic forces: the electrostatic repulsion between the surface charges and Coulomb forces from the electric field caused by the applied voltage [48]. The jet elongates until reaching the collector and forms a randomly oriented fiber matrix. The jet has a linear trajectory and then the jet begins to whip out due to bending instability, following a helical path. Further higher order instability occurring at the onset of bending instability leads to a chaotic trajectory [68-72].

The electric field strength on the Taylor cone can be estimated using Equation 1 below, where gamma is the surface tension of the polymer solution, $R$ is the radius of curvature of the rounded off cone apex, and epsilon is the permittivity of the free space. The presence of the curved Taylor cone proved useful in efficient fiber collection [54].

\section{Equation 1:}

$$
E=\sqrt{\frac{4 \gamma}{R \varepsilon_{O}}}
$$




\section{Jet Stages}

Electrospinning process involves nonlinear electrohydrodynamics at high speeds, complex rheology, and transport of charge, mass, and heat within the jet. There are three main stages of the process: jet initiation, jet elongation with or without branching, and the solidification of the jet into nanofibers $[48,73]$.

Jet initiation is when the Taylor cone is formed and the intensity of the electric field reaches a critical value, in Equation 2 determined by Taylor below, and the surface tension is overcome and the liquid jet is forced from the tip of the cone, where the highest charge density is located [53].

\section{Equation 2:}

$$
V_{c}=4\left(\frac{H^{2}}{L^{2}}\right)\left(\ln \frac{2 L}{R}-1.5\right)(0.117 \pi R \gamma)
$$

In the above equation, $\mathrm{H}$ is the air-gap distance, $\mathrm{L}$ is the length of the capillary tube, $\mathrm{R}$ is the radius of the tube and gamma is the surface tension.

Jet thinning occurs once the jet is spiraling towards the grounded collector [48]. Due to the opposing forces the jet is exposed to, numerous instabilities occur while the jet is traveling [54]. Because of the instabilities the jet begins splaying or branching off due to changes in shape and charge density as the jet elongates and the solvent evaporates [74]. This process occurs more in concentrated solutions and higher applied voltages [71]. The crucial instability required for reducing fiber diameter to the nanometer level is nonaxisymmetric or whipping instability. Then as the jet becomes thinner, the charge distribution is more volatile. The bending instabilities stack on each other and create a trajectory diagramed in Figure 9 below. Each loops continues to grow longer and thinner until reaching the collector [68]. 


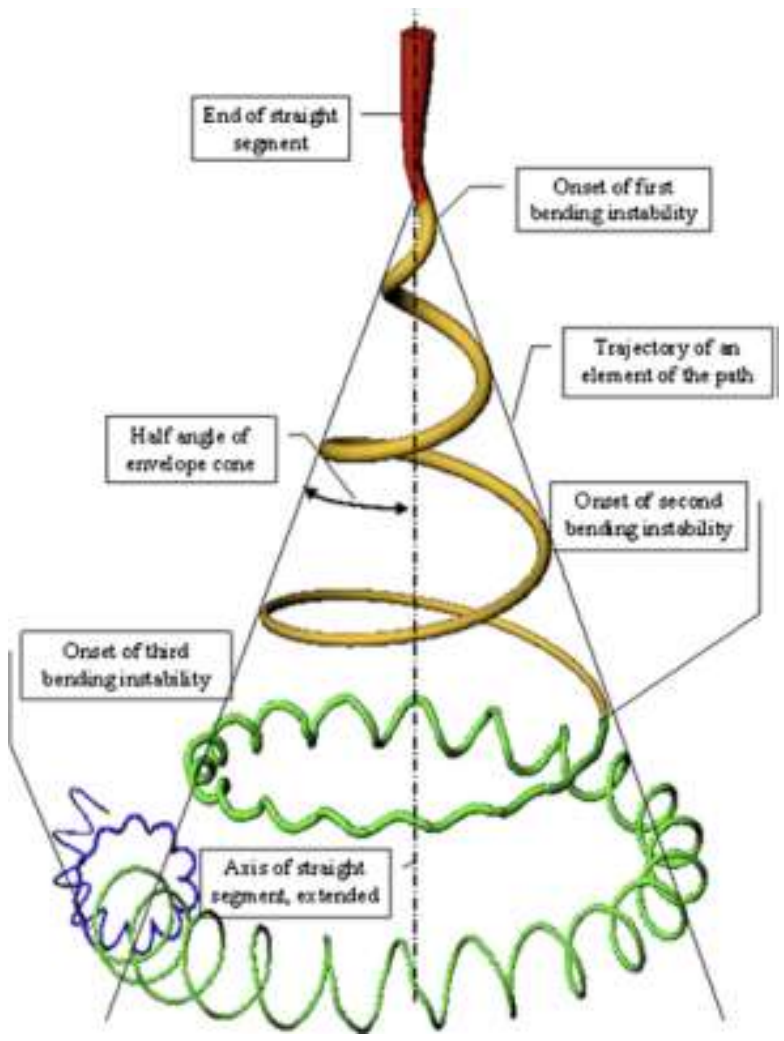

Figure 9: Onset and development of bending instability during electrospinning jet elongation [71].

There are three types of bending instabilities. Rayleigh instability is axisymmetric and occurs due to opposing forces on the surface of the jet. The instability stems from the electrostatic repulsion increasing the surface area, and the surface tension seeking to decrease the surface area. The two forces break the jet up into droplets if the viscosity is low, and if it is high then the jet diameter just continually decreases [75]. If the droplets continue to form and shrink, electrospraying occurs because the droplets cannot coalesce [70]. The final two instabilities are whipping instability and another axisymmetric instability. 


\section{Applications}

In the medical field, tissue engineering, and also wound dressing, and controlled drug release systems are a common use of thin fibered materials created by electrospinning. The tissue engineering aspect applies to more than cardiovascular applications, including skin, bone, and spinal function regeneration [76-78]. The electrospinning process is ideal desirable for these applications because the resulting scaffolds have a high porosity and naturally interconnecting fibrous matrix ideal for cell adhesion or diffusion, and requires no contact. It also is not as complex as selfassembly and many more materials can be used than in phase separation. Also, the resulting characteristics can be controlled, such as geometry, tensile strength, and material composition $[48,49,77,79]$.

Recently electrospinning has been honed for tissue engineering by spinning biodegradable polymers or natural polymers. PGA, PLA, as well as blends of the twosuch as PLGA—and PCL and PDO have been successfully spun and analyzed [79-100]. Researchers have successfully spun natural polymers such as collagen (types I-IV), gelatin, elastin, silk, fibrogen, hemoglobin, and myoglobin [89,96,98,101-144].

\subsubsection{Electrospinning Parameters}

The resulting material's characteristics are dependent on the processing parameters, the ambient environment, such as temperature, humidity, and air velocity, and the polymer and solvent used, including viscosity, conductivity and surface tension $[29,54]$. The processing parameters that have affected fiber diameter most, and will be discussed in detail separately, are the applied voltage, the solution concentration, the distance from the needle tip to the collector (gap distance), and the flow rate.

The relative humidity of the electrospinning chamber can affect the time it takes for the jet to solidify due to water absorbed by the solution, and thereby cause changes 
in the morphology of the fibers [145]. Temperature affects both the evaporation of the solvent. The lower the temperature, the slower the rate of evaporation [145].

Viscosity has also been a parameter researched. One of the early pioneers, Simons determined that short fine fibers were formed from more viscous solutions, and that longer continuous fibers resulted from higher viscosity solutions [56]. Researchers determined that as viscosity of the polymer solvent decreased, the cone changed from hemispherical to conical. The other parameters mentioned, such as conductivity and surface tension [146]. However, recent studies have discovered that most of the variables involved are tightly intertwined, such as viscoelastic response and solvent evaporation rate $[71,147-149]$.

\section{Solution Concentration}

Solution concentration is the concentration of the polymer within the solvent solution. Solution concentration affects fiber diameter and is crucial to successful fiber collection. Solution concentration that is too low or high results in an unstable jet [54]. Studies show a strong correlation to fiber diameter [150]. For concentrated solutions, a second population of small fibers appears in addition the normal fibers [151].

Fiber diameter and the concentration of the solution are proportional, meaning to obtain a smaller diameter, a low concentration of solution is ideal. However, merely lowering the solution concentration is not enough, due to interactions between the parameters.

\section{Applied Voltage}

The applied voltage is the voltage the power supply applies to the needle tip. In the Cal Poly laboratory, the applied voltage is the potential difference between the collector and the needle, however some set ups allow negative polarity and various 
ways to alter the potential difference [152]. The voltage not only affects the fiber diameter, but various elements of the scaffold morphology. The voltage can affect the fibrils in that the deposition pattern as voltage becomes too high the fibril deposition is no longer random, and the shapes of the fibers becomes less circularly uniform and globular shapes appear [54]. The globular or bead formations that can result in on the fiber matrix can be attributed to a shape change in the jet, which can be caused due by an increase in applied voltage [151]. A higher charge density, meaning more voltage for a more dense solution, and low surface tension of the solution result in the suppression of beads [153].

For the fiber diameter purposes however, the applied voltage will result in a smaller fiber diameter if increased, but only to a certain point, where the jet diameter begins to increase again. Thus there is an ideal applied voltage that results in a minimum fiber diameter depending on the polymer and interacting parameters [146]. Studies have reported that a higher voltage can result in a larger fiber diameter because more fluid is ejected, however depending on the type of polymer, such as silk-like polymers, a higher voltage can result in a decrease of fiber diameter [154,155].

\section{Gap Distance}

The gap distance is the distance between the tip of the needle where solution is ejected and the grounded collector, measured as depicted in Figure 10 below. The maximum distance possible with the current set up is 17.5 inches. This distance is where the liquid jet branches. The diameter of the jet has been measured during the spinning process and it was found that jet diameter and the gap distance-measured from the apex of the Taylor cone-were inversely proportional $[54,156]$. 


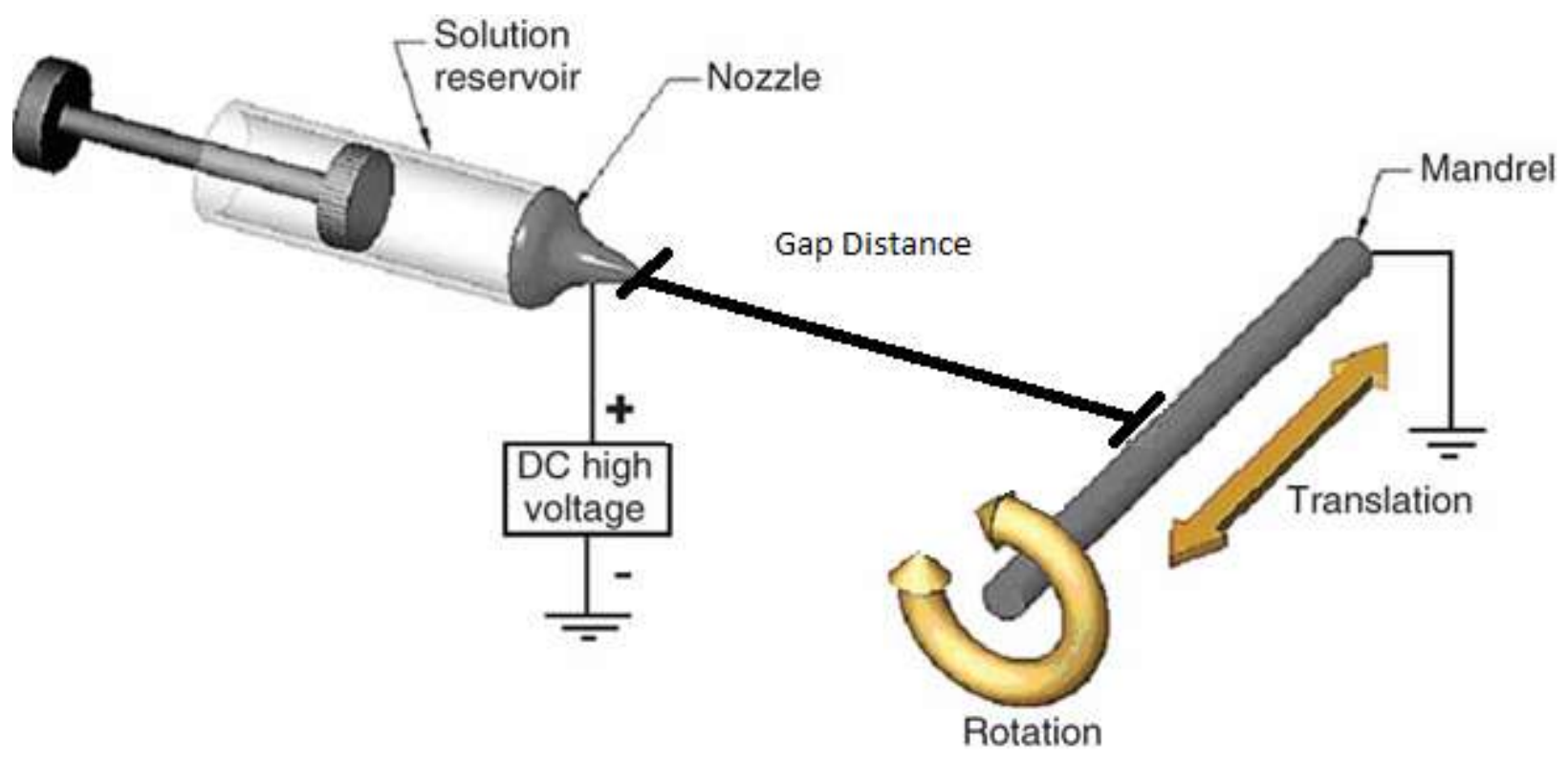

Figure 10: Mandrel electrospinning set up diagraming the movement of the mandrel (translation and rotation), as well as the measurement of gap distance. Modified from C. Ayres 2009 publication [109].

The gap distance can affect the electric field between the needle tip and the collector, which can be analyzed by determining the potential difference between the needle tip and the collector. Though a larger gap distance results in a weaker electric field, theoretically the larger travel distance should result in a fully evaporated solution.

\section{Flow Rate}

The flow rate is the rate at which the solution is ejected from the charge needle tip. The flow rate largely impacts the jet thinning stage discussed above, where the jet is elongated. Studies have determined the flow rate to be inversely proportional to the rate of jet thinning, suggesting the lower the flow rate, the higher the rate jet thinning, and the smaller the fibers [48]. The flow rate can also affect the size and morphology of the resulting fiber. Low flow rates correlated with smaller fiber diameters and vice versa. It was theorized that with a higher feed rate, the droplet/Taylor cone at the tip of the needle is larger, and the solution moves faster, so the fibers do not have as much chance to elongate and branch. The solvent may not completely evaporate, resulting in large 
beads and junctions on the fiber matrix [154]. A slow flow rate, which may not be time effective, is ideal for nanofibrous scaffolding.

\subsubsection{Nanofibrous Scaffolding}

Nanofribrous matrices are more successful when it comes to cell adhesion and proliferation because the fiber diameters that vary between 50 - 500 nanometers matches the dimensions of collagen $[10,77,79]$. Nanofibers also provide less resistance to diffusion across the matrix, or in this case the scaffold [157].

Electrospun scaffolds are ideal for tissue engineered scaffolding because they can have submicron fiber diameters, a large surface to volume ratio, high porosity, variable pore size distribution, all which can be tailored to match the ECM $[70,152]$. The fiber diameter can be controlled, and studies have shown that biocompatibility increases with decreasing fiber diameter [102]. Therefore, the goal of this thesis will be to further enhance our control over the in-house electrospinning process, by minimizing fiber diameter. 


\section{Summary and Aims of Thesis}

Electrospinning has been developed as in-house technique for the creation of scaffolding for BVMs. Currently, the resulting scaffolds made with PLGA are consistent and can create a viable environment for the proliferation of cells, though ideally, the cells would form a more confluent layer. Research as summarized above indicates that nanofibers better mimic the ECM, and that the size of these fibers can be controlled through optimizing the various parameters. However the current in-house scaffolds produced are composed of micron sized fibers. Using data from preliminary studies, a DOE was developed by another student. The purpose of the DOE is to investigate the interactions of different variables that influence the process in an attempt to minimize fiber diameter. Gap distance, flow rate, applied voltage, and solution concentration were all varied and the resulting fiber diameter was measured for each scaffold. Statistical analysis was performed to determine an equation that could be applied to the current setup to be able to predict fiber diameter, and use it to find a set of parameters that produces a scaffold with an average fiber diameter of 100 to 200 nanometers. 


\section{Chapter 2: Preliminary Electrospinning Trials}

\section{Introduction}

In order to better mimic the physiologic microstructure of a blood vessel, specifically the ECM, the fiber diameter of electrospun scaffolds should be decreased [102]. Studies successfully creating scaffolds that mimicked the architecture of the ECM were composed of fibers between 80-500 nanometers [48]. When these trials were performed, the Cal Poly lab standard protocol was producing scaffolds with an average fiber diameter between 5 and 6 microns [28]. Gap distance, flow rate, voltage, and solution concentration have been shown to have the greatest effect on the fiber diameter of electrospun polymer scaffolds $[70,150]$. While nanofibers have been created with more expensive blends, the purpose of the following spins was to apply relationships theorized from past studies to a cheaper polymer solvent solution without the aid of collagen to promote cell adhesion. PLGA — a copolymer found to be biocompatible and biodegradable — was mixed with chloroform and manipulated only via electrospinning variables to attempt to determine a standard protocol for smaller fiber diameters consistently distributed throughout the scaffold. 


\section{Methods and Results}

\section{General}

Each scaffold was created with 3 milliliters of solution (PLGA plus chloroform) that mixed between 24 and 48 hours prior to electrospinning. Spin 1 was performed using the standard protocol determined by Tiffany Pena [28], and each subsequent spin varied one of the key process parameters. Each spun scaffold was then imaged to assess the presence and continuity of fibers. A full protocol for electrospinning and imaging steps can be found in Appendix C-F. For most spins, after 48 hours in a desiccator to remove excess moisture, the scaffold was cut into four equal pieces, and from each piece, half a centimeter was removed for SEM imaging. This provided 4 sections per spin for imaging. For each section, four images were taken between 500 and 800 magnification depending on the size of the fibers. Microsoft Excel was then used to generate eight random coordinates where fiber diameter was measured. Measurements were averaged across the entire length of the scaffold. In some cases, the scaffolds were not fibrous, and could either not be removed from the mandrel, or upon imaging, could not be measured due to the lack of fibers. In addition, some scaffold images were lost and could not be reproduced, however notes from the spin detail the results below.

For each spin in this preliminary phase of the project, the purpose, concentration, voltage, flow rate, gap distance, and results are documented below. 


\section{Spin 1}

Purpose:

This protocol was tested for consistency with a previous grad student and the scaffold produced served as a control/comparison for the rest of the spun scaffolds.

Concentration: $\quad 15 \%$

Voltage: $\quad 15 \mathrm{kV}$

Flow Rate: $\quad 5.5 \mathrm{ml} / \mathrm{hr}$

Gap Distance: $\quad 10$ inches

Results: $\quad$ The electrospinning process was completed without any change

to parameters during the spin. The average fiber diameter was

5.12 microns, and is imaged in Figure 11 below.

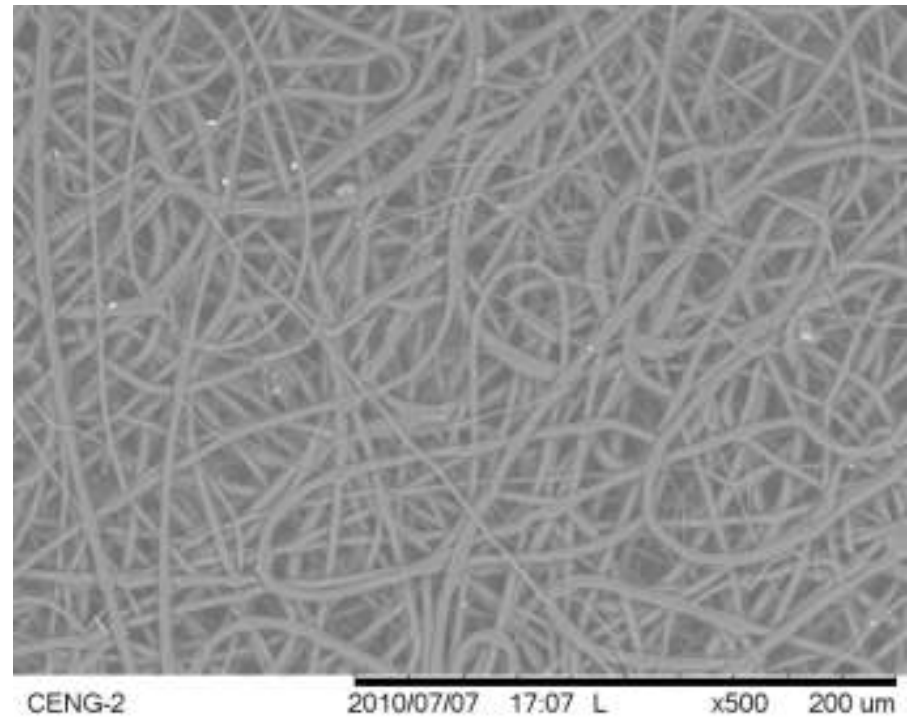

Figure 11: Spin 1 lumen imaged at 500x, spun with the standard protocol. 


\section{Spin 2}

Purpose:

To isolate solution concentration.

Concentration: $\quad 12 \%$

Voltage: $\quad 15 k \mathrm{~V}$

Flow Rate: $\quad 5.5 \mathrm{ml} / \mathrm{hr}$

Gap Distance: $\quad 10$ inches

Results: $\quad$ No changes were observed during the electrospinning process.

Upon SEM imaging the fibers were oriented normally, however

some of the fibers bulged and beads were present as seen in

Figure 12. Fiber diameter was not measured because of the

larger variation in the fiber diameter.

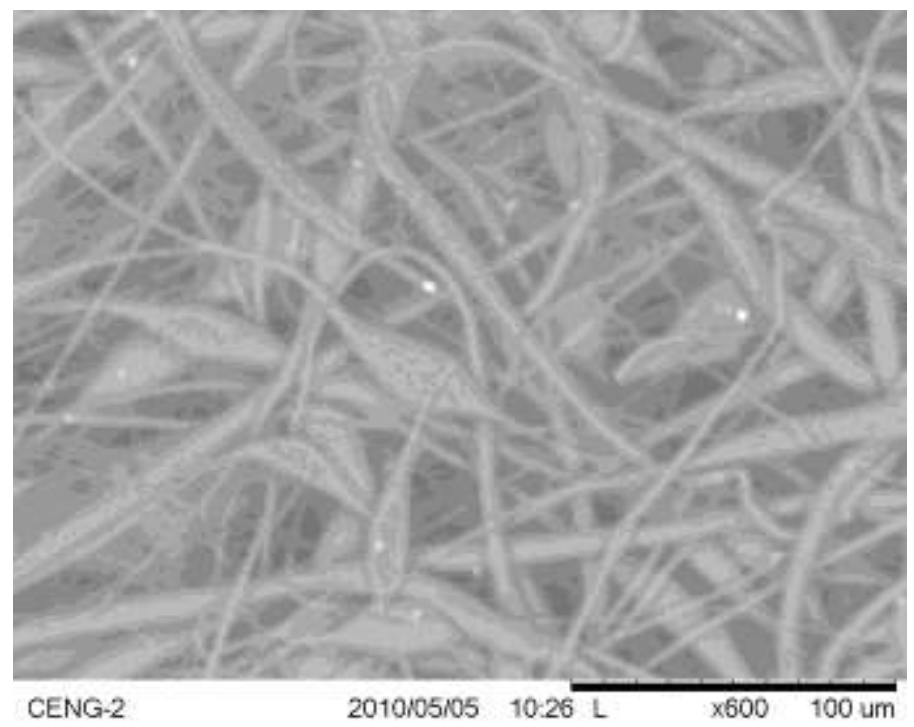

Figure 12: Spin 2 SEM image at 600x with standard electrospinning protocol and $12 \%$ solution concentration depicting uneven fiber diameter. 


\section{Spin 3}

Purpose: $\quad$ To isolate solution concentration.

Concentration: $\quad 10 \%$

Voltage: $\quad 15 \mathrm{kV}$

Flow Rate: $\quad 5.5 \mathrm{ml} / \mathrm{hr}$

Gap Distance: $\quad 10$ inches

Results: $\quad$ The solution was notably less viscous after mixing. A sample of the inner lumen is illustrated in, Figure 13, and just by visual inspection, there are more beads dispersed in the fibers. Fiber diameter was not measured because the beads would create too much variation, and not result in a smaller fiber diameter.

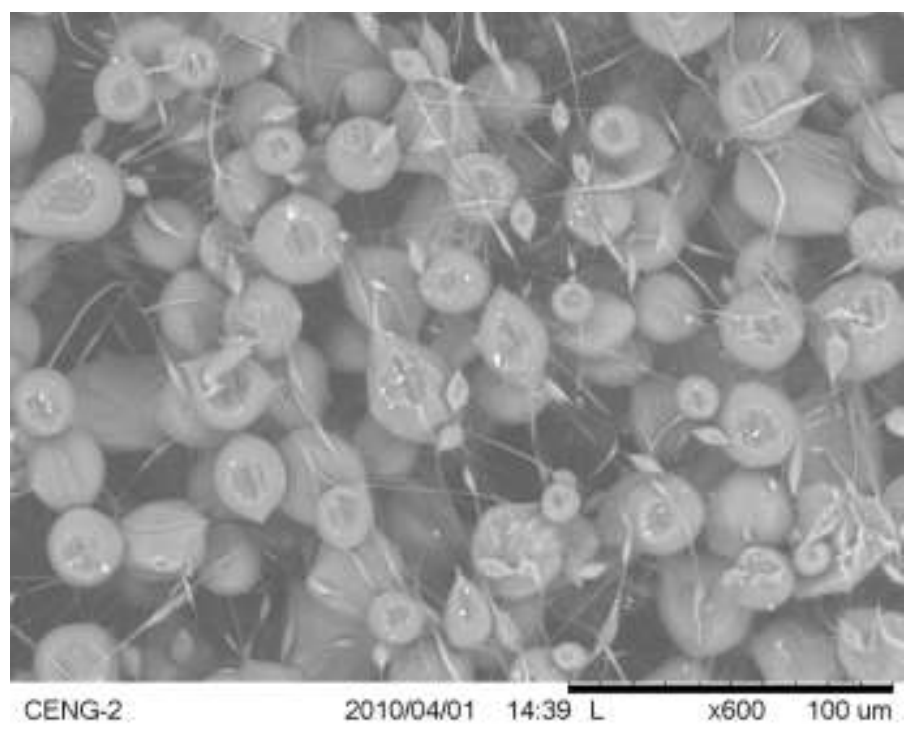

Figure 13: Spin 3 SEM image at 600x depicting globular formations. 


\section{Spin 4}

Purpose: $\quad$ To isolate solution concentration.

Concentration: $\quad 8 \%$

Voltage: $\quad 15 \mathrm{kV}$

Flow Rate: $\quad 5.5 \mathrm{ml} / \mathrm{hr}$

Gap Distance: $\quad 10$ inches

Results: The mixed solution was not as viscous as well, and during the electrospinning the solution being ejected from the needle was spraying from the needle opening instead of from the Taylor cone. The scaffold could not be prepped for SEM imaging because there was little fiber actually on the mandrel, and what was attached could not be removed without breaking the material. 


\section{Spin 5}

Purpose: $\quad$ To isolate flow rate.

Concentration: $\quad 15 \%$

Voltage: $\quad 15 \mathrm{kV}$

Flow Rate: $\quad 6.0 \mathrm{ml} / \mathrm{hr}$

Gap Distance: $\quad 10$ inches

Results: $\quad$ During the spin the solution coming out of the needle dripped and a droplet of about half a centimeter long consistently remained on the tip of the needle. Fibers still stuck onto the mandrel however. Figure 14 is a SEM sample of the lumen, where the average fiber diameter is 3.87 microns. The fibers below in Figure 14 are not consistent, but rather some are thin, while others are thick.

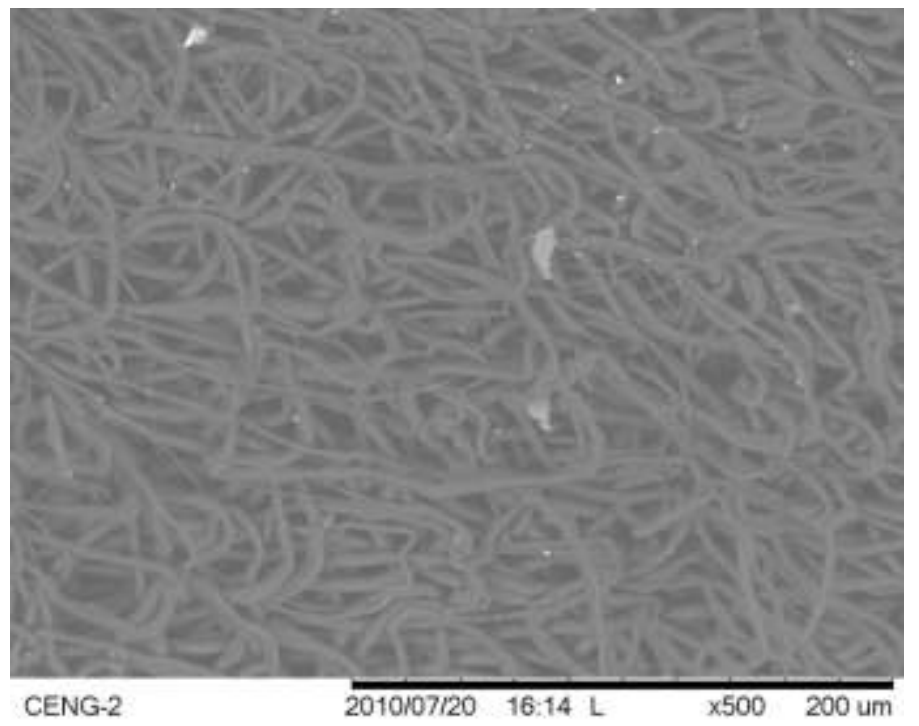

Figure 14: Spin 5 SEM image at 500x with inconsistent fiber diameters. 


\section{Spin 6}

Purpose: $\quad$ To isolate flow rate.

Concentration: $\quad 15 \%$

Voltage: $\quad 15 \mathrm{kV}$

Flow Rate: $\quad 7.0 \mathrm{ml} / \mathrm{hr}$

Gap Distance: $\quad 10$ inches

Results: $\quad$ During the spin the solution dripped enough so that the voltage was increased and decreased during the spin to either charge the droplet enough so it would begin to spiral off the needle, or to lower the charge enough for the droplet to sink off, respectively. This resulted in a very uneven scaffold with visible defects including thick balls of material and an uneven distribution of fibers along the scaffold length. No SEM images were taken. 


\section{Spin 7}

Purpose: $\quad$ To isolate flow rate.

Concentration: $\quad 15 \%$

Voltage: $\quad \sim 15 \mathrm{kV}$

Flow Rate: $\quad 8.0 \mathrm{ml} / \mathrm{hr}$

Gap Distance: $\quad 10$ inches

Results: $\quad$ Again with the high flow rate the solution dripped and the voltage was altered in order to get rid of the drop. However, when the voltage was increased above $18 \mathrm{kV}$ sparks ran along the needle and syringe pump and the spin was stopped. Only $1.4 \mathrm{ml}$ of solution was ejected from the needle. The result of this spin was a very thin mat of fibers on the mandrel that could not be removed. No SEM images were taken.

\section{Spin 8}

Purpose: $\quad$ To isolate gap distance.

Concentration: $\quad 15 \%$

Voltage: $\quad 15 \mathrm{kV}$

Flow Rate: $\quad 5.5 \mathrm{ml} / \mathrm{hr}$

Gap Distance: $\quad 12$ inches

Results: $\quad$ No abnormalities were observed during the electrospinning process. Upon SEM imaging the fibers were oriented normally however the fibers were noticeably larger than the standard protocol's resulting fibers. The images for this scaffold were lost. 


\section{Spin 9}

Purpose: $\quad$ To isolate gap distance.

Concentration: $\quad 15 \%$

Voltage: $\quad 15 \mathrm{kV}$

Flow Rate: $\quad 5.5 \mathrm{ml} / \mathrm{hr}$

Gap Distance: $\quad 8$ inches

Results: $\quad$ All other variables were kept consistent during this spin. Figure 15

shows a more consistent fiber orientation, however there were very thick fibers randomly distributed throughout. The larger fibers may be due to a handling error. When cutting the scaffold and placing it for imaging, fibers may have been smashed onto the lumen. The average fiber diameter was 2.54 microns.

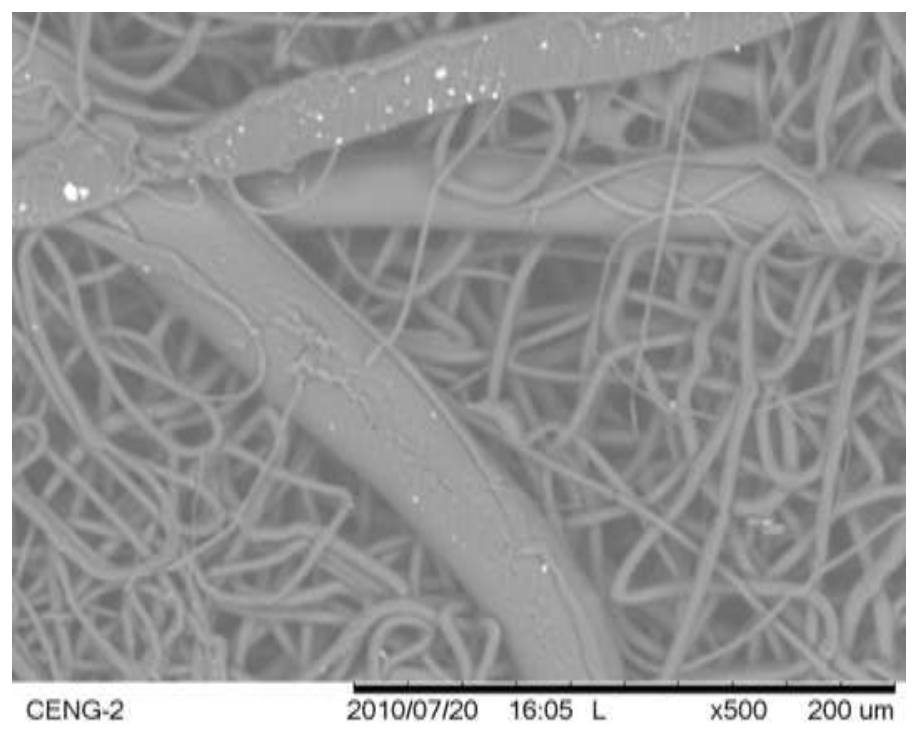

Figure 15: Spin 9 SEM image at 500x with large fibers dispersed. 
Spin 10

Purpose: $\quad$ To determine the interaction between gap distance and flow rate.

Concentration: $\quad 15 \%$

Voltage: $\quad \sim 15 \mathrm{kV}$

Flow Rate: $\quad 6.0 \mathrm{ml} / \mathrm{hr}$

Gap Distance: $\quad 8$ inches

Results: The faster flow rate resulted in solution dripping from the needle, so voltage was varied for a couple seconds to higher voltages between 16 and $18 \mathrm{kV}$. Figure 16 is an SEM sample of the lumen, and after measuring the fibers the average was 2.8 microns.

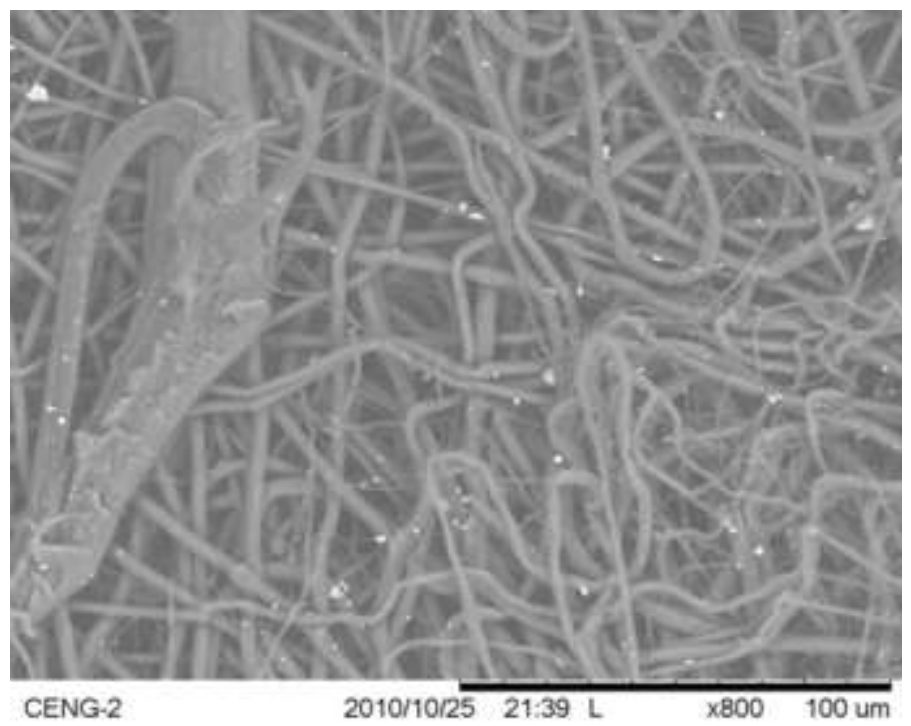

Figure 16: SEM image of Spin 10 at $800 x$ depicting fibers with a mean fiber diameter of 2.8 microns. 


\section{Spin 11}

Purpose: $\quad$ To isolate gap distance.

Concentration: $\quad 15 \%$

Voltage: $\quad 15 \mathrm{kV}$

Flow Rate: $\quad 5.5 \mathrm{ml} / \mathrm{hr}$

Gap Distance: $\quad 7$ inches

Results: No variables were altered during the spinning process. The fibers are evenly distributed and fairly consistent with an average diameter of 2.735 microns. The images were lost and cannot be reproduced.

\section{Spin 12}

Purpose: $\quad$ To determine the interaction between flow rate and voltage.

Concentration: $\quad 15 \%$

Voltage: $\quad \sim 15 \mathrm{kV}$

Flow Rate: $\quad 6.0 \mathrm{ml} / \mathrm{hr}$

Gap Distance: $\quad 7$ inches

Results: $\quad$ During the spin, the applied voltage was varied between $15 \mathrm{kV}$ and $20 \mathrm{kV}$ volts to maintain the Taylor cone for seconds at a time but mainly kept at 15000 volts. The average fiber diameter was 2.67 microns. The images were lost for this spin and could not be reproduced. 


\section{Spin 13}

Purpose: $\quad$ To combine results of fiber diameter, voltage, and flow rate to minimize fiber diameter.

Concentration: $\quad 15 \%$

Voltage: $\quad \sim 18 \mathrm{kV}$

Flow Rate: $\quad 6.0 \mathrm{ml} / \mathrm{hr}$

Gap Distance: $\quad 8$ inches

Results: $\quad$ During the spin the voltage was set at $18 \mathrm{kV}$ and was maintained for the majority of the time, however it was increased and decreased $(+/-3 \mathrm{kV})$ to maintain a steady flow of fiber. A sample of the lumen is shown below in Figure 17. The fiber size is not consistent, and the machine was not functioning $100 \%$, in that the mandrel was not translating evenly, thus the unclear sections in the image. The average fiber diameter was 2.46 microns.

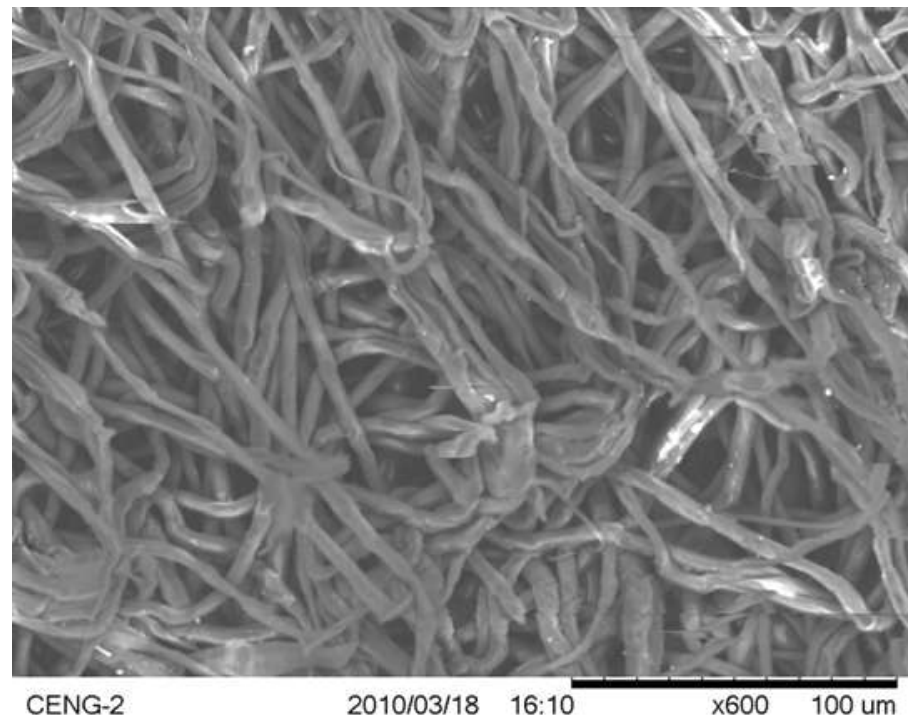

Figure 17: Spin 13 SEM image at $600 x$ with standard protocol with $18 \mathrm{kV}$ applied voltage, $6.0 \mathrm{ml} / \mathrm{hr}$ flow rate, and a gap distance of 8 inches. 


\section{Discussion and Conclusion}

Fiber diameter was successfully decreased through experimentation with gap distance, flow rate, voltage, and solution concentration. A decrease in gap distance resulted in smaller fiber diameters, but only to a certain point. This is surprising because literature has linked a larger gap distance to smaller fiber diameter, linking the larger gap distance as more time for jet instabilities to occur and branch off, resulting in smaller fibers [48]. When decreasing to 7 inches, the average fiber size actually increased, however it is inaccurate to make a strong conclusion because the averages are not paired with standard deviations and with only one spin for each variation, consistency cannot be assumed. Because at times multiple variables were altered, a systematic method of studying the effect on fiber diameter was necessary.

Decreasing the solution concentration did visibly decrease the fiber size; however the beads and inconsistencies in the fiber orientation were not ideal. Solution concentration was not tested against other variables and because of the low viscosity; a higher flow rate and voltage may need to be paired with a lower solution concentration, however research suggests a lower solution concentration is correlated with lower fiber diameters [150]. While gap distance did not interact greatly with other variables during the spin, voltage and flow rate greatly affected one another. An increase in flow rate needed to be paired with an increase in voltage or the solution would drip out of the needle. It is visibly apparent while spinning, and the literature describes that in order to maintain a steady jet, the voltage needs to be high enough to counteract the surface tension. If the flow rate is high, with too low of a voltage, the Coulombic forces give way to the surface tension and the solution drips from the needle [68]. Thus, it is difficult to isolate only one variable, when a variable is directly correlated with another. Also, some of the images had fibers that were two different sizes. Though some of the fibers were 
less than three microns, there were also larger ones. It is unclear whether cells would be more likely to stick to a consistent middle ground, or to an inconsistent lumen half made up of smaller fibers. However, literature suggests smaller fiber diameters promote cell adhesion [102].

While these preliminary spins provided insight into the interaction of electrospinning process parameters and which ones affected fiber diameter, no statistical significance can be drawn from the pooled data. The variables need to be isolated and left alone during the spin to effectively observe the relationship with fiber diameter, and multiple spins need to be done for each test. These results can be used to create a design of experiment (DOE) establishing the amount of sample needed to determine significance and how to select which variables are tested and to what range of values during spinning. Thus, a DOE was carried out, and will be described in the next chapter. 


\section{Chapter 3: Design of Experiment}

\subsection{Introduction}

The preliminary electrospinning trials described in Chapter 2 provided data that served as a pilot study in order to create a DOE that would test the interaction of variables that affect fiber diameter. Having selected solution concentration, gap distance, voltage, and flow rate as the variables that would affect the fiber diameter most, an experiment was designed as a senior project by Biomedical Engineering Undergraduate student Steffi Wong [158]. The purpose of the DOE is to determine the effect of each factor on the response variable, in this case the average fiber diameter. In addition, because each factor is related to at least one other factor, the DOE also allows a determination of those interactions. With an understanding of the process, the DOE and subsequent experimentation allows for the reduction of common cause variation, and leaves - if research and preliminary trials prove to be useful-a potential process optimization of fiber diameter that is statistically significant and consistent.

A complete report on the DOE can be found in Ms. Wong's senior project (provided in Appendix B.) But in summary, the DOE includes four different factors that have been shown from literature and experimentation affect the response variable, fiber diameter. Each factor has two levels and a center point, and every treatment combination is performed to assess the effect of the different levels on the response variable. The experimental runs of the DOE are listed below in Table 2. 
Table 2: Design of Experiment Set up including the run order and factor selection for each trial.

\section{Each combination is only performed once [159].}

\begin{tabular}{|c|c|c|c|c|c|c|}
\hline StdOrder & RunOrder & CenterPt & Concentration & Voltage & Gap Distance & Flow Rate \\
\hline 2 & 1 & 1 & 15.0 & 24 & 7.0 & 4.5 \\
\hline 8 & 2 & 1 & 15.0 & 30 & 10.0 & 4.5 \\
\hline 5 & 3 & 1 & 10.0 & 24 & 10.0 & 4.5 \\
\hline 17 & 4 & 1 & 10.0 & 24 & 7.0 & 4.5 \\
\hline 28 & 5 & 1 & 15.0 & 30 & 7.0 & 6.5 \\
\hline 20 & 6 & 1 & 15.0 & 30 & 7.0 & 4.5 \\
\hline 24 & 7 & 1 & 15.0 & 30 & 10.0 & 4.5 \\
\hline 27 & 8 & 1 & 10.0 & 30 & 7.0 & 6.5 \\
\hline 21 & 9 & 1 & 10.0 & 24 & 10.0 & 4.5 \\
\hline 6 & 10 & 1 & 15.0 & 24 & 10.0 & 4.5 \\
\hline 25 & 11 & 1 & 10.0 & 24 & 7.0 & 6.5 \\
\hline 26 & 12 & 1 & 15.0 & 24 & 7.0 & 6.5 \\
\hline 14 & 13 & 1 & 15.0 & 24 & 10.0 & 6.5 \\
\hline 23 & 14 & 1 & 10.0 & 30 & 10.0 & 4.5 \\
\hline 3 & 15 & 1 & 10.0 & 30 & 7.0 & 4.5 \\
\hline 22 & 16 & 1 & 15.0 & 24 & 10.0 & 4.5 \\
\hline 31 & 17 & 1 & 10.0 & 30 & 10.0 & 6.5 \\
\hline 13 & 18 & 1 & 10.0 & 24 & 10.0 & 6.5 \\
\hline 29 & 19 & 1 & 10.0 & 24 & 10.0 & 6.5 \\
\hline 1 & 20 & 1 & 10.0 & 24 & 7.0 & 4.5 \\
\hline 33 & 21 & 0 & 12.5 & 27 & 8.5 & 5.5 \\
\hline 18 & 22 & 1 & 15.0 & 24 & 7.0 & 4.5 \\
\hline 15 & 23 & 1 & 10.0 & 30 & 10.0 & 6.5 \\
\hline 12 & 24 & 1 & 15.0 & 30 & 7.0 & 6.5 \\
\hline 7 & 25 & 1 & 10.0 & 30 & 10.0 & 4.5 \\
\hline 16 & 26 & 1 & 15.0 & 30 & 10.0 & 6.5 \\
\hline
\end{tabular}




\subsection{Methods}

\subsubsection{Mixing Solution}

PLGA 75:25 (MW = 66,000-107,000, PDI unavailable) purchased from SigmaAldrich and dissolved in chloroform comprised every solution with varying percentages of the polymer. Appendix $C$ includes the full protocol followed for mixing the PLGA in chloroform. Every solution was mixed with 4 milliliters of chloroform, measured with a pipette, and a specified amount of PLGA determined with Equation 3 below, based on the indicated solution concentration for the spin.

\section{Equation 3:}

$$
w t \%=\frac{\text { grams of polymer }}{\text { grams of polymer }+ \text { grams of chloroform }}
$$

The weight percent (wt\%) corresponds to the given parameter "concentration" listed in the DOE. For example, to create a 15.0 concentration, 1.04 grams of polymer would be used.

$$
\begin{aligned}
& 4 \mathrm{ml} \text { of chloroform } \times \frac{1.48 \text { grams }}{\text { ml of chloroform }}=5.92 \text { grams of chloroform } \\
& 15.0 \%=\frac{\text { grams of polymer }}{\text { grams of polymer }+5.92 \text { grams of chloroform }}
\end{aligned}
$$

1.04 grams of polymer needed to obtain $15.0 \%$ solution

The polymer was measured with a scale and each solution mixed in a foil-wrapped 10 milliliter glass vial on a shake table for 24 to 48 hours before spinning. 


\subsubsection{Electrospinning}

Each scaffold was spun onto a 12 centimeter long, $4 \mathrm{~cm}$ diameter $303 \mathrm{~L}$ stainless steel mandrel. The detailed protocol for setting up the electrospinner prior to spinning can be found in Appendix D. Once the electrospinner was set to spin, the mandrel rotation and translation were set to 2660 rotations per minute and 55 oscillations per minute, respectively, for every spin. In addition, the range of translation-which can be set with a dial at the back of the electrospinner-was examined to ensure nothing had come loose. The voltage, flow rate, and gap distance all varied depending on the parameters set by the DOE. Once the syringe pump was turned on, the voltage was not applied until a droplet formed at the end of the needle.

In order to ensure 3 milliliters of solution were spun each time, the volume dripped by the syringe pump was accounted for by adding that volume to the total volume to be spun. For example, if the droplet formed once the syringe pump had released 0.18 milliliters of fluid, even though it was all air, then 3.18 milliliters were spun as opposed to just 3.00 milliliters.

Once the voltage had been applied, then the solution was allowed to run without interference until a full 3.00 milliliters of solution had been spun onto the mandrel. The voltage, syringe pump, and mandrel rotation and translation were then shut off and everything was unplugged. After about five minutes the scaffold and mandrel were removed from the collector and placed into a desiccator for at least 48 hours to remove any moisture. For each spin, observations were recorded regarding the ability to run at the determined settings, including the presence of a Taylor cone or buildup of solution at the needle, any arcing, and a description of the resulting scaffold. 


\subsubsection{Imaging}

After remaining in the desiccator for at least 48 hours the scaffolds were removed and sections were measured and cut from the steel mandrel using a razor blade according to Figure 18 below. The longer pieces were cut in case samples were damaged, and the smaller $0.5 \mathrm{~cm}$ pieces were used for imaging.

\begin{tabular}{|c|c|c|c|c|c|c|c|c|}
\hline A & & B & & C & & D & & E \\
\hline 0.5 & 2.375 & 0.5 & 2.375 & 0.5 & 2.375 & 0.5 & 2.375 & 0.5 \\
\hline \multicolumn{8}{|c|}{$12 \mathrm{~cm}$}
\end{tabular}

Figure 18: Diagram of scaffold preparation for imaging. Smaller pieces labeled A-E were imaged $(0.5 \mathrm{~cm})$ and longer pieces saved in case of damaged/lost images

The samples were imaged with a table top scanning electron microscope, which allowed for quick manipulation of images, with enough quality and control for the magnification and detail needed to visualize the fibers. Each tubular section was cut in half longitudinally (to expose the lumen), and four images of the lumen were taken at $600 \mathrm{x}$ for each half to make a total of 40 images per $12 \mathrm{~cm}$ scaffold.

Image $\mathrm{J}$, an image analysis program, was used to take measurements of the fiber diameters. Detailed methods of imaging as well as imaging preparation can be found in Appendix E. Briefly, the scaffold was measured against a ruler and the pieces in Figure 18 were sliced, and then slid off the mandrel. Each smaller piece was cut in half longitudinally and imaged. 


\subsection{Parameters and Results}

The parameter settings for each spin are detailed below, along with the results obtained after imaging and measurements. The results include the mean fiber diameter obtained by measuring a sample of fibers from each image of each spin, and the standard deviation of those measurements, as well as observations taken during the electrospinning.

Note that some of the scaffolds with a low concentration of polymer had a grainy structure that easily dissolved or fell apart upon contact. These scaffolds will be mentioned in the results, but because of the difficulty when handling, the small tubular sections were not used, but rather strips had to be peeled or cut off in each section were prepared for imaging. The majority of these scaffolds were not measured, due to the globular structure of the fibers.

In addition, all of the samples as imaged, as well as each individual measurement taken can be found in Appendix G, formatted similarly to Figure 19 below.

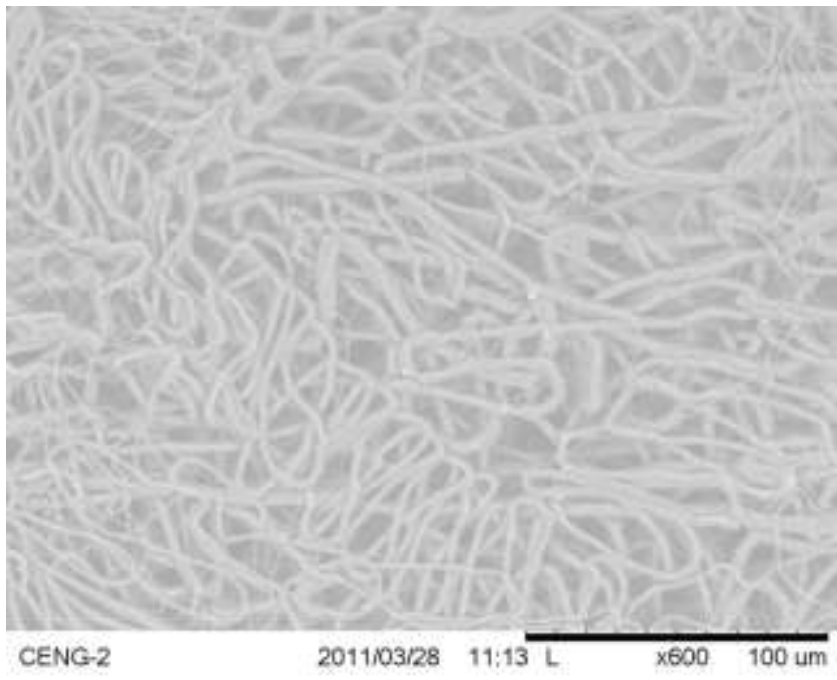

\begin{tabular}{|r|r|}
\hline 1 & 1.2796 \\
\hline 2 & 2.9188 \\
\hline 3 & 3.5972 \\
\hline 4 & 2.5974 \\
\hline 5 & 1.7704 \\
\hline 6 & 3.667 \\
\hline
\end{tabular}

Figure 19: Spin 1, section B, image 3 SEM image with corresponding measurements, as will be including for each image in Appendix G. 


\section{Spin 1}

\begin{tabular}{|l|l|l|l|l|l|}
\hline $\begin{array}{l}\text { Voltage } \\
(\mathrm{kV})\end{array}$ & $\begin{array}{l}\text { Flow Rate } \\
(\mathrm{ml} / \mathrm{hr})\end{array}$ & $\begin{array}{l}\text { Solution } \\
\text { Concentration }(\%)\end{array}$ & $\begin{array}{l}\text { Gap } \\
\text { Distance (in.) })\end{array}$ & $\begin{array}{l}\text { Mean } \\
\text { Fiber } \\
\text { Diameter } \\
(\mu \mathrm{m})\end{array}$ & $\begin{array}{l}\text { Standard } \\
\text { Deviation } \\
(\mu \mathrm{m})\end{array}$ \\
\hline 24 & 4.5 & 15 & 7.0 & 3.318 & 1.281 \\
\hline
\end{tabular}

During Spin 1 there was a consistent line of fiber, however the polymer solution

did collect into a ball at the tip of needle until it became too large and would fall off.

Then another ball would form and repeat the collection process. The fibers evenly

distributed along the mandrel, as imaged in Figure 20, and the scaffold was successfully imaged.

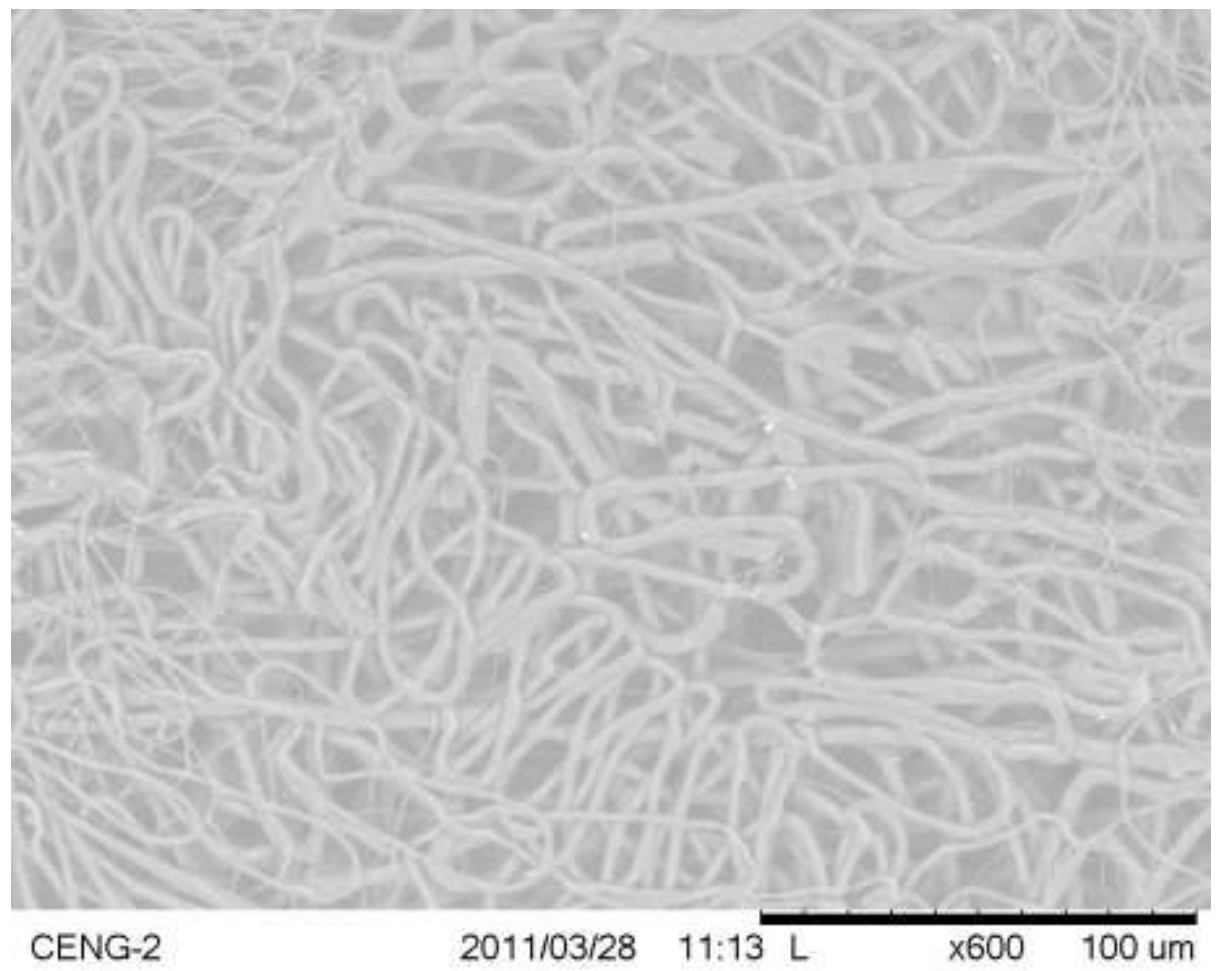

Figure 20: SEM image at 600x of Spin 1, section B, image 3. 


\section{Spin 2}

\begin{tabular}{|l|l|l|l|l|l|}
\hline $\begin{array}{l}\text { Voltage } \\
(\mathrm{kV})\end{array}$ & $\begin{array}{l}\text { Flow Rate } \\
(\mathrm{ml} / \mathrm{hr})\end{array}$ & $\begin{array}{l}\text { Solution } \\
\text { Concentration (\%) }\end{array}$ & $\begin{array}{l}\text { Gap } \\
\text { Distance (in.) }\end{array}$ & Mean & $\begin{array}{l}\text { Standard } \\
\text { Deviation }\end{array}$ \\
\hline 30 & 4.5 & 15 & 10.0 & 3.340 & 1.053 \\
\hline
\end{tabular}

During the Spin 2 no Taylor cone was apparent, however an even distribution of fibers collected on the mandrel. The scaffold was successfully cut and imaged below in Figure 21.

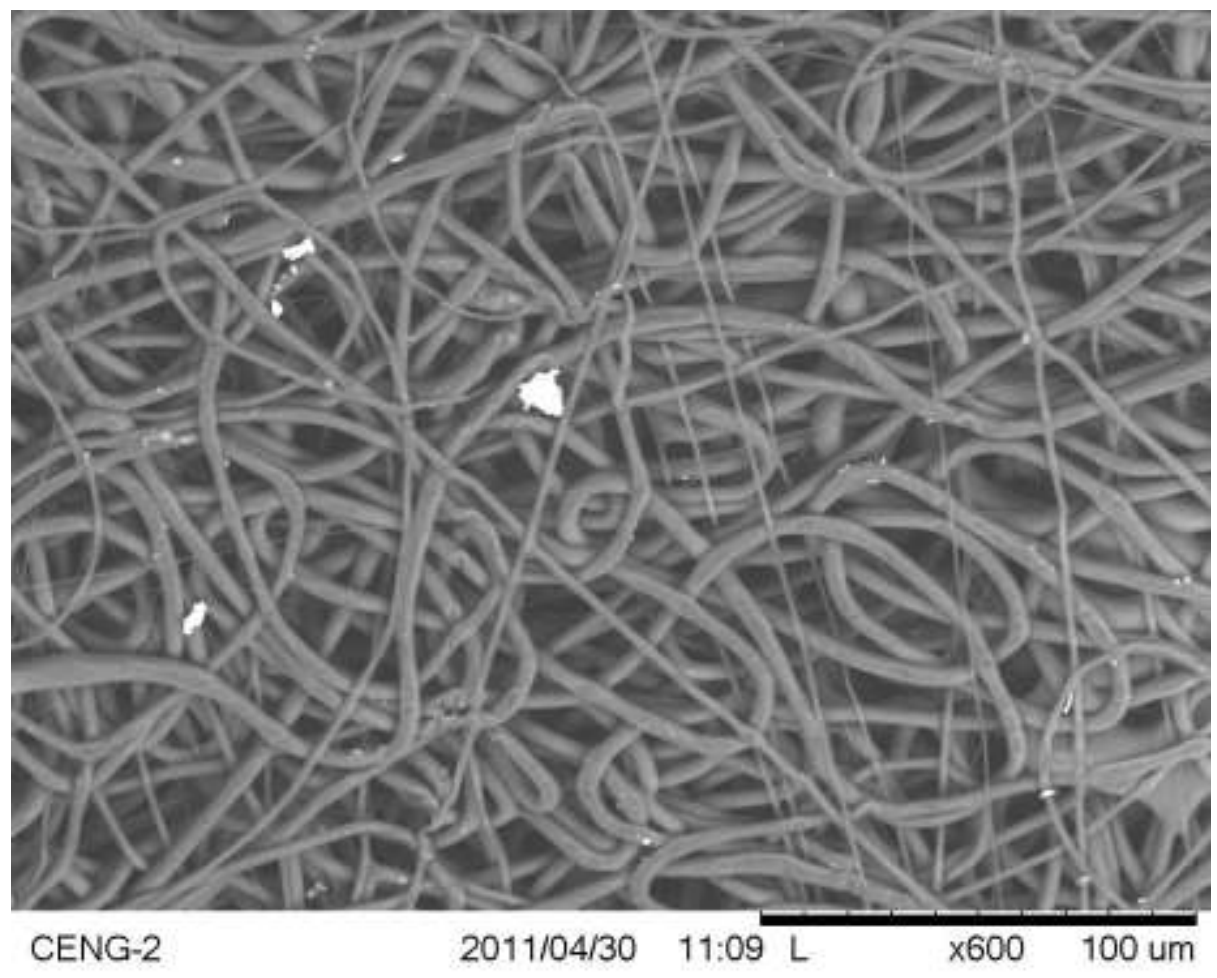

Figure 21: SEM image at 600x of Spin 2, section A, image 7. 


\section{Spin 3}

\begin{tabular}{|l|l|l|l|l|l|}
\hline $\begin{array}{l}\text { Voltage } \\
(\mathrm{kV})\end{array}$ & $\begin{array}{l}\text { Flow Rate } \\
(\mathrm{ml} / \mathrm{hr})\end{array}$ & $\begin{array}{l}\text { Solution } \\
\text { Concentration (\%) }\end{array}$ & $\begin{array}{l}\text { Gap } \\
\text { Distance (in.) }\end{array}$ & Mean & $\begin{array}{l}\text { Standard } \\
\text { Deviation }\end{array}$ \\
\hline 24 & 4.5 & 10 & 10.0 & - & - \\
\hline
\end{tabular}

Due to the lower solution concentration, the combination of voltage, gap

distance, and flow rate could not sustain a continuous fiber jet, and the resulting scaffold was not composed of a fibrous tube, but rather the globular mat imaged in Figure 22 below. Because of the globular structure, the scaffold was weak and difficult to handle. Only a few images of the lumen were taken and no fiber diameter measurements were taken.

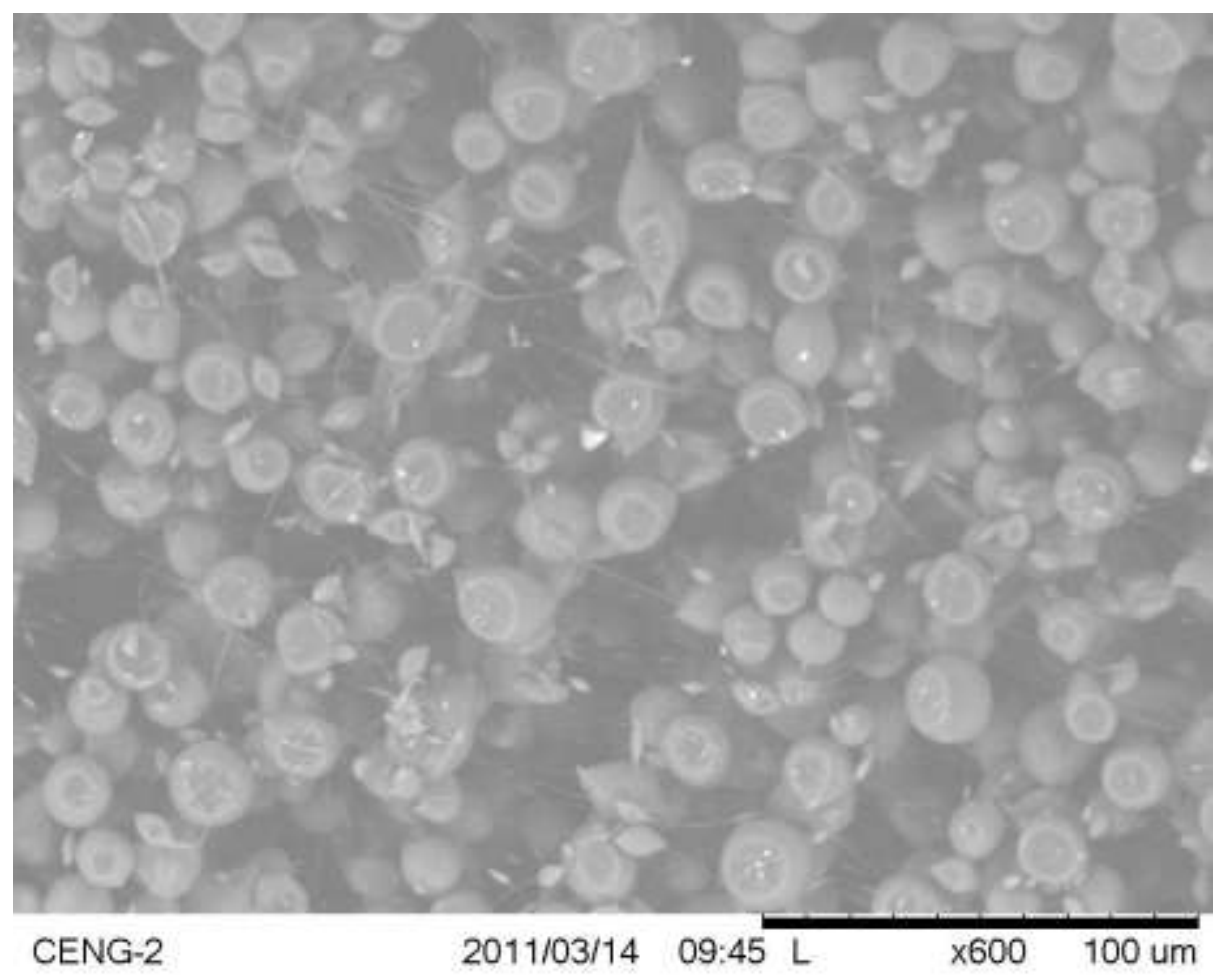

Figure 22: SEM image at 600x of Spin 3 lumen. 


\section{Spin 4}

\begin{tabular}{|l|l|l|l|l|l|}
\hline $\begin{array}{l}\text { Voltage } \\
(\mathrm{kV})\end{array}$ & $\begin{array}{l}\text { Flow Rate } \\
(\mathrm{ml} / \mathrm{hr})\end{array}$ & $\begin{array}{l}\text { Solution } \\
\text { Concentration (\%) }\end{array}$ & $\begin{array}{l}\text { Gap } \\
\text { Distance (in.) }\end{array}$ & Mean & $\begin{array}{l}\text { Standard } \\
\text { Deviation }\end{array}$ \\
\hline 24 & 4.5 & 10 & 7.0 & - & - \\
\hline
\end{tabular}

During the electrospinning process no Taylor cone was noted. At times, the

process appeared to be spraying the fibers as opposed to ejecting the single fiber; however a solid scaffold still resulted. Note in Figure 23 the scaffold appears flaky. The scaffold began to disintegrate upon contact and for that reason was not SEM imaged or measured for a fiber diameter average.

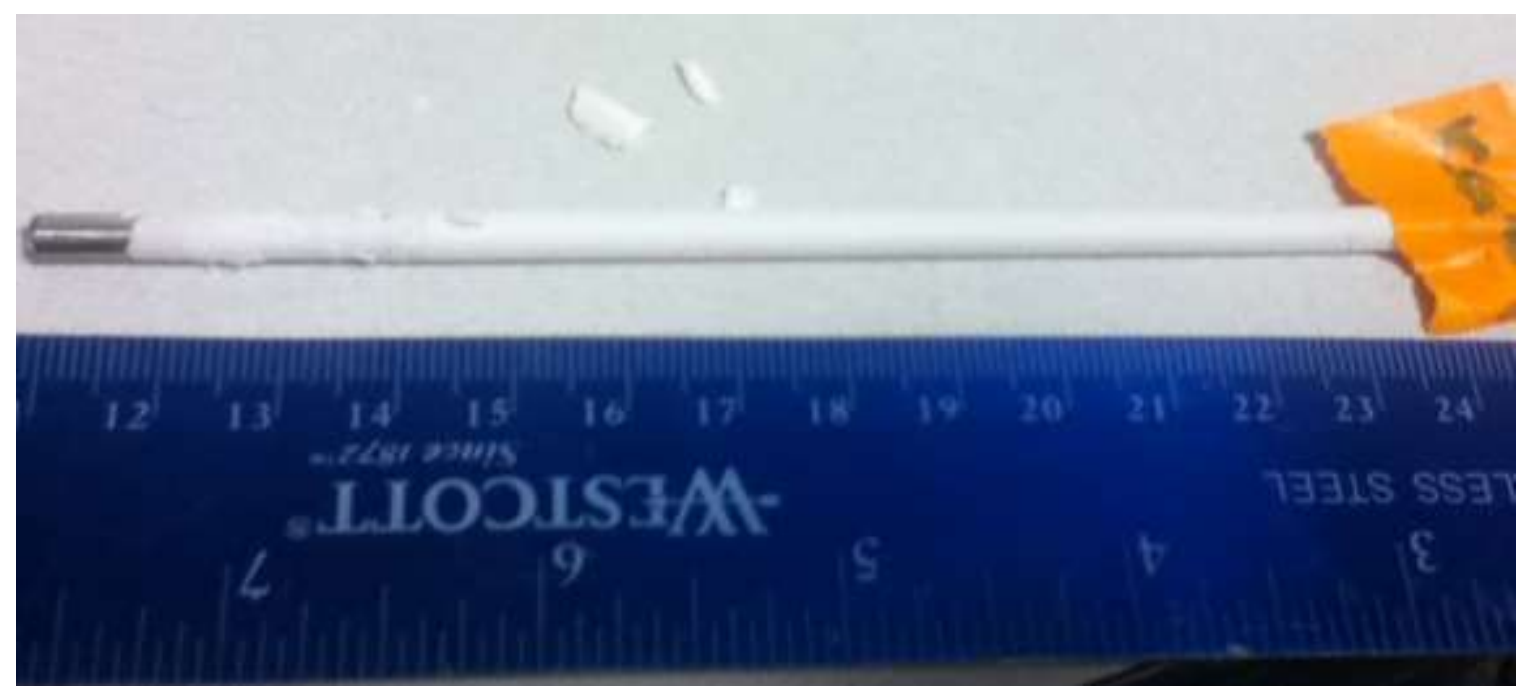

Figure 23: Image of Spin 4 exterior. Note flaky material adjacent to scaffold. 


\section{Spin 5}

\begin{tabular}{|l|l|l|l|l|l|}
\hline $\begin{array}{l}\text { Voltage } \\
(\mathrm{kV})\end{array}$ & $\begin{array}{l}\text { Flow Rate } \\
(\mathrm{ml} / \mathrm{hr})\end{array}$ & $\begin{array}{l}\text { Solution } \\
\text { Concentration (\%) }\end{array}$ & $\begin{array}{l}\text { Gap } \\
\text { Distance (in.) }\end{array}$ & Mean & $\begin{array}{l}\text { Standard } \\
\text { Deviation }\end{array}$ \\
\hline 30 & 6.5 & 15 & 7.0 & 3.506 & 1.403 \\
\hline
\end{tabular}

During Spin 5 the Taylor cone was evident. The scaffold had an even distribution

of fibers however when imaged there was a large variation in fiber diameter size, exemplified in Figure 24 below.

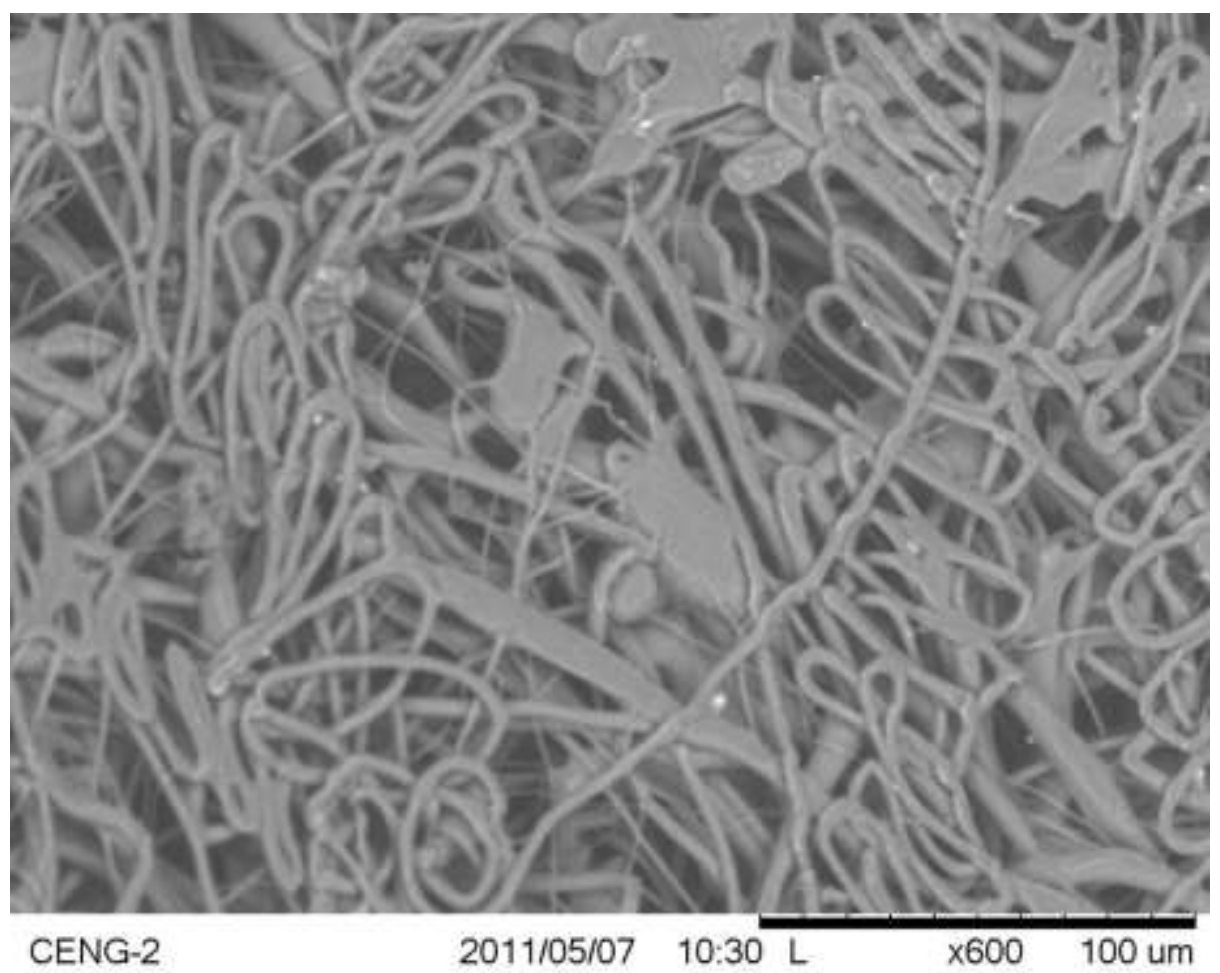

Figure 24: SEM image at 600x of Spin 5, section D, image 4. 


\section{Spin 6}

\begin{tabular}{|l|l|l|l|l|l|}
\hline $\begin{array}{l}\text { Voltage } \\
(\mathrm{kV})\end{array}$ & $\begin{array}{l}\text { Flow Rate } \\
(\mathrm{ml} / \mathrm{hr})\end{array}$ & $\begin{array}{l}\text { Solution } \\
\text { Concentration (\%) }\end{array}$ & $\begin{array}{l}\text { Gap } \\
\text { Distance (in.) }\end{array}$ & Mean & $\begin{array}{l}\text { Standard } \\
\text { Deviation }\end{array}$ \\
\hline 30 & 4.5 & 15 & 7.0 & 5.362 & 1.960 \\
\hline
\end{tabular}

During the Spin 6 there was often a buildup of solution at the tip of the needle that would drip to the floor of the electrospinning chamber, and then begin to collect again. When imaged, the fibers appeared to have a lot of variation, with both fibers much larger and smaller than usual, as imaged in Figure 25 below. While the small fibers were ideal, there were more larger fibers, thus the larger mean fiber diameter.

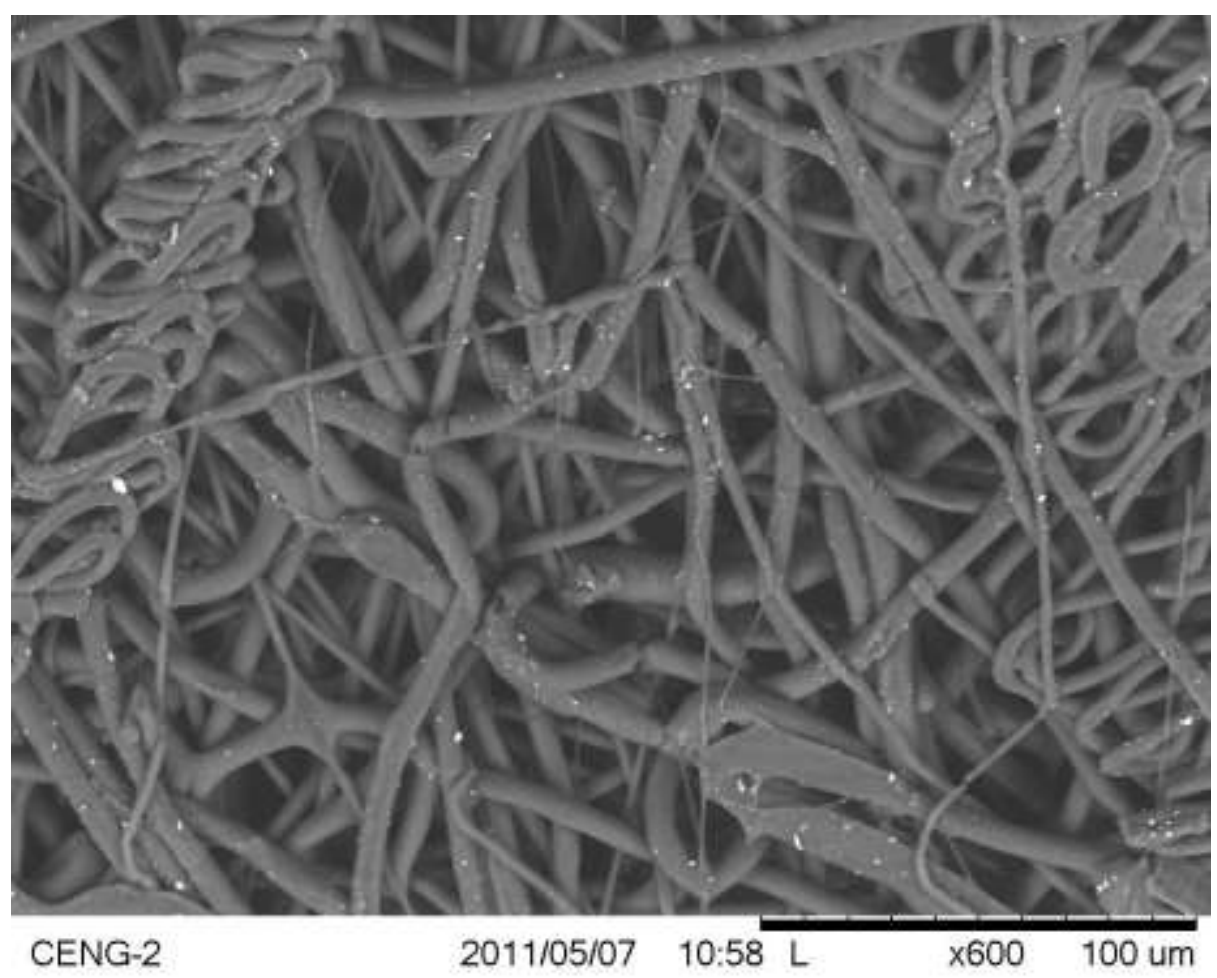

Figure 25: SEM image at 600x of Spin 6, section B, image 1. 


\section{Spin 7}

\begin{tabular}{|l|l|l|l|l|l|}
\hline $\begin{array}{l}\text { Voltage } \\
(\mathrm{kV})\end{array}$ & $\begin{array}{l}\text { Flow Rate } \\
(\mathrm{ml} / \mathrm{hr})\end{array}$ & $\begin{array}{l}\text { Solution } \\
\text { Concentration (\%) }\end{array}$ & $\begin{array}{l}\text { Gap } \\
\text { Distance (in.) }\end{array}$ & Mean & $\begin{array}{l}\text { Standard } \\
\text { Deviation }\end{array}$ \\
\hline 30 & 4.5 & 15 & 10.0 & 4.587 & 1.363 \\
\hline
\end{tabular}

During the electrospinning process, solution would build up on the tip of the needle, then fall, and begin to collect again. The resulting scaffold had an even distribution of fibers, and when imaged below in Figure 26, there was little variation in the fiber diameter size with the exception of the wispy fibers distributed throughout.

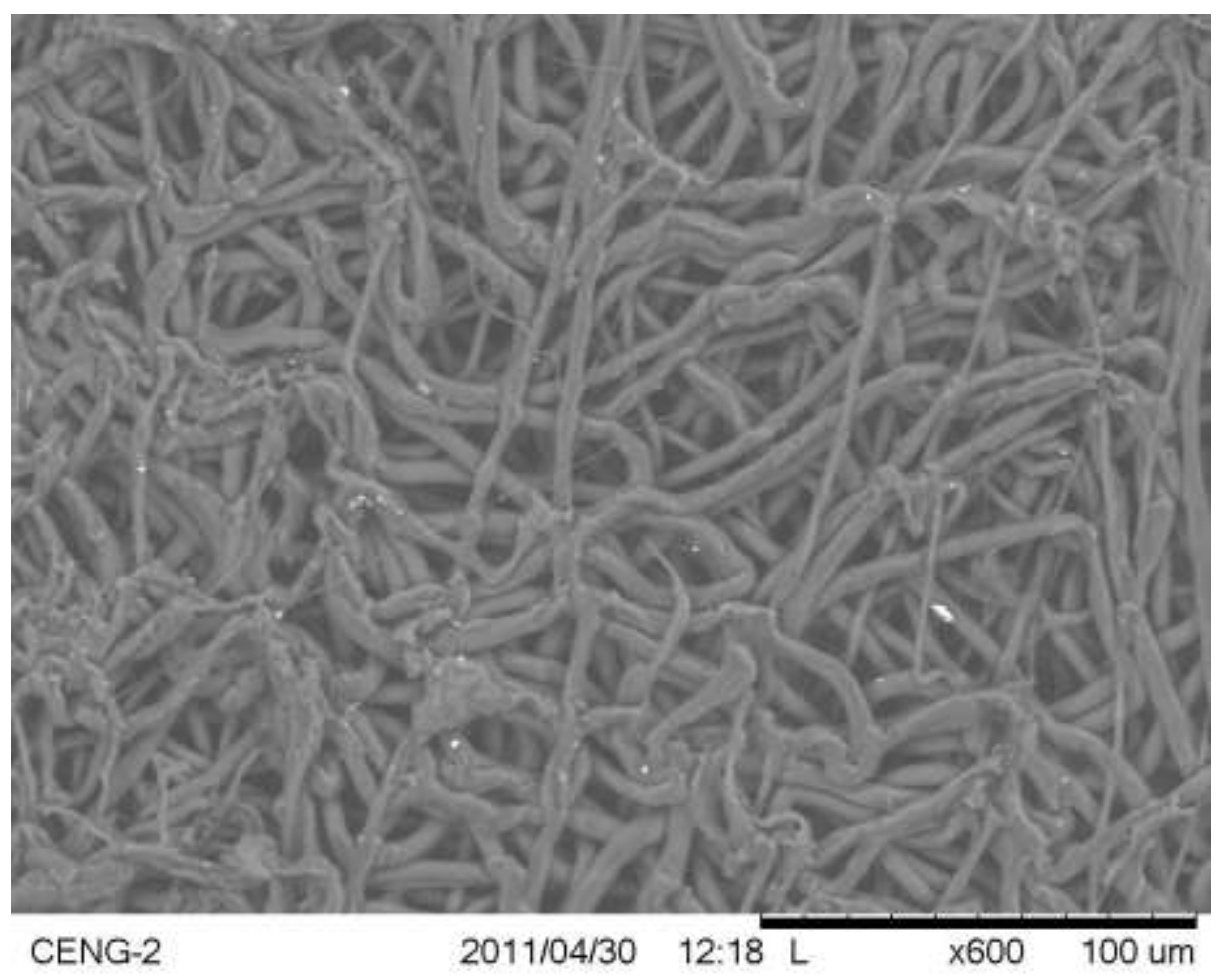

Figure 26: SEM image at 600x of Spin 7, section A, image 4. 


\section{Spin 8}

\begin{tabular}{|l|l|l|l|l|l|}
\hline $\begin{array}{l}\text { Voltage } \\
(\mathrm{kV})\end{array}$ & $\begin{array}{l}\text { Flow Rate } \\
(\mathrm{ml} / \mathrm{hr})\end{array}$ & $\begin{array}{l}\text { Solution } \\
\text { Concentration (\%) }\end{array}$ & $\begin{array}{l}\text { Gap } \\
\text { Distance (in.) }\end{array}$ & Mean & $\begin{array}{l}\text { Standard } \\
\text { Deviation }\end{array}$ \\
\hline 30 & 6.5 & 10 & 7.0 & - & - \\
\hline
\end{tabular}

During the Spin 8 no Taylor cone was evident. In addition, the distribution of fibers-or bead formations in this case-was uneven. In Figure 27 below the scaffold is thicker on the right side. The exterior was composed of a very delicate matrix, thus could not be imaged.

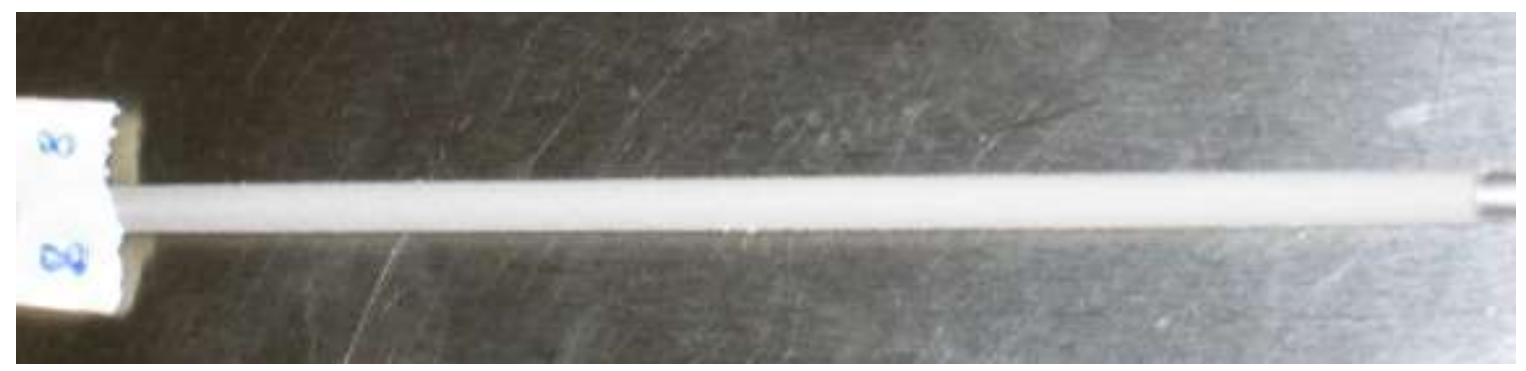

Figure 27: Image of Spin 8 exterior since lumen could not be SEM imaged. 


\section{Spin 9}

\begin{tabular}{|l|l|l|l|l|l|}
\hline $\begin{array}{l}\text { Voltage } \\
(\mathrm{kV})\end{array}$ & $\begin{array}{l}\text { Flow Rate } \\
(\mathrm{ml} / \mathrm{hr})\end{array}$ & $\begin{array}{l}\text { Solution } \\
\text { Concentration (\%) }\end{array}$ & $\begin{array}{l}\text { Gap } \\
\text { Distance (in.) }\end{array}$ & Mean & $\begin{array}{l}\text { Standard } \\
\text { Deviation }\end{array}$ \\
\hline 24 & 4.5 & 10 & 10.0 & - & - \\
\hline
\end{tabular}

During the electrospinning process there was little evidence of a Taylor cone, though a bubble would form on the tip of the needle periodically. Figure 28 depicts flattened bead formations that made up the entire length of the scaffold. Because of this, it was not imaged by the normal protocol.

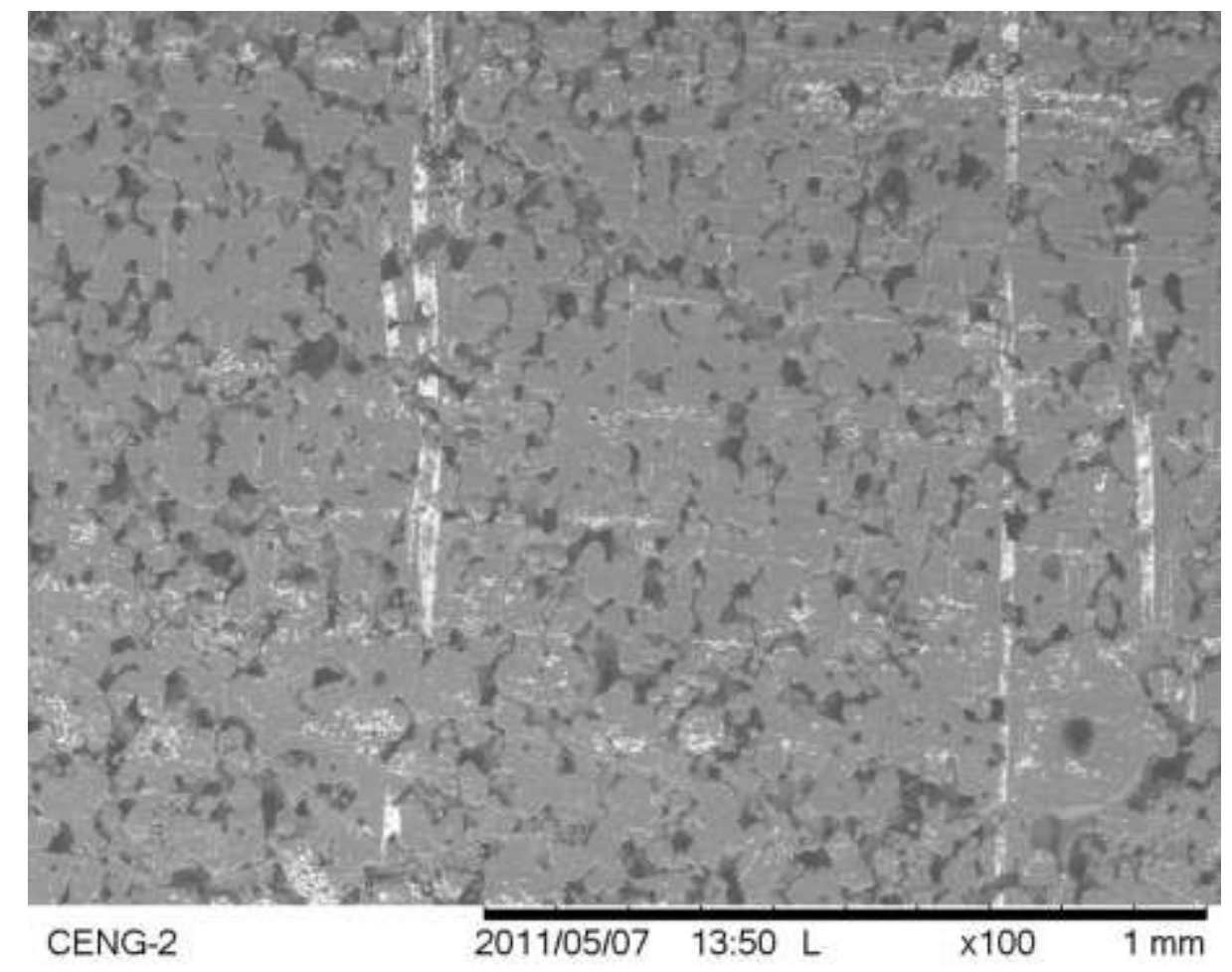

Figure 28: SEM image of Spin 9 at 100x. 


\section{Spin 10}

\begin{tabular}{|l|l|l|l|l|l|}
\hline $\begin{array}{l}\text { Voltage } \\
(\mathrm{kV})\end{array}$ & $\begin{array}{l}\text { Flow Rate } \\
(\mathrm{ml} / \mathrm{hr})\end{array}$ & $\begin{array}{l}\text { Solution } \\
\text { Concentration (\%) }\end{array}$ & $\begin{array}{l}\text { Gap } \\
\text { Distance (in.) }\end{array}$ & Mean & $\begin{array}{l}\text { Standard } \\
\text { Deviation }\end{array}$ \\
\hline 24 & 4.5 & 15 & 10.0 & 2.742 & 1.279 \\
\hline
\end{tabular}

Throughout the electrospinning process a Taylor cone was present. Figure 29

depicts a bimodal distribution of fibers that make up the scaffold; however the average taken was still taken from the entire set of fibers as a single average and standard deviation. Both values were ideal given the aims of the BVM. (Note: "bimodal" was a qualitative observation, and was not numerically quantified in the results.)

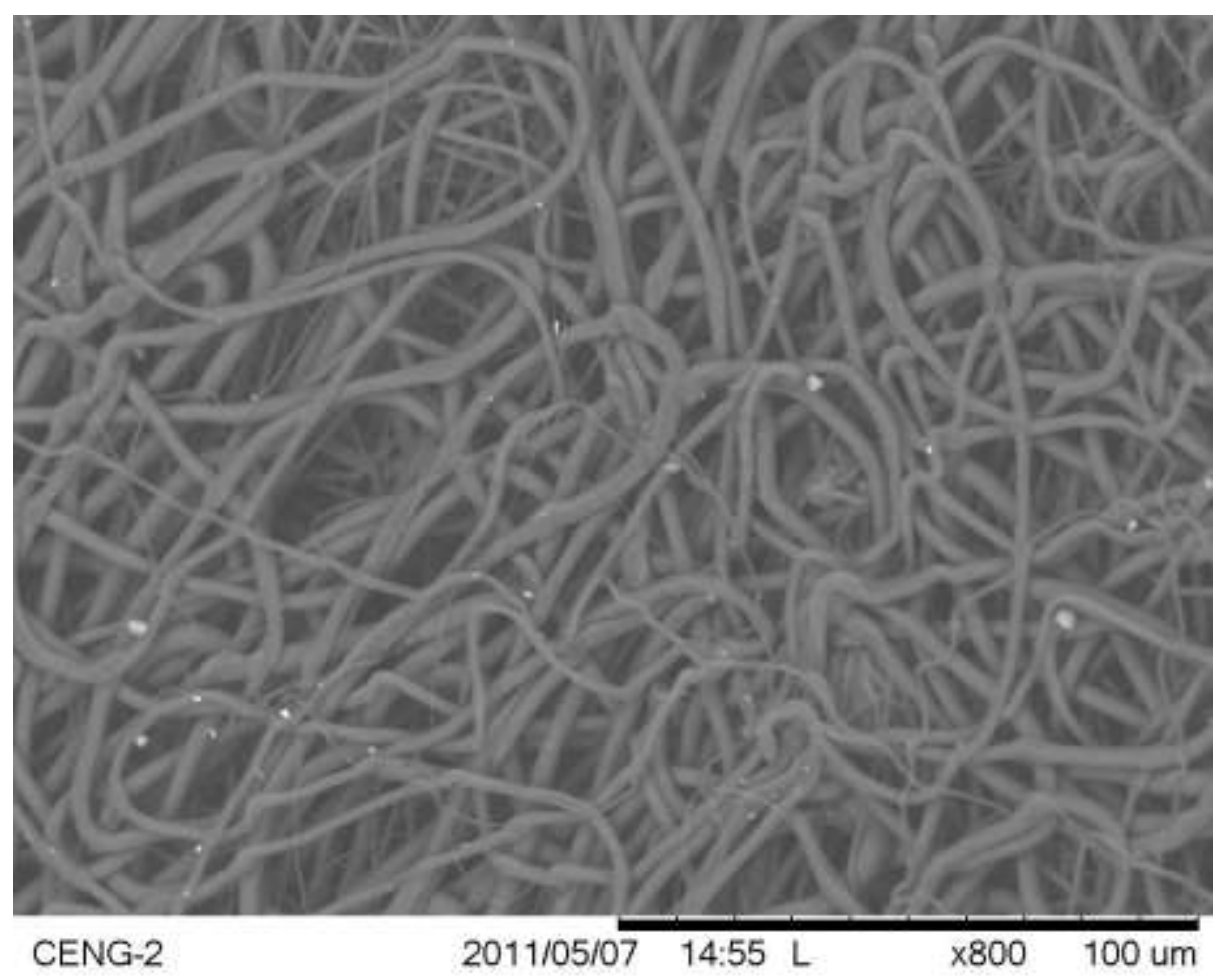

Figure 29: SEM image at $800 x$ of Spin 10, section B, image 1. 


\section{Spin 11}

\begin{tabular}{|l|l|l|l|l|l|}
\hline $\begin{array}{l}\text { Voltage } \\
(\mathrm{kV})\end{array}$ & $\begin{array}{l}\text { Flow Rate } \\
(\mathrm{ml} / \mathrm{hr})\end{array}$ & $\begin{array}{l}\text { Solution } \\
\text { Concentration (\%) }\end{array}$ & $\begin{array}{l}\text { Gap } \\
\text { Distance (in.) }\end{array}$ & Mean & $\begin{array}{l}\text { Standard } \\
\text { Deviation }\end{array}$ \\
\hline 24 & 6.5 & 10 & 7.0 & - & - \\
\hline
\end{tabular}

scaffold were scraped off in order to attain the image in Figure 30. The flattened globular formations are due to handling. No Taylor cone was evident during the Spin 11.

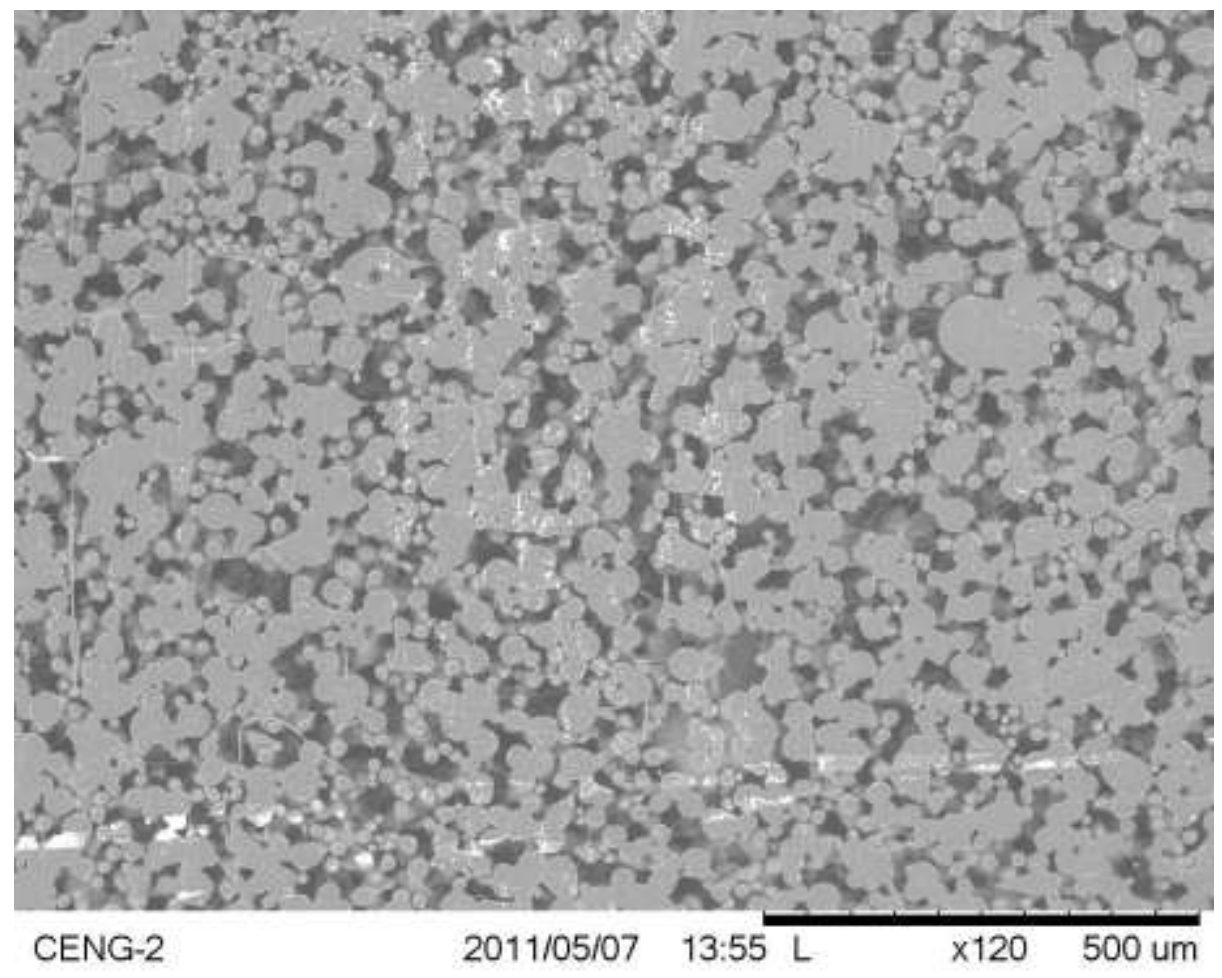

Figure 30: SEM image at 120x of Spin 11 lumen. 


\section{Spin 12}

\begin{tabular}{|l|l|l|l|l|l|}
\hline $\begin{array}{l}\text { Voltage } \\
(\mathrm{kV})\end{array}$ & $\begin{array}{l}\text { Flow Rate } \\
(\mathrm{ml} / \mathrm{hr})\end{array}$ & $\begin{array}{l}\text { Solution } \\
\text { Concentration (\%) }\end{array}$ & $\begin{array}{l}\text { Gap } \\
\text { Distance (in.) }\end{array}$ & Mean & $\begin{array}{l}\text { Standard } \\
\text { Deviation }\end{array}$ \\
\hline 24 & 6.5 & 15 & 7.0 & 4.003 & 2.897 \\
\hline
\end{tabular}

During the Spin 12 there was consistently a Taylor cone, however the size and

shape varied. Figure 31 depicts a very random matrix, with small fibers, larger fibers, and bead formations dispersed throughout. The standard deviation reflected inconsistent fibers.

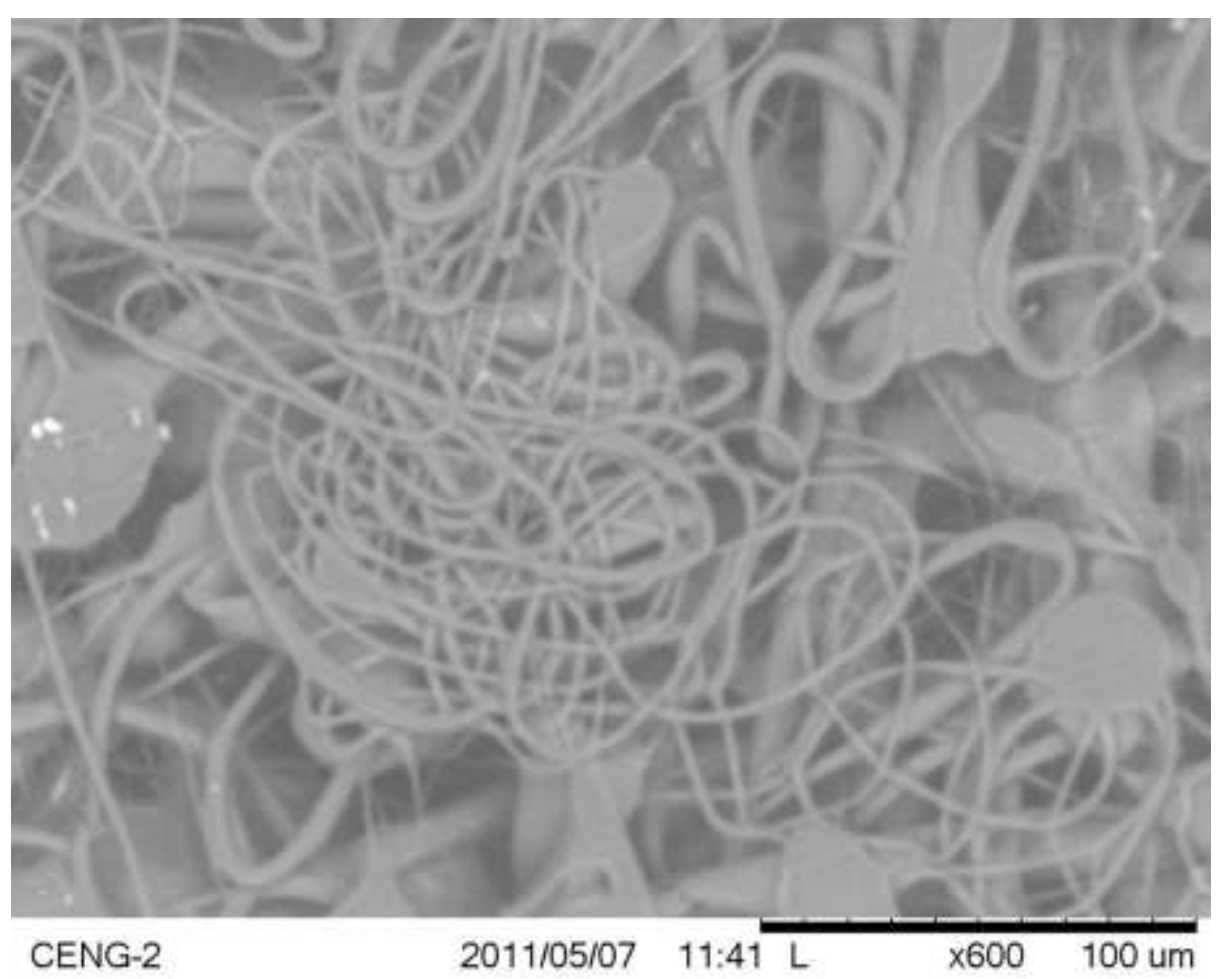

Figure 31: SEM image at 600x of Spin 12, Section B, image 2. 


\section{Spin 13}

\begin{tabular}{|l|l|l|l|l|l|}
\hline $\begin{array}{l}\text { Voltage } \\
(\mathrm{kV})\end{array}$ & $\begin{array}{l}\text { Flow Rate } \\
(\mathrm{ml} / \mathrm{hr})\end{array}$ & $\begin{array}{l}\text { Solution } \\
\text { Concentration (\%) }\end{array}$ & $\begin{array}{l}\text { Gap } \\
\text { Distance (in.) }\end{array}$ & Mean & $\begin{array}{l}\text { Standard } \\
\text { Deviation }\end{array}$ \\
\hline 24 & 6.5 & 15 & 10.0 & 4.281 & 1.124 \\
\hline
\end{tabular}

While spinning, a constant and consistent Taylor cone was present. Figure 32

depicts a fairly consistent distribution of fibers however there are smaller fibers present, as well as very small stringy fibers over laid on the fiber matrix. The standard deviation was ideal for consistency.

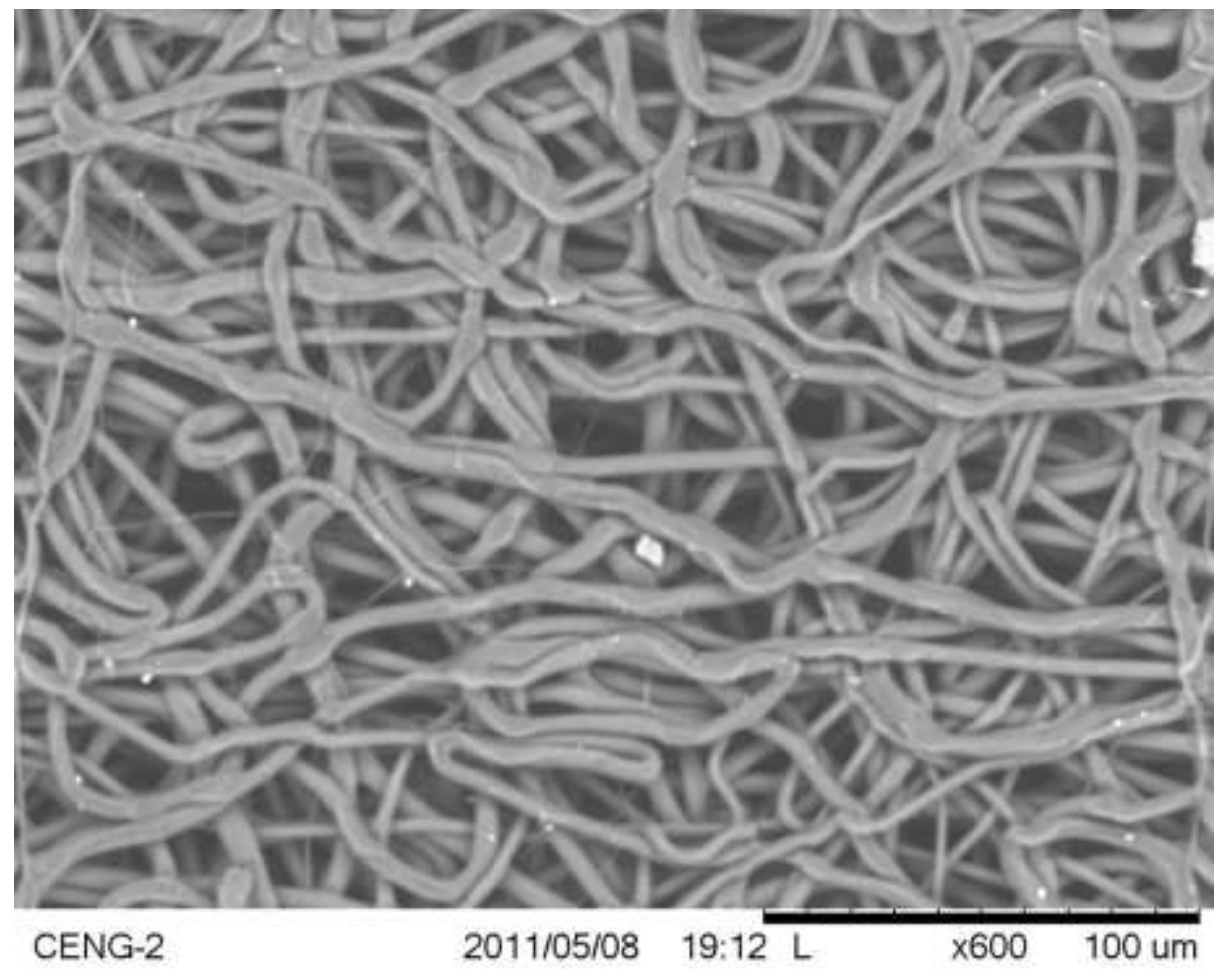

Figure 32: SEM image at 600x of Spin 13, section A, image 4. 


\section{Spin 14}

\begin{tabular}{|l|l|l|l|l|l|}
\hline $\begin{array}{l}\text { Voltage } \\
(\mathrm{kV})\end{array}$ & $\begin{array}{l}\text { Flow Rate } \\
(\mathrm{ml} / \mathrm{hr})\end{array}$ & $\begin{array}{l}\text { Solution } \\
\text { Concentration (\%) }\end{array}$ & $\begin{array}{l}\text { Gap } \\
\text { Distance (in.) }\end{array}$ & Mean & $\begin{array}{l}\text { Standard } \\
\text { Deviation }\end{array}$ \\
\hline 30 & 4.5 & 10 & 10.0 & - & - \\
\hline
\end{tabular}

During the spinning of Spin 14 no Taylor cone was present and the collector

appeared "wet". The resulting scaffold was too fragile to handle, imaged in Figure 33 above, so no SEM images were taken.

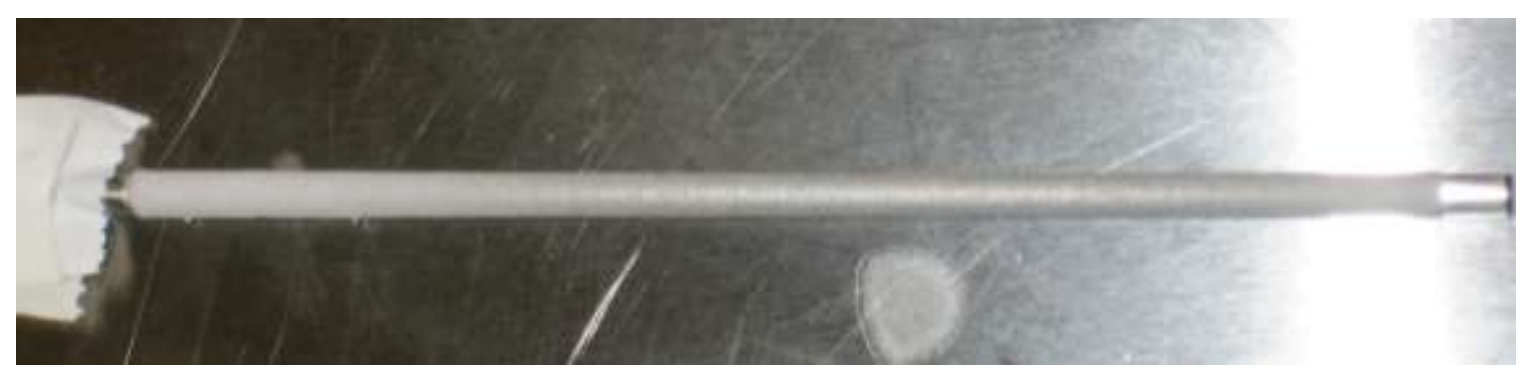

Figure 33: Exterior image of Spin 14, since lumen could not be imaged. 


\section{Spin 15}

\begin{tabular}{|l|l|l|l|l|l|}
\hline $\begin{array}{l}\text { Voltage } \\
(\mathrm{kV})\end{array}$ & $\begin{array}{l}\text { Flow Rate } \\
(\mathrm{ml} / \mathrm{hr})\end{array}$ & $\begin{array}{l}\text { Solution } \\
\text { Concentration (\%) }\end{array}$ & $\begin{array}{l}\text { Gap } \\
\text { Distance (in.) }\end{array}$ & Mean & $\begin{array}{l}\text { Standard } \\
\text { Deviation }\end{array}$ \\
\hline 30 & 4.5 & 10 & 7.0 & - & - \\
\hline
\end{tabular}

Spin 15 showed no evidence of a Taylor cone during spinning. The resulting

scaffold, imaged in Figure 34 below was composed of entirely beads and globular formations. The delicate scaffold was not imaged by the normal protocol because the scaffold could not be cut correctly.

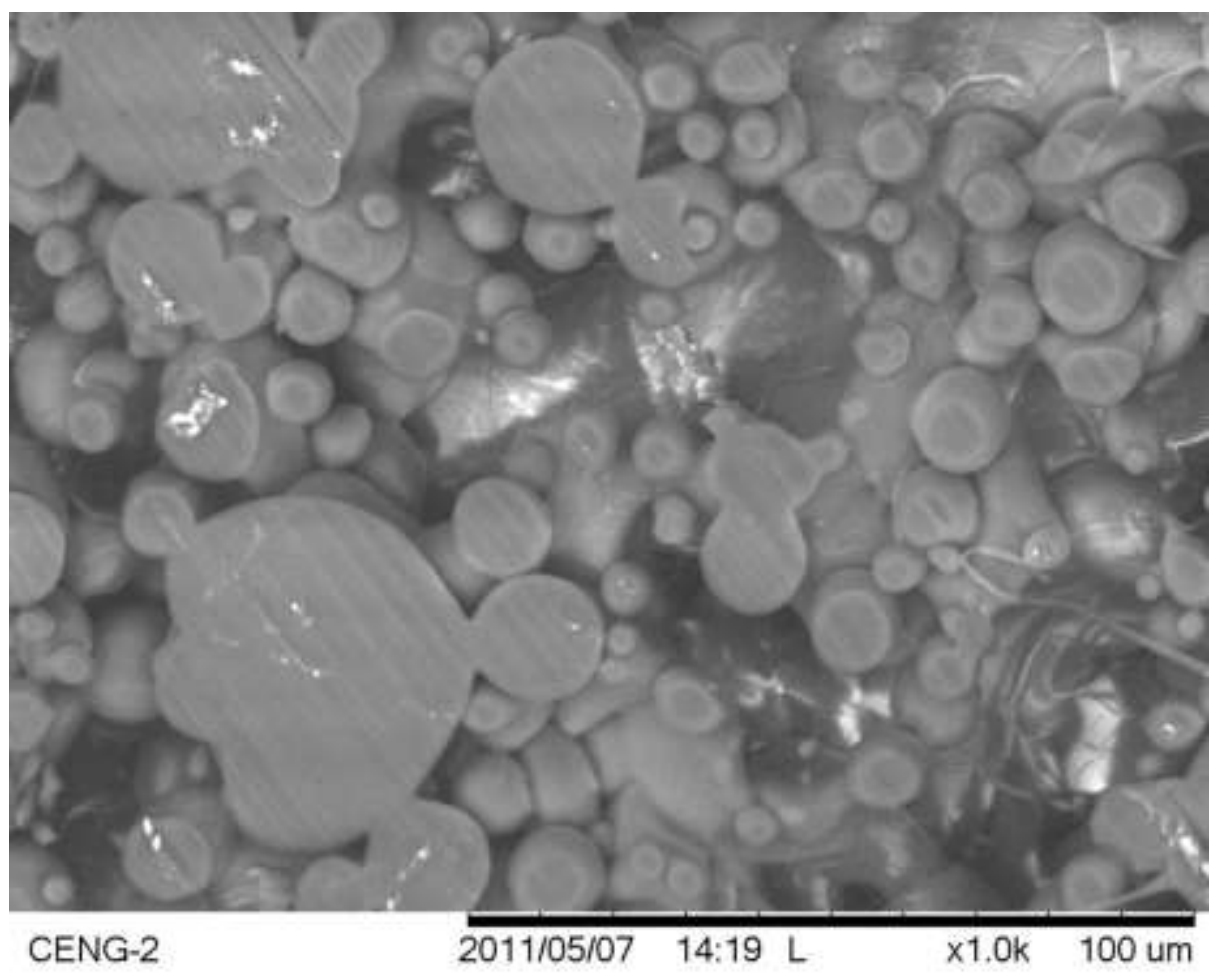

Figure 34: SEM image at 1000x of Spin 15 lumen. 


\section{Spin 16}

\begin{tabular}{|l|l|l|l|l|l|}
\hline $\begin{array}{l}\text { Voltage } \\
(\mathrm{kV})\end{array}$ & $\begin{array}{l}\text { Flow Rate } \\
(\mathrm{ml} / \mathrm{hr})\end{array}$ & $\begin{array}{l}\text { Solution } \\
\text { Concentration (\%) }\end{array}$ & $\begin{array}{l}\text { Gap } \\
\text { Distance (in.) }\end{array}$ & Mean & $\begin{array}{l}\text { Standard } \\
\text { Deviation }\end{array}$ \\
\hline 24 & 4.5 & 15 & 10.0 & 4.396 & 2.212 \\
\hline
\end{tabular}

During Spin 17 a Taylor cone was evident throughout the process. The resulting

scaffold, imaged in Figure 35 depicts a bimodal distribution of fibers, and therefore a larger standard deviation. The resulting mean fiber diameter was consistent with past student findings, and too large for the aims of this study.

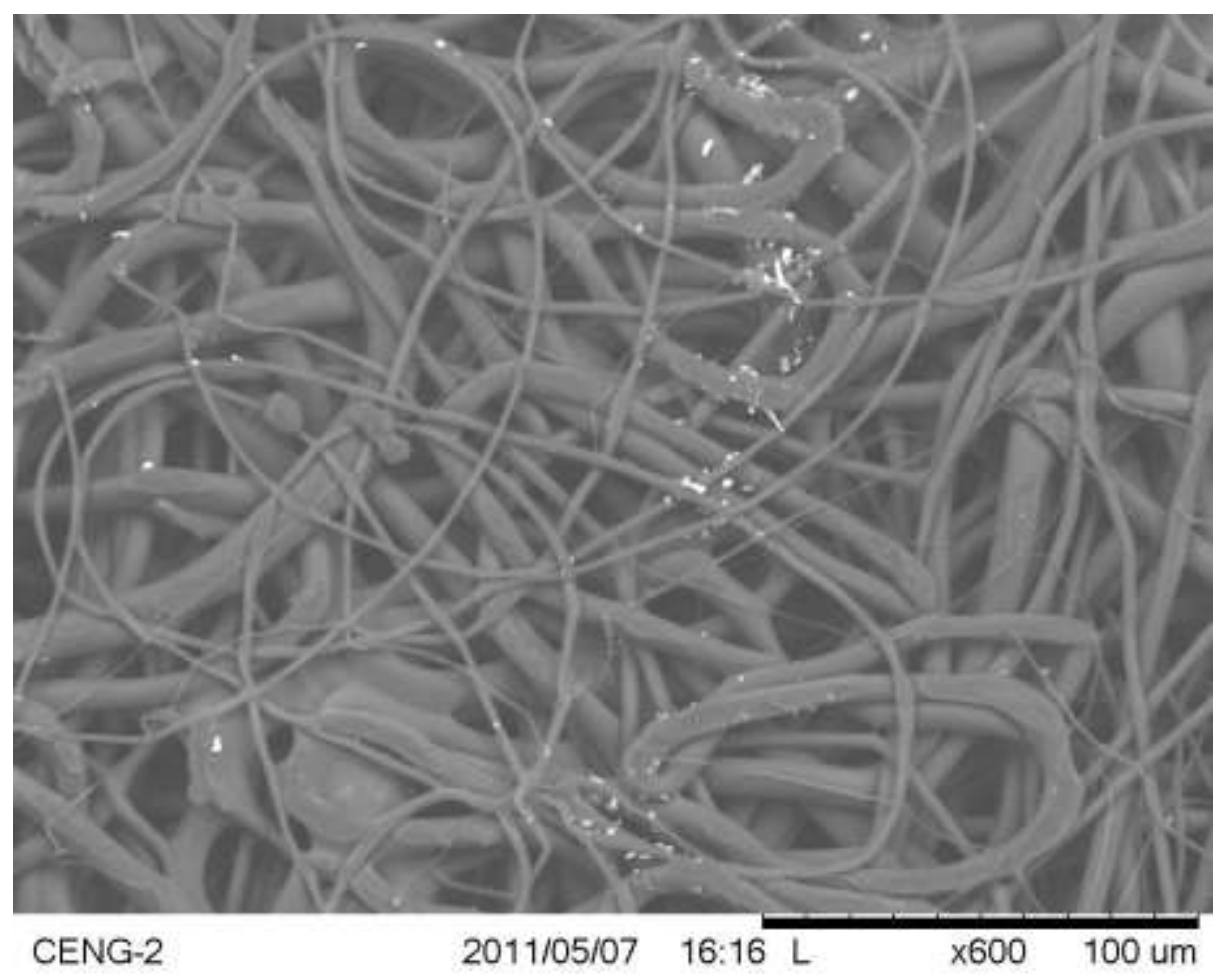

Figure 35: SEM image at $600 x$ of Spin 16, section B, image 6. 


\section{Spin 17}

\begin{tabular}{|l|l|l|l|l|l|}
\hline $\begin{array}{l}\text { Voltage } \\
(\mathrm{kV})\end{array}$ & $\begin{array}{l}\text { Flow Rate } \\
(\mathrm{ml} / \mathrm{hr})\end{array}$ & $\begin{array}{l}\text { Solution } \\
\text { Concentration (\%) }\end{array}$ & $\begin{array}{l}\text { Gap } \\
\text { Distance (in.) }\end{array}$ & $\begin{array}{l}\text { Mean } \\
\text { Standard } \\
\text { Deviation }\end{array}$ \\
\hline 30 & 6.5 & 10 & 10.0 & - & - \\
\hline
\end{tabular}

scaffold that was very delicate and could not be imaged properly. Figure 36 depicts a very beady scaffold that also lacked porosity.

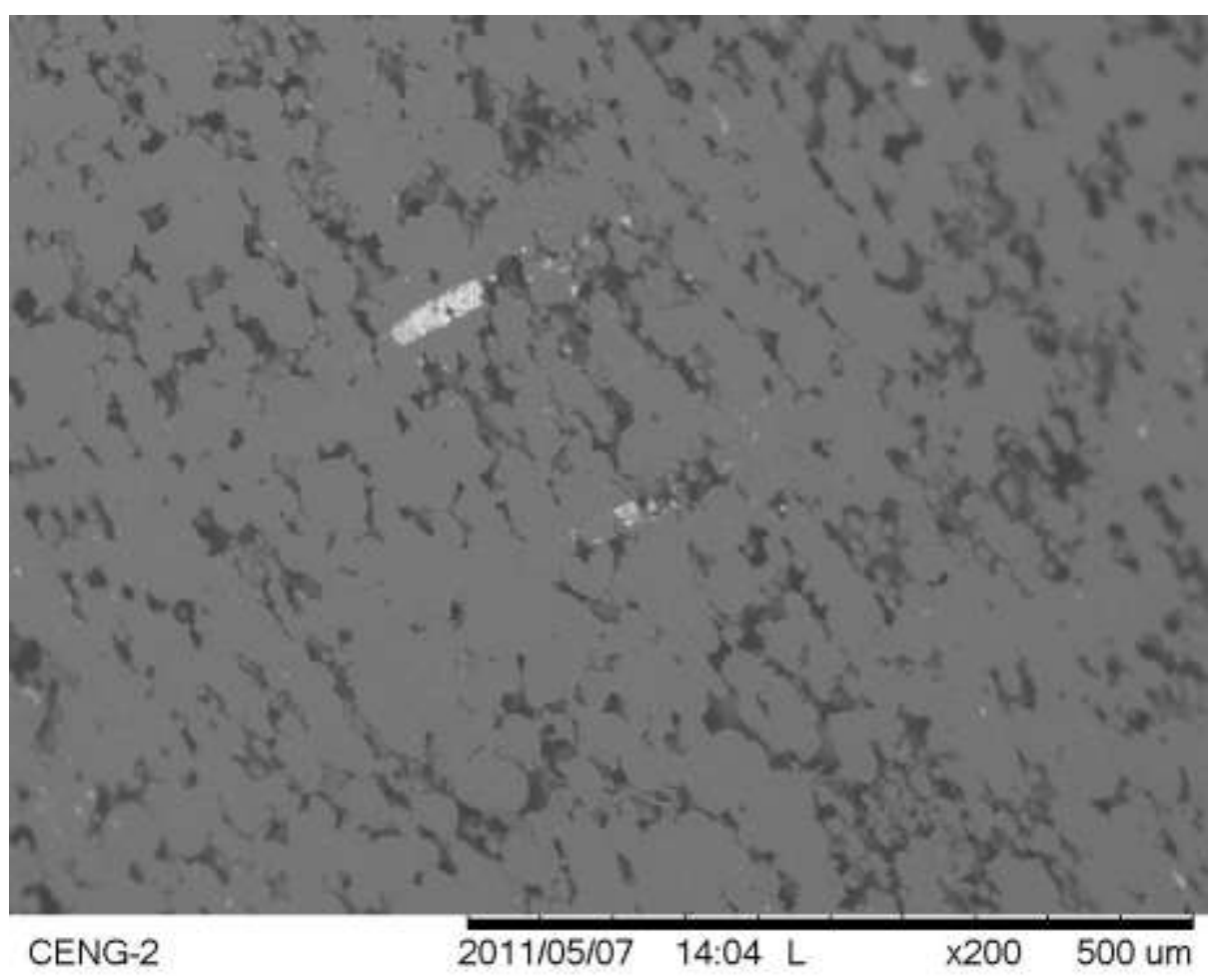

Figure 36: SEM image at 200x of Spin 17 lumen. 


\section{Spin 18}

\begin{tabular}{|l|l|l|l|l|l|}
\hline $\begin{array}{l}\text { Voltage } \\
(\mathrm{kV})\end{array}$ & $\begin{array}{l}\text { Flow Rate } \\
(\mathrm{ml} / \mathrm{hr})\end{array}$ & $\begin{array}{l}\text { Solution } \\
\text { Concentration (\%) }\end{array}$ & $\begin{array}{l}\text { Gap } \\
\text { Distance (in.) }\end{array}$ & $\begin{array}{l}\text { Mean } \\
\text { Standard } \\
\text { Deviation }\end{array}$ \\
\hline 24 & 6.5 & 10 & 10.0 & - & - \\
\hline
\end{tabular}

was difficult to handle and had a rough, however flaky and delicate exterior. The scaffold was not imaged according to the imaging protocol.

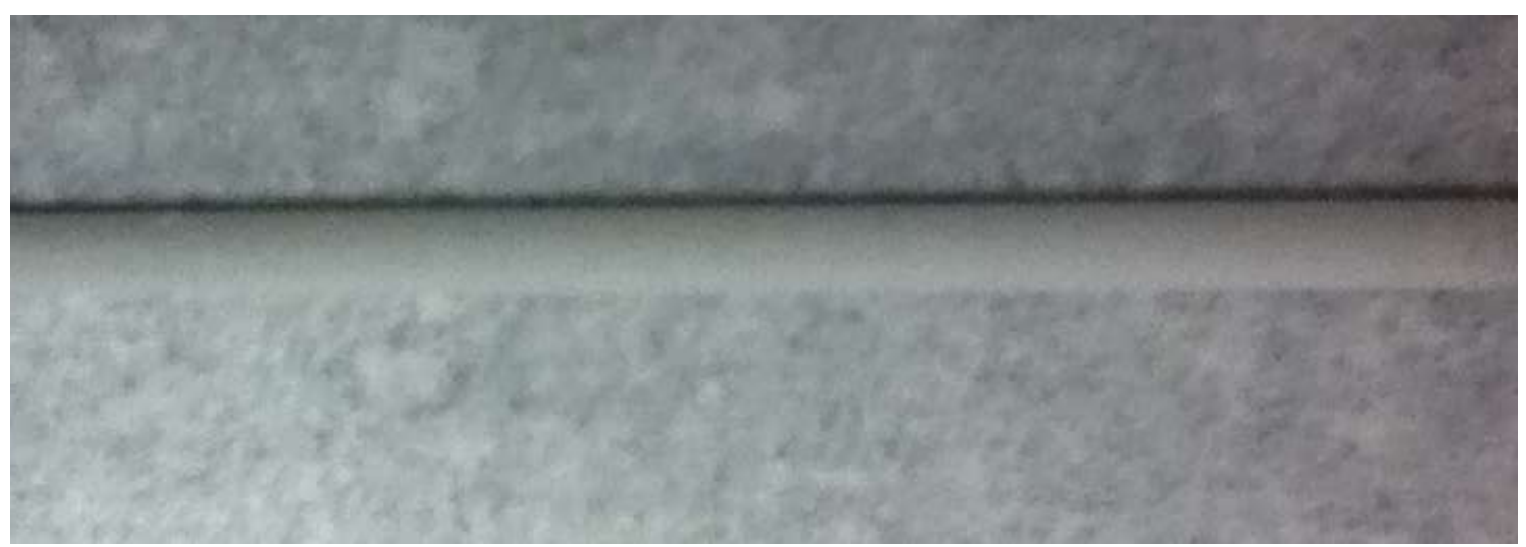

Figure 37: Exterior image of Spin 18. 


\section{Spin 19}

\begin{tabular}{|l|l|l|l|l|l|}
\hline $\begin{array}{l}\text { Voltage } \\
(\mathrm{kV})\end{array}$ & $\begin{array}{l}\text { Flow Rate } \\
(\mathrm{ml} / \mathrm{hr})\end{array}$ & $\begin{array}{l}\text { Solution } \\
\text { Concentration (\%) }\end{array}$ & $\begin{array}{l}\text { Gap } \\
\text { Distance (in.) }\end{array}$ & $\begin{array}{l}\text { Mean } \\
\text { Standard } \\
\text { Deviation }\end{array}$ \\
\hline 24 & 6.5 & 15 & 10.0 & - & - \\
\hline
\end{tabular}

entirely beads. Figure 38 depicts a flattened beady scaffold with little porosity. Note the flattened beads are most likely due to handling.

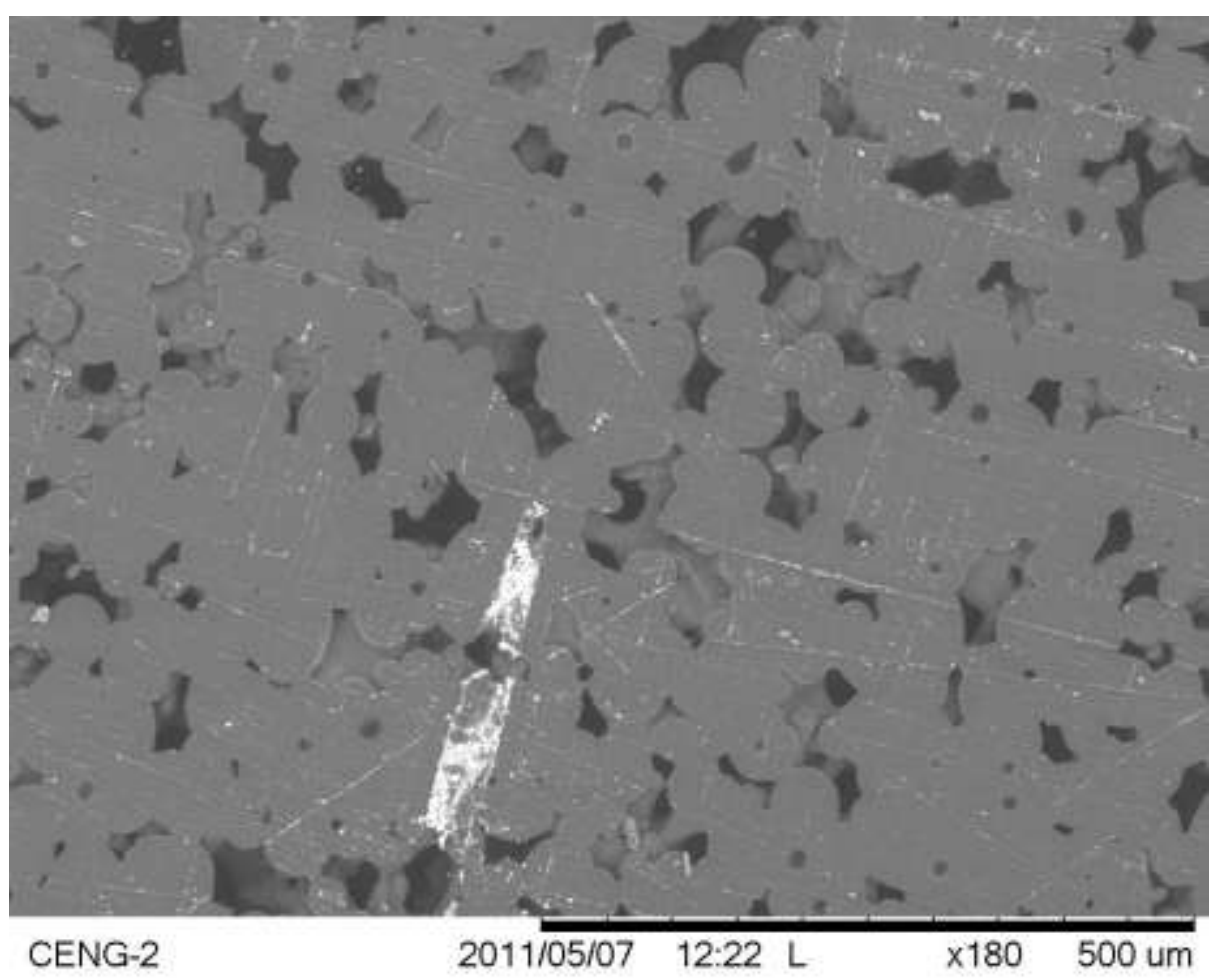

Figure 38: SEM image at 180x of Spin 19 lumen. 


\section{Spin 20}

\begin{tabular}{|l|l|l|l|l|l|}
\hline $\begin{array}{l}\text { Voltage } \\
(\mathrm{kV})\end{array}$ & $\begin{array}{l}\text { Flow Rate } \\
(\mathrm{ml} / \mathrm{hr})\end{array}$ & $\begin{array}{l}\text { Solution } \\
\text { Concentration (\%) }\end{array}$ & $\begin{array}{l}\text { Gap } \\
\text { Distance (in.) }\end{array}$ & $\begin{array}{l}\text { Mean } \\
\text { Standard } \\
\text { Deviation }\end{array}$ \\
\hline 24 & 4.5 & 10 & 7.0 & - & - \\
\hline
\end{tabular}

scaffold with numerous small beads and very few fibrous structures. No Taylor cone was evident during the electrospinning process.

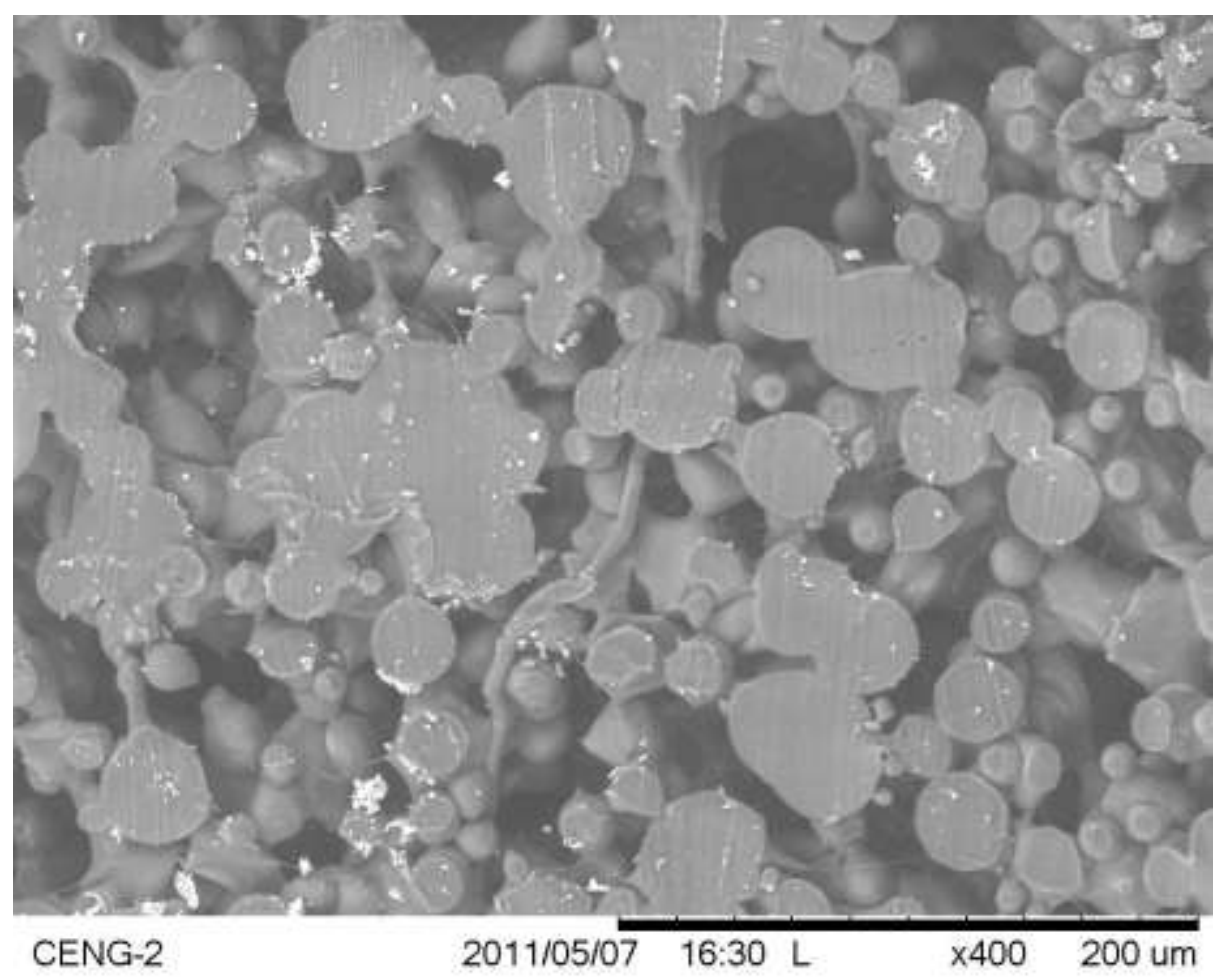

Figure 39: SEM image at 400x of Spin 20 lumen. 


\section{Spin 21}

\begin{tabular}{|l|l|l|l|l|l|}
\hline $\begin{array}{l}\text { Voltage } \\
(\mathrm{kV})\end{array}$ & $\begin{array}{l}\text { Flow Rate } \\
(\mathrm{ml} / \mathrm{hr})\end{array}$ & $\begin{array}{l}\text { Solution } \\
\text { Concentration (\%) }\end{array}$ & $\begin{array}{l}\text { Gap } \\
\text { Distance (in.) }\end{array}$ & Mean & $\begin{array}{l}\text { Standard } \\
\text { Deviation }\end{array}$ \\
\hline 27 & 5.5 & 12.5 & 8.5 & 4.350 & 1.157 \\
\hline
\end{tabular}

Spin 21 had a continuous Taylor cone ejected from the needle. Figure 40

depicts an even distribution of fibers that make up the fiber matrix, which resulted in fiber diameter similar to those found by previous students.

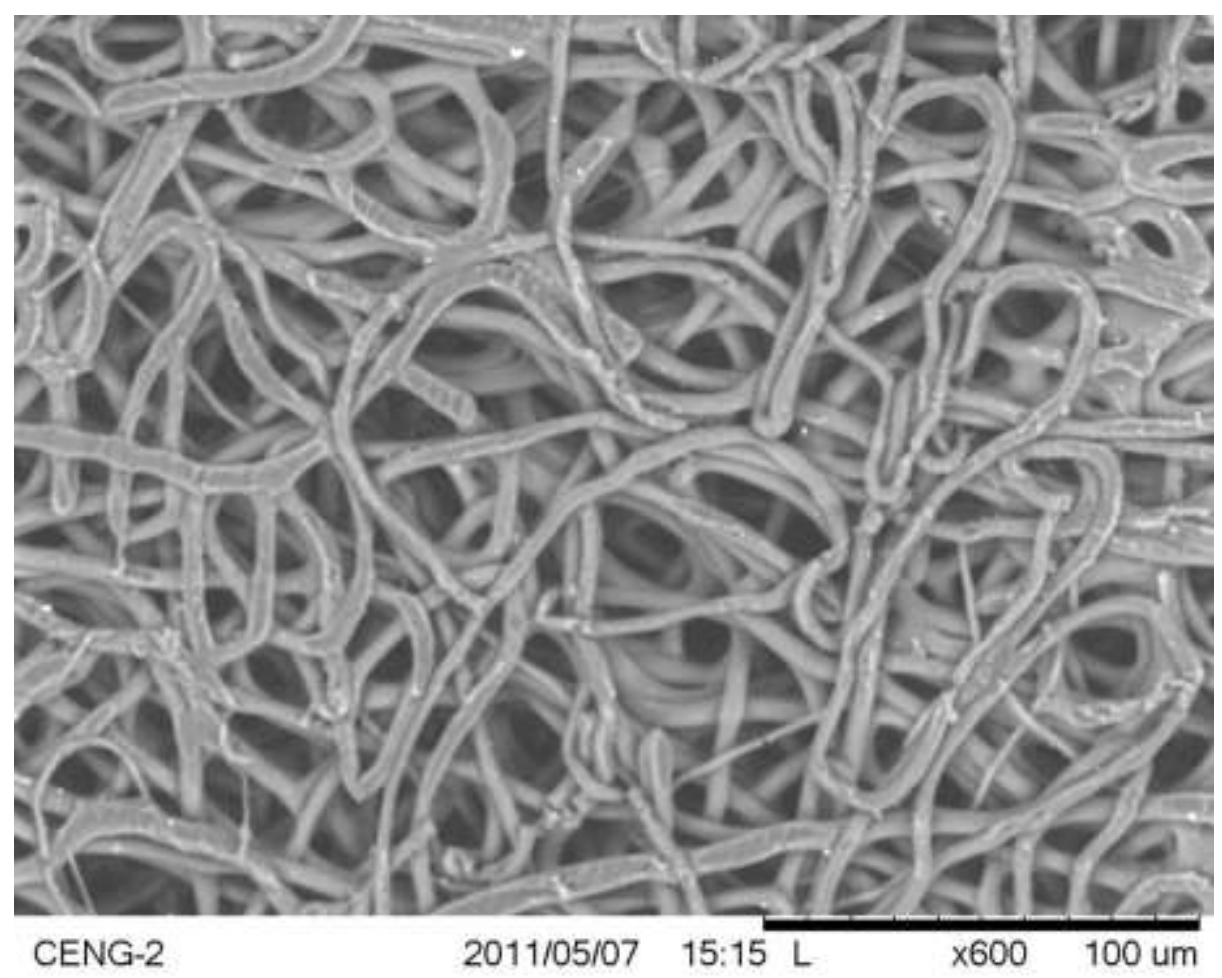

Figure 40: SEM image at 600x of Spin 21, section A, image 3. 


\section{Spin 22}

\begin{tabular}{|l|l|l|l|l|l|}
\hline $\begin{array}{l}\text { Voltage } \\
(\mathrm{kV})\end{array}$ & $\begin{array}{l}\text { Flow Rate } \\
(\mathrm{ml} / \mathrm{hr})\end{array}$ & $\begin{array}{l}\text { Solution } \\
\text { Concentration (\%) }\end{array}$ & $\begin{array}{l}\text { Gap } \\
\text { Distance (in.) }\end{array}$ & Mean & $\begin{array}{l}\text { Standard } \\
\text { Deviation }\end{array}$ \\
\hline 24 & 4.5 & 15 & 7.0 & 4.062 & 1.762 \\
\hline
\end{tabular}

Figure 41 depicts an evident bimodal distribution of fibers. While average sized

fibers exist, there are stringy fibrous structures distributed throughout. Despite this observation, the resulting fiber diameter was rather consistent. During the Spin 22 there was an evident Taylor cone.

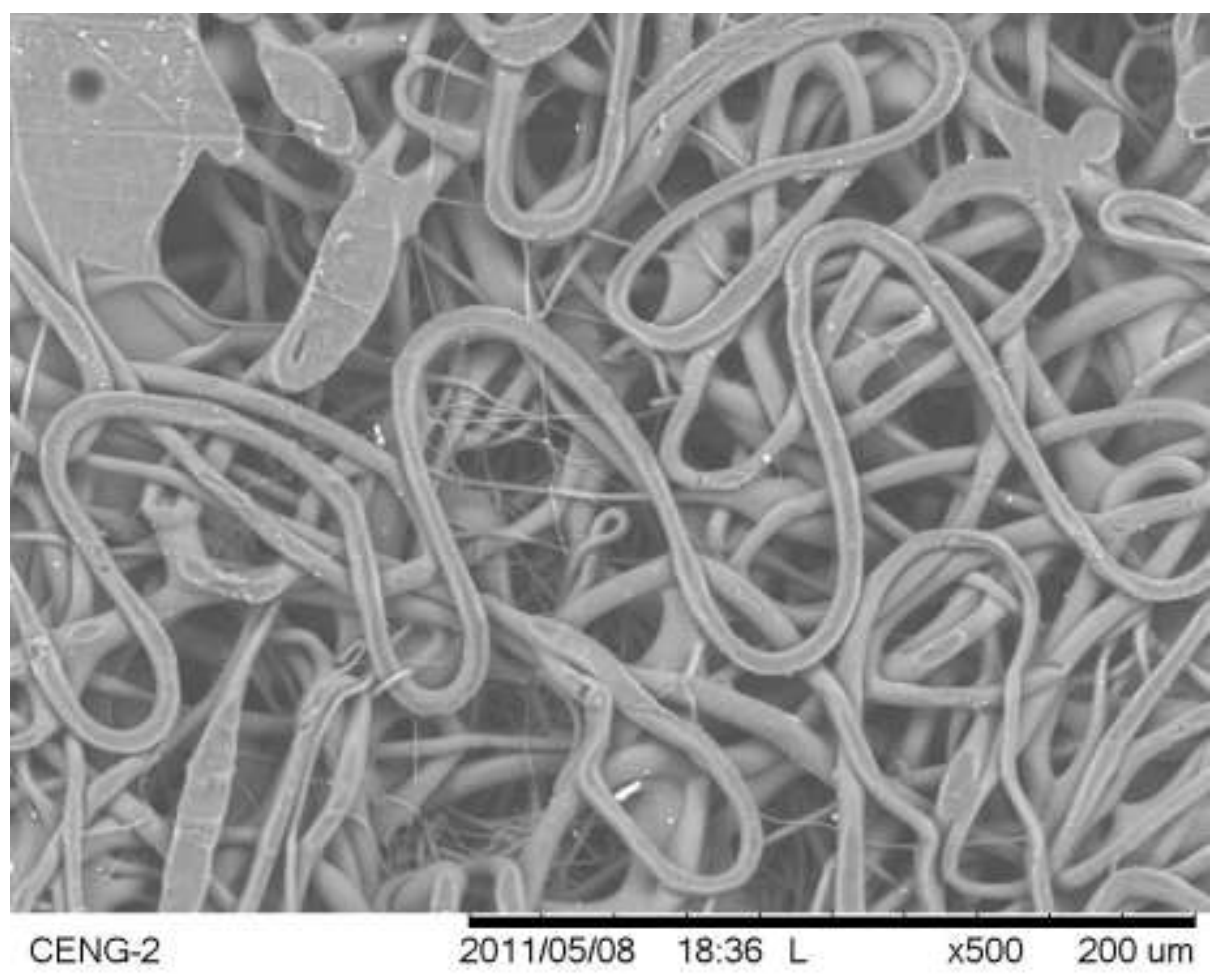

Figure 41: SEM image at 500x of Spin 22, section B, image 2. 


\section{Spin 23}

\begin{tabular}{|l|l|l|l|l|l|}
\hline $\begin{array}{l}\text { Voltage } \\
(\mathrm{kV})\end{array}$ & $\begin{array}{l}\text { Flow Rate } \\
(\mathrm{ml} / \mathrm{hr})\end{array}$ & $\begin{array}{l}\text { Solution } \\
\text { Concentration (\%) }\end{array}$ & $\begin{array}{l}\text { Gap } \\
\text { Distance (in.) }\end{array}$ & Mean & $\begin{array}{l}\text { Standard } \\
\text { Deviation }\end{array}$ \\
\hline 30 & 6.5 & 10 & 10.0 & - & - \\
\hline
\end{tabular}

of the scaffold which is composed of bead formations as opposed to fibrous structures.

The scaffold was not imaged according to the imaging protocol because the scaffold was not easily handled.

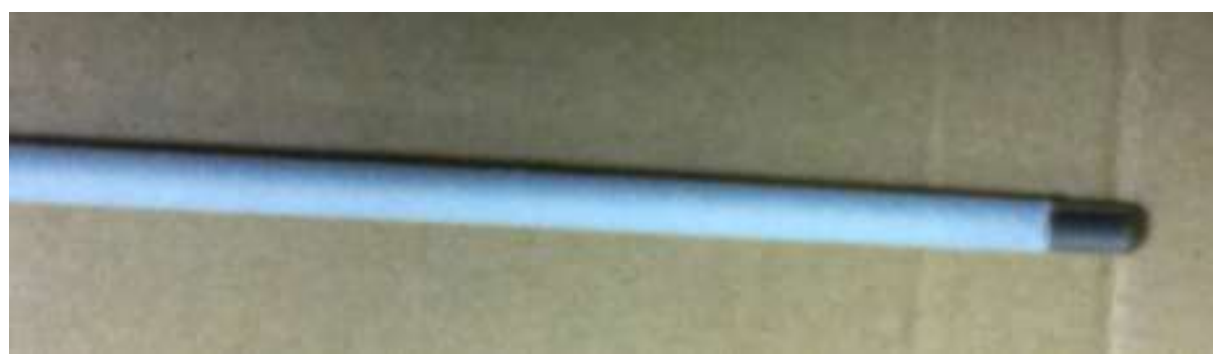

Figure 42: Exterior image of Spin 23. 


\section{Spin 24}

\begin{tabular}{|l|l|l|l|l|l|}
\hline $\begin{array}{l}\text { Voltage } \\
(\mathrm{kV})\end{array}$ & $\begin{array}{l}\text { Flow Rate } \\
(\mathrm{ml} / \mathrm{hr})\end{array}$ & $\begin{array}{l}\text { Solution } \\
\text { Concentration (\%) }\end{array}$ & $\begin{array}{l}\text { Gap } \\
\text { Distance (in.) }\end{array}$ & Mean & $\begin{array}{l}\text { Standard } \\
\text { Deviation }\end{array}$ \\
\hline 30 & 6.5 & 15 & 7.0 & 5.410 & 2.329 \\
\hline
\end{tabular}

Figure 43 depicts a bimodal distribution of fibers composing Spin 24, which

resulted in a large standard deviation. A Taylor cone was evident; however there are

large and small fibers, in addition to what appears to be elongated globular formations.

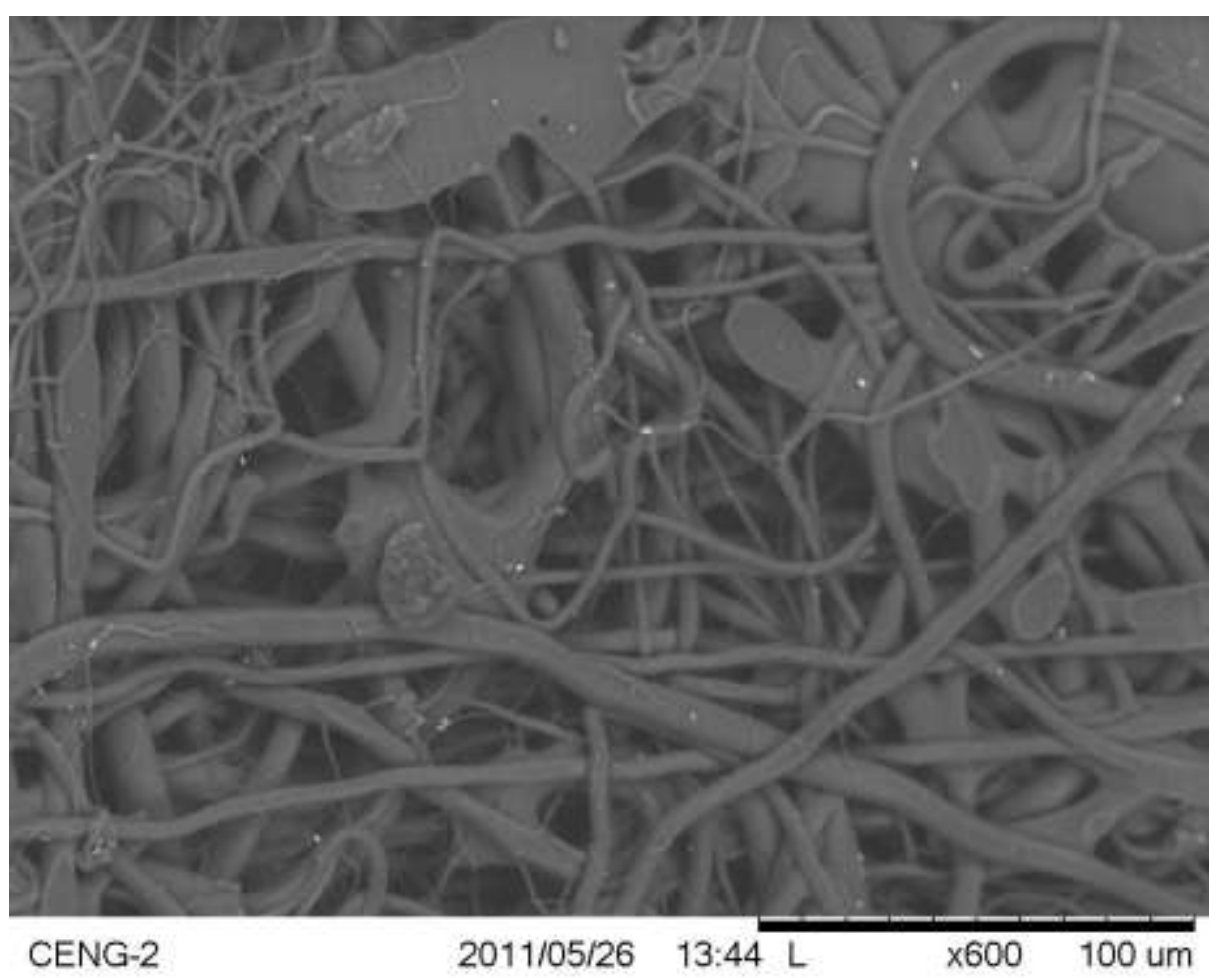

Figure 43: SEM image at 600x of Spin 24, section D, image 4. 


\section{Spin 25}

\begin{tabular}{|l|l|l|l|l|l|}
\hline $\begin{array}{l}\text { Voltage } \\
(\mathrm{kV})\end{array}$ & $\begin{array}{l}\text { Flow Rate } \\
(\mathrm{ml} / \mathrm{hr})\end{array}$ & $\begin{array}{l}\text { Solution } \\
\text { Concentration (\%) }\end{array}$ & $\begin{array}{l}\text { Gap } \\
\text { Distance (in.) }\end{array}$ & Mean & $\begin{array}{l}\text { Standard } \\
\text { Deviation }\end{array}$ \\
\hline 30 & 4.5 & 10 & 10.0 & - & - \\
\hline
\end{tabular}

There was no Taylor cone evident during Spin 25. Figure 44 depicts the lumen

of the scaffold to be composed entirely of beads as opposed to fibrous structure. The scaffold was not imaged according to the protocol, in that only a few lumen images were taken since the scaffold could not be removed entirely from the mandrel.

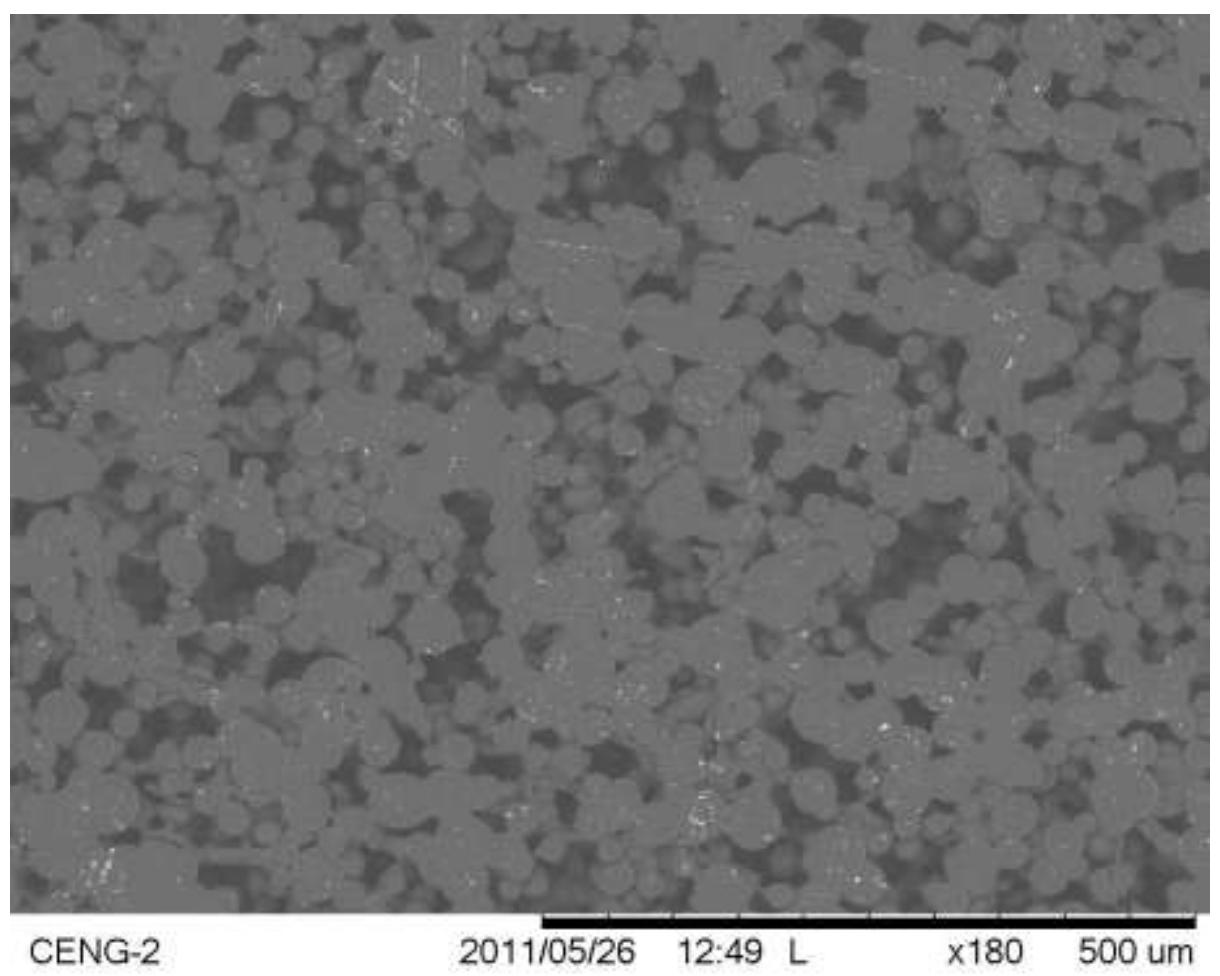

Figure 44: SEM image at 180x of Spin 25 lumen. 


\section{Spin 26}

\begin{tabular}{|l|l|l|l|l|l|}
\hline $\begin{array}{l}\text { Voltage } \\
(\mathrm{kV})\end{array}$ & $\begin{array}{l}\text { Flow Rate } \\
(\mathrm{ml} / \mathrm{hr})\end{array}$ & $\begin{array}{l}\text { Solution } \\
\text { Concentration (\%) }\end{array}$ & $\begin{array}{l}\text { Gap } \\
\text { Distance (in.) }\end{array}$ & Mean & $\begin{array}{l}\text { Standard } \\
\text { Deviation }\end{array}$ \\
\hline 30 & 6.5 & 15 & 10.0 & 6.051 & 2.939 \\
\hline
\end{tabular}

Figure 45 depicts two distinct types of fibers imaged for Spin 26. There are

ideally small fibers; however the thicker fibers appear to be over four times the size.

However, the larger fibers were still used in calculating the mean fiber diameter and standard deviation, which resulted in the large mean and standard deviation of fiber diameter.

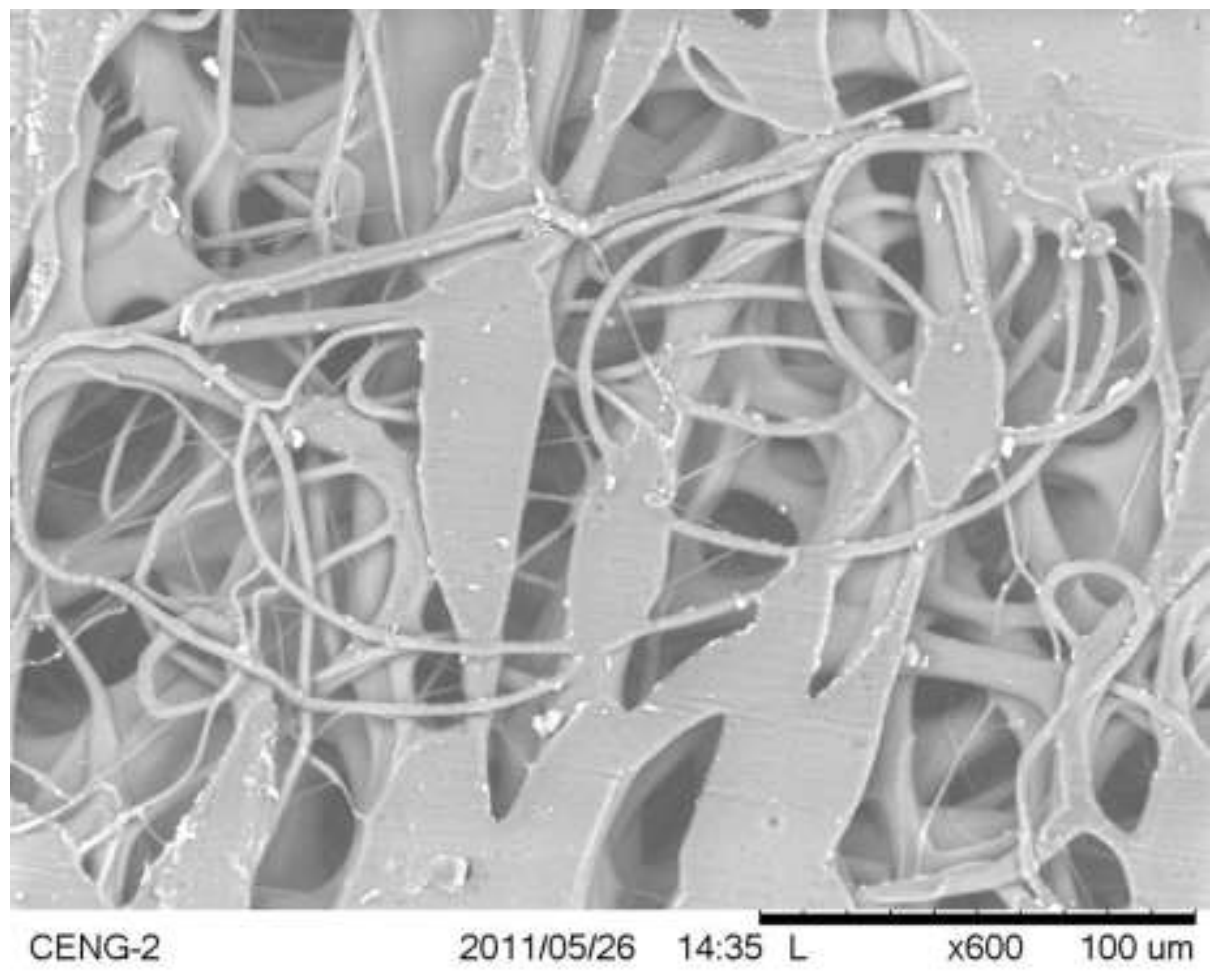

Figure 45: SEM image at 600x of Spin 26, section E, image 4. 


\section{Spin 27}

\begin{tabular}{|l|l|l|l|l|l|}
\hline $\begin{array}{l}\text { Voltage } \\
(\mathrm{kV})\end{array}$ & $\begin{array}{l}\text { Flow Rate } \\
(\mathrm{ml} / \mathrm{hr})\end{array}$ & $\begin{array}{l}\text { Solution } \\
\text { Concentration (\%) }\end{array}$ & $\begin{array}{l}\text { Gap } \\
\text { Distance (in.) }\end{array}$ & Mean & $\begin{array}{l}\text { Standard } \\
\text { Deviation }\end{array}$ \\
\hline 30 & 4.5 & 10 & 7.0 & - & - \\
\hline
\end{tabular}

Figure 46 images the lumen of Spin 27 that is composed entirely of beads as

opposed to fibrous structures. The scaffold was fragile and multiple images along the length of the scaffold were not taken.

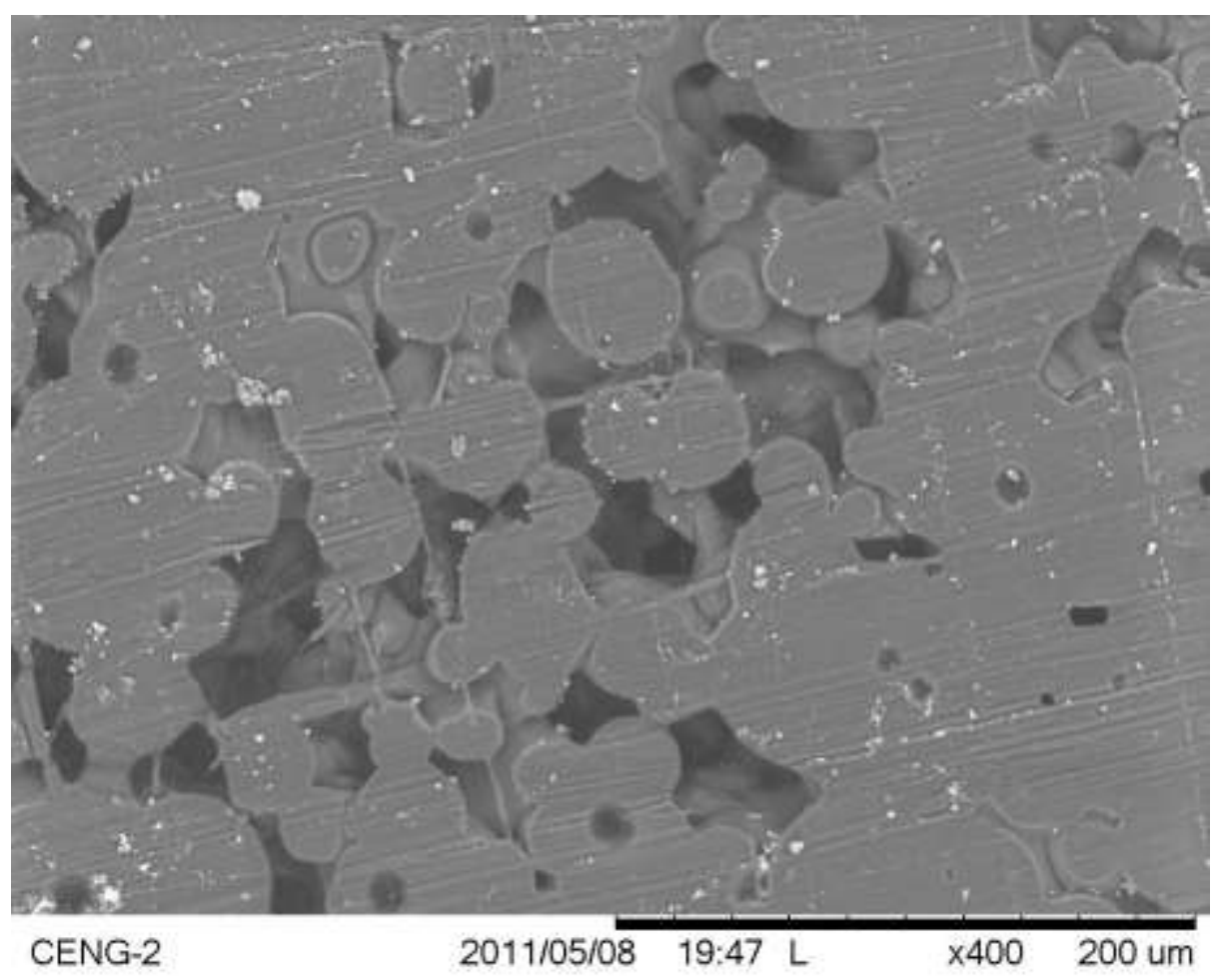

Figure 46: SEM image of Spin 27 lumen. 


\section{Spin 28}

\begin{tabular}{|l|l|l|l|l|l|}
\hline $\begin{array}{l}\text { Voltage } \\
(\mathrm{kV})\end{array}$ & $\begin{array}{l}\text { Flow Rate } \\
(\mathrm{ml} / \mathrm{hr})\end{array}$ & $\begin{array}{l}\text { Solution } \\
\text { Concentration (\%) }\end{array}$ & $\begin{array}{l}\text { Gap } \\
\text { Distance (in.) }\end{array}$ & Mean & $\begin{array}{l}\text { Standard } \\
\text { Deviation }\end{array}$ \\
\hline 30 & 6.5 & 15 & 10.0 & 4.050 & 2.155 \\
\hline
\end{tabular}

Figure 47 depicts a bimodal distribution of fibers that made up Spin 28, which

had a large standard deviation. A Taylor cone was evident throughout the Spin 28, however its continuity of shape and size was not observed. The resulting scaffold also had few globular formations, and the resulting mean fiber diameter was larger than ideal.

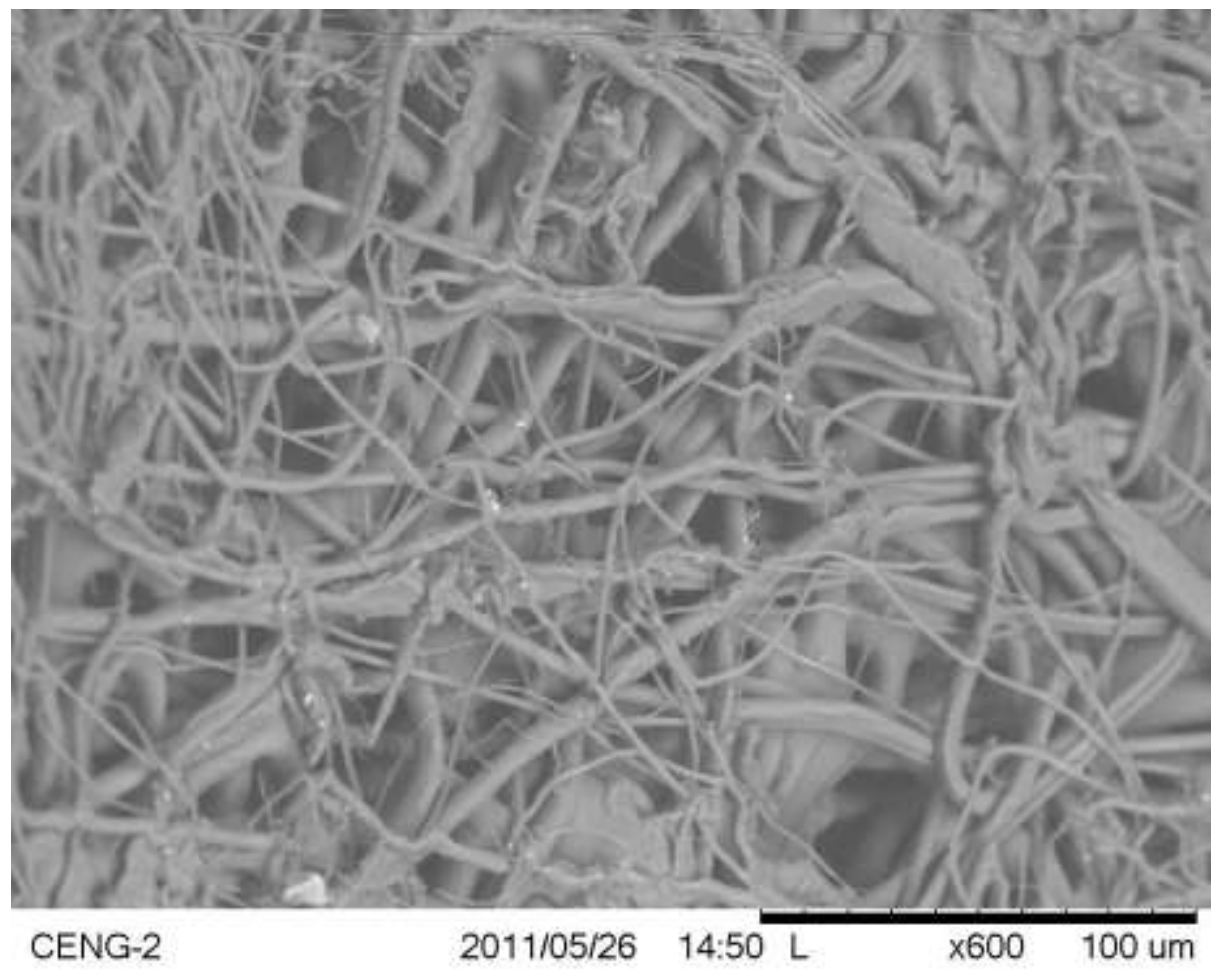

Figure 47: SEM image at 600x of Spin 28, section A, image 2. 


\section{Spin 29}

\begin{tabular}{|l|l|l|l|l|l|}
\hline $\begin{array}{l}\text { Voltage } \\
(\mathrm{kV})\end{array}$ & $\begin{array}{l}\text { Flow Rate } \\
(\mathrm{ml} / \mathrm{hr})\end{array}$ & $\begin{array}{l}\text { Solution } \\
\text { Concentration (\%) }\end{array}$ & $\begin{array}{l}\text { Gap } \\
\text { Distance (in.) }\end{array}$ & Mean & $\begin{array}{l}\text { Standard } \\
\text { Deviation }\end{array}$ \\
\hline 30 & 4.5 & 15 & 7.0 & 4.252 & 1.852 \\
\hline
\end{tabular}

Figure 48 depicts a somewhat random distribution of fibers that make up Spin 29, however there are large globular formations that have elongated, but did not quite form fibers. During the Spin 29 there was always a Taylor cone present. The resulting mean fiber diameter was larger than the goal fiber diameter.

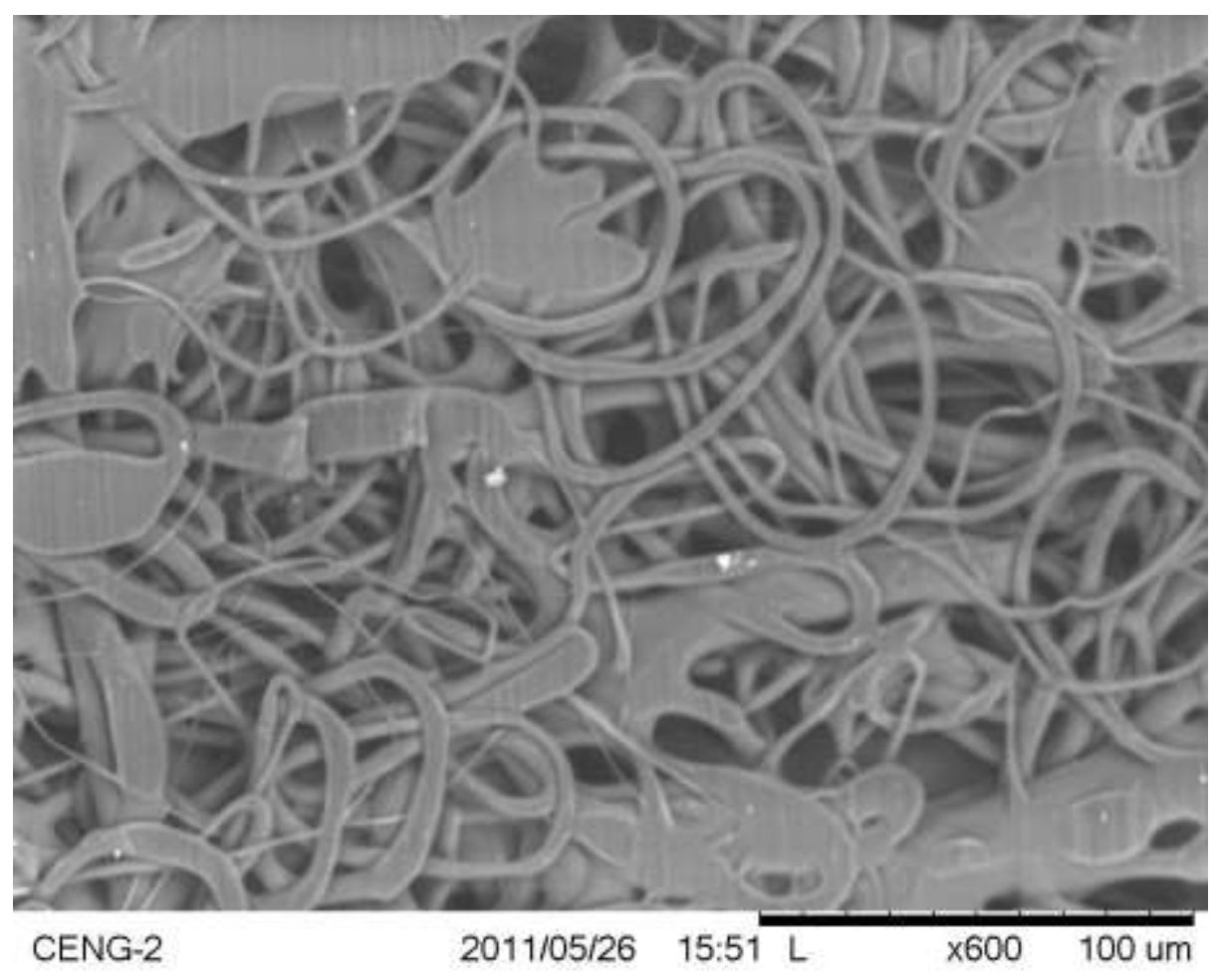

Figure 48: SEM image at $600 x$ of Spin 29, section B, image 4. 


\section{Spin 30}

\begin{tabular}{|l|l|l|l|l|l|}
\hline $\begin{array}{l}\text { Voltage } \\
(\mathrm{kV})\end{array}$ & $\begin{array}{l}\text { Flow Rate } \\
(\mathrm{ml} / \mathrm{hr})\end{array}$ & $\begin{array}{l}\text { Solution } \\
\text { Concentration (\%) }\end{array}$ & $\begin{array}{l}\text { Gap } \\
\text { Distance (in.) }\end{array}$ & Mean & $\begin{array}{l}\text { Standard } \\
\text { Deviation }\end{array}$ \\
\hline 24 & 6.5 & 15 & 7.0 & 6.707 & 3.504 \\
\hline
\end{tabular}

Figure 49 depicts a bimodal distribution of fiber structures. The resulting average

fiber diameter was larger than what was currently being produced, and the standard deviation was large. Spin 30 did not have a consistent Taylor cone, however build up would occur at the needle, then drop to the floor of the electrospinning chamber before collecting again.

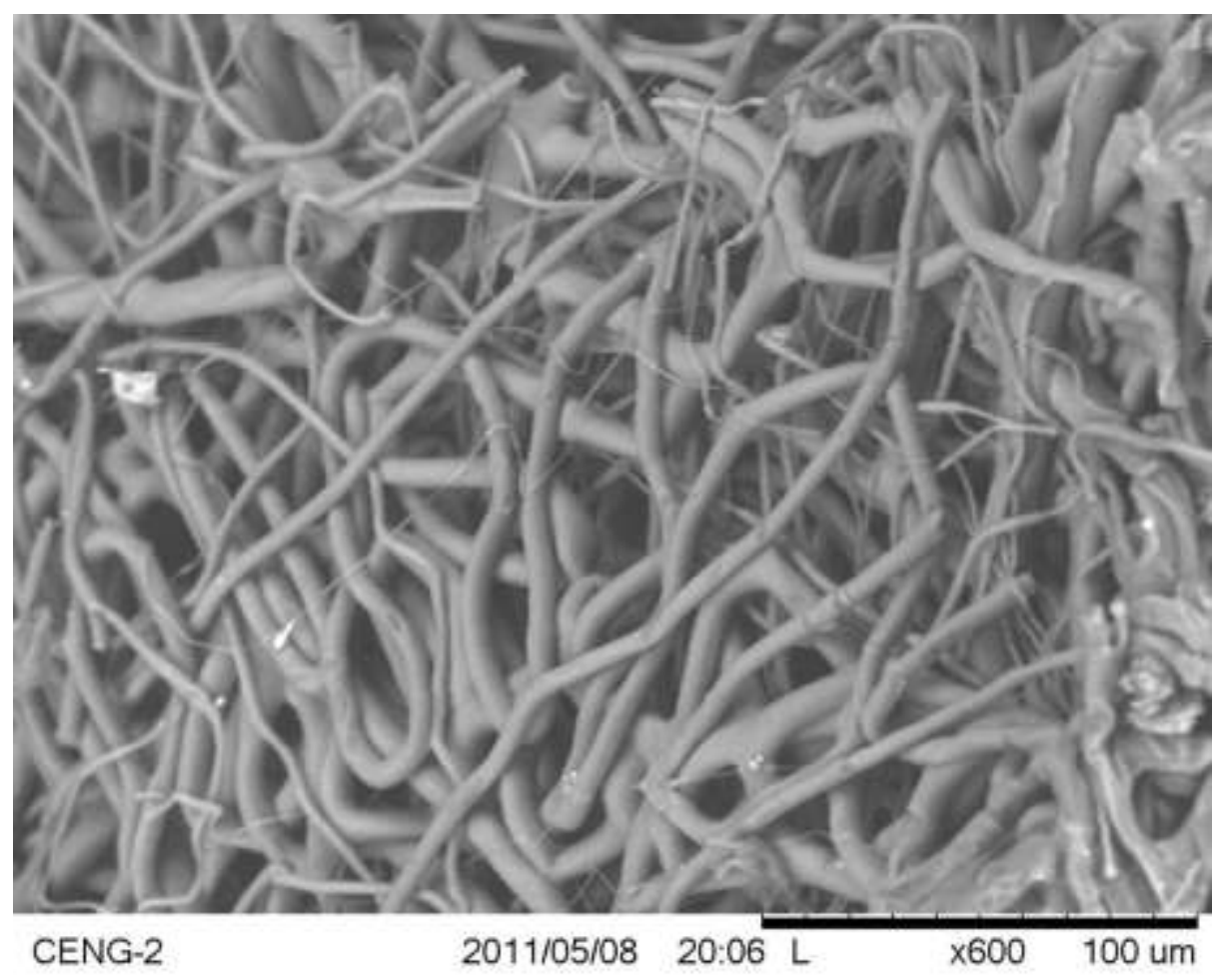

Figure 49: SEM image at 600x of Spin 30, section E, image 2. 


\section{Spin 31}

\begin{tabular}{|l|l|l|l|l|l|}
\hline $\begin{array}{l}\text { Voltage } \\
(\mathrm{kV})\end{array}$ & $\begin{array}{l}\text { Flow Rate } \\
(\mathrm{ml} / \mathrm{hr})\end{array}$ & $\begin{array}{l}\text { Solution } \\
\text { Concentration (\%) }\end{array}$ & $\begin{array}{l}\text { Gap } \\
\text { Distance (in.) }\end{array}$ & Mean & $\begin{array}{l}\text { Standard } \\
\text { Deviation }\end{array}$ \\
\hline 30 & 6.5 & 10 & 7.0 & - & - \\
\hline
\end{tabular}

Spin 31 did not have Taylor cone, and resulted in a scaffold composed

completely of beads, imaged in Figure 50. The scaffold was difficult to remove from the mandrel and few images of the lumen were taken.

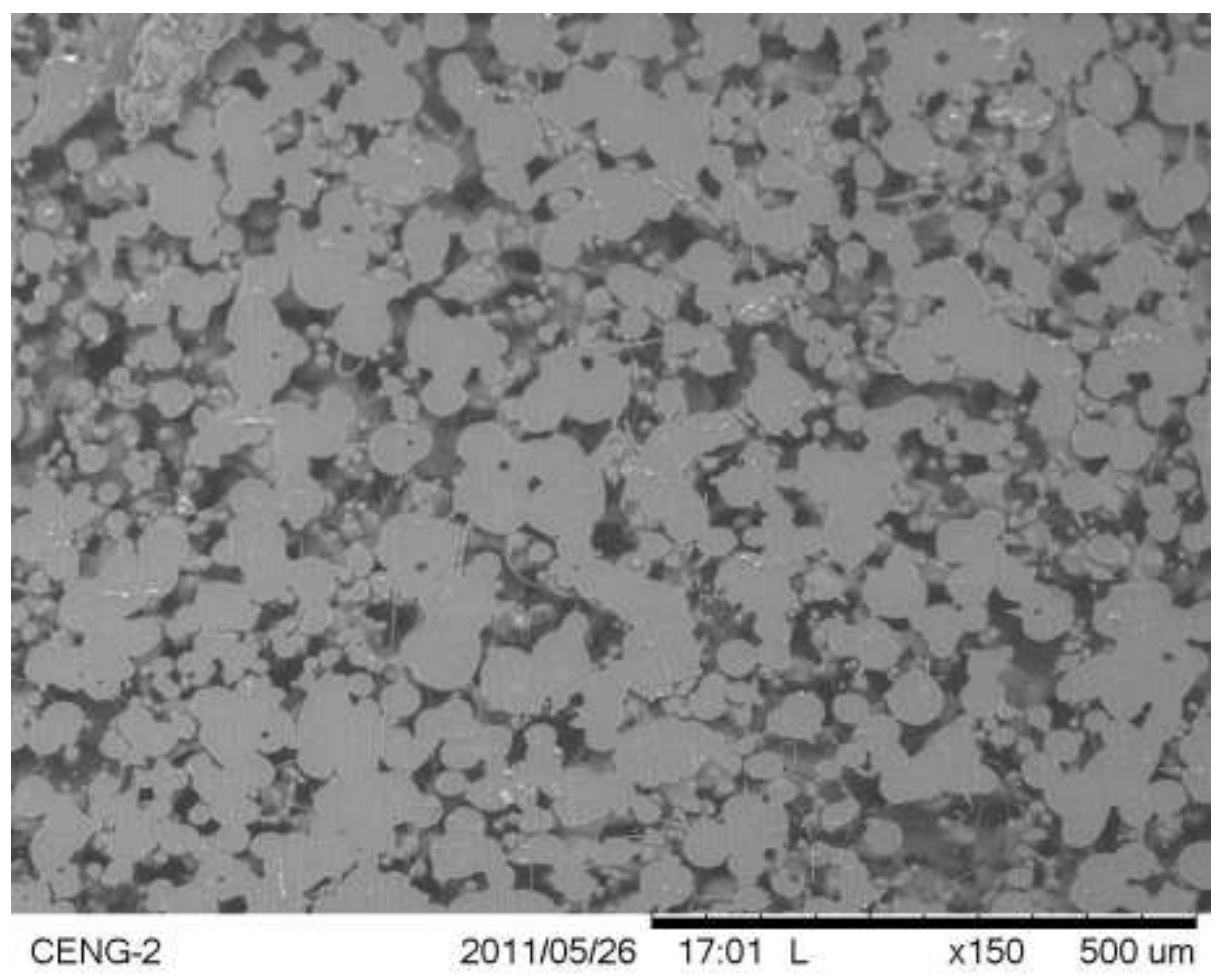

Figure 50: SEM image at 150x of Spin 31 lumen. 


\section{Spin 32}

\begin{tabular}{|l|l|l|l|l|l|}
\hline $\begin{array}{l}\text { Voltage } \\
(\mathrm{kV})\end{array}$ & $\begin{array}{l}\text { Flow Rate } \\
(\mathrm{ml} / \mathrm{hr})\end{array}$ & $\begin{array}{l}\text { Solution } \\
\text { Concentration (\%) }\end{array}$ & $\begin{array}{l}\text { Gap } \\
\text { Distance (in.) }\end{array}$ & $\begin{array}{l}\text { Mean } \\
\text { Standard } \\
\text { Deviation }\end{array}$ \\
\hline 24 & 6.5 & 10 & 7.0 & - & - \\
\hline
\end{tabular}

Figure 51. The scaffold was not composed of fibers and therefore could not be imaged and analyzed. The composition was "beady" and flaky.

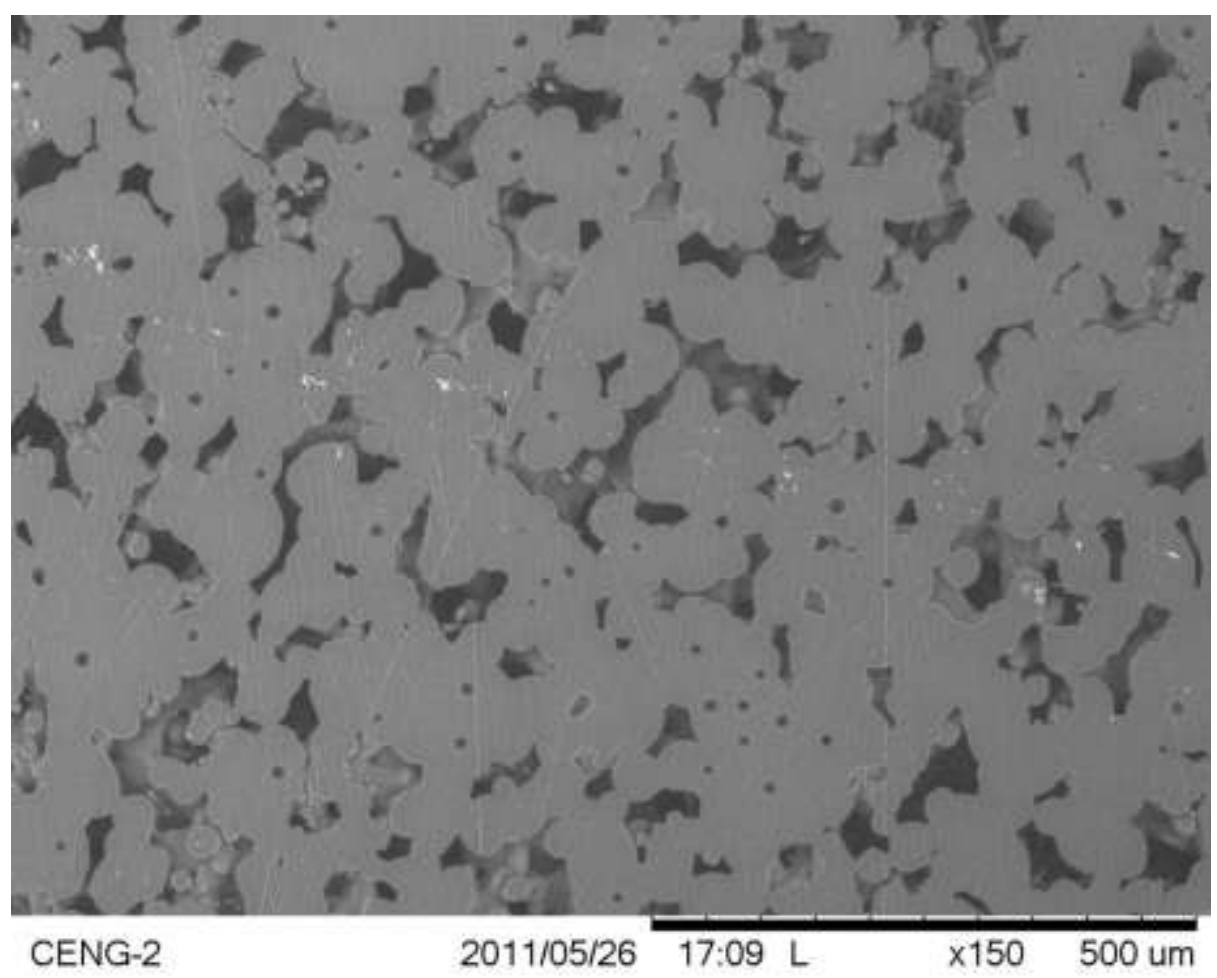

Figure 51: SEM image at 150x of Spin 32. 


\section{Spin 33}

\begin{tabular}{|l|l|l|l|l|l|}
\hline $\begin{array}{l}\text { Voltage } \\
(\mathrm{kV})\end{array}$ & $\begin{array}{l}\text { Flow Rate } \\
(\mathrm{ml} / \mathrm{hr})\end{array}$ & $\begin{array}{l}\text { Solution } \\
\text { Concentration (\%) }\end{array}$ & $\begin{array}{l}\text { Gap } \\
\text { Distance (in.) }\end{array}$ & Mean & $\begin{array}{l}\text { Standard } \\
\text { Deviation }\end{array}$ \\
\hline 24 & 6.5 & 15 & 10.0 & 4.458 & 2.233 \\
\hline
\end{tabular}

Figure 52 depicts a bimodal and inconsistent distribution of fibers. The standard deviation is large. While a Taylor cone was apparent during the Spin 33, it would appear and disappear, and often changed shape and size. The matrix is composed of both small and larger fibers, as well as globular structures that are not completely elongated into fibers.

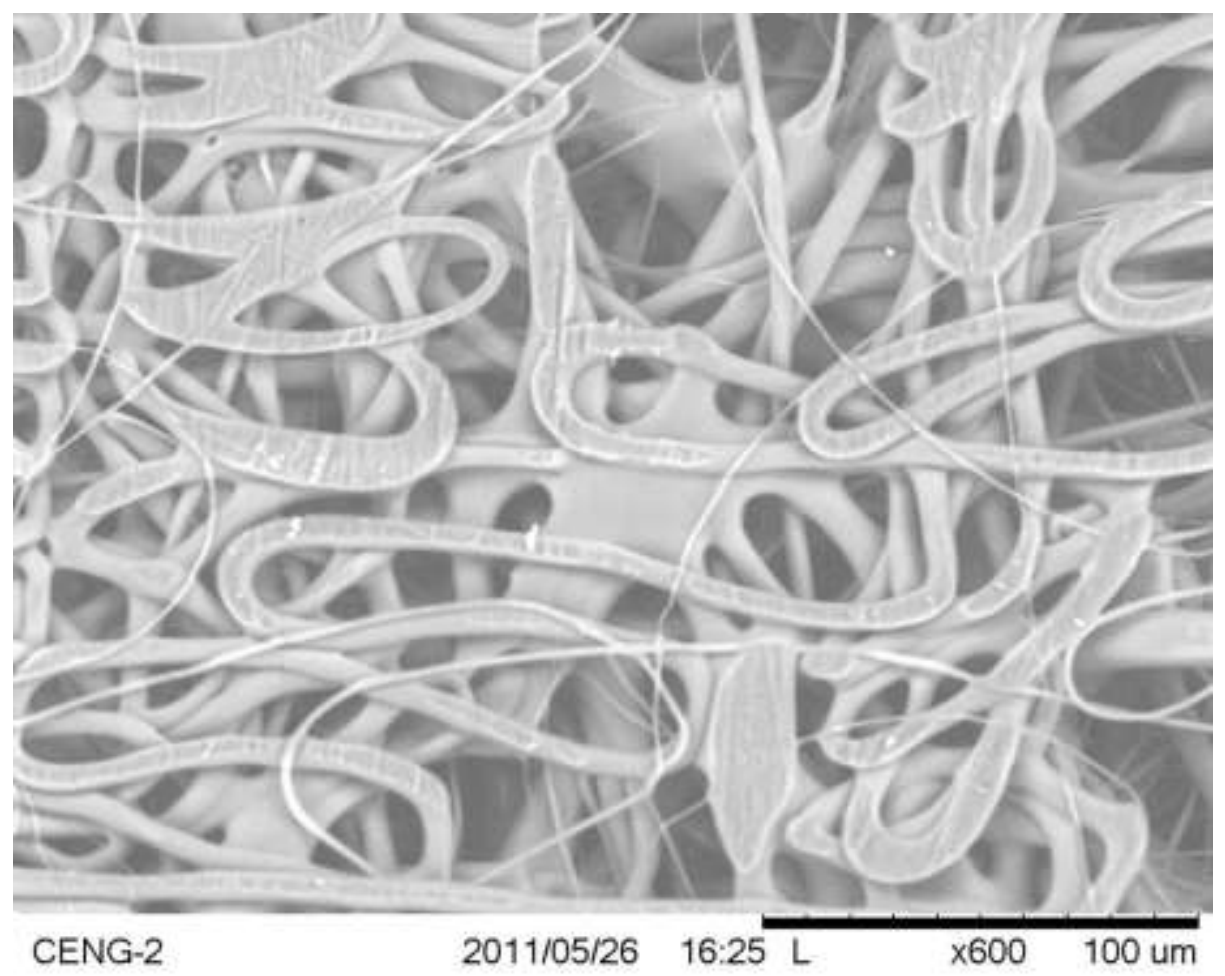

Figure 52: SEM image at $600 x$ of Spin 33, section A, image 1. 


\section{Summary of DOE Measurements and Observations}

The DOE was successfully completed as indicated and all resulting scaffolds that could be analyzed were imaged. From the fiber measurements taken, an average fiber diameter was used to create a model describing the effect of the parameters-gap distance, voltage, solution concentration, flow rate-and their interactions on the resulting mean fiber diameter. Because some of the scaffolds were not fibrous, thereby preventing fiber measurements to be taken, not all scaffolds were used in creating the model. None of the scaffolds used to create the model came from a $10 \%$ solution concentration mix, as all had globular formations and would fall apart when removed from the mandrel. Observations during the spins indicated that a Taylor cone often lead to a fibrous scaffolds. While some spins without a Taylor cone were still fibrous, a bead of solution at the tip of the needle may be crucial to creating a continuous jet of fibers. 


\subsection{Statistical Analysis}

Once the average fiber diameter and data for each scaffold had been compiled, seen in Table 3, statistical analysis was performed using MiniTab.

Table 3: Spin with factor settings and mean fiber diameter and standard deviation.

\begin{tabular}{|l|l|l|l|l|l|l|}
\hline Spin & $\begin{array}{l}\text { Voltage } \\
(\mathrm{kV})\end{array}$ & $\begin{array}{l}\text { Flow } \\
\text { Rate(ml/hr) }\end{array}$ & $\begin{array}{l}\text { Solution } \\
\text { Concentration } \\
(\%)\end{array}$ & $\begin{array}{l}\text { Gap } \\
\text { Distance } \\
\text { (in) }\end{array}$ & $\begin{array}{l}\text { Mean Fiber } \\
\text { Diameter } \\
\text { (um) }\end{array}$ & $\begin{array}{l}\text { Std. } \\
\text { Deviation } \\
\text { (um) }\end{array}$ \\
\hline 1 & 24 & 4.5 & 15 & 7.0 & 3.318 & 1.281 \\
\hline 2 & 30 & 4.5 & 15 & 10.0 & 3.340 & 1.053 \\
\hline 3 & 24 & 4.5 & 10 & 10.0 & - & - \\
\hline 4 & 24 & 4.5 & 10 & 7.0 & - & - \\
\hline 5 & 30 & 6.5 & 15 & 7.0 & 3.506 & 1.403 \\
\hline 6 & 30 & 4.5 & 15 & 7.0 & 5.362 & 1.960 \\
\hline 7 & 30 & 4.5 & 15 & 10.0 & 4.587 & 1.363 \\
\hline 8 & 30 & 6.5 & 10 & 7.0 & - & - \\
\hline 9 & 24 & 4.5 & 10 & 10.0 & - & - \\
\hline 10 & 24 & 4.5 & 15 & 10.0 & 2.742 & 1.279 \\
\hline 11 & 24 & 6.5 & 10 & 7.0 & - & - \\
\hline 12 & 24 & 6.5 & 15 & 7.0 & 4.003 & 2.897 \\
\hline 13 & 24 & 6.5 & 15 & 10.0 & 4.281 & 1.124 \\
\hline 14 & 30 & 4.5 & 10 & 10.0 & - & - \\
\hline 15 & 30 & 4.5 & 10 & 7.0 & - & - \\
\hline 16 & 24 & 4.5 & 15 & 10.0 & 4.396 & 2.212 \\
\hline 17 & 30 & 6.5 & 10 & 10.0 & - & - \\
\hline 18 & 24 & 6.5 & 10 & 10.0 & - & - \\
\hline 19 & 24 & 6.5 & 15 & 10.0 & - & - \\
\hline 20 & 24 & 4.5 & 10 & 7.0 & - & - \\
\hline 21 & 27 & 5.5 & 12.5 & 8.5 & 4.350 & 1.157 \\
\hline 22 & 24 & 4.5 & 15 & 7.0 & 4.062 & 1.762 \\
\hline 23 & 30 & 6.5 & 10 & 10.0 & - & - \\
\hline 24 & 30 & 6.5 & 15 & 7.0 & 5.410 & 2.329 \\
\hline 25 & 30 & 4.5 & 10 & 10.0 & - & - \\
\hline 26 & 30 & 6.5 & 15 & 10.0 & 6.051 & 2.939 \\
\hline 27 & 30 & 4.5 & 10 & 7.0 & - & - \\
\hline 28 & 30 & 6.5 & 15 & 10.0 & 4.050 & 2.155 \\
\hline 29 & 30 & 4.5 & 15 & 7.0 & 4.252 & 1.852 \\
\hline 30 & 24 & 6.5 & 15 & 7.0 & 6.707 & 3.504 \\
\hline 31 & 30 & 6.5 & 10 & 7.0 & - & - \\
\hline 32 & 24 & 6.5 & 10 & 7.0 & - & - \\
\hline 33 & 24 & 6.5 & 15 & 10.0 & 4.458 & 2.233 \\
\hline & & & & & & \\
\hline
\end{tabular}


As mentioned, the purpose of the analysis was to determine how each factor impacted the resulting fiber diameter, and if/how each factor interacted with one another. A number of tests were run to determine the equation that best fit in predicting average fiber diameter, and the full Minitab output can be seen in Appendix $\mathrm{H}$. The output includes the representation of data that lead to the types of regression models tested, as well as the transformations of variables assessed within different regression models, and their resulting significance.

It is important to note that the experiment was not balanced, and the combinations of factors that did not create a suitable scaffold were dropped. Most of those involved solution concentrations that were lower that $15 \%$ so it was assumed that solution concentration was no longer a viable predictor to test. Because all of the data came from solution concentrations at $15 \%$, and one at $12.5 \%$, the center point, solution concentration is basically a constant for the scaffolds that measurements were gathered from. If the parameter does not vary, then it cannot be tested as a predictor.

The analysis began with a graphical representation of the data, as a method to detect possible interactions between predictors, and the type of transformations that may be necessary later in the analysis. Each variable was tested, excluding solution concentration, and interactions were tested as well. Finally, a second analysis, which will be discussed in detail later, was done to determine if the presence of a Taylor cone affected whether or not a viable scaffold resulted.

\subsubsection{Settings as a predictor for Average Fiber Diameter of a Scaffold}

A general regression was performed to find a model to fit the data. A regression model is an additive model that can test how multiple predictors can be combined to affect a resulting variable-in this case fiber diameter. The regression model has the versatility to test for interactions as well as different relationships between variables by 
transforming data into its logarithmic or inverse form. It can also test for square and cubic relationships. Finally, each variable is tested for significance within the model. For example, within a model, two variables may be included as predictors, however each has their own $\mathrm{p}$-value, indicated the strength of the relationship between the individual predictor and the resulting variable. The data is normal given the Anderson-Darling normality test $(p=0.193)$, with a testing sample size of 17 , since the some of the original 33 were thrown out, for reasons to follow. This normality test is good when working with data coming from multiple observations. When the $p$-value is above alpha, which is 0.05 in this case, the data is considered to be normal. When using a regression model, it is important for the data to be normal. The model selected to predict fiber diameter was: Average Fiber Diameter (um)

$$
\begin{aligned}
& =-0.216866+0.400438 \text { Flow Rate }\left(\frac{m l}{h r}\right)+0.0539792 \text { Voltage }(k V) \\
& +\left(\frac{7.93223}{\text { Gap Distance }(\text { inches })}\right)
\end{aligned}
$$

This model had a p-value of 0.36 and explained $21.15 \%$ according to the R-squared value. The $p$-value is greater than alpha $(0.05)$ and suggests the model is insignificant. This is due to a large amount of variation coupled with few observations $(n=17)$. The Rsquared value determines how much of the data directly fits the proposed model. For example, if one were to take each spin and plot it on the plot of the model, $21.15 \%$ would lay on the model line. However, in many scientific studies an R-squared value of $25 \%$ is considered good because of variation in real world situations that never fit a clean equation meant to describe a situation. These values suggest the model does not fit perfectly but can still be used to attempt to control fiber diameter.

The strongest predictor was flow rate $(p=0.13)$ with a positive correlation, indicating that a lower flow rate will result in a scaffold with a lower mean fiber diameter. 
The other predictors include gap distance and voltage, which were weaker predictors ( $p$ $=0.5)$.

Table 4 below indicates examples of settings suitable for the current set up, which could result in 2 microns of fiber diameters. Note that many electrospinning set ups run at a minimum of $30 \mathrm{kV}$, however due to grounding and voltage amplification problems, lower voltages combinations are shown below, especially since the given regression model results in a lower fiber diameter with a lower voltage.

Table 4: Possible factor combinations and expected mean fiber diameter based on DOE model. The highlighted rows are combinations ideal for the current electrospinning setup.

\begin{tabular}{|r|r|r|r|r|}
\hline $\begin{array}{l}\text { Voltage } \\
(\mathrm{kV})\end{array}$ & $\begin{array}{l}\text { Gap Distance } \\
\text { (inches) }\end{array}$ & $\begin{array}{l}\text { Flow Rate } \\
\text { (ml/hr) }\end{array}$ & $\begin{array}{l}\text { Solution } \\
\text { Concentration }\end{array}$ & $\begin{array}{l}\text { Expected Mean } \\
\text { Fiber Diameter }\end{array}$ \\
\hline 24 & 10 & 4 & 15 & 3.47361 \\
\hline 18 & 10 & 4.5 & 15 & 3.349954 \\
\hline 24 & 12 & 4 & 15 & 3.341406 \\
\hline 15 & 12 & 4.5 & 15 & 3.055812 \\
\hline 15 & 16 & 4.5 & 15 & 2.890557 \\
\hline 15 & 18 & 4.5 & 15 & 2.835472 \\
\hline 15 & 18 & 4.5 & 15 & 2.835472 \\
\hline 15 & 20 & 4.5 & 15 & 2.791405 \\
\hline 15 & 20 & 4 & 15 & 2.591186 \\
\hline 18 & 20 & 4.5 & 15 & 2.953342 \\
\hline
\end{tabular}

\section{Discussion}

The highlighted values indicate ideal suggestions for the current set up, since some of the gap distances or voltages may prove dangerous or will not fit within the electrospinning box. The combinations indicated are values derived from the DOE model. They will not necessarily result in the expected outcome, nor will they work the same for polymers other than PLGA. In addition, one issue with the results from the DOE is that none of the spins resulted in an average fiber diameter below 2 microns, and only three settings from each parameter were tested. The "ideal" parameter combinations in 
Table 4 suggest data that is outside of the limits of the data, which is dangerous to do in case the data shifts beyond the limits of the modeled equation.

The strongest indicator of the fiber diameter was flow rate. PLGA has not been tested at a flow rate below approximately $4.0 \mathrm{ml} / \mathrm{hr}$. Currently, it takes $30-45$ minutes to electrospun a scaffold and further lowering the flow rate would nearly double the process time, which could be a disadvantage because someone must be present during the electrospinning and less scaffolds could be produced in a set amount of time. The relationship between gap distance and the resulting mean fiber diameter is an inverse relationship, which follows with the research that a larger gap distance gives the fiber more time to separate due to instabilities [156]. Literature has suggested that voltage is directly proportional to the fiber diameter, in that a higher applied voltage results in the jet moving through the air faster, leaving less time to branch off into smaller fibers; however, an applied voltage too low would lead to a charge density overcome by surface tension, and the fibers would not branch [78]. 


\subsubsection{Taylor Cone Importance}

As previously mentioned, many of the trial runs resulted in a beady and flaky scaffold, as depicted in Figure 53 below.

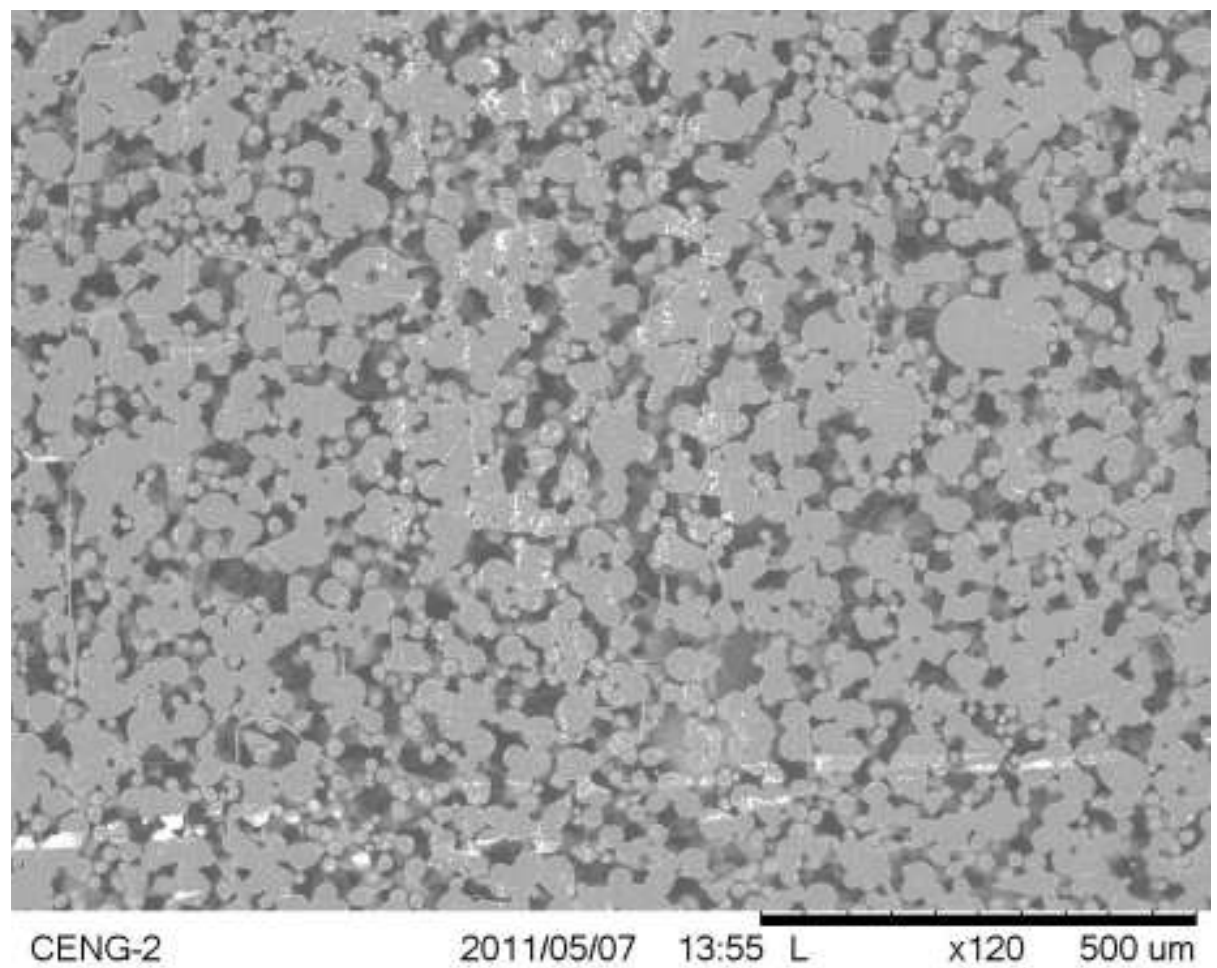

Figure 53: SEM image of Spin 11 lumen depicting globular structure rather than preferred fibrous structure.

These scaffolds were not able to be imaged as per the SEM protocol and would not function as a matrix upon which to seed endothelial cells. Also, the majority of the runs that resulted in beady scaffolds lacked a Taylor cone, which is a coned bubble of the solution that sits on the tip of the needle, ejecting the fiber from the tip of the cone, as imaged in Figure 54. 


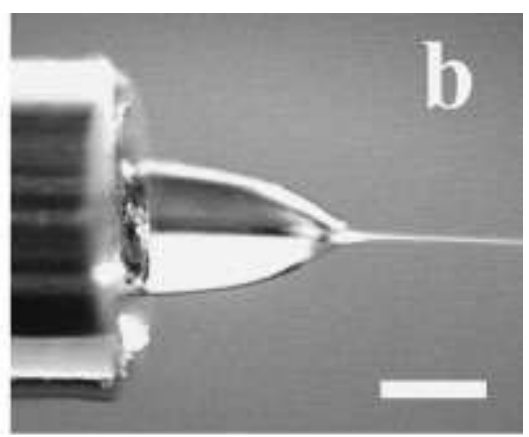

Figure 54: Ideal Taylor cone with a single jet of solution ejecting from the tip [160].

Based solely on the observations and results from this study, without a Taylor cone present, a useful scaffold never resulted. Confirmed in Figure 55, a fibrous scaffold never resulted when no Taylor cone was observed during the electrospinning process. The presence or lack of the Taylor cone was not an accurate method to determine whether or not a fibrous scaffold resulted, however qualitative data gathered with the DOE suggests a strong correlation. 


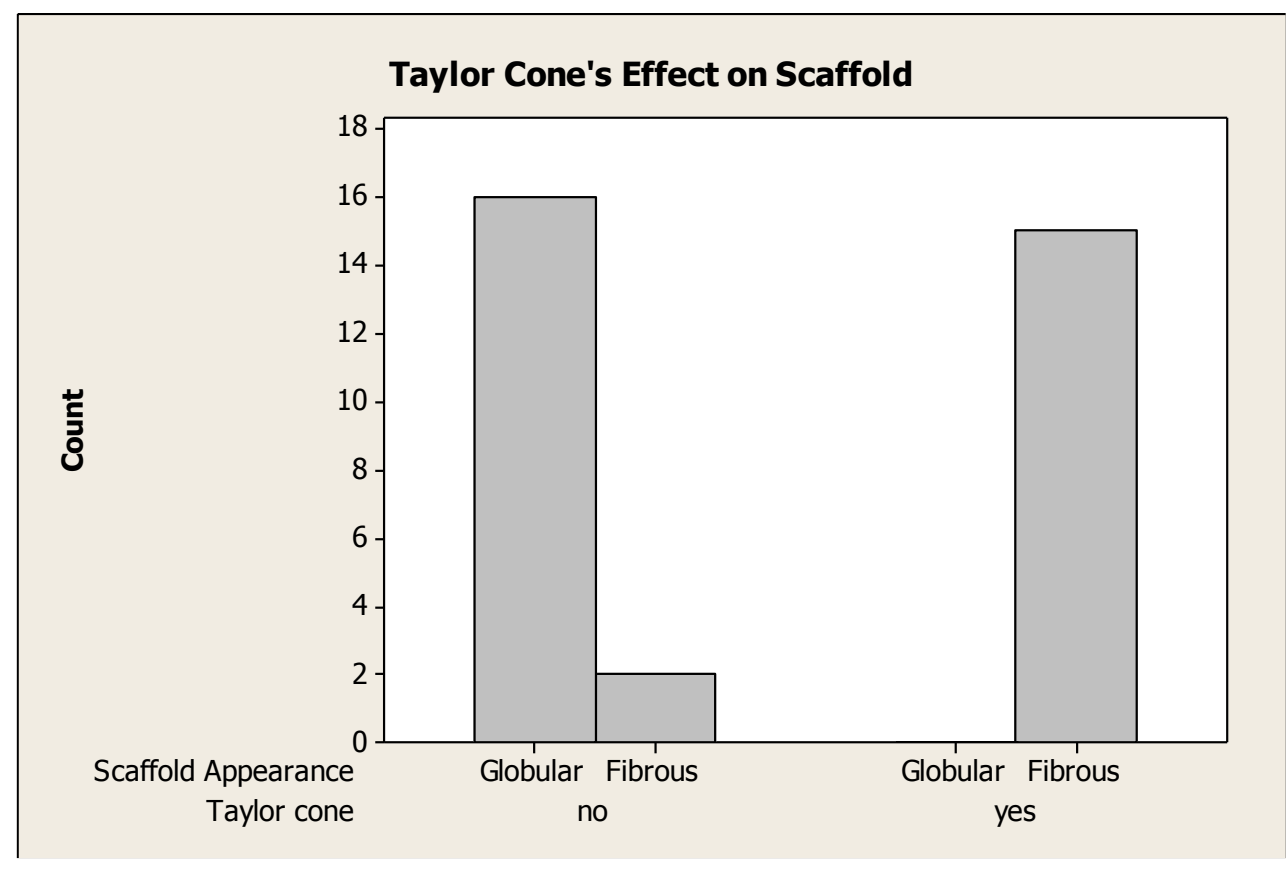

Figure 55: Bar chart depicting relationship between Taylor cone appearance and the structure of the scaffold.

\subsubsection{Variation of fibers along the length of the scaffold}

In addition to determining a mean fiber diameter and standard deviation for each scaffold, a mean and standard deviation was determined for each section (A-E) of the scaffold, detailed below in Table 5. The purpose of dividing the scaffold into sections is to ensure the scaffold is consistent. The data in Table 5 below was analyzed using an ANOVA in Minitab-the full output can be found in Appendix $\mathrm{H}$-and there was found to be no statistical evidence of a difference between the mean for each section of a scaffold $(p=0.973)$. The scaffolds are consistent across the length mandrel.

Table 5: Table of mean fiber diameter and standard deviations for each section of the fibrous scaffolds.

\begin{tabular}{|c|c|c|c|c|c|c|c|}
\hline Spin & Section & Mean (um) & Std. Dev. (um) & Spin & Section & Mean (um) & Std. Dev. (um) \\
\hline 1 & A & 3.248 & 1.236 & 21 & A & 4.496 & 1.119 \\
\hline 1 & B & 3.293 & 1.178 & 21 & B & 4.146 & 1.149 \\
\hline 1 & C & 3.352 & 1.627 & 21 & C & 4.111 & 1.067 \\
\hline 1 & D & 3.243 & 1.365 & 21 & D & 4.493 & 1.236 \\
\hline
\end{tabular}




\begin{tabular}{|c|c|c|c|c|c|c|c|}
\hline Spin & Section & Mean (um) & Std. Dev. (um) & Spin & Section & Mean (um) & Std. Dev. (um) \\
\hline 1 & $\mathrm{E}$ & 3.455 & 0.941 & 21 & $\mathrm{E}$ & 4.506 & 1.185 \\
\hline 2 & $A$ & 3.471 & 0.824 & 22 & A & 4.244 & 1.560 \\
\hline 2 & B & 3.064 & 0.926 & 22 & B & 4.134 & 1.665 \\
\hline 2 & C & 3.111 & 1.011 & 22 & C & 4.065 & 1.764 \\
\hline 2 & $\mathrm{D}$ & 3.445 & 1.207 & 22 & D & 4.069 & 1.713 \\
\hline 2 & $E$ & 3.608 & 1.180 & 22 & $\mathrm{E}$ & 3.798 & 2.104 \\
\hline 5 & A & 3.358 & 1.556 & 24 & $A$ & 5.470 & 2.695 \\
\hline 5 & B & 3.773 & 1.299 & 24 & B & 4.864 & 2.281 \\
\hline 5 & C & 3.242 & 1.221 & 24 & C & 5.315 & 2.469 \\
\hline 5 & D & 3.276 & 1.266 & 24 & D & 5.452 & 2.117 \\
\hline 5 & $E$ & 3.881 & 1.562 & 24 & $\mathrm{E}$ & 5.948 & 1.976 \\
\hline 6 & $A$ & 5.255 & 1.956 & 26 & $A$ & 6.087 & 3.317 \\
\hline 6 & B & 5.713 & 2.106 & 26 & B & 5.877 & 2.736 \\
\hline 6 & C & 5.251 & 2.002 & 26 & C & 6.224 & 2.775 \\
\hline 6 & D & 5.171 & 1.820 & 26 & D & 6.139 & 2.829 \\
\hline 6 & $E$ & 5.419 & 1.940 & 26 & $\mathrm{E}$ & 5.928 & 3.106 \\
\hline 7 & A & 4.472 & 1.166 & 28 & A & 4.144 & 2.051 \\
\hline 7 & B & 4.571 & 0.940 & 28 & B & 3.720 & 2.162 \\
\hline 7 & C & 4.928 & 1.708 & 28 & C & 4.050 & 2.305 \\
\hline 7 & D & 4.569 & 1.358 & 28 & D & 3.968 & 2.079 \\
\hline 7 & $E$ & 4.394 & 1.508 & 28 & $E$ & 4.368 & 2.205 \\
\hline 10 & A & 2.651 & 1.201 & 29 & A & 4.342 & 2.182 \\
\hline 10 & B & 2.420 & 1.039 & 29 & B & 4.530 & 2.034 \\
\hline 10 & C & 2.363 & 1.086 & 29 & C & 4.081 & 1.616 \\
\hline 10 & D & 3.401 & 1.359 & 29 & D & 4.355 & 1.788 \\
\hline 10 & $E$ & 2.874 & 1.431 & 29 & $\mathrm{E}$ & 3.954 & 1.587 \\
\hline 12 & A & 4.160 & 3.377 & 30 & A & 6.725 & 2.883 \\
\hline 12 & B & 3.829 & 2.406 & 30 & B & 6.754 & 4.140 \\
\hline 12 & C & 4.050 & 2.837 & 30 & C & 5.674 & 1.454 \\
\hline 13 & A & 4.435 & 1.066 & 33 & A & 4.765 & 2.733 \\
\hline 13 & B & 4.784 & 0.911 & 33 & B & 5.057 & 2.323 \\
\hline 13 & C & 4.494 & 0.978 & 33 & C & 4.528 & 2.125 \\
\hline 13 & $D$ & 4.143 & 1.134 & 33 & D & 3.708 & 1.884 \\
\hline 13 & $E$ & 3.547 & 1.146 & 33 & $\mathrm{E}$ & 4.233 & 1.828 \\
\hline 16 & $A$ & 4.278 & 2.502 & & & & \\
\hline 16 & B & 4.442 & 2.314 & & & & \\
\hline 16 & C & 4.799 & 2.406 & & & & \\
\hline 16 & $D$ & 4.677 & 1.866 & & & & \\
\hline 16 & $\mathrm{E}$ & 3.786 & 1.830 & & & & \\
\hline
\end{tabular}




\section{Interpretation of Results}

The four parameters chosen were elements research suggested highly affected the resulting fiber diameter of the scaffold. The parameter excluded-solution concentration—can still have a large effect on the resulting fiber diameter. Research has indicated lower solution concentrations for similar polymers will yield a scaffold with a smaller mean fiber diameter [150]. While spinning the runs with lower solution concentrations, electrospraying appeared to be an issue, which can explain the beads and wet appearance of the resulting scaffolds. This is not to say that lower solution concentrations cannot run on the electrospinner. Initially, the standard protocol for PLGA involved running with voltages of approximately $15 \mathrm{kV}$. Most research done in electrospinning with nanofibrous scaffolding runs at a minimum of $30 \mathrm{kV}$ of applied voltage [48]. The highest applied voltage used in the current electrospinning set up was $30 \mathrm{kV}$ and arcing occurred, so safety of the user was in question. After further insulating the syringe pump stand, $30 \mathrm{kV}$ was achieved but nothing higher. A higher voltage may give the solution enough charge to completely reach instabilities needed to stretch into a fiber and begin to branch into smaller fibers. However, experimentation should be done to determine what applied voltage is needed since there is a range where morphology is optimal and it is dependent on the polymer and solvent as well [48].

Flow rate was confirmed to be the strongest predictor of fiber diameter, both statistically and by observation. The smallest mean fiber diameter came from parameters that had $4.5 \mathrm{ml} /$ hour flow rate. The max mean fiber diameter also resulted from $6.5 \mathrm{ml} /$ hour flow rate. This aligns with research because a slower flow rate means that the speed of the fiber as it flies through the air is slower, thereby giving the fiber more time to branch off into smaller fibers [151]. 
Though not a strong predictor, the model indicated there was an inverse relationship between gap distance and the resulting mean fiber diameter. For the current set up, the largest gap distance tested was approximately 12 inches, so more testing beyond this limit is advised. The reason for the inverse relationship is similar to the logic behind the direct relationship between flow rate and mean fiber diameter. The fiber will be in the air longer if the grounded collector is farther away. The longer the fiber is in the air, the more times it can branch off into smaller fibers, resulting in smaller fibers landing on the collector to form the scaffold [48].

The most surprising element of the model equation is the direct relationship between voltage and mean fiber diameter. The predictor does not have strong statistical significance, however suggests that by continually lowering the voltage, a smaller fiber will result. This contradicts literature. The issue there is that if the voltage is too low, the fiber will not be charged enough and will result in a scaffold with beads or globular formations because the fiber did not become charged enough to reach certain instabilities. While this element of the equation may be accurate, I think there is an important interaction missing having to do with solution concentration, in that the solution concentration affects the charge density and surface tension of the jet [53] and the applied voltage needs to be high enough to overcome the charge density, but not too high where the jet moves too quickly through the air, not allowing for adequate time to branch off into smaller fibers. However, because solution concentration was excluded from the model because not all scaffolds could be used for valid data, this interaction could not be measured and added to the model. Given research and observations made during electrospinning past trials and the DOE, the interaction variable would be a negative relationship, emphasizing a balance between solution concentration and voltage, and not allowing one to lower too much, without raising the other one. 
Overall, the DOE successfully compiled data from four of the parameters, each at three different settings. When designing an experiment, ideally the experiment would be balanced and have a large enough sample size to detect the difference between chance variation and assignable cause variation—in this case assignable cause being the parameter settings. The DOE was not balanced however, in that there were three different settings for each factor, but they were not run the same amount of times. It was designed as such to get the most out of a limited amount of data. The limiting factor is cost. An ideal DOE would include all of the 33 run in this thesis, but also repeats of the centerlines compared against other settings, as well as a larger reach so the equation could be applied to possible extremes if needed. Finally a subgroup size of at least five would create an actual average resulting from each scaffold, by removing any chance variation. The averages used come from a single scaffold, so if anything had gone wrong with the single scaffold, it would be reflected in the data and DOE equation. The cost of scaling up the experiment as described would cost approximately $\$ 2500$ in materials directly used (PLGA and chloroform), not including the cost of wear on the machinery used for the experiment. It would take approximately 200 hours of lab work, not including time spent waiting for solutions to mix. These numbers are based on a 48 spin experiment, with 16 different combinations all performed 3 times, a bare minimum to rule out chance variation in statistical analysis.

Overall, the DOE provided insight into how PLGA with chloroform reacts to changes in parameter settings. While the goal of 200 nanometer fibers was not reached, smaller fibers were observed. Future directions should be focused on efficacy of the fibers currently achieved or into systematically decreasing fiber diameter further. 


\section{Chapter 4: Conclusions and Future Work}

\section{Summary}

The goal of this thesis was to systematically determine the effects of four parameters-gap distance, voltage, solution concentration, and flow rate-on the mean fiber diameter of the resulting electrospun PLGA scaffolds, through the use of a DOE. In addition, the DOE provided means for a regression model allowing for the prediction of the mean fiber diameter of a scaffold given the four parameters listed above. For the purposes of the Cal Poly tissue engineering lab, the scaffolds created are meant to act as an artificial scaffold for an endothelium for tissue engineered blood vessels. Because of this, the goal of the regression model was to predict a scaffold with fibers in the 100200 nanometer range, to effectively mimic the endothelium ECM and be suitable for endothelial cell proliferation [102]

Due to discontinuous solution jets during spins with $10 \%$ solution concentrations, solution concentration was not included in the model, because the resulting scaffolds were not fibrous, and fiber measurements could not be taken. The final regression model included only flow rate, gap distance, and voltage; no statistically significant interactions between these variables were determined with data found. No scaffolds with a mean fiber diameter below 2.0 microns were created in the DOE runs, however several possible sets of electrospinning parameters were proposed. 


\section{Findings}

The interactions between the four parameters were visibly obvious and confirmed in literature. Solution concentration was not included in the model because of the globular structures occurring with runs with lower solution concentrations. Spins with the same voltage, gap distance, and flow rate settings, resulted in scaffolds with different morphologies based on the solution concentration, so solution concentration does play a role in the fibrous structure, it just could not be tested quantitatively in this study. Past studies have observed this element of electrospinning and have attempted to create models mathematically supporting the data [53]. Literature suggests solution concentration is a very strong predictor of fiber diameter [48] Demir et al. [150] determined a power law relationship between solution concentration stating the mean fiber diameter of a scaffold was proportional to the solution concentration, meaning a decrease in one meant a decrease in the other. Unfortunately, the parameters used while spinning concentrations of $10 \%$ did not support a fibrous scaffold, and no quantitative data was extracted from those spins.

Flow rate-found to be the strongest predictor by the DOE model—was determined to be directly proportional to fiber diameter. The lower the flow rate, the smaller the fibers of the scaffold. Deitzal et al. [151] determined that when the flow rate is slower, the radius of the solution jet flowing from the needle decays rapidly. In addition, the slower moving jet has more time to branch off into smaller radius fibers [154].

The DOE model suggests voltage is directly proportional to fiber diameter, while gap distance is inversely proportional. Literature confirms these relationships[48,78], however because only three settings of each parameter were tested, and the range by which they can be altered is large, it is difficult to assess the accuracy of the relationship. 
Also, many scaffold images depicted fibers with a large variation in size-there were very small fibers, and very large fibers. Literature has reported instances of bimodal fibers however the cause is unclear, as is the effect the variation in fibers will have on cell proliferation [150].

\section{Limitations}

The DOE planned for 33 runs, which were all successfully completed, however because all runs completed with a $10 \%$ solution concentration were not fibrous, the regression model included only 17 runs. Studies should have at least a sample size of 30. In addition, because solution concentration was excluded from the model, possibly significant interactions between the variables were unable to be confirmed.

A two factorial design, with a center point, was the basis of the DOE. This worked well for the means of the study because it required less runs to be completed, however this in itself is a limitation. The study was not balanced, in that there was only one center point run. A balanced study would allow for the same amount of observations for each combination of parameters. Doing so would better determine interactions between variables and rule out variation.

Another limitation is that each spin was only run once. While averages were gathered for each combination, the average comes from the same experimental run. This is similar to weighing an object multiple times and creating an average. While that takes account for variation within an individual, it does not account for variation across individuals with the same treatment. Multiple runs of a single combination would provide for a real mean fiber diameter and have a greater ability to differentiate between cause variation and chance variation. 
While it is clear that more runs are better, cost and time are large limiting factors. Though creating a single scaffold is fairly economical, up scaling the performed DOE would be costly in materials. In addition, on average it takes about an hour in lab time to both mix and spin each scaffold. The imaging can take another two hours in preparation, imaging, and fiber measurements. It would take significant man power to complete a larger study than the completed DOE.

Finally, no scaffolds of the desired mean fiber diameter were created in the DOE, and have not been successfully created in our lab. The DOE model could be used to find the right parameter settings to create the desired fiber diameter, however that would be erroneous. The regression model fits the data that was used to create it. Extending the equation farther than the limits of the study could lead to faulty results. For example, consider data fitting a linear relationship between a specific range. While extrapolation of the line would consider all data to be linear, in truth, the line may drop off to a cubed relationship, and may even begin to decrease. The linear relationship may be only true within a certain range, and thus caution must be taken when using the regression model found by the data gathered from the DOE.

\section{Future Work}

Because solution concentration is important to the resulting mean fiber diameter, and unfortunately was not included in the final analysis, a small study should be performed to find the voltage needed to have a fibrous scaffold form with lower solution

concentration. Unfortunately, in this study, once the parameter settings were in place, nothing was changed once the electrospinning started to ensure the results came from constant parameter settings. In checking the voltage required for the lower solution concentrations, I recommend adjusting the voltage-while listening for a static sound indicating arcing may soon occur-until a steady Taylor cone is evident with a 
continuous fiber leaving the tip of the cone. Once an approximate voltage for a certain solution concentration is determined, a designed experiment focusing on solution concentration should be performed. This will save cost by eliminating waste spins that will not yield data, and possibly allow repeat spins of other parameter combinations.

Other future experimentation recommended is to use the DOE to run spins that should result is smaller fiber diameters. The mean fiber diameter should be measured for each scaffold and then accuracy of model could be tested, by plotting the resulting fiber diameter against the plot of the model. Below, the largest gap distance mentioned is 16 inches; however the current set up has a gap distance of 17.5 inches. Specifically, the recommended next runs would include:

- Keeping the voltage and solution concentration at the standard settings of the protocol, and lowering the flow rate to $4.5 \mathrm{ml} / \mathrm{hr}$ and increasing the gap distance to 16 inches. The resulting mean fiber diameter should be 2.89 microns.

- Keeping the voltage and solution concentration at the standard settings of the protocol, and lowering the flow rate to $4.0 \mathrm{ml} / \mathrm{hr}$ and increasing the gap distance to 16 inches. The resulting mean fiber diameter of 2.69 microns.

Previously, the appearance of a bimodal distribution was mentioned. With the images taken for the DOE, many have a bimodal distribution of fibers. Using the images, instead of determining a single mean fiber diameter, the fibers could be separated into two or three groups and two or three averages can be determined. For example instead of taking a single measurement at a point on an SEM image, the measurements could be doubled. For every measurement of a "large fiber", a smaller fiber could be measured as well. Multiple analyses could be performed with the data. The same study done with the DOE could be performed, but rather have two mean fiber diameters acting as the predicted variables, as opposed to just one as done so in this 
thesis. The standard deviation should decrease. Also, variables could be assessed to determine what causes the bimodal distribution, since it did not always occur. The predicted variable could be a binomial distribution indicating the presence or lack thereof a bimodal distribution of fibers measured against the four parameters.

In addition with the bimodal scaffolds, a physical study could be performed. Previously, the goal was to create a scaffold with a predictable continuous fiber diameter. The bimodal fibrous scaffold was not investigated. By repeating a few of the spins that resulted in the bimodal distribution of fibers, the scaffolds can be seeded with cells and studied to see if the bimodal fiber distribution changes the cell interaction at all. Smaller fibers are supposed to mimic the endothelial ECM better [102], but how the presence of two distinct fiber sizes affects the cells has not been systematically investigated, only observed [161]. Chen et al. [161] successfully seeded cells onto bimodal distributions of fibers, but did not compare it against a normal distribution of fibers.

After the completion of the DOE, the electrospinning set up was remodeled with a power supply that allows for a negative polarity. Studies have used negative polarity set ups and produced scaffolds with ideal nanofibrous morphology [151].

In addition, the current electrospinner setup is exposed to the ambient air. As discussed previously the temperature and humidity can have an effect on resulting scaffold. A possible investigation could look at the effect of spinning in nitrogen or another gas as opposed to air. While this is no literature on this, some set ups, including dual spinners and process now termed bubble electrospinining use pressurized nitrogen gas to insert bubbles into the droplet at the tip of the needle. The effect of having the jet whip and solidify in nitrogen or another gas may affect the morphology of the fibers [176]. 
Outside of the solution concentration, no other material variables-such as the viscosity or molecular weight were investigated. While few studies specifically discuss the PDI of a polymer to be electrospun, studies have investigated the morphologies of fibers as affected by the viscosity, surface tension, and the polymer ratio. Fiber diameters have been found to decrease in a study working with PVO, as the molecular weight decreased [177]. In addition an increase in viscosity has led to better fiber morphologies at higher applied voltages [32]. The material parameters have a large effect on how the jet thins out in the air. However, further investigation of the electrospinning parameters may prove useful as well. There is little discussion on the effect of the rotation and translation of the electrospinner mandrel on the fiber size and morphology of the fibers. Both the translation and rotation speed can affect the alignment of the fibers on the mandrel. Faster speeds can cause more random placement, however since cells tend to prefer a more organized lumen, slower speeds may be beneficial to investigate $[25,32]$.

Finally, if a certain combination is determined to be useful, a consistency study is recommended to ensure the same scaffold results each time. In addition, mechanical testing should be performed to ensure the strength does not change from scaffold to scaffold with smaller fibers and that the scaffold is strong enough to last in a dynamic bioreactor. Past students have also encouraged the use of a radial tensile tester, to better measure the strength of a tubular scaffold, and compare it to that of a native vessel. There is a significant difference in tensile strength when testing the scaffold as is done currently_by cutting the scaffold into small pieces-and performing strength testing in its tubular form [60].

Overall, the data did create a model to possibly predict fiber diameter. While it is not perfect, it can be used as a guide when working with PLGA to determine what parameter 
combinations can result in a certain mean fiber diameter range. The results give insight into how future experiments with endpoint analysis should be designed for the electrospinning process and what future experiments would be valid next steps with investigations in tissue engineering applications. 


\section{Works Cited}

[1] A. H. Association, "Atherosclerosis," 15 November 2011. [Online]. Available: http://www.heart.org/HEARTORG/Conditions/Cholesterol/WhyCholesterolMatters/ Atherosclerosis_UCM_305564_Article.jsp\#.T2Ji8RFul-4. [Accessed 2011].

[2] A. H. Association, "Heart Disease and Stroke Statistics--2012 Update: A Report From the American Heart Association," Circulation, Journal of the American Heart Association, no. 13, 2011.

[3] B. M. K. a. B. A. Stanton, "Berne and Levy Physiology," Mosby Elsevier, 2010, p. 282.

[4] M. Unverdorben, "Paclitaxel-Coated Balloon Catheter Versus Paclitaxel-Coated Stent for the Treatment of Coronary In-Stent Restenosis," Circulation, Journal of the American Heart Association, no. 119, pp. 2986-2999, 2009.

[5] D. L. Fischmann, "A Randomized Comparison of Coronary-Stent Placement and Balloon Angioplasty in the Treatment of Coronary Artery Disease," The New England Journal of Medicine, no. 331, pp. 496-501, 1994.

[6] B. Mann, "Tissue engineering in the cardiovascular system: Profress toward a tissue engineering heart," The Anatomical Record, vol. 4, no. 263, pp. 367-371, 2001.

[7] A. C. Thomas, "Advances in Vascular Tissue Engineering," Cardiovascular Pathology, vol. 12, no. 5, pp. 271-276, October 2003. 
[8] B. Conklin, "Development and evaluation of a novel decellularized vascular xenograft," Medical Engineering Physiology, vol. 3, no. 24, pp. 173-183, 2002.

[9] F. Couet, "Macromolecular Biomaterials for Scaffold-Based Vascular Tissue Engineering," Macromolecular Bioscience, vol. 7, pp. 701-718, 2007.

[10] V. Thomas, "Functionally graded electrospun scaffolds with tunable mechanical properties for vascular tissue regeneration," Biomedical Materials, no. 2, pp. 224232, 2007.

[11] H. Sonoda, "Coaxial double-tubular compliant arterial graft prosthesis: Timedependent morphogenesis and compliance changes after implantation," Journal of Biomedical Materials Research, vol. 65A, no. 2, pp. 170-181, 2003.

[12] A. G. Mikos, "Engineering Complex Tissues," Tissue Engineering, vol. 12, no. 12, pp. 3307-3339, 2006.

[13] S. Goldman, "Long-term patency of saphenous vein and left internal mammary artery grafts after coronary artery bypass surgery: Results from a Department of Veterans Affairs Cooperative Study," Journal of the American College of Cardiology, vol. 44, no. 11, pp. 2149-2156, 2004.

[14] O. E. Teebken, "Tissue Engineering of Small Diameter Vascular Grafts," European Journal of Vascular and Endovascular Surgery, vol. 23, no. 6, pp. 475-485, 2002.

[15] S. A. Guelcher, An Introduction to Biomaterials, Boca Raton, FL: Taylor \& Francis Group, 2006. 
[16] Boston Scientific, "Angioplastyy and Stent Implantation," [Online]. Available: http://www.bostonscientific.com/lifebeat-online/cardiac-procedures/angioplastyand-stents.html. [Accessed 223 2012].

[17] Food and Drug Association, "Product Classification - Stent, Coronary," 05032012. [Online]. Available:

http://www.accessdata.fda.gov/scripts/cdrh/cfdocs/cfPCD/classification.cfm?ID=91 7. [Accessed 1502 2012].

[18] D. E. Delagrammaticas, Development of an in-vitro Tissue Engineered Blood Vessel Mimic using Human Large Vessel Cell Sources, San Luis Obispo, CA: California Polytechnic State University, 2009.

[19] L. Freed, Tissue engineering bioreactors, J. Vacanti, Ed., San Diego, CA: Academic, 2000, pp. 143-156.

[20] J. Campbell, "Novel vascular graft grown within recipient's own peritoneal cavity," Circulatory Research, vol. 12, no. 85, pp. 1173-1178, 1999.

[21] R. Carrier, "Cardiac tissue engineering: cell seeding, cultivation parameters, and tissue construct characterization," Biotechnology and Bioengineering, vol. 5, no. 64, pp. 580-589, 1999.

[22] D. A. Vorp, "Molecular Aspects of Vascular Tissue Engineering," Frontiers in Bioscience, vol. 10, pp. 768-789, 2005.

[23] J. M. Chupa, "Vascular cell responses to polysaccharide materials: in vitro and in vivo evaluations," Biomaterials, vol. 21, no. 22, pp. 2315-2322, 2000. 
[24] J. Nikolovski, "Smooth muscle cell adhesion to tissue engineering scaffolds," Biomaterials, vol. 21, no. 20, pp. 2025-2032, 2000.

[25] C. H. Lee, "Nanofiber alignment and direction of mechanical strain affect the ECM production of human ACL fibroblast," Biomaterials, vol. 26, no. 11, pp. 1261-1270, 2005.

[26] S. R. Bhattarai, "Novel biodegradable electrospun membrane: scaffold for tissue engineering," Biomaterials, vol. 25, no. 13, pp. 2595-2602, 2004.

[27] A. N. Smith, Characterization and Implementation of a Decellularized Porcine Vessel as a Biologic Scaffold for a Blood Vessel Mimic, CA: California Polytechnic State University, 2011, p. 57.

[28] T. R. Pena, "Preparation and Characterization of electrospun poly(d,I-lactide-coglycolide) scaffolds for vascular tissue engineering and the advancement of an in vitro blood vessel mimic," San Luis Obispo, 2009.

[29] S. A. Sell, "Electrospun polydioxanone-elastin blends: potential for bioresorbable vascular grafts," Biomedical Materials, vol. 1, pp. 72-80, 2006.

[30] J. Stitzel, "Controlled fabrication of a biological vascular substitute," Biomaterials, vol. 27, pp. 1088-1094, 2006.

[31] J. Anderson, "Perspectives on the in vivo responses of biodegradable polymers," Biomedical Applications of Synthetic Biodegradable Polymers, pp. 223-233, 1995.

[32] J. M. Anderson, "Inflammation and the foreign body response," Prob. Gen. Surgery, vol. 11, pp. 147-160, 1994. 
[33] J. M. Anderson, "Biodegradation and biocompatibility of PLA and PLGA microspheres," Advanced Druge Delivery Reviews, vol. 28, pp. 5-24, 1997.

[34] L. Beck, "Systematic and local delivery of contraceptive steriods using biodegradable microsphers," Biodegradables and Delivery Systems for Contraception, vol. 1, pp. 63-82, 1980.

[35] K. A. Athanasiou, "Sterilization, toxicity, biocompatibility and clinical applications of polylactic acid/polyglycolic acid copolymers," Biomaterials, vol. 19, pp. 93-102, 1996.

[36] F. Rozema, "The effects of different steam-sterilization programs on material properties of poly(L-lactide)," Applications of Biomaterials, vol. 2, pp. 23-28, 1991.

[37] G. D. Reed, "Biodegradable polymers for use in surgery--polyglycolic/poly(lactic acid) homo- and copolymers," Polymer, vol. 20, pp. 1459-1464, 1979.

[38] V. S. Kilpikari, "Strength and strength retention in vitro, of absorbable, selfreinforced polyglycolide (PGA) rods for fracture fixation," Biomaterials, vol. 8, pp. 46-48, 1987.

[39] O. Laitinen, "Mechanical properties of biodegradable ligament augmentation device of poly(L-lactide) in vitro and in vivo," Biomaterials, vol. 13, pp. 1012-1016, 1992.

[40] C. Chu, "The effect of gamma irradiation on the enzymatic degradation of polyglycolic acid absorbable sutures," Journal of Biomedical Materials Research, vol. 17, pp. 1029-1040, 1983. 
[41] P. Vink, "Aeration of ethylene oxide-sterilized polymers," Journal of Biomaterials, vol. 7, pp. 225-230, 1986.

[42] I. Matthews, "Enhancements of the kinetics of the aeration of ethylene oxide sterilized polymers using microwave radiation," Journal of Biomedical Materials Research, vol. 23, pp. 143-156, 1985.

[43] A. v. Sliedregt, "The effect of the molecular weight of polylactic acid on in vitro biocompatibility," Advances in Biomaterials, vol. 9, pp. 207-212, 1990.

[44] A. v. Sliedregt, "In vitro biocompatibility testing of polylactides. Part I: Proliferation of different cell types," Material Science, vol. 3, pp. 365-370, 1992.

[45] A. Mikos, "Laminated three-dimensional biodegradable foams for use in tissue engineering," Biomaterials, vol. 14, pp. 323-330, 1993.

[46] M. Taylor, "Six bioabsorbable polymers: in vitro acute toxicity of accumulated degradation products," Journal of Applied Biomaterials, vol. 5, pp. 151-157, 1994.

[47] H. K. Makadia, "Poly Lactic-co-Glycolic Acid (PLGA) as Biodegradable Controlled Drug Delivery Carrier," Polymers, vol. 3, pp. 1377-1397, 2011.

[48] K. Garg, "Electrospinning jets and nanofibrous structures," Biomicrofluidics, vol. 5, no. $013403,2011$.

[49] D. Li, "Electrospinning of Nanofibers: Reinventing the Wheel?," Advanced Materials, vol. 16, no. 14, pp. 1151-1170, July 2004.

[50] F. Anton.United States Patent 2158415, 16 May 1939. 
[51] F. Anton.United States Patent 2349950, 30 May 1944.

[52] F. Anton.United States Patent 1975504, 2 October 1934.

[53] G. Taylor, "Electrically Driven Jets," Proceeedings of the Royal Society, vol. 313, no. 1515 , pp. 453-475, 1969.

[54] J. Doshi, "Electrospinning Process and Applications of Electrospun Fibers," Journal of Electrostatics, vol. 35, pp. 151-160, 1995.

[55] A. G. Bailey, Electrostatic spraying of liquids, Taunton, Somerset, England, and New York: Research Studies Press, 1988.

[56] H. Simons, "Process and Apparatus for Producing Patterned Non-Woven Fabrics". United States Patent 3280229, 1966.

[57] A. Bornat, "Electrostatic Spinning of Tubular Products". United States Patent 4323525, 1982.

[58] T. How, "Synthetic Vascular Grafts and Methods of Manufacturing Such Grafts". United States Patent 4552707, 1985.

[59] A. Bornat, "Production of Electrostatically Spun Products". United States Patent 4689186, 1987.

[60] J. P. Berry, "Method and Apparatus for Manufacturing Electrostatically Spun Structure". United States Patent 5024789, 1991.

[61] S. Ramakrishna, An Introduction to Electrospinning and Nanofibers, Singapore: World Scientific, 2005. 
[62] C. Henriques, "A Systematic Study of Solution and Processing Parameters on Nanofiber Morphology Using a New Electrospinning Apparatus," Journal of Nanoscience and Nanotechnology, vol. 9, pp. 3535-3545, 2009.

[63] M. Kerker, "The Scattering of Light, and Other Electromagnetic Radiation," Academic Press, 1969.

[64] L. Larrondo, "Electrostatic fiber spinning from polymer melts. I: Experimental observations on fiber formation and properties," Journal of Polymer Science: Polymer Physics Edition, vol. 19, no. 6, pp. 909-920, 1981.

[65] L. Larrondo, "Electrostatic fiber spinning from polymer melts. II: Examination of the flow field in an electrically driven jet.," Journal of Polymer Science: Polymer Physics Edition, vol. 19, no. 6, pp. 921-932, 1981.

[66] L. Larrondo, "Electrostatic fiber spinning from polymer melts. III: Electrostatic deformation of a pendant drop of polymer melt," Journal of Polymer Science: Polymer Physics Edition, vol. 19, no. 6, pp. 933-940, 1981.

[67] A. L. Yarin, "Taylor cone and jetting from liquid droplets in electrospinning of nanofibers," Journal of Applied Physics, vol. 90, no. 4836, p. 11, 2001.

[68] D. H. Reneker, "Bending instability of electrically charged liquid jets of polymer solutions in electrospinning," Journal of Applied Physics, vol. 87, no. 4531, p. 17, 2000.

[69] Z.-M. Huang, "A review on polymer nanofibers by electrospinning and their applications in nanocomposites," Composites Science and Technology, vol. 63, no. 15, pp. 2223-2253, 2003. 
[70] C. Burger, "Nanofibrous materials and their applications," Annual Review of Materials Research, vol. 36, pp. 333-368, 2006.

[71] D. H. Reneker, "Electrospinning jets and polymer nanofibers," Polymer, vol. 49, no. 10, pp. 2387-2425, 2008.

[72] A. L. Yarin, "Bending instability in electrospinning nanofibers," Journal of Applied Physics, vol. 89, no. 3018, p. 9, 2001.

[73] J. Zeleny, "Instability of electrified liquid surfaces," Physical Review, vol. 10, no. 1, pp. 1-6, 1917.

[74] S. Koombhongse, "Flat polymer ribbons and other shapes by electrospinning," Polymer Physics, vol. 39, no. 21, pp. 2598-2606, 2001.

[75] L. Rayleigh, "Further observations upon liquid jets, in continuation of those recorded in the Royal Society's 'Proceedings' for March and May, 1879," Proceedings of the Royal Society of London, vol. 34, pp. 130-145, 1882-1883.

[76] S. Liao, "Biomimetic electrospun nanofibers for tissue regeneration," Biomedical Materials, vol. 1, pp. R45-R53, 2006.

[77] S. A. Catledge, "An electrospun triphasic nanofibrous scaffold for bone tissue engineering," Biomedical Materials, vol. 2, pp. 142-150, 2007.

[78] Q.P. Pham, "Electrospinning of Polymeric Nanofibers for Tissue Engineering Applications: A Review," Tissue Engineering, vol. 12, pp. 1197-1211, 2006. 
[79] J. Venugopal, "Fabrication of modified and functionalized polycaprolactone nanofibre scaffolds for vascular tissue engineering," Nanotechnology, vol. 16, pp. 2138-2142, 2005.

[80] Y. You, "In vitro degradation behaviour of electrospun polyglycolid, polylactide, and poly (lactide-co-glycolide)," Journal of Applied Polymer Science, vol. 95, no. 2, pp. 193-200, 2005.

[81] F. Yang, "Electrospinning of nano/micro scale poly(L-lactic acid) aligned fibers and their potential in neural tissue engineering," Biomaterials, vol. 26, no. 15, pp. 26032610, 2005.

[82] C. C. Chue, "The study of thermal and gross morphologic properties of polyglycolic acid upon annealing and degradation treatments," Journal of Biomedical Materials Research, vol. 22, no. 8, pp. 699-712, 1988.

[83] E. D. Boland, "Tailoring tissue engineering scaffolds using electrostatic processing techniques: A study of poly (glycolic acid) electrospinning," Journal of Macromolecular Science, Part A: Pure and Applied Chemistry, vol. 38, no. 12, pp. 1231-1243, 2001.

[84] W.-J. Li, "Electrospun nanofibrous structure: A novel scaffold for tissue engineering," Journal of Biomedical Materials Research, vol. 60, no. 4, pp. 613621, 2002.

[85] X. Zong, "Electrospun fine-textured scaffolds for heart tissue constructs," Biomaterials, vol. 26, no. 26, pp. 5330-5338, 2005. 
[86] J. D. Stitzel, "Arterial Smooth Muscle Cell Proliferation on a Novel Biomimicking, Biodegradable Vascular Graft Scaffold," Journal of Biomaterial Applications, vol. 16, no. 1, pp. 22-33, 2001.

[87] K. Kim, "Control of degradation rate and hydrophilicity in electrospun non-woven poly (D,L-lactide) nanofiber scaffolds for biomedical applications," Biomaterials, vol. 24, no. 27, pp. 4977-4985, 2003.

[88] X. Zong, "Structure and Morphology Changes during in Vitro Degradation of Electrospun Poly (glycolide-co-lactide) Nanofiber Membrane," Biomacromolecules, vol. 4, no. 2, pp. 416-423, 2003.

[89] H.-W. Kim, "Nanofibrous matrices of poly(lactic acid) and gelatin polymeric blends for the improvement of cellular responses," Journal of Biomedical Materials Research, vol. 87A, no. 1, pp. 25-32, 2008.

[90] D. H. Reneker, "Nanofiber garlands of polycaprolactone by electrospinning," Polymer, vol. 43, no. 25, pp. 6785-6794, 2002.

[91] H. Yoshimoto, "A biodegradable nanofiber scaffold by electrospinning and its potential for bone tissue engineering," Biomaterials, vol. 24, no. 12, pp. 2077-2082, 2003.

[92] M. J. McClure, "A three-layered electrospun matrix to mimic native arterial architecture using polycaprolactone, elastin, and collagen: A preliminary study," Acta Biomaterialia, vol. 6, no. 7, pp. 2422-2433, 2010. 
[93] J. Zeng, "Enzymatic degradation of poly(L-lactide) and poly (e-caprolactone) electrospun fibers," Macromolecular, vol. 4, no. 12, pp. 1118-1125, 2004.

[94] C. Fecek, "Chondrogenic Derivatives of Embryonic Stem Cells Seeded into 3D Polycaprolactone Scaffolds Generated Cartilage Tissue in vivo," Tissue Engineering, Part A, vol. 14, no. 8, pp. 1403-1413, 2008.

[95] K. Fujihara, "Guided bone regeneration membrane made of polycaprolactone/calcium carbonate composite nano-fibers," Biomaterials, vol. 26, no. 19, pp. 4139-4147, 2005.

[96] M. J. McClure, "Electrospinning-aligned and random polydioxanonepolycaprolactone-silk-fibroin-blended scaffolds: geometry for a vascular matrix," Biomedical Materials, vol. 4, no. 5, 2009.

[97] B. W. Tillman, "The in vivo stability of electrospun polycaprolactone-collagen scaffolds in vascular reconstruction," Biomaterials, vol. 30, no. 4, pp. 583-588, 2009.

[98] J. Venugopal, "In vitro culture of human dermal fibroblasts on electrospun polycaprolactone collagen nanofibrous membrane," Artificial Organs, vol. 30, no. 6, pp. 440-446, 2006.

[99] M. R. Williamson, "Gravity spun polycaprolactone fibres for soft tissue engineering: Interaction with fibroblasts and myoblasts in cell culture," Biomaterials, vol. 27, no. 7, pp. 1019-1026, 2006. 
[100] P. Wutticharoenmongkol, "Novel bone scaffolds of electrospun polycaprolactone fibers filled with nanoparticles," Journal of Nanoscience and Nanotechnology, vol. 6, no. 2, pp. 514-522, 2006.

[101] C. P. Barnes, "Cross-linking electrospun type II collagen tissue engineering scaffolds with carbodiimide in ethanol," Tissue Engineering, vol. 13, no. 7, pp. 1593-1605, 2007.

[102] E. D. Boland, "Electrospinning collagen and elastin: Preliminary vascular tissue engineering," Frontiers in Bioscience, vol. 9, pp. 1422-1432, 2004.

[103] J. A. Matthews, "Electrospinning of collagen nanofibers," Biomacromolecules, vol. 3, no. 2, pp. 232-238, 2002.

[104] J. S. Choi, "The influence of electrospun aligned poly(e-caprolactone)/collagen nanofiber meshes on the formation of self-aligned skeletal muscle myotubes," Biomaterials, vol. 29, no. 19, pp. 2899-2906, 2008.

[105] B. Dong, "Electrospinning of collagen nanofiber scaffolds from benign solvents," Macromolecular Rapid Communications, vol. 30, no. 7, pp. 539-542, 2009.

[106] L. Huang, "Engineering collagen-PEO nanofibers and fabrics," Journal of Biomaterials Science, Polymer Edition, vol. 12, no. 9, pp. 979-993, 2001.

[107] I. K. Kwon, "Co-electrospun nanofiber of poly(L-lactide-co-e-caprolactone) with Type I collagen or heparin," Biomacromolecules, vol. 6, no. 4, pp. 2096-2105, 2005. 
[108] S. Zhong, "Formation of collagen-glycosaminoglycan blended nanofibrous scaffolds and their biological properties," Biomacromolecules, vol. 6, no. 6, pp. 2998-3004, 2005.

[109] C. E. Ayres, "Incremental changes in anisotropy induce incremental changes in the material properties of electrospun scaffolds," Acta Biomaterialia, vol. 3, no. 5, pp. 651-661, 2007.

[110] K. Garg, "Angiogenic potential of human macrophages on electrospun bioresorbable vascular grafts," Biomedical Materials, vol. 4, no. 3, 2009.

[111] C. E. Ayres, "Measuring fiber alignment in electrospun scaffolds: a user's guide to the 2D fast Fourier transform approach," Journal of Biomaterials Science, Polymer Edition, vol. 19, no. 5, pp. 603-621, 2008.

[112] E. J. Chong, "Evaluation of electrospun PCL/gelatin nanofibrous scaffold for wound healing and layered dermal reconstitution," Acta Biomaterialia, vol. 3, no. 3, pp. 321-330, 2007.

[113] L. Ghasemi-Mobarakeh, "Electrospun poly(e-caprolactone)/gelatin nanofibrous scaffolds for nerve tissue engineering," Biomaterials, vol. 29, no. 34, pp. 45324539, 2008.

[114] H. Kim, "Nanofiber generation of gelatin-hydroxyapatite biomimetics for guided tissue regeneration," Advanced Functional Materials, vol. 15, no. 12, pp. 19881994, 2005. 
[115] J. Li, "Gelatin and gelatin-hyaluronic acid nanofibrous membranes produced by electrospinning of their aqueous solutions," Biomacromolecules, vol. 7, no. 7, pp. 2243-2247, 2006.

[116] M. Li, "Electrospinning polyaniline-contained gelatin nanofibers for tissue engineering applications," Biomaterials, vol. 27, no. 13, pp. 2705-2715, 2006.

[117] M. Li, "Co-electrospun poly(lactide-co-glycolide), gelatin, and elastin blends for tissue engineering scaffolds," Journal of Biomedical Materials Research, vol. 79A, no. 4, pp. 963-973, 2006.

[118] H. M. Powell, "Fiber density of electrospun gelatin scaffolds regulates morphology of dermal-epidermal skin substitutes," Journal of Biomedical Research, vol. 84A, no. 4, pp. 1078-1086, 2008.

[119] K. Sisson, "Evaluation of cross-linking methods for electrospun gelatin on cell growth and viability," Biomacromolecules, vol. 10, no. 7, pp. 1675-1680, 2009.

[120] J.-H. Song, "Production of electrospun gelatin nanofiber by water-based co-solvent approach," Materials in Medicine, vol. 19, no. 1, 2008.

[121] P. Songchotikunpan, "Extraction and electrospinning of gelatin from fish skin," International Journal of Biological Macromolecules, vol. 42, no. 3, pp. 247-255, 2008.

[122] H. Tan, "Gelatin/chitosan/hyaluronan scaffold integrated with PLGA microspheres for cartilage tissue engineering," Acta Biomaterialia, vol. 5, no. 1, pp. 328-337, 2009. 
[123] S. Zhang, "Gelatin nanofibrous membrane fabricated by electrospinning of a gelatin solution for guided tissue regeneration," Journal of Materials Research Part A, vol. 90A, no. 3, pp. 671-679, 2009.

[124] Y. Zhang, "Preparation of core-shell structured PCL-r-gelatin Bi-component nanofibers by coaxial electrospinning," Chemistry of Materials, vol. 16, no. 18, pp. 3406-3409, 2004.

[125] Y. Zhang, "Electrospinning of gelatin fibers and gelatin/PCL composite fibrous scaffolds," Journal of Biomedical Materials Research, Part B, vol. 72B, no. 1, pp. 156-165, 2005.

[126] L. Buttafoco, "Electrospinning of collagen and elastin for tissue engineering applications," Biomaterials, vol. 27, no. 5, pp. 724-734, 2006.

[127] S. Sell, "Preliminary investigation of airgap electrospun silk-fibroin-based structures for ligament analogue engineering," Journal of Biomaterials Science, Polymer Edition, vol. 22, no. 10, pp. 1253-1273, 2011.

[128] A. Alessandrino, "Electrospun silk fibroin mats for tissue engineering," Engineering in Life Sciences, vol. 8, no. 3, pp. 219-225, 2008.

[129] H.-J. Jin, "Human bone marrow stromal cell responses on electrospun silk fibroin mats," Biomaterials, vol. 25, no. 6, pp. 1039-1047, 2004.

[130] S. S. Silva, "Genipin-modified silk-fibroin nanometric nets," Macromolecular, vol. 8, no. 8, pp. 766-774, 2008. 
[131] Y. Kawahara, "Structure for electro-spun silk fibroin nanofibers," Journal of Applied Polymer Science, vol. 107, no. 6, pp. 3681-3684, 2008.

[132] C. Li, "Electrospun silk-BMP-2 scaffolds for bone tissue engineering," Biomaterials, vol. 27, no. 6, pp. 3115-3124, 2006.

[133] B.-M. Min, "Regenerated silk fibroin nanofibers: Water vapor-induced structural changes and their effects on the behavior of normal human cells," Macromolecular Bioscience, vol. 6, no. 4, pp. 285-292, 2006.

[134] B.-M. Min, "Electrospinning of silk fibroin nanofibers and its effect on the adhesion and spreading of normal human keratinocytes and fibroblasts in vitro," Biomaterials, vol. 25, no. 7-8, pp. 1289-1297, 2004.

[135] S. Sukigara, "Regeneration of Bombyx mori silk by electrospinning--part 1: processing parameters and geometric properties," Polymer, vol. 44, no. 19, pp. 5721-5727, 2003.

[136] S. Sukigara, "Regeneration of Bombyx mori silk by electrospinning. part 2. Process optimization and empirical modeling using response surface methodology," Polymer, vol. 45, no. 11, pp. 3701-3708, 2004.

[137] M. Wang, "Mechanical properties of electrospun silk fibers," Macromolecules, vol. 37, no. 18, pp. 6856-6864, 2004.

[138] S. Wang, "Fabrication and properties of the electrospun polylactide/silk fibroin gelatin composite tubular scaffold," Biomacromolecules, vol. 10, no. 8, pp. 22402244, 2009. 
[139] J. Zhou, "A novel three-dimensional tubular scaffold prepared from silk fibroin by electrospinning," International Journal of Biological Macromolecules, vol. 45, no. 5, pp. 504-510, 2009.

[140] M. C. McManus, "Mechanical properties of electrospun fibrinogen structures," Acta Biomaterialia, vol. 2, no. 1, pp. 19-28, 2006.

[141] M. C. McManus, "Electrospun fibrinogen: Feasibility as a tissue engineering scaffold in a rat cell culture model," Journal of Biomedical Materials Research, Part A, vol. 81A, no. 2, pp. 299-309, 2007.

[142] S. Sell, "Scaffold permeability as a means to determine fiber diameter and pore size of electrospun fibrinogen," Journal of Biomedical Materials Research, Part A, vol. $85 \mathrm{~A}$, no. 1, pp. 115-126, 2008.

[143] S. A. Sell, "Cross-linking methods of electrospun fibrinogen scaffolds for tissue engineering applications," Biomedical Materials, vol. 3, no. 4, 2008.

[144] G. E. Wnek, "Electrospinning of nanofiber fibrinogen structures," Nanoletters, vol. 3, no. 2, pp. 213-216, 2003.

[145] S. D. V. e. al., "The effect of temperature and humidity on electrospinning," Journal of Material Science, vol. 44, pp. 1357-1362, 2009.

[146] P. K. Baumgarten, "Electrospinning of acrylic microfibers," Journal of Colloid and Interface Science, vol. 36, no. 1, pp. 71-79, 1971.

[147] M. M. Hohman, "Electrospinning and electrically forced jets. I. Stability theory," Physics of Fluids, vol. 13, no. 8, 2001. 
[148] M. M. Hohman, "Electrospinning and electrically forced jets. II. Applications," Physics of Fluids, vol. 13, no. 8, p. 16, 2001.

[149] J. Feng, "Stretching of a straight electrically charged viscoelastic jet," Journal of Non-Newtonian Fluid Mechanics, vol. 116, no. 1, pp. 55-70, 2003.

[150] M. Demir, "Electrospinning of polyurethane fibers," Polymer, vol. 43, no. 11, pp. 3303-3309, 2002.

[151] J. M. Deitzel, "The effect of processing variables on the morphology of electrospun nanofibers and textiles," Polymer, vol. 42, no. 1, pp. 261-272, 2001.

[152] A. Greiner, "Electrospinning: A fascinating method for the preparation of ultrathin fibers," Angewandte Chemie International Edition, vol. 46, no. 30, pp. 5670-5703, 2007.

[153] J.-Y. Park, "Modeling and Optimization of Electrospun Polyvinylacetate (PVAc) by Nanofibers by Response Surface Methodology (RSM)," Journal of Nanoscience and Nanotechnology, vol. 11, pp. 1359-1363, 2011.

[154] X. Zong, "Structure and process relationship of electrospun bioabsorbable nanofiber membranes," Polymer, vol. 43, no. 16, pp. 4403-4412, 2002.

[155] Q. P. Phan, "Electrospinning of polymeric nanofibers tissue engineering applications: A Review," Tisse Engineering, vol. 12, no. 5, pp. 1197-1211, 2006.

[156] R. Jaeger, "Electrospinning of ultra-thin polymer fibers," Macromolecular Symposia, vol. 127, no. 1, pp. 141-150, 1998. 
[157] P. W. Gibson, "Electrospun fiber mats: Transport properties," AIChE, vol. 45, no. 1, pp. 190-195, 1999.

[158] S. Wong, An Investigation of Process Parameters to Optimize the Fiber Diameter of Electrospun Vascular Scaffolds through Experimental Design, San Luis Obispo, CA: California Polytechnic State University, 2010.

[159] S. Wong, An Investigation of Process Parameters to Optimize the Fiber Diameter of Electrospun Vascular Scaffolds through Experimental Design, San Luis Obispo: California Polytechnic State University, 2010.

[160] G. Larsen, "Use of Coaxial Gas Jackets to Stabilize Taylor Cones of Volatile Solutions and to Induce Particle-to-Fiber Transitions," Advanced Materials, vol. 16, no. 2, 2004.

[161] M. Chen, "Role of Fiber Diameter in Adhesion and Proliferation of NIH 3T3 Fibroblast on Electrospun Polycaprolactone Scaffolds," Tissue Engineering, vol. 13, no. 3, pp. 579-587, 2007.

[162] D. D. Swartz, "Engineering of fibrin-based functional and implantable smalldiameter blood vessels," American Journal of Physiology: Heart and Circulatory Physiology, vol. 288, no. 3, pp. H1451-H1460, 2005.

[163] B.-S. Kim, "Engineered Smooth Muscle Tissues: Regulation Cell Phenotype with the Scaffold," Experimental Cell Research, vol. 251, no. 2, pp. 318-328, 1999.

[164] B. Mann, "Tissue engineering in the cardiovascular system: Progress toward a tissue engineered heart," The Anatomical Record, vol. 4, no. 263, pp. 367-371, 2001. 
[165] L. E. Niklason, "Functional arteries grown in vitro," Science, vol. 284, no. 5413, pp. 489-493, 1999.

[166] V. Barron, "Bioreactors for Cardiovascular Cell and Tissue Growth: A Review," Annals of Biomedical Engineering, vol. 31, pp. 1017-1030, 2003.

[167] D. Seliktar, "The role of matrix metalloproteinase-2 in the remodeling of cellseeded vascular constructs subjected to cyclic strain," Annals of Biomedical Engineering, vol. 11, no. 29, pp. 923-934, 2001.

[168] Z. Sun, "Compound core-shell polymer nanofibers by co-electrospinning," Advance Materials, vol. 15, no. 22, pp. 1929-1932, 2003.

[169] S. Kidoaki, "Mesoscopic spatial designs of nano- and microfiber meshes for tissueengineering matrix and scaffold based on newly devised multilayering and mixing electrospinning techniques," Biomaterials, vol. 26, no. 1, pp. 37-46, 2005.

[170] M. J. Smith, "Suture-reinforced electrospun polydioxanone-elastin small-diameter tubes for use in vascular tissue engineering: A feasibility study," Acta Biomaterialia, vol. 4, no. 1, pp. 58-66, 2008.

[171] T. Telemeco, "Regulation of cellular infiltration into tissue engineering scaffolds composed of submicron diameter fibrils by electrospining," Acta Biomaterialia, vol. 1, no. 4, pp. 377-385, 2005.

[172] C. Vaz, "Design of scaffolds for blood vessel tissue engineering using a multilayering electrospinning technique," Acta Biomerialia, vol. 1, no. 5, pp. 575-582, 2005. 
[173] S. A. Sell, "The use of natural polymers in tissue engineering: A focus electrospun extracellular matrix analogues," Polymers, vol. 2, no. 4, pp. 522-553, 2010.

[174] J. G. Meinhart, "Clinical autologous in vitro endothelialization of 153 infrainguinal ePTFE grafts," The Annals of Thoracic Surgery, vol. 71, no. 5, pp. S327-S331, 2001.

[175] R. S. a. R. V.-O. Gustavo Larsen, "Use of Coaxial Gas Jackets to Stabilize Taylor Cones of Volatile Solutions and to Induce Particle-to-Fiber Transitions," Advanced Materials, vol. 16, no. 2, 2004.

[176] Yong Llu and Ji-Huan He. "Bubble electrospinning for mass production of nanofibers" INTERNATIONAL JOURNAL OF NONLINEAR SCIENCES AND NUMERICAL SIMULATION 8 (2007): 393-396. Available at: http://works.bepress.com/ji huan he/5.

[177] Koski, A. "Effect of molecular weight on fibrous PVA produced by electrospinning" Materials Letters (2004): 493-497. 


\section{Appendix A: List of Abbreviations}

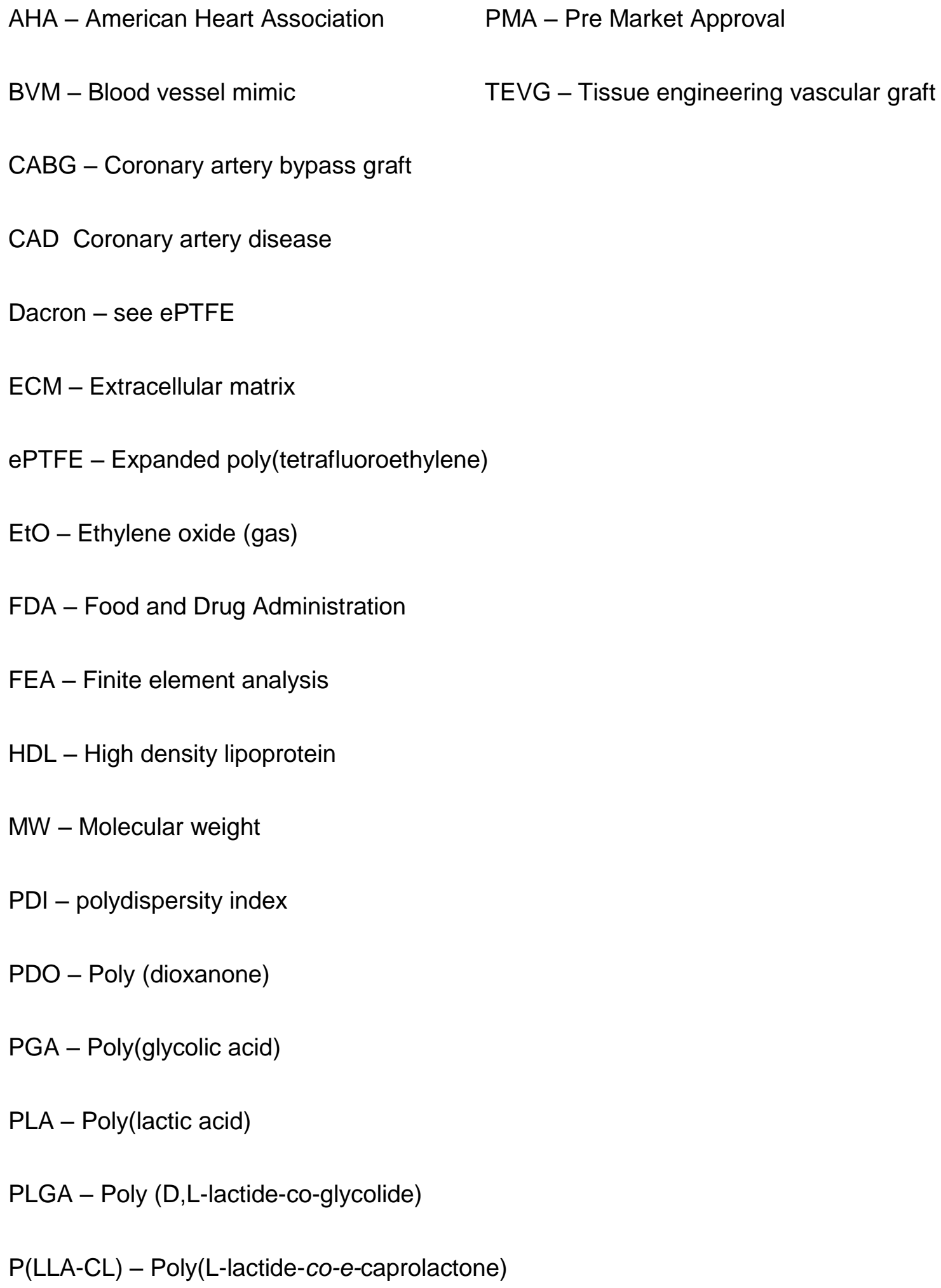




\section{Appendix B: Design of Experiment}

The following was taken directly from Steffi Wong's Senior Project [158].

\section{Fabrication}

The electrospinning procedure that will be followed comes from previous tester, Tiffany

Richelle Pena's thesis in 2009. (Appendix B) The investigator must follow these exact

procedures for every spin that is performed. The only variation between spins should be the values at which the parameters are set.

\section{Design of Experiment (DOE)}

Any designed experiment has a few basic components and underlying concepts.

The

response variable represents the outcome that is measured and although it is possible to identify more than one, the main response variable for this report is the fiber diameter. The factors are variables that are deliberately changed for the expressed purpose of measuring the effect of the change of the response variable. In this experiment the factors will be fixed values because the electrospinning process only produces continuous fibers when parameter settings are at a specific range. The fixed factors are solution concentration, applied voltage, gap distance, and flow rate. A level of a factor is the specific condition of the factor at which we wish to observe the response variable. If more levels are to be examined, more treatments are required to be tested. $A$ treatment is the set of conditions under which the response variable is to be 
observed. This experiment consists of several factors and one treatment is a specific combination of the different factor levels (10, pg 2-8).

For this experiment, a $2 f$ full factorial experiment with one center point is recommended due to its versatility and efficiency where the base, 2, indicates each factor to have two levels and $f=4$ as we have four factors (10,pg 140). A full factorial design includes every treatment combination of factor levels possible and a center point would be an extra run including each factor at the midpoint between its two treatment levels. The purpose of the center point is to detect curvature in the fitted data. If there is curvature that involves the center of the design, the response at the center point will be either higher or lower than the fitted value of the factorial points.

The base values for the parameters come from analysis of the electrospinning device's previous tests. The most current runs being performed have used the polymer Poly (D,LLactide- co-glycolide) (PLGA) due to its ability to be electrospun into fibrous, porous constructs, and its ability to elicit appropriate cellular responses under physiological pulsatile flow. Tiffany Pena performed a solvent concentration analysis and concluded that a solution of 15 wt\% PLGA in chloroform produced the optimal fibers. Currently, this solution concentration for testing has been used based on Tiffany's findings. The values of the testing variables for this design of experiment are based on the most recent electrospinning tests. The recommended set of spins and parameters as stated previously are listed in Table 3 as a 4 factor, 2-level full factorial, with 1 center point and 2 replications. Two replications are required in an experiment in order 
to analyze interactions between factors. Minitab was used to generate the "Run Order" to ensure a randomized experiment rather than following the "Standard Order" which is the order in which the runs would be performed according to the Yates factorial analysis. Minitab created a DOE requiring 33 runs to be performed in order to observe all main and interaction effects (Appendix C). This is necessary because not all the parameter interactions have been analyzed thus far and the significant interactions must be determined in order to be able to run fewer runs with blocked insignificant interactions in future. The parameter values were chosen based on previous data such that the difference between the 'high' and 'low' values would most likely have a statistical significance. The center point run is the middle value between each 'high' and 'low' parameter setting. There is a possibility that not all spins will produce continuous fibers due to new parameter settings that have not previously been tested. If this is the case and the tester makes adjustments, they must be recorded and the real values of the parameters should be altered in the Minitab table. If any of the values must be altered, the experiment can still be analyzed using the same methods given, however Minitab will note that some factors might have more than two levels or that the design has some "botched" runs. The program will automatically analyze the experiment using a regression approach, which is also used to investigate and model the relationship between a response variable and its predictors. 


\begin{tabular}{|c|c|c|c|c|c|c|}
\hline StdOrder & RunOrder & CenterPt & Concentration & Voltage & Gap Distance & Flow Rate \\
\hline 2 & 1 & 1 & 15.0 & 24 & 7.0 & 4.5 \\
\hline 8 & 2 & 1 & 15.0 & 30 & 10.0 & 4.5 \\
\hline 5 & 3 & 1 & 10.0 & 24 & 10.0 & 4.5 \\
\hline 17 & 4 & 1 & 10.0 & 24 & 7.0 & 4.5 \\
\hline 28 & 5 & 1 & 15.0 & 30 & 7.0 & 6.5 \\
\hline 20 & 6 & 1 & 15.0 & 30 & 7.0 & 4.5 \\
\hline 24 & 7 & 1 & 15.0 & 30 & 10.0 & 4.5 \\
\hline 27 & 8 & 1 & 10.0 & 30 & 7.0 & 6.5 \\
\hline 21 & 9 & 1 & 10.0 & 24 & 10.0 & 4.5 \\
\hline 6 & 10 & 1 & 15.0 & 24 & 10.0 & 4.5 \\
\hline 25 & 11 & 1 & 10.0 & 24 & 7.0 & 6.5 \\
\hline 26 & 12 & 1 & 15.0 & 24 & 7.0 & 6.5 \\
\hline 14 & 13 & 1 & 15.0 & 24 & 10.0 & 6.5 \\
\hline 23 & 14 & 1 & 10.0 & 30 & 10.0 & 4.5 \\
\hline 3 & 15 & 1 & 10.0 & 30 & 7.0 & 4.5 \\
\hline 22 & 16 & 1 & 15.0 & 24 & 10.0 & 4.5 \\
\hline 31 & 17 & 1 & 10.0 & 30 & 10.0 & 6.5 \\
\hline 13 & 18 & 1 & 10.0 & 24 & 10.0 & 6.5 \\
\hline 29 & 19 & 1 & 10.0 & 24 & 10.0 & 6.5 \\
\hline 1 & 20 & 1 & 10.0 & 24 & 7.0 & 4.5 \\
\hline 33 & 21 & 0 & 12.5 & 27 & 8.5 & 5.5 \\
\hline 18 & 22 & 1 & 15.0 & 24 & 7.0 & 4.5 \\
\hline 15 & 23 & 1 & 10.0 & 30 & 10.0 & 6.5 \\
\hline 12 & 24 & 1 & 15.0 & 30 & 7.0 & 6.5 \\
\hline 7 & 25 & 1 & 10.0 & 30 & 10.0 & 4.5 \\
\hline 16 & 26 & 1 & 15.0 & 30 & 10.0 & 6.5 \\
\hline 19 & 27 & 1 & 10.0 & 30 & 7.0 & 4.5 \\
\hline 32 & 28 & 1 & 15.0 & 30 & 10.0 & 6.5 \\
\hline 4 & 29 & 1 & 15.0 & 30 & 7.0 & 4.5 \\
\hline 10 & 30 & 1 & 15.0 & 24 & 7.0 & 6.5 \\
\hline 11 & 31 & 1 & 10.0 & 30 & 7.0 & 6.5 \\
\hline 9 & 32 & 1 & 10.0 & 24 & 7.0 & 6.5 \\
\hline 30 & 33 & 1 & 15.0 & 24 & 10.0 & 6.5 \\
\hline
\end{tabular}

\section{Full Factorial Design}

$\begin{array}{lrlr}\text { Factors: } & 4 & \text { Base Design: } & 4,16 \\ \text { Runs: } & 17 & \text { Replicates: } & 1 \\ \text { Blocks: } & 1 & \text { Conter pts (tota1): } & 1\end{array}$

Blocks: 1 Center pts (total):

All terms are free from aliasing.

Design Table (randomized)

$\begin{array}{rrrrr}\text { Run } & \text { A } & \text { B } & \text { C } & \text { D } \\ 1 & + & - & - & + \\ 2 & + & + & - & + \\ 3 & - & + & - & - \\ 4 & + & - & - & - \\ 5 & - & - & - & + \\ 6 & - & + & + & - \\ 7 & + & + & + & + \\ 8 & - & - & + & - \\ 9 & - & + & - & + \\ 10 & 0 & 0 & 0 & 0 \\ 11 & + & - & + & - \\ 12 & - & - & - & - \\ 13 & + & - & + & + \\ 14 & - & - & + & + \\ 15 & + & + & + & - \\ 16 & - & + & + & + \\ 17 & + & + & - & -\end{array}$

Figure 1: Minitab Output for DO

$(+)=$ upper level treatment

$(-)=$ lower level treatment

$(0)=$ midpoint between treatment levels 
Once all the runs in the experimental design are completed and fiber diameter measurements are collected, the mean fiber diameter for each treatment test should be calculated.

\section{Analysis of Factorial Design}

Using Minitab, an analysis of the experiments can be performed (Appendix C). The following steps can be done using the calculated output data:

\section{Observational Method}

The response data can be plotted several ways to see if any trends or anomalies appear that would not be accounted for by the standard linear response model. Look at the distribution of all responses irrespective of the factor levels. A normal probability plot, a box plot, and a histogram of the response variable would be most appropriate (Figure 2). The normal probability plot of the residuals should follow a linear trend because this is an assumption that is made when making statistical conclusions. The histogram should have a bell-shaped curve, like a normal distribution would. In this case, the data is slightly skewed to the right. Next, responses versus Run Order can be examined to ensure there is no time sequence component affecting the response data. Next, plots of the responses sorted by factor columns should be made. It should be noted if plotted response data is very different between factor levels. 


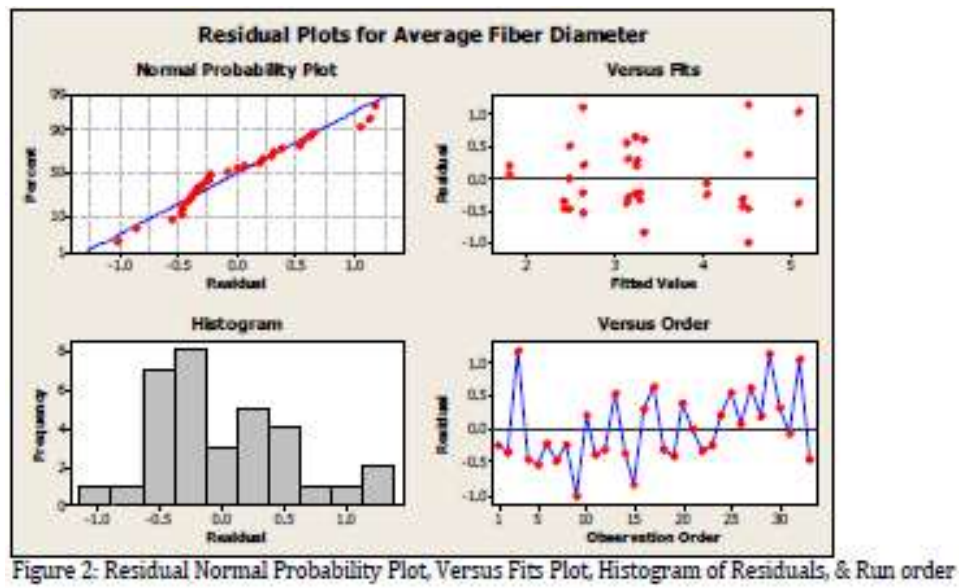

\section{Theoretical Model}

With a 24 full factorial, a model will contain a mean term, all 4 main effect terms, all 62 -factor interaction terms, all 43 -factor interaction terms, and the 4-factor interaction term. However, initially the assumption that all 3-factor and higher interaction terms are non-existent should be made (it is rare for such high-order interactions to be significant and are difficult to interpret). Minitab reports a p-value for each interaction term, which can be used to determine its significance (Figure 3). If the value is less than .05 , the corresponding term would have a significant effect on the fiber diameter. This allows an accumulation of the sum of squares for these terms to be estimated in the error term. The theoretical model to be used will then have 11 unknown constants in which the data is predicted to clarify which are significant main effects and interactions. Also, in the Analysis of Variance, an R2 value will be calculated. This value must be relatively high because its purpose is to indicate the variability of the prediction of future outcomes based on the current information. If $\mathrm{R}_{2}$ is low, it indicates that there may be other independent variables that affect the dependent variable (fiber diameter) besides the factors being investigated (14). 


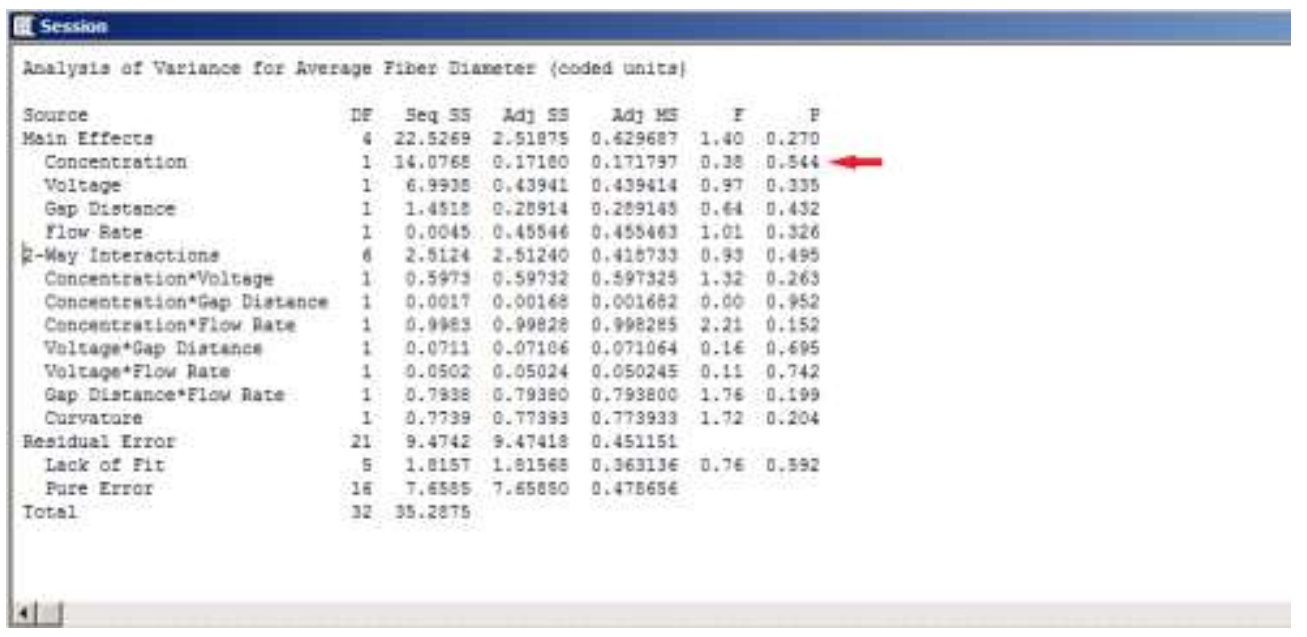

3. A model can be selected in which only the most important factors are included.

Previous step (significance of p-values) is a good indicator of these factors. Minitab's Stepwise Regression tool can help remove unnecessary terms (Appendix C). Minitab will produce Fiber Diameter as a response to the effects that have a greater significance level than .15 (standard value of significance). The value of R2 will assumingly be adjusted to a number closer to 1.0 or $100 \%$, reducing the variability of the predictors.

4. Before conclusions can be made, the model assumptions must be tested using residual graphs and a normality test. In the analysis of the factorial design, residuals were stored in a specified column. A normality test for these residuals should be performed (Appendix C). In a normality test, the null hypothesis is that the residuals are normally distributed therefore a high p-value (>.05) would confirm our assumption. This would allow conclusions to be made in the examined the ANOVA.

5. Use the results to answer the questions in your experimental objective (which factors had the greatest effect on fiber diameter). If desired, an optimization plot can be performed, in which Minitab will calculate parameter values that are predicted to minimize the resultant fiber diameter (Appendix C). An experimental spin at these settings may be run to test the level of prediction. 


\section{Appendix C: Mixing PLGA Solutions}

Note: Protocol used comes from Tiffany R. Pena's thesis. Deviations are in red.

\section{Table 6: Bill of Materials}

\begin{tabular}{|l|l|l|l|}
\hline Materials/Equipment & Vendor & $\begin{array}{l}\text { Part } \\
\text { Number }\end{array}$ & Quantity \\
\hline Poly (DL-lactide-co-glycolide) (PLGA) & Sigma-Aldrich & P1941 & 5 grams \\
\hline Lactide: Glycolide (75:25) & & & \\
\hline Mol wt 66,000 - 107,000 & & & \\
\hline $\begin{array}{l}\text { Chloroform, extra dry, water <50ppm, } \\
\text { stabilized }\end{array}$ & Fisher Scientific, Inc & 326820010 & 1 Liter \\
\hline 10 ml Syringe, Luer-Lok tip & BD & 309604 & $100 /$ Pack \\
\hline $\begin{array}{l}\text { Blunt Fill Needle, 18G 1 1/2 (1.2 mm x } \\
40 \text { mm) }\end{array}$ & BD & 305180 & $100 /$ Pack \\
\hline Analytical Balance & Acculab & ALC-80.4 & 1 \\
\hline Orbital Shaker & & & 1 \\
\hline Vacuum-Pressure Pipette Aid & Drummon Scientific Co. & P-80991 & 1 \\
\hline Serological Pipet 5 x 1/10 ml & VWR International & $53283-706$ & NA \\
\hline Clear Glass Vial 20 ml & VWR International & $15900-002$ & $72 / C S$ \\
\hline
\end{tabular}

\section{Procedure}

1. Calculate the amount of PLGA resin necessary for the desired weight percent polymer solution using the following equation. (Density of chloroform is 1.48 $\mathrm{g} / \mathrm{ml}$.)

$$
\begin{gathered}
\text { WPP }=\mathrm{m} 1 /(\mathrm{m} 1+\mathrm{m} 2 \mathrm{~b}) \\
\text { WPP }=\text { Weight percent polymer solution } \\
\mathrm{m} 1=\text { mass of polymer }(\mathrm{g}) \\
\mathrm{m} 2=\text { mass of solvent }(\mathrm{ml}) \\
\mathrm{b}=\text { density of solvent }(\mathrm{g} / \mathrm{ml})
\end{gathered}
$$

2. Put on safety gloves. (WARNING: Chloroform can have serious side-effects if it comes in contact with skin, eyes or is inhaled or swallowed. Target organs to be effected are kidneys, heart, central nervous system, liver, eyes, reproductive 
system and skin. Always open chloroform in a hood and wear protective clothing!!

3. Remove PLGA (Figure 56) from the freezer and allow it to reach room temperature (5-10 minutes). Doing so prevents condensation when the polymer is exposed to air.

4. Weigh out the calculated amount of PLGA using the Acculab Balance (Figure 57) and place the polymer in a $20 \mathrm{ml}$ clear vial. Close the lid immediately.

5. Return unused PLGA to the freezer.

6. Retrieve the chloroform (Figure 58) for the hazardous chemical cabinet and place it in the fume hood immediately.

7. Gather the Pipette-Aid, a $10 \mathrm{ml}$ disposable pipette and the vial of weighed PLGA and place in the hood with the chloroform.

8. Pipette the desired volume of chloroform into the vial with PLGA. Immediately cap the vial as well as the chloroform container to prevent evaporation of chloroform since it is highly volatile.

9. Properly label the solution vial with the WPP, date and your initials (Figure 59).

10. Wrap vial in aluminum foil to prevent light from entering the solution (chloroform is highly sensitive to light).

\section{Figure 57:}

\section{Acculab Balance}

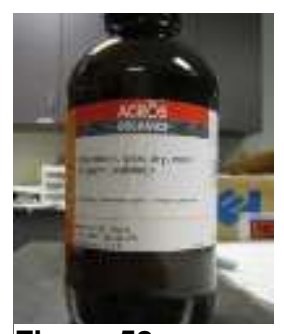

Figure 58:

Bottled chloroform

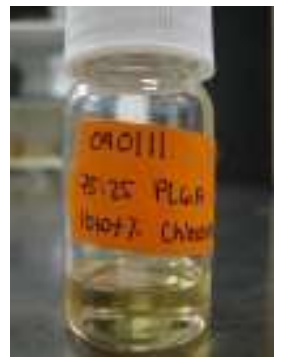

WPP 
11. Place the vial on the shake table. Set the shake table to approximately 3 revolutions per second. Use tape to ensure that the vial will stay upright while on the shake table. Turn the table on.

12. Allow the solution to mix for 24 hours. After mixing is complete, the solution is usable for up to 48 hours.

13. Remove chloroform container from hood and place back into chemical cabinet.

14. Properly dispose of the pipette tip.

15. Clean up work area. 


\section{Appendix D: Electrospinning Setup and Protocol}

\section{Note: Protocol used taken from Tiffany R. Pena's thesis. Deviations are in red.}

WARNING: This electrospinning process requires extremely high voltages! Always wear

shoes, gloves, and be mindful of what you are touching. Do not attempt to use the

electrospinner unless you have been trained by a qualified user.

1. Put on safety gloves and protective clothing. (WARNING: Chloroform can have serious side-effects if it comes in contact with skin, eyes or is inhaled or swallowed. Target organs to be effected are kidneys, heart, central nervous system, liver, eyes, reproductive system and skin. It is possible for residual chloroform to be present on and around the electrospinner during and after a spin!! Make sure to read the MSDS for all chemicals you are working with and know the necessary emergency procedures.)

2. The green ground wire located on the backside of the collector can be removed by pulling it straight out. Unplug the green ground wire from the collector (Figure 60).

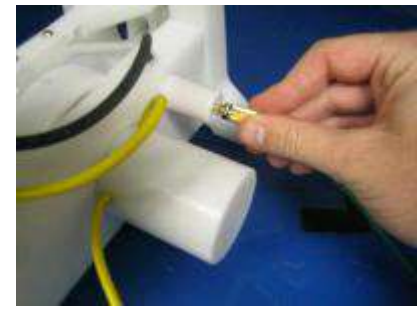

Figure 60: Green ground wire location on back of the collector

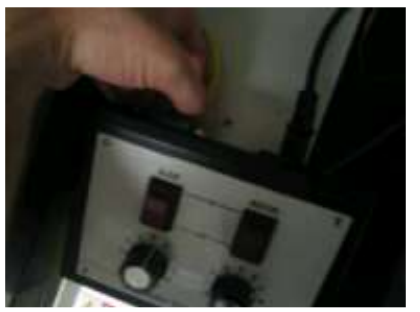

Figure 61: Location of the yellow power wire on the DC motor control box control box. The yellow power wire comes off the DC motor control box by unscrewing the connection head. Unscrew the yellow power wire from the DC motor control box (Figure 61).

4. The collector can now be removed from the containment chamber. Remove the collector from the containment chamber

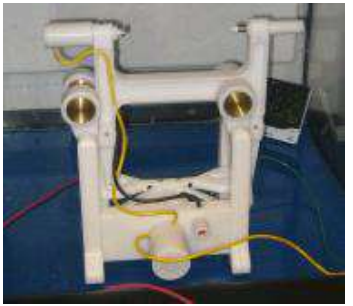

Figure 62: Entire electrospinner in the containment chamber 
and place it on the counter outside the fume hood (Figure 62).

5. During a spin, stray polymer preferentially builds up on exposed metal, wires and the motor casing. Cleaning before each spin is necessary to remove any residual polymer or dust from the collector that may potentially interfere with the next spin process. Clean the collector using IPA and paper towels. Ensure all residues from both the front and back of the collector including the wires are removed (Figure 63).

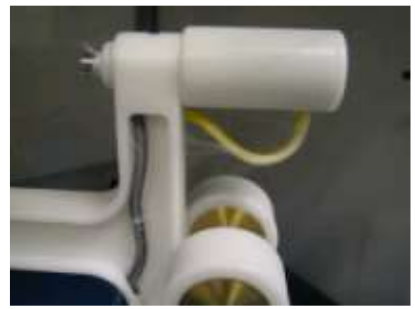

Figure 63: Polymer build up on collector that needs cleaning

6. During a spin, stray polymer can attach to any wall of the containment chamber and even form webs of polymer between walls. If necessary, clean the inside of the containment chamber with IPA.

7. Replace the collector back inside the containment chamber and reconnect the green ground and yellow power wires.

8. Prepare the mandrel for spinning. Clean the mandrel with IPA to remove any dust, residual polymer from a previous spin, or metal particles. If the mandrel surface is scratched, fine grit sand paper can be used to re-smooth the surface of the mandrel. If sanding is necessary, clean the mandrel with IPA when finished.

9. Attach the mandrel to the collector. When inserting the mandrel, rotate the turn knob until most of the metal chuck is covered, you will feel some resistance. If you go too far the turn knob will spring back.

10. There are three power cords to the right of the fume hood; one for the external power supply, one for the main power and one for the DC motor control box. Plug in all the equipment.

11. Using a multimeter, check the resistance between the ground connection and the mandrel. Verify that there is some

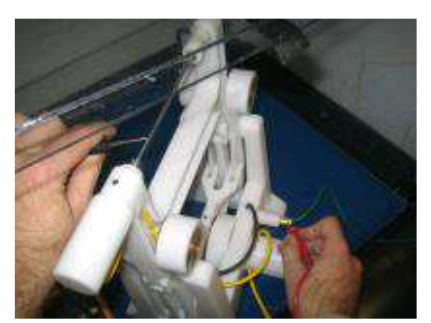

Figure 64: Multimeter lead placement to measure resistance 
conductivity. Record your measurements (Figure 64).

12. In the fume hood, prepare a $10 \mathrm{ml}$ syringe with an $18 \mathrm{GA}$ fill needle.

13. Remove aluminum foil from the PLGA solution vial for better visibility when working with the solution.

14. Solutions may be highly viscous and filling the syringe may take time and require some strength. Make sure to not release pressure on the plunger when drawing solution into the syringe. Acquire just over 3 $\mathrm{ml}$ of the polymer solution into the prepared $10 \mathrm{ml}$ syringe (Figure $65)$.

15. Once the solution has been acquired in the syringe, replace the fill needle with an 18GA Blunt needle.

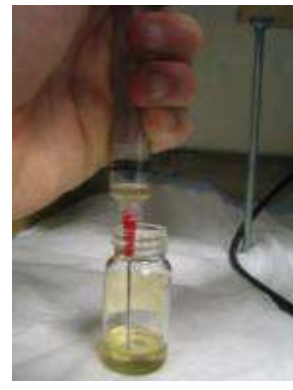

Figure 65: Syringe usage to acquire polymer solution

16. Push the plunger back into the syringe until most of the air is removed and the solution is just in the needle.

WARNING: If you push too hard too fast the polymer melt may squirt out. If this happens you will need to attach a new needle.

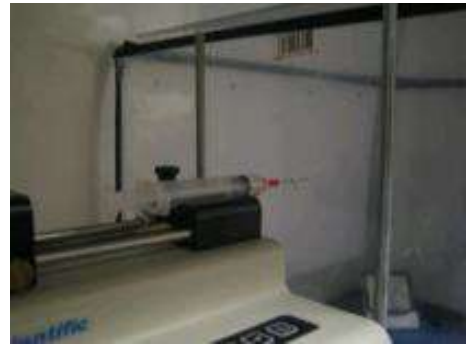

Figure 66: Syringe/needle placement on syringe pump and within needle hole on containment chamber.

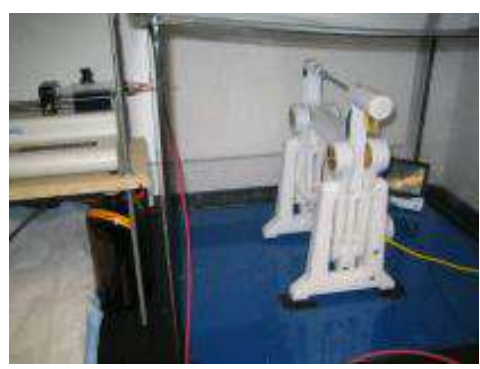

Figure 67: Position of collector for electrospinning of inches apart and perpendicular to each other, by lining the collector against the marked ruler (Figure 67). NOTE: The side of the collector with green ground wire connection should face away from the needle. 
19. Hang the exposed metal of the red high voltage wire on the needle tip inside the containment chamber. You can secure the wire on the needle by taping the wire to the containment chamber wall (Figure 68). WARNING: If the wire falls off the needle during the spin, the external $10 \mathrm{~V}$ power source used to regulate high voltage output will burn out. Be sure to hang the wire on the needle securely!

20. The power switch for the syringe pump is located on the back of the pump. Turn the syringe pump on.

21. Enter the desired flow rate and solution volume. The solution volume will determine when the pump will stop. Make sure the screen remains on volume. NOTE: Syringe pump instructions are located in a cabinet close to the fume hood if you need further instructions.

22. Turn on the "Rotate" and "Slide" functions of the collector at the DC motor control box. Ensure the collector is now

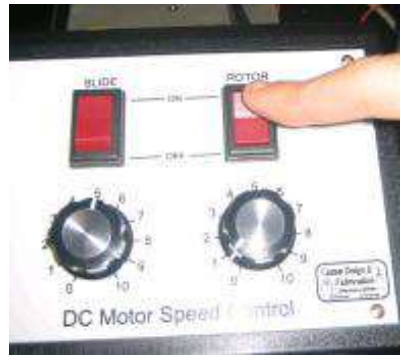

Figure 69: DC motor control box oscillating back and forth and the mandrel is rotating. If the mandrel is not rotating, you can tap it gently to get it started (Figure 69).

23. Secure the containment chamber by sliding close the front wall.

24. Turn on the external power source and set it to the desired voltage. Turn the external power source off (Figure 70).

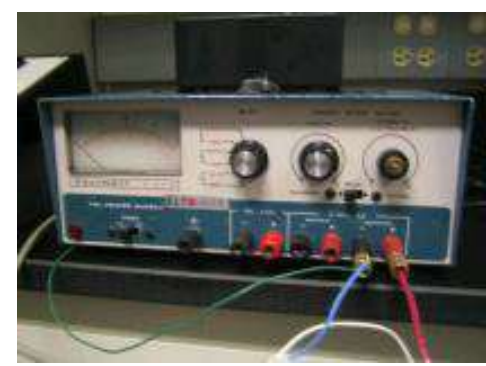

Figure 70: External power source 


\section{Read Steps 25-40 BEFORE beginning the electrospinning process. The following steps for turning ON and OFF the electrospinning system must be followed in the exact order listed.}

25. Press the "Run" button on the syringe pump. The volume count will begin on the screen and an arrow will flash meaning the solution is now being pushed through the needle.

26. When a droplet forms on the tip of the needle, the process is ready to begin.

27. Turn on the "Main Power" (left switch). Power is on if the light on the AC/DC power converter turns green (Figure

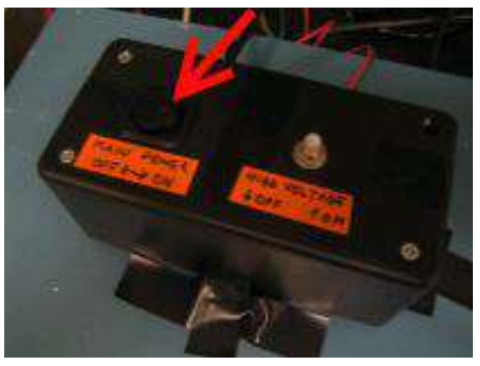

Figure 71: Main power switch 71).

28. Turn on the external source.

29. Prepare to turn on the High Voltage (right switch) (Figure 72). Look at the droplet of polymer on the end of the

syringe and turn High Voltage on. The droplet should disappear.

30. Monitor the process for the entire spin. The mandrel should slowly start to become coated with the polymer.

31. When the entire polymer solution has been spun, the process should be shut down in the following order.

a. Press the RUN/STOP button on the syringe pump.

b. Turn the HV switch to OFF

c. Turn the Main Power OFF 
d. Turn the ROTATE and SLIDE functions on the DC Motor Control box OFF.

32. In order to allow the solvent to fully evaporate, wait a few minutes before removing the mandrel from the containment chamber.

33. Remove the front containment chamber wall.

34. Remove the mandrel with PLGA scaffold.

35. Touch the red high voltage wire to the green ground wire to remove any residual charge.

36. Remove syringe from syringe pump and dispose in sharps container.

37. Unplug all equipment.

38. Properly dispose of all waste and clean up your work station.

39. Transfer the mandrel with the PLGA scaffold to the desiccators for further drying of the scaffold. Allow the scaffold to remain on the desiccators for 24 hours.

40. Remove the scaffold from the mandrel using gauze and carefully twist the scaffold off. 


\section{Appendix E: Imaging Protocol}

\section{Part I: Scaffold Preparation}

1. Post electrospinning, place scaffold/mandrel in desiccator to remove excess moisture for at least 48 hours.

2. Remove scaffold from the dessicator and gather a razor and a ruler.

3. Cut the scaffold into pieces as diagramed below. Slide each cut piece off and place onto a glass rod in order, and label the rod with material, date, and spin information. NOTE: The pieces will be imaged. The pieces are in case new images need to be taken, or if they need to be used for other testing purposes.

\section{Part II: SEM Imaging}

1. Gather scaffolds already prepped as detailed in Part I.
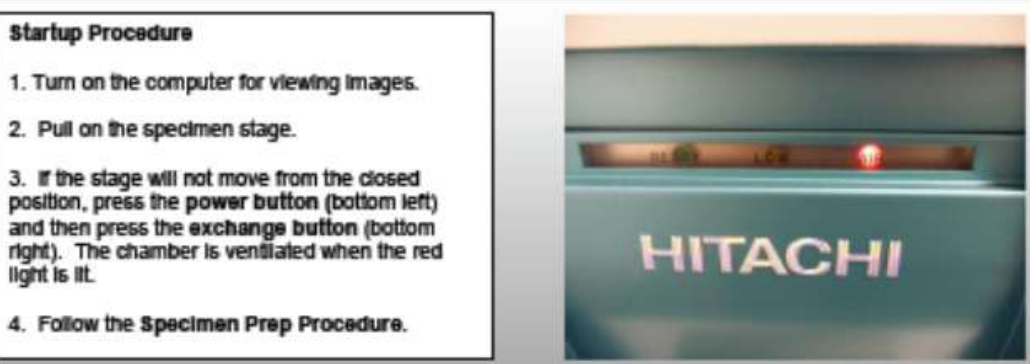

Specimen Prep Procedure

1. Apply a plece of non-conducting double-aided tape to the specimen stand 2. Place the specimen on the tape. centered on the stand.

3. Use the specimen height gage. The sample shouid have a clearance of abou one militimeter.

4. Place the specimen stand in the specimen stage.

5. Foliow the Evacuation Procedure.

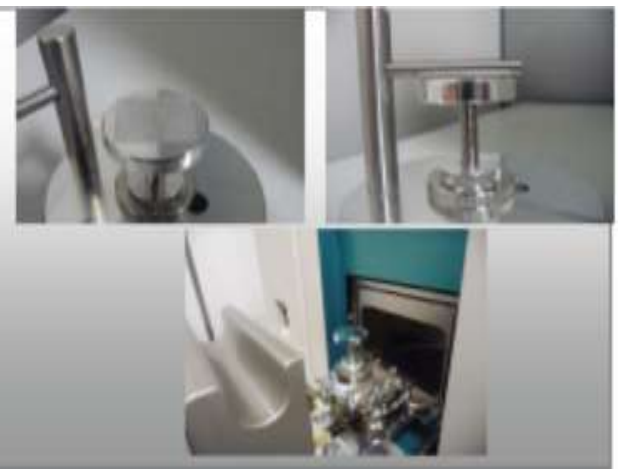


Evacuation Procedure

1. If the microscope is ofr, press the power button on the botiom left of the microscope

2. Check that specimen stage is completely Inside the microscope.

3. Click the TM-1000 icon on the desktop.

3. Press the exchange button on the bottom right of the microscope.

4. The chamber is evacuated when the green

Ilght is it on the top center display. The

progress is also displayed in the viewing

progress

5. Follow the Vlewing Procedure.

\section{I $M-1000$}

1. Now evacuating the specimen

chamber. Please wait

(Code1550)
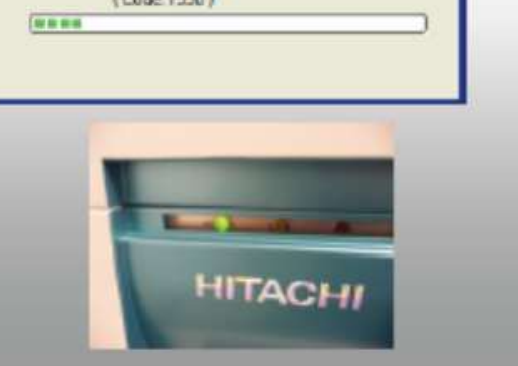

Viewing Procedure

1. Press the start Button in the vewing program.

2. To save an inage: press Quick save for iow resolution or save for high resclution.

3. When finished viewing, exit the program.

4. Press the Exchange Button. Wait for evacuation to be complete. The red light will be ight.

5. Remove the specimen and close the specimen stage.

6. Press the Power Button

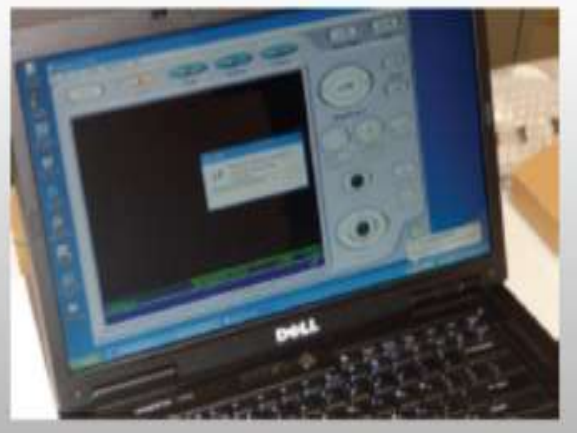




\section{Appendix F: Image J Protocol}

Note: Protocol used taken from Tiffany R. Pena's thesis. Any deviations are in red.

1. Open program ImageJ. The following screen will appear.

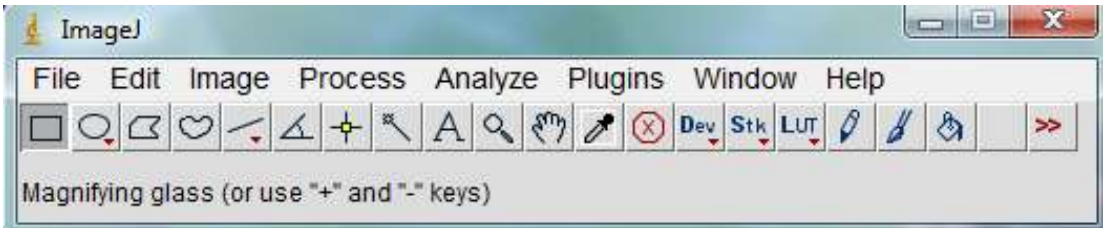

2. Select File > Open. Open a saved SEM image. The image will appear in a separate screen.

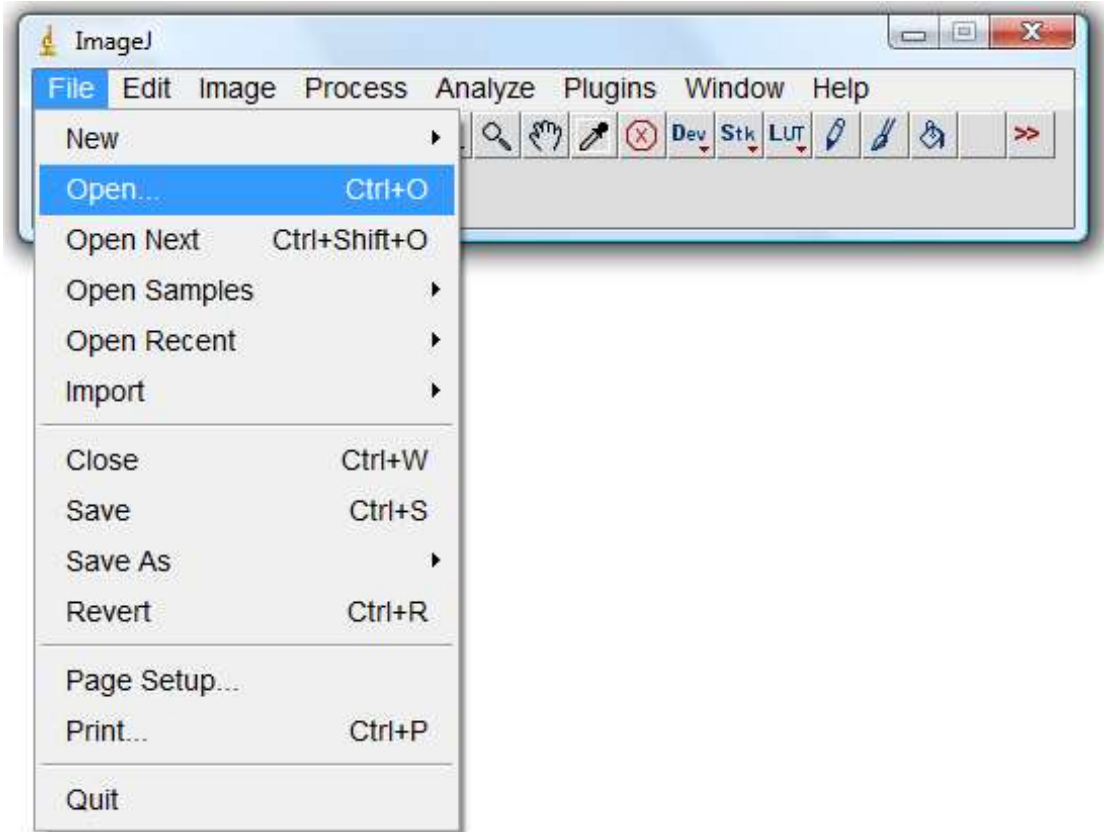

3. Select and draw a line along the SEM image's scale bar. Visually ensure the line is as close to the length of the scale bar as possible as this will affect the outcome of fiber diameter measurements (See image under Step 4 for further clarification).

4. On the tool bar, select Analyze > Set Scale. 


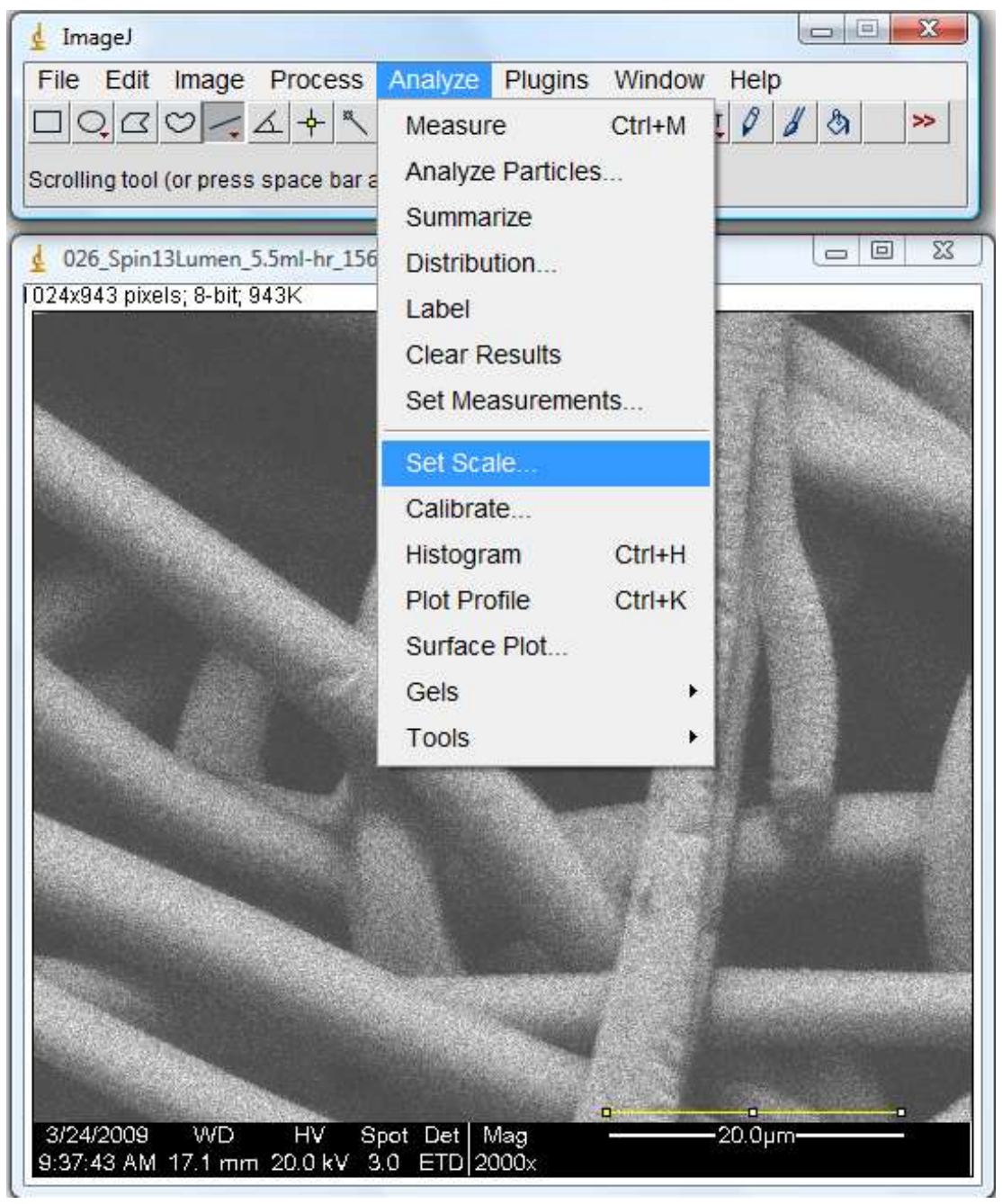

5. Insert known image scale bar distance (ex. 20 $\mu \mathrm{m}$ ). Set pixel aspect ratio to 1.0 and set appropriate unit length $(\mathrm{ex} . \mu \mathrm{m})$. Select OK. ImageJ is now calibrated to the image,

\begin{tabular}{|r|r|}
\hline Set Scale & \\
\hline Distance in Pixels: & 322.00 \\
Known Distance: & 20 \\
Pixel Aspect Ratio: & 1.0 \\
Unit of Length: & um \\
Scale: 16.100 pixels/um \\
$\Gamma$ Global \\
Reset \\
\hline
\end{tabular}


6. From the tool bar, select $\because$. Draw a line across the diameter of a single fiber to be measured.

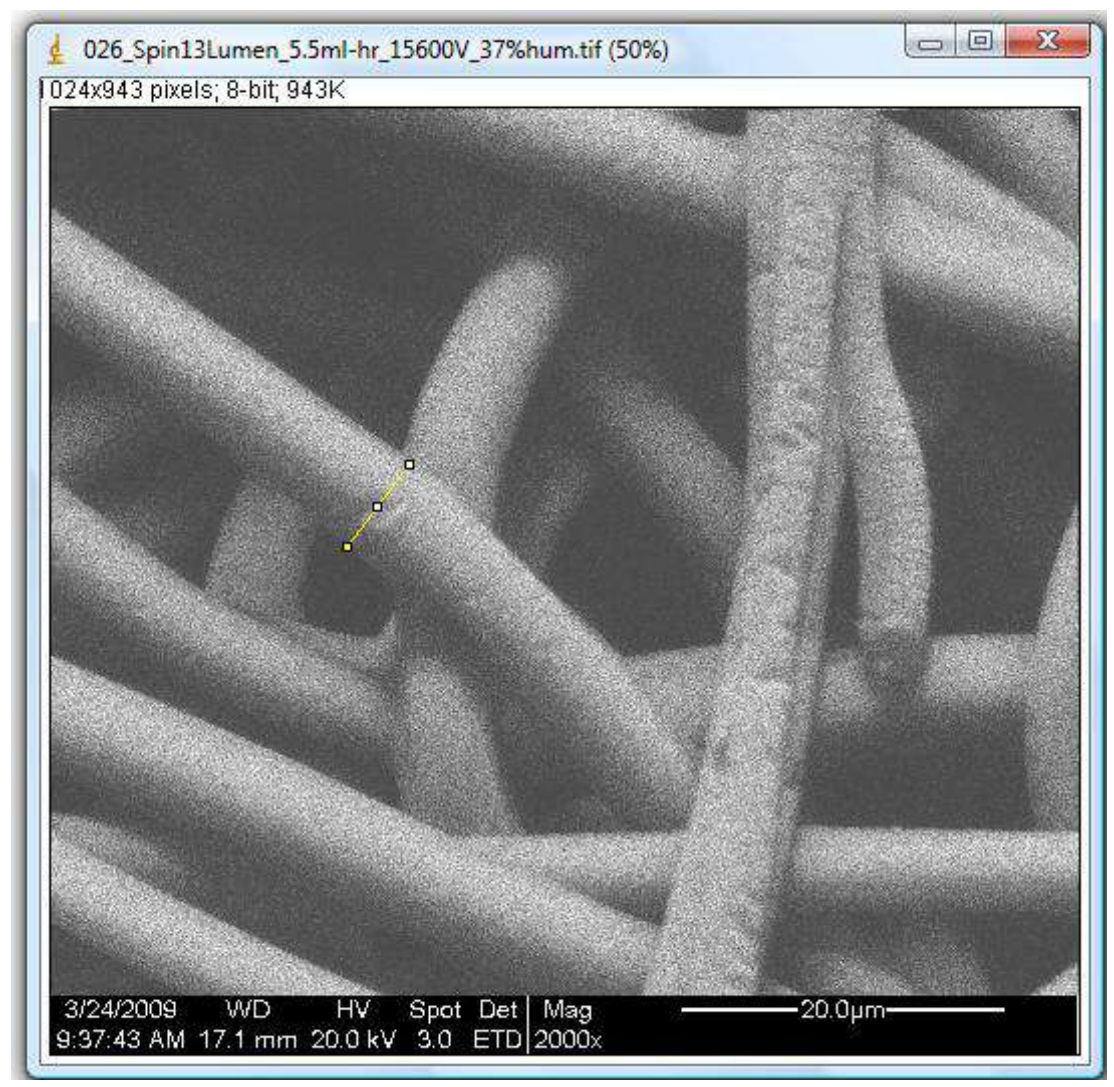

7. From the toolbar select Analyze > Measure. ImageJ will open a new window reporting Results. Fiber diameter is reported as Length in the Results window in proper units (ex. $\mu \mathrm{m})$.

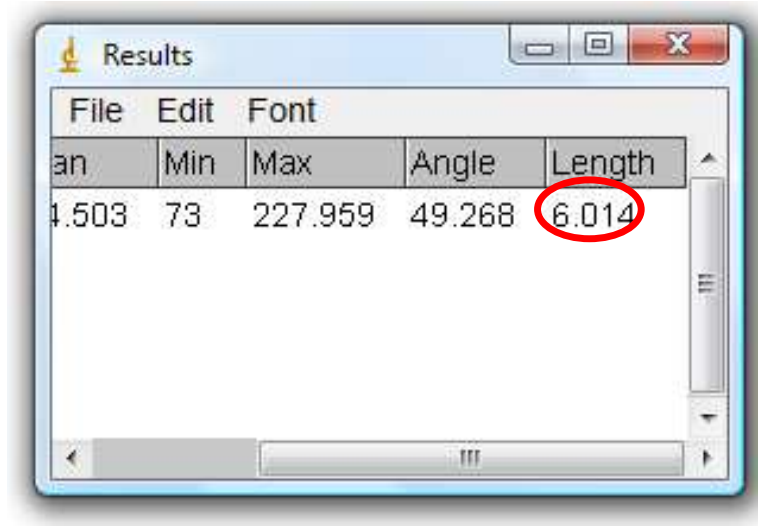

8. Leave the Measure window open and repeat Step 6 for all fiber measurements for the image.

9. Repeat for all images. NOTE: Calibration is only necessary for the first image if all images are being analyzed at the SAME magnification. Re-calibration is necessary for images taken at different magnifications. 


\section{Appendix G: List of Images and Measurements}

List of images and measurements can be found in electronic copy. 


\section{Appendix H: MiniTab Output}

NOTE: Not all output is included, only output found to be relevant to the analysis and results. Multiple regressions were analyzed with different variable relationships and variable transformations. While the output was used to define the next step in analysis, the output ad residual graphs are not included.

Scatterplot of Mean Fiber D vs Voltage, Flow Rate, Solution Con, ...

Scatterplot of mean fiber diameter versus varying parameters

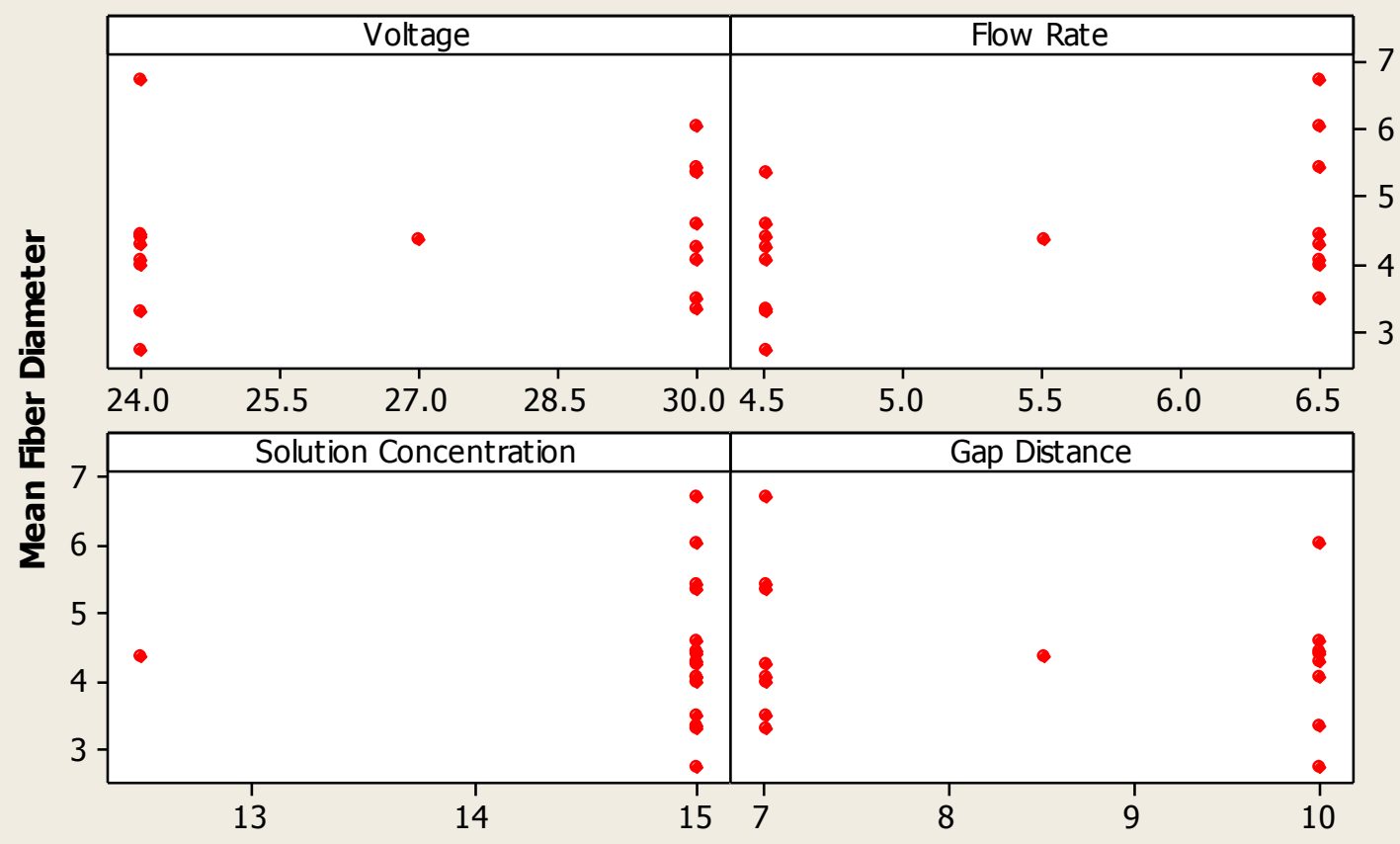




\section{Probability Plot of Mean Fiber Diameter}

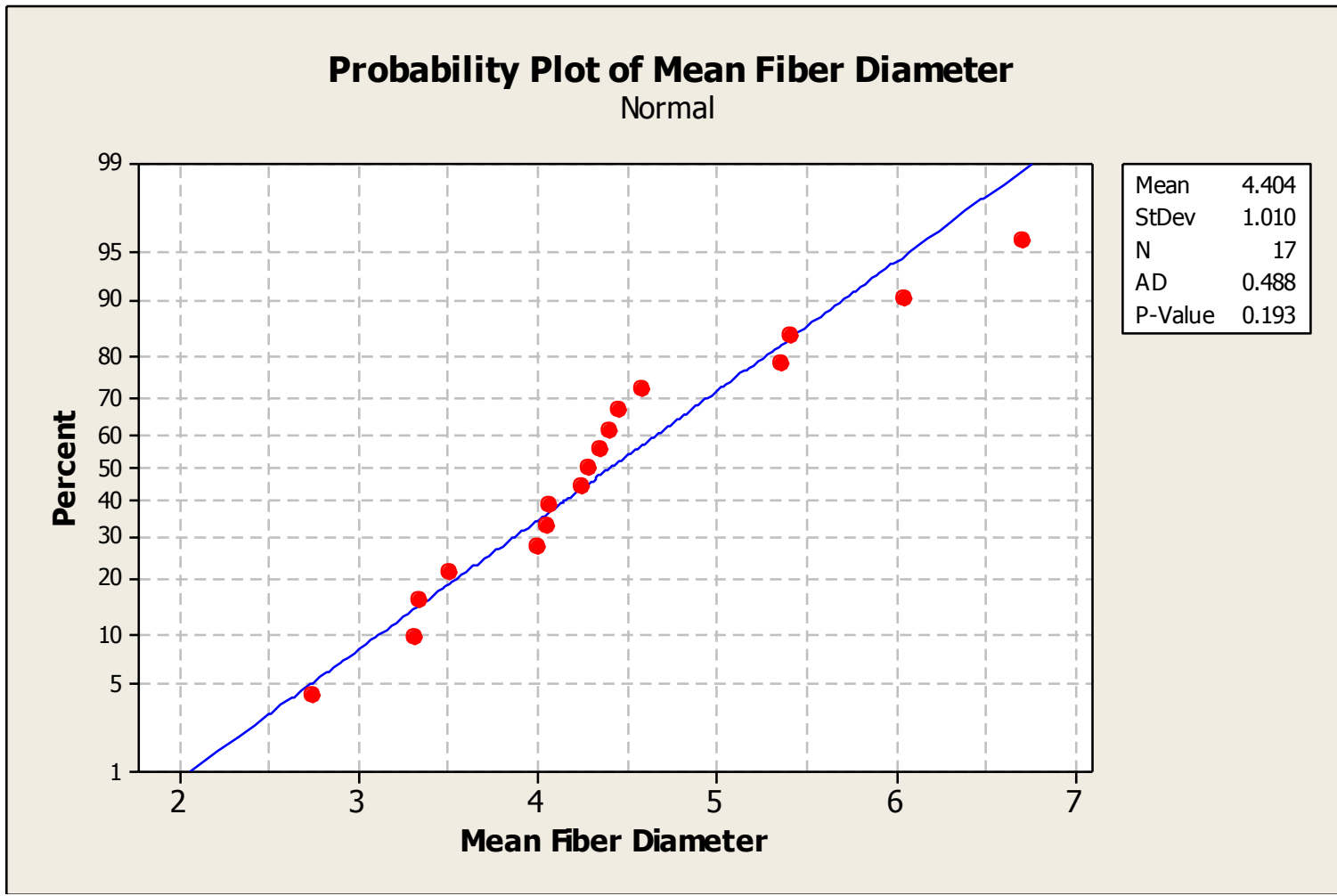

General Regression Analysis: Mean Fiber D versus Voltage, Flow Rate, ...

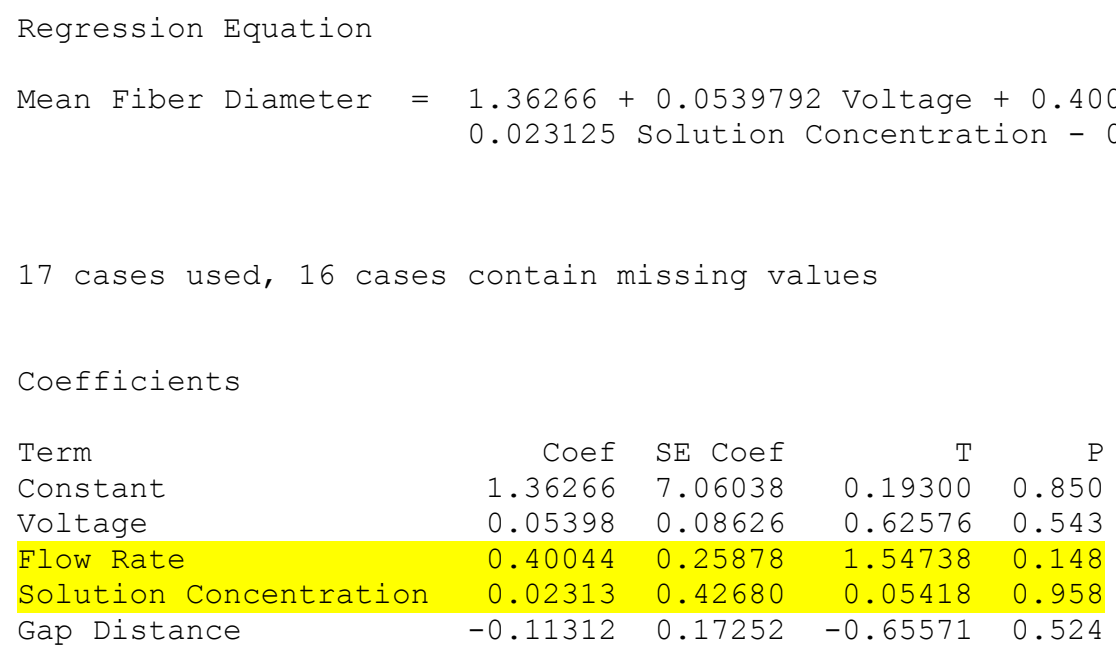

17 cases used, 16 cases contain missing values

$\begin{array}{lrrrr}\text { Coefficients } & & & & \\ \text { Term } & \text { Coef } & \text { SE Coef } & \text { T } & \text { P } \\ \text { Constant } & 1.36266 & 7.06038 & 0.19300 & 0.850 \\ \text { Voltage } & 0.05398 & 0.08626 & 0.62576 & 0.543 \\ \text { Flow Rate } & 0.40044 & 0.25878 & 1.54738 & 0.148 \\ \text { Solution Concentration } & 0.02313 & 0.42680 & 0.05418 & 0.958 \\ \text { Gap Distance } & -0.11312 & 0.17252 & -0.65571 & 0.524\end{array}$

Summary of Model

$\mathrm{S}=1.03513 \quad \mathrm{R}-\mathrm{Sq}=21.15 \% \quad \mathrm{R}-\mathrm{Sq}(\mathrm{adj})=-5.13 \%$

PRESS $=\star \quad$ R-Sq (pred) $=\star * \circ$

Analysis of Variance

$\begin{array}{lllllllll}\text { Source } & \text { DF } & \text { Seq SS } & \text { Adj SS Adj MS } & \text { F } & \text { P }\end{array}$ 


$\begin{array}{lrrrrrr}\text { Regression } & 4 & 3.4490 & 3.4490 & 0.86226 & 0.80472 & 0.545297 \\ \quad \text { Voltage } & 1 & 0.4196 & 0.4196 & 0.41958 & 0.39158 & 0.543188 \\ \text { Flow Rate } & 1 & 2.5656 & 2.5656 & 2.56560 & 2.39440 & 0.147727 \\ \quad \text { Solution Concentration } & 1 & 0.0031 & 0.0031 & 0.00315 & 0.00294 & 0.957681 \\ \quad \text { Gap Distance } & 1 & 0.4607 & 0.4607 & 0.46070 & 0.42996 & 0.524382 \\ \text { Error } & 12 & 12.8580 & 12.8580 & 1.07150 & & \\ \quad \text { Lack-of-Fit } & 4 & 2.3338 & 2.3338 & 0.58344 & 0.44350 & 0.774663 \\ \quad \text { Pure Error } & 8 & 10.5243 & 10.5243 & 1.31553 & & \\ \text { Total } & 16 & 16.3071 & & & & \end{array}$

Fits and Diagnostics for Unusual Observations

\begin{tabular}{|c|c|c|c|c|c|c|}
\hline Obs & $\begin{array}{l}\text { ean Fiber } \\
\text { Diameter }\end{array}$ & Fit & SE Fit & Residual & St Resid & \\
\hline 21 & 4.350 & 4.350 & 1.03513 & 0.000 & $\star$ & $x$ \\
\hline 30 & 6.707 & 4.816 & 0.51757 & 1.891 & 2.10943 & $\mathrm{R}$ \\
\hline
\end{tabular}

\section{General Regression Analysis: Mean Fiber D versus Voltage, Flow Rate, ...}

\begin{tabular}{|c|c|c|c|c|}
\hline \multicolumn{5}{|l|}{ Regression Equation } \\
\hline Mean Fiber Diameter & $\begin{array}{l}1.36266 \\
0.023125\end{array}$ & $\begin{array}{c}+0.053979 \\
\text { Solution }\end{array}$ & $\begin{array}{l}92 \text { Voltage } \\
\text { Concentrat }\end{array}$ & $\begin{array}{l}+0.400 \\
\text { ion - }\end{array}$ \\
\hline 17 cases used, 16 cases & contain & missing va & ralues & \\
\hline \multicolumn{5}{|l|}{ Coefficients } \\
\hline Term & Coef & SE Coef & $\mathrm{T}$ & $\mathrm{P}$ \\
\hline Constant & 1.36266 & 7.06038 & 0.19300 & 0.850 \\
\hline Voltage & 0.05398 & 0.08626 & 0.62576 & 0.543 \\
\hline Flow Rate & 0.40044 & 0.25878 & 1.54738 & 0.148 \\
\hline Solution Concentration & 0.02313 & 0.42680 & 0.05418 & 0.958 \\
\hline Gap Distance & -0.11312 & 0.17252 & -0.65571 & 0.524 \\
\hline
\end{tabular}

Summary of Model

$\begin{array}{lrrrrrr}\text { Source } & \text { DF } & \text { Seq SS } & \text { Adj SS } & \text { Adj MS } & \text { F } & P \\ \text { Regression } & 4 & 3.4490 & 3.4490 & 0.86226 & 0.80472 & 0.545297 \\ \quad \text { Voltage } & 1 & 0.4196 & 0.4196 & 0.41958 & 0.39158 & 0.543188 \\ \quad \text { Flow Rate } & 1 & 2.5656 & 2.5656 & 2.56560 & 2.39440 & 0.147727 \\ \quad \text { Solution Concentration } & 1 & 0.0031 & 0.0031 & 0.00315 & 0.00294 & 0.957681 \\ \quad \text { Gap Distance } & 1 & 0.4607 & 0.4607 & 0.46070 & 0.42996 & 0.524382 \\ \text { Error } & 12 & 12.8580 & 12.8580 & 1.07150 & & \\ \quad \text { Lack-of-Fit } & 4 & 2.3338 & 2.3338 & 0.58344 & 0.44350 & 0.774663 \\ \quad \text { Pure Error } & 8 & 10.5243 & 10.5243 & 1.31553 & & \\ \text { Total } & 16 & 16.3071 & & & & \end{array}$




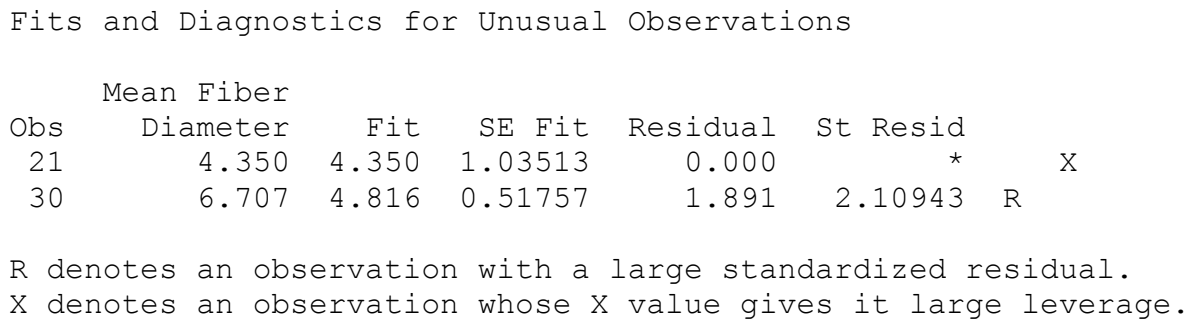

\section{Normplot of Residuals for Mean Fiber Diameter}

\section{Residuals vs Fits for Mean Fiber Diameter}

\section{General Regression Analysis: Mean Fiber D versus Flow Rate, Voltage, inverseGap}

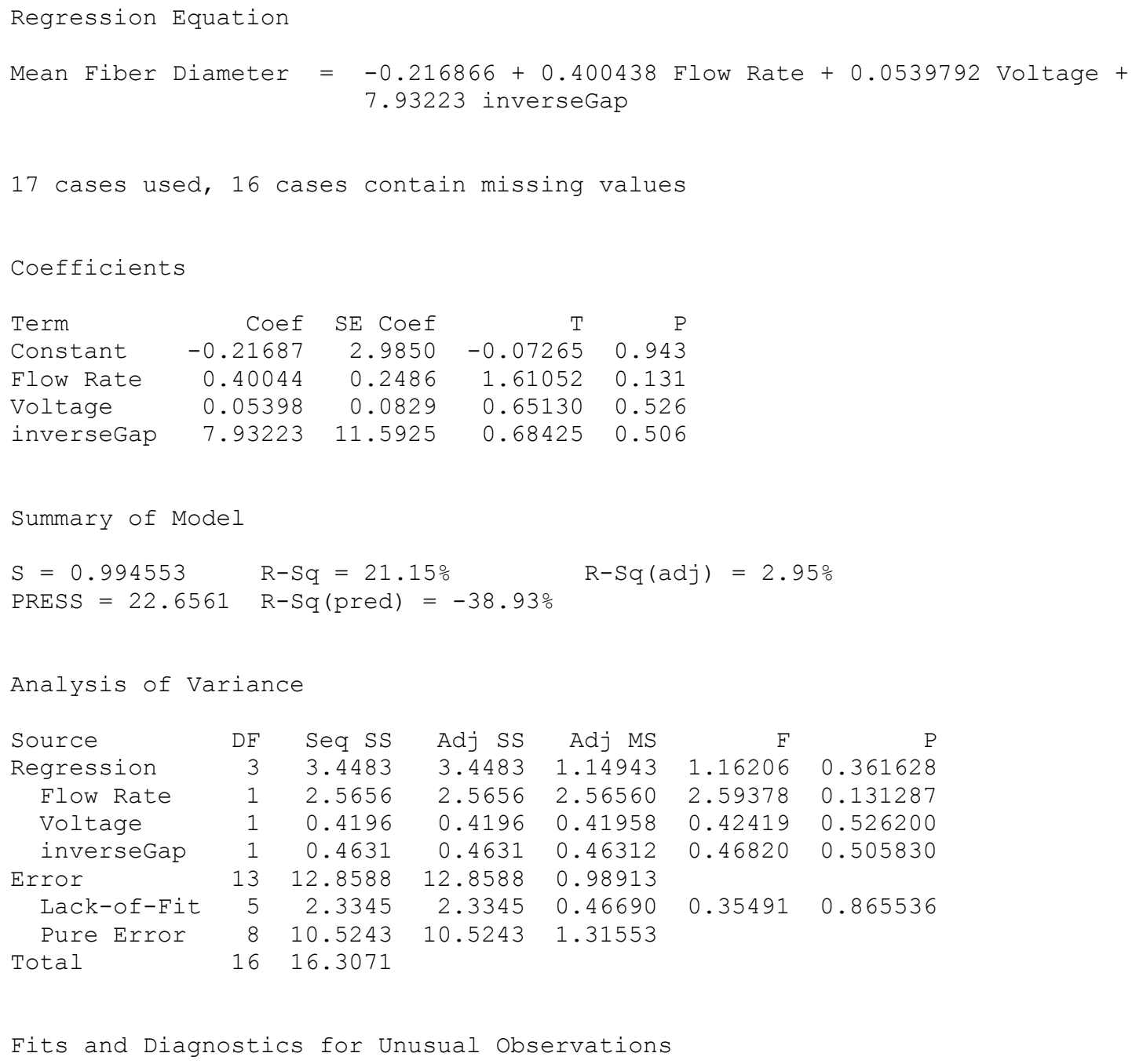




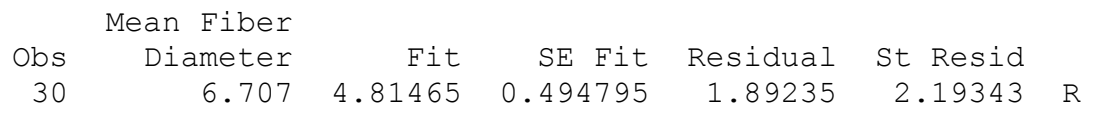

$\mathrm{R}$ denotes an observation with a large standardized residual.

\section{Normplot of Residuals for Mean Fiber Diameter}

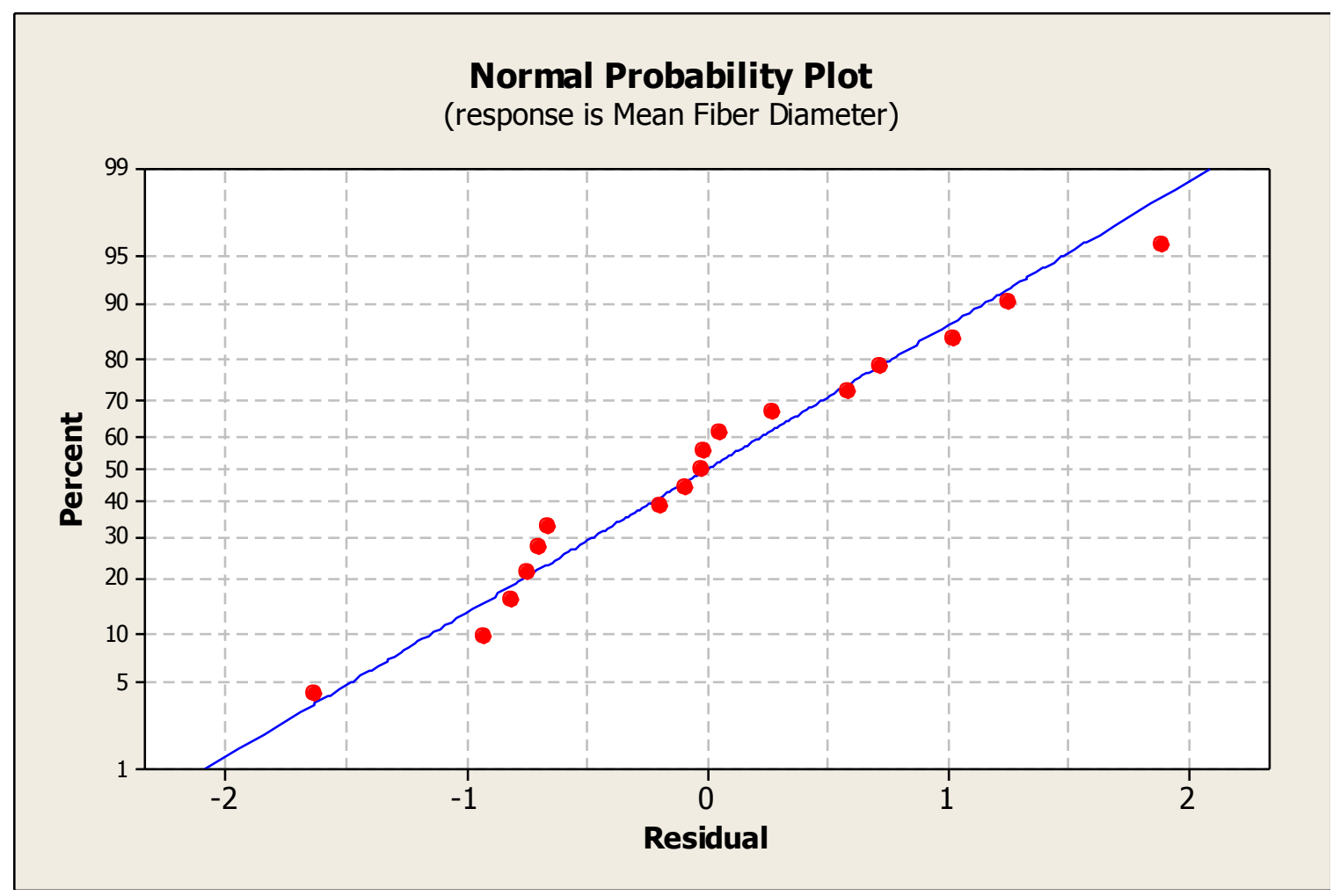




\section{Residuals vs Fits for Mean Fiber Diameter}

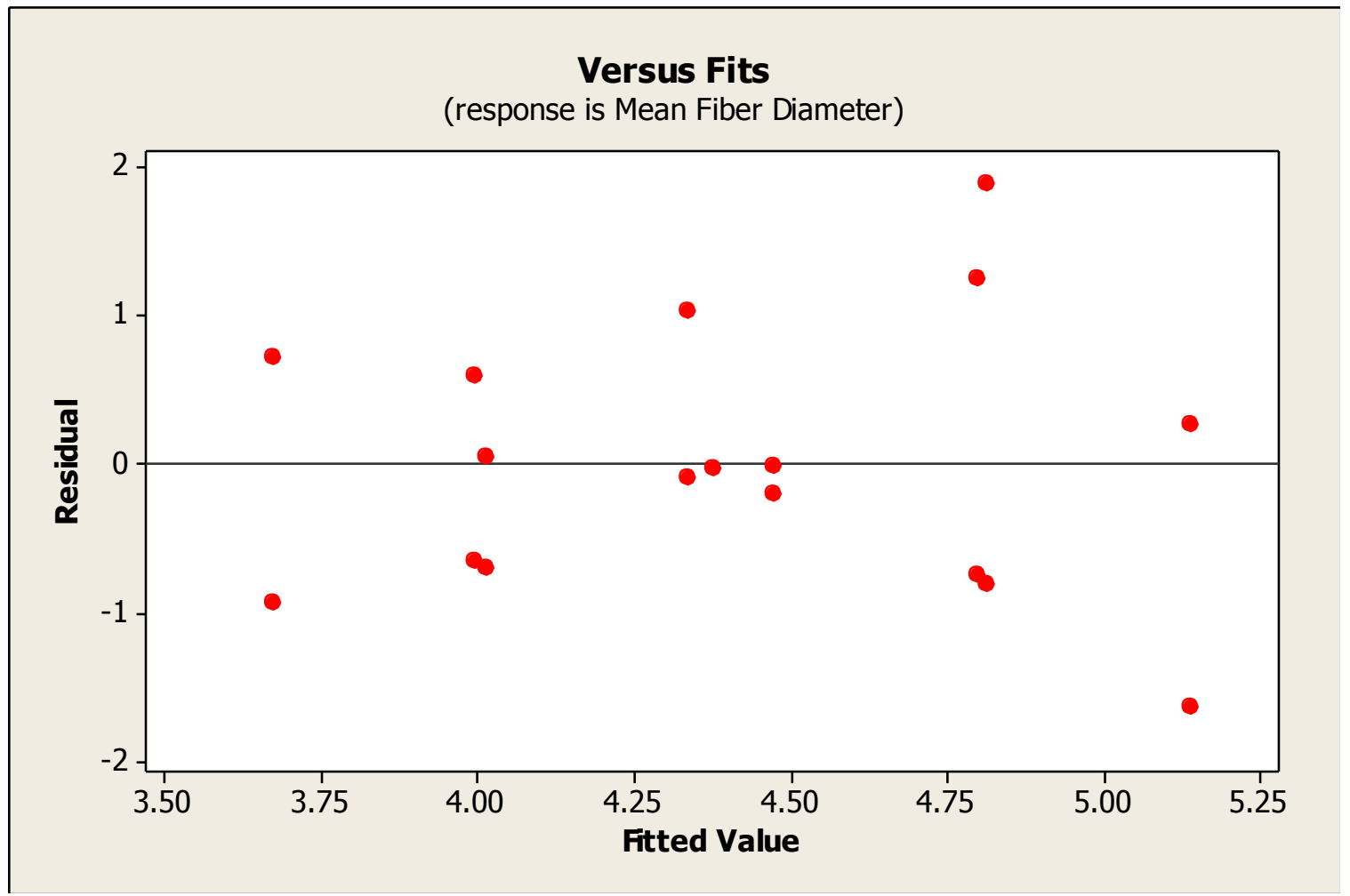

One-way ANOVA: Mean versus Section

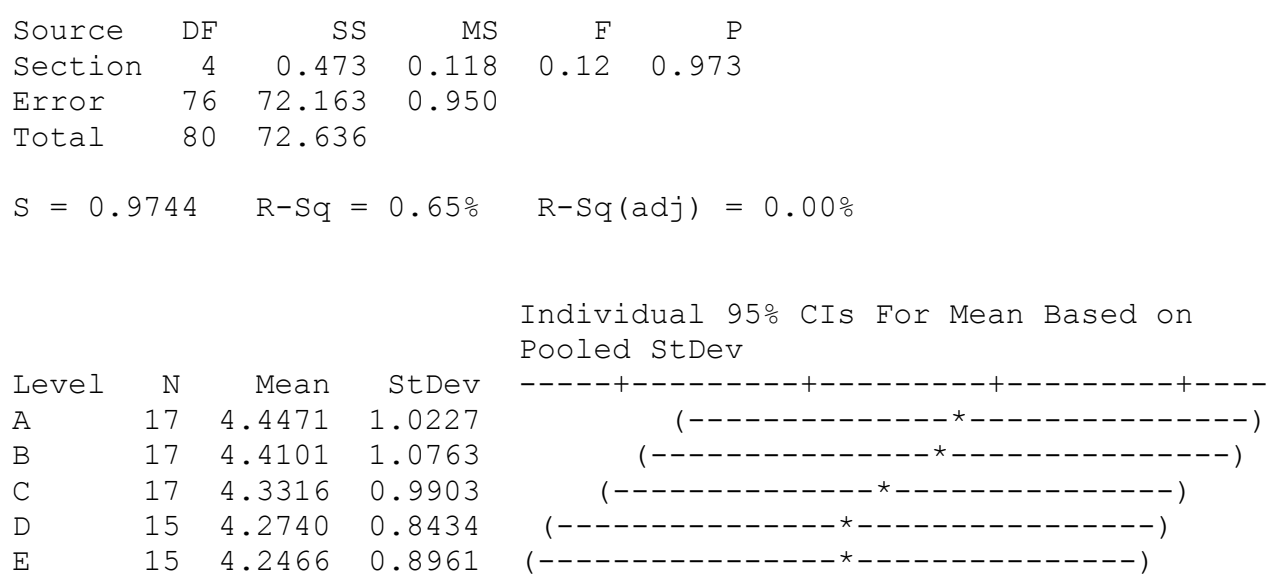




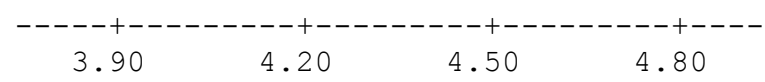

Pooled StDev $=0.9744$

Grouping Information Using Tukey Method

$\begin{array}{lrrl}\text { Section } & \text { N } & \text { Mean } & \text { Grouping } \\ \text { A } & 17 & 4.4471 & \text { A } \\ \text { B } & 17 & 4.4101 & \text { A } \\ \text { C } & 17 & 4.3316 & \text { A } \\ \text { D } & 15 & 4.2740 & \text { A } \\ \text { E } & 15 & 4.2466 & \text { A }\end{array}$

Means that do not share a letter are significantly different.

Tukey 95\% Simultaneous Confidence Intervals

All Pairwise Comparisons among Levels of Section

Individual confidence level $=99.34 \%$

Section = A subtracted from:

$\begin{array}{lrrr}\text { Section } & \text { Lower } & \text { Center } & \text { Upper } \\ \mathrm{B} & -0.9705 & -0.0370 & 0.8965\end{array}$

$\begin{array}{llll}\text { C } & -1.0490 & -0.1154 & 0.8181\end{array}$

D $\quad-1.1372-0.1731 \quad 0.7910$

E $\quad-1.1646-0.2005 \quad 0.7636$
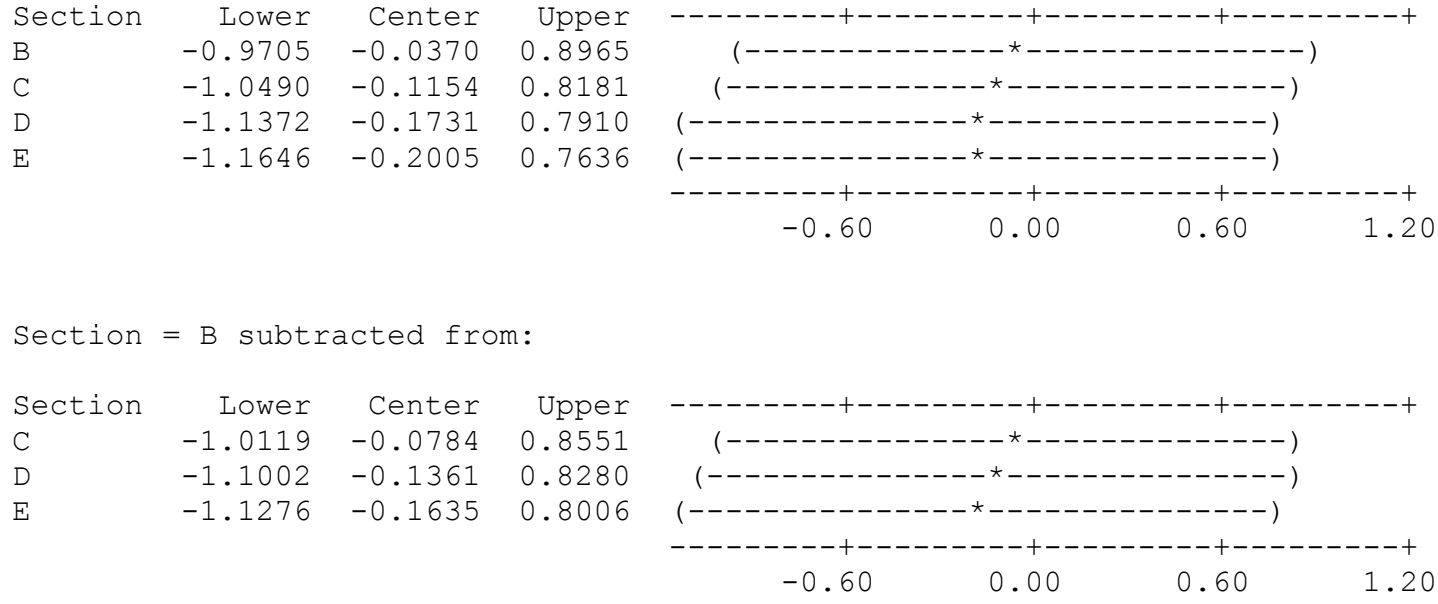

Section $=$ C subtracted from:

Section Lower Center Upper

$\begin{array}{llll}\text { D } & -1.0218 & -0.0577 & 0.9065\end{array}$

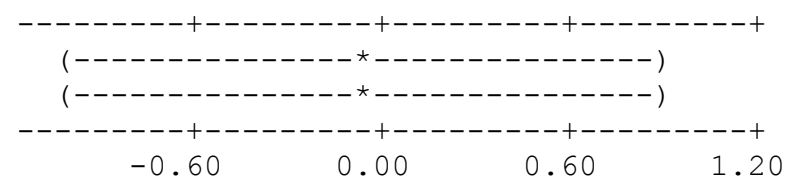

Section $=$ D subtracted from:

Section Lower Center Upper

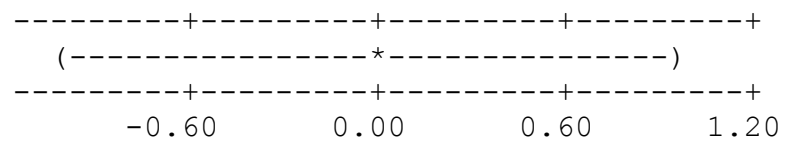

